\title{
Geobiology of Marine Magnetotactic Bacteria
}

by

Sheri Lynn Simmons

A.B., Princeton University, 1999

Submitted in partial fulfillment of the requirements for the degree of

Doctor of Philosophy in Biological Oceanography

at the

\section{MASSACHUSETTS INSTITUTE OF TECHNOLOGY}

and the

WOODS HOLE OCEANOGRAPHIC INSTITUTION

June 2006

(c)Woods Hole Oceanographic Institution, 2006.

Author

Joint Program in Oceanography Massachusetts Institute of Technology and Woods Hole Oceanographic Institution

May 19, 2006

Certified by

Katrina J. Edwards

Associate Scientist, Department of Marine Chemistry and Geochemistry, Woods Hole Oceanographic Institution

Thesis Supervisor

Accepted by

Ed DeLong

Chair, Joint Committee for Biological Oceanography Massachusetts Institute of Technology-Woods Hole Oceanographic 


\title{
Geobiology of Marine Magnetotactic Bacteria
}

\author{
by \\ Sheri Lynn Simmons \\ Submitted to the \\ MASSACHUSETTS INSTITUTE OF TECHNOLOGY \\ and the \\ WOODS HOLE OCEANOGRAPHIC INSTITUTION \\ on May 19, 2006, in partial fulfillment of the \\ requirements for the degree of \\ Doctor of Philosophy in Biological Oceanography
}

\begin{abstract}
Magnetotactic bacteria (MTB) biomineralize intracellular membrane-bound crystals of magnetite $\left(\mathrm{Fe}_{3} \mathrm{O}_{4}\right)$ or greigite $\left(\mathrm{Fe}_{3} \mathrm{~S}_{4}\right)$, and are abundant in the suboxic to anoxic zones of stratified marine environments worldwide. Their population densities (up to $10^{5}$ cells $\mathrm{ml}^{-1}$ ) and high intracellular iron content suggest a potentially significant role in iron cycling, but very little is known about their population dynamics and regulation by environmental geochemistry.

The MTB community in Salt Pond (Falmouth, MA), a small stratified marine basin, was used as a model system for quantitative community studies. Magnetiteproducing MTB predominate slightly above the oxic-anoxic interface and greigiteproducing MTB predominate in sulfidic waters. A quantitative PCR (QPCR) assay was developed and applied to enumerate four major groups of MTB in Salt Pond: magnetite-producing cocci, barbells, the greigite-producing many-celled magnetotactic prokaryote (MMP), and a greigite-producing rod. The barbells were identified as $\delta$-Proteobacteria while the rod was identified as the first MTB in the $\gamma$-Proteobacteria. The MMP, previously thought to be a single species, consists of at least five clades with greater than $5 \%$ divergence in their $16 \mathrm{~s}$ rRNA. Fluorescent in situ hybridization probes showed significant variation in clade abundances across a seasonal cycle in salt marsh productivity. FISH also showed that aggregates consist of genetically identical cells.

QPCR data indicated that populations are finely layered around the oxic-anoxic interface: cocci immediately above the dissolved Fe(II) peak, barbells immediately below, the MMP in microsulfidic waters, and the greigite-producing rod in low numbers $\left(100\right.$ cells $\mathrm{ml}^{-1}$ ) below the gradient region. The barbell reached $1-10 \%$ of total eubacteria in the late season, and abundances of cocci and barbells appeared to vary inversely. Calculations based on qPCR data suggest that MTB are significant unrecognized contributors to iron flux in stratified environments.

Barbells can respond to high oxygen levels by swimming toward geomagnetic
\end{abstract}


south, the opposite of all previously reported magnetotactic behavior. This behavior is at least partially dependent on environmental oxidation-reduction potential. The co-existence of MTB with opposing polarities in the same redox environment conflicts with current models of the adaptive value of magnetotaxis.

Thesis Supervisor: Katrina J. Edwards

Title: Associate Scientist, Department of Marine Chemistry and Geochemistry, Woods Hole Oceanographic Institution 


\section{Acknowledgments}

The possession of knowledge does not kill the sense of wonder and mystery.

There is always more mystery.

-Anaïs Nin, Diary

I thank my advisor Katrina Edwards for taking a chance on someone who initially knew nothing about magnetotactic bacteria, microbial ecology, or microbiology, and giving me the freedom and support to pursue my own interests and questions. In her lab, I've learned how to be an independent researcher.

I am grateful for many people's help with sampling in Salt Pond, particularly our wonderful WHOI summer student fellows and guest students: Ronnie Yoo, Sara Selgrade, and Lindsay Hirt. Cara Santelli, Dan Rogers, and Peter Canovas in the Edwards lab all helped with dragging the rowboat into the pond every summer for four years.

Craig Taylor shared his tremendous engineering expertise with me to get a finelayer sampler designed and built for Salt Pond by the WHOI shop, and also provided advice on an in situ carbon fixation experiment. Steve Molyneaux also helped with the in situ carbon fixation experiment. Greg Druschel and Dan Rogers shared their time and expertise teaching a complete novice about voltammetric microelectrodes. Matt Charette helped me implement a sampling protocol for nutrients in Salt Pond and generously provided the use of his nutrient autoanalyzer. Stefan Sievert taught me the ins and outs of DGGE, and Eric Webb introduced me to quantitative PCR.

Dennis Bazylinski had great patience in dealing with a novice microbiologist and shared many fascinating conversations about the behavior of magnetotactic bacteria, as did Richard Frankel. I thank both of them for their support and encouragement.

I was supported by a National Defense Science and Engineering Graduate Fellowship and by the WHOI Academic Programs office. Funding for the research described in this thesis was provided by the Rinehart Coastal Research Center at WHOI, the WHOI Ocean Life Institute, and the WHOI Ocean Venture Fund. This thesis would not have been possible without the generosity of these programs, and I sincerely thank 
them.

This thesis is dedicated to my husband Michael Desai, whose advice and encouragement have been invaluable. He is the best scientist and person that I know. 


\section{Contents}

1 Introduction 12

2 Spatio-temporal distribution of marine magnetotactic bacteria in a seasonally stratified coastal salt pond $\quad 29$

2.1 Introduction . . . . . . . . . . . . . . . . 30

2.2 Methods . . . . . . . . . . . . . . . . . . . . 33

2.3 Results . . . . . . . . . . . . . . . . . . . . . . 38

2.4 Discussion . . . . . . . . . . . . . . . . . . . . . . . . . . 41

3 Population dynamics of marine magnetotactic bacteria in a meromic$\begin{array}{ll}\text { tic salt pond described with quantitative PCR } & 60\end{array}$

3.1 Introduction . . . . . . . . . . . . . . . . . . . . . 61

3.2 Methods . . . . . . . . . . . . . . . . . . . . . 64

3.2.1 Water collection and chemistry ............. 64

3.2 .2 Sample preservation . . . . . . . . . . . . . . 65

3.2 .3 DNA extraction . . . . . . . . . . . . . 66

3.2.4 Sequencing and probe/primer design $\ldots \ldots \ldots 6$

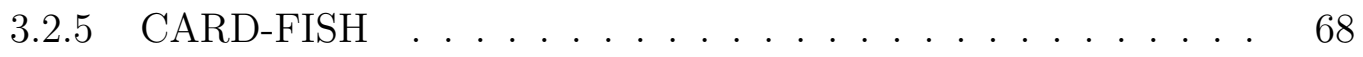

3.2 .6 Quantitative PCR standards . . . . . . . . . . . . . . . 69

3.2.7 Quantitative PCR optimization . . . . . . . . . . 70

3.2.8 Electron microscopy and magnetosome analysis _ . . . . . 72

3.3 Results . . . . . . . . . . . . . . . . . . . . . . . . . . . . 72

3.3 .1 Water chemistry . . . . . . . . . . . . . . 72 
3.3.2 FISH and CARD-FISH . . . . . . . . . . . . . . . 73

3.3.3 QPCR reaction efficiencies . . . . . . . . . . . . 74

3.3.4 QPCR results for MTB and Eubacteria . . . . . . . . . 75

3.3.5 Fe sequestration by MTB . . . . . . . . . . . . 77

3.4 Discussion . . . . . . . . . . . . . . . . . 80

3.4.1 Technical issues with SybrGreen quantitative PCR . . . . . 80

3.4 .2 MTB ecology in Salt Pond . . . . . . . . . . . . . . . 83

3.4.3 The contribution of MTB to Fe flux in euxinic basins . . . . 86

3.4.4 Conclusions and future work . . . . . . . . . . . . . 89

3.5 Acknowledgments . . . . . . . . . . . . . . . . . . . . . . . 91

4 South seeking magnetotactic bacteria in the Northern Hemisphere 106

4.1 Supplementary Online Material . . . . . . . . . . . . . . . . . . 114

5 Unexpected diversity in populations of the many-celled magnetotac$\begin{array}{ll}\text { tic prokaryote } & 118\end{array}$

5.1 Introduction . . . . . . . . . . . . . . . . . . . . . . . 118

5.2 Results . . . . . . . . . . . . . . . . . . . . . . . . 121

5.3 Discussion . . . . . . . . . . . . . . . . . . . . . . . . . . . . 124

5.3.1 Diversity and the concept of a microbial niche . . . . . . 125

5.3.2 Possible environmental niches for the MMP . . . . . . . 126

$5.3 .3 \quad$ Aggregates are clonal . . . . . . . . . . . . . . . . . . 128

5.3 .4 Conclusions . . . . . . . . . . . . . . . . . . . . . . . . 129

5.4 Materials and Methods . . . . . . . . . . . . . . . . . . 129

5.4.1 Sample site and collection . . . . . . . . . . . . . . . 129

5.4 .2 Amplification and sequencing . . . . . . . . . . . . 131

5.4 .3 Phylogenetic analysis . . . . . . . . . . . . . . . . . . . 132

5.4 .4 Probe design and use . . . . . . . . . . . . . 133

5.4 .5 Image analysis . . . . . . . . . . . . . . . . . . . 134 
6 Conclusion 143

6.1 Introduction . . . . . . . . . . . . . . . . . . . . . . . 143

6.1.1 Magnetofossils as paleoindicators . . . . . . . . . . 146

6.2 The ecology of MTB in stratified marine environments . . . . . . 148

6.2.1 Salt marshes and salt ponds . . . . . . . . . . . . . . 148

6.2.2 Methods for studying MTB population dynamics . . . . . . 150

6.2.3 Layered populations of MTB . . . . . . . . . . . . . . . 155

6.2 .4 Protist grazing of MTB . . . . . . . . . . . . . . . . 157

6.3 Thermodynamic constraints on MTB . . . . . . . . . . . . . 159

6.3.1 Thermodynamics of mineral synthesis helps regulate MTB distribution . . . . . . . . . . . . . . . . . . 159

6.3.2 The energetic yield of mineral synthesis . . . . . . . . . . 160

6.3.3 The magnetite/maghemite battery hypothesis . . . . . . . . 162

6.4 The influence of MTB on reduced Fe cycling . . . . . . . . . . . . . 164

6.4.1 The contribution of MTB to reactive Fe flux . . . . . . . 164

6.4 .2 Integrated studies . . . . . . . . . . . . . 166

A Development of a fine-layer sampler and application of voltammetric microelectrodes to MTB studies in Salt Pond 181

A.1 Proposal to the Ocean Venture Fund . . . . . . . . . . . . . . . 182

A.2 Preliminary results . . . . . . . . . . . . . . . . . . . 192

$\begin{array}{lll}\text { B Ancillary data for chapter 3 } & 200\end{array}$

C Measurements of in situ carbon fixation in Salt Pond 207

C.1 Protocol for Salt Pond C fixation experiments, September 2003 . . . . 211

C.1.1 Measurement of DIC . . . . . . . . . . . . . . . . . . . 211

C.1.2 Calculation of C incorporation rates . . . . . . . . . . . 211

C.1.3 Protocol for in situ fixation experiments . . . . . . . . . . 212

C.1.4 Protocol for timecourse experiment . . . . . . . . . . . . 215 


\section{List of Figures}

1-1 Depth profile of Salt Pond . . . . . . . . . . . . . . . . . . 19

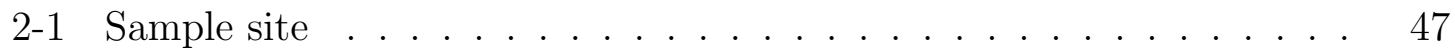

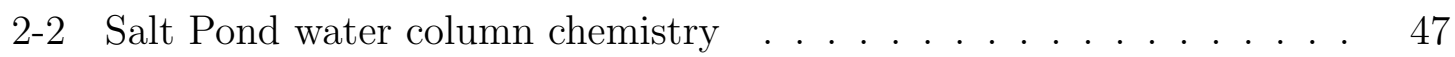

$2-3$ Cell counts. . . . . . . . . . . . . . . . . . . . . 48

2-4 Depth stratification of MB in Salt Pond. . . . . . . . . . . 49

$2-5$ Greigite $\operatorname{rod}$ images . . . . . . . . . . . . . . . . . . 49

$2-6$ Salt Pond phylogenetic tree $\ldots \ldots \ldots \ldots$

$2-7$ MB distribution cartoon $\ldots \ldots \ldots \ldots \ldots \ldots \ldots$

3-1 Sequences for greigite $\operatorname{rod} \ldots \ldots \ldots \ldots 2 \ldots$

3-2 Chemical profiles of Salt Pond . . . . . . . . . . . . . . . 92

$3-3$ CARD-FISH of greigite $\operatorname{rod} \ldots \ldots \ldots \ldots$

3-4 TEM images of MTB from Salt Pond . . . . . . . . . . . . 93

3-5 Trends in MTB abundance as shown with qPCR in summer 2003 . . 94

$3-6$ Log abundances of barbells and cocci with qPCR . . . . . . . 94

$3-7$ The MTB iron pump . . . . . . . . . . . . . . . . 95

4-1 The barbell and small rod have south polarity in Salt Pond. . . . . . 111

$4-2$ The barbell is a $\delta$ - proteobacterium. . . . . . . . . . . . . . 112

4-3 South polarity is related to environmental oxidation-reduction potential $(\mathrm{ORP}) . \ldots \ldots \ldots \ldots \ldots$

5-1 Phylogenetic tree showing distinct MMP clades . . . . . . . . . 135

5-2 Cells in an MMP aggregate are genetically identical . . . . . . . 136 
5-3 Abundance and size of different MMP clades in salt marsh sediments

6-1 Schematic of MTB distribution in Salt Pond . . . . . . . . . . . . . 168

6-2 The use of sequencing and ISH to identify MTB . . . . . . . . . . . 169

6-3 Magnetotactic protists . . . . . . . . . . . . . . . . 170

A-1 Schematic of MTB distribution . . . . . . . . . . . . . . . . . . 189

A-2 Sample $\mathrm{E}_{h} / \mathrm{pH}$ diagram for Salt Pond . . . . . . . . . . . . . . 189

A-3 Composite of sampler and STEM images of MTB . . . . . . . . 195

C-1 Timecourse of radiocarbon incubation in Salt Pond . . . . . . . . . 208

C-2 C incorporation rates in Salt Pond . . . . . . . . . . . . . . 210 


\section{List of Tables}

2.1 Phylogenetic distribution of clones from Salt Pond chemocline . . . . 42

3.1 qPCR primers .......................... 66

3.2 Properties of $\mathrm{qPCR}$ primers . . . . . . . . . . . . . 74

3.3 CARD-FISH probes . . . . . . . . . . . . 75

3.4 Magnetosome counts for Salt Pond MTB . . . . . . . . . . . . . 79

3.5 Estimated Fe flux due to MTB . . . . . . . . . . . . . . . . 89

5.1 Oligonucleotide probes for MMP clades . . . . . . . . . . . . . . 122

5.2 Existing probes for the Desulfosarcina genus . . . . . . . . . . . . 123

B.1 qPCR sample identification codes . . . . . . . . . . . . . 201

C.1 DIC concentrations in Salt Pond on 9/24/2003 . . . . . . . . . . 209 


\section{Chapter 1}

\section{Introduction}

A research proposal requesting support to search for geomagnetically sensitive bacteria would then have been met by peer review with exactly the same degree of attention as one submitted today proposing to detect sound production by bacteria.

Richard Blakemore (1982), describing his discovery of magnetotactic bacteria in 1975

Magnetotactic bacteria (MTB) were first reported by Richard Blakemore from sediments of Eel Pond in Woods Hole, MA (Blakemore, 1975). The concept of bacteria that appear to use the earth's geomagnetic field to navigate grips the imagination, but thirty years after the intial discovery we are still far from understanding why this behavior exists. Numerous observations show that MTB contain intracellular compass needles: chains of small, highly structured crystals of magnetite $\left(\mathrm{Fe}_{3} \mathrm{O}_{4}\right)$ or greigite $\left(\mathrm{Fe}_{3} \mathrm{~S}_{4}\right)$. These membrane-bound single domain iron minerals, whose location and synthesis are genetically encoded (Komeili et al., 2005, Scheffel et al., 2005, Schüler, 2004), produce a net dipole moment sufficient to align the cell with local geomagnetic fields. Because the vertical component of the Earth's geomagnetic field points downwards into the sediments as one moves from the equator towards the poles, it has long been thought that MTB aligned with this field are able to swim faster to optimal locations in vertical chemical gradients than bacteria lacking magnetosomes 
(Spring and Bazylinski, 2000). This assumption has still never been directly tested, and is brought into question by some of the results presented in this thesis (Chapter 4; Simmons et al. (2006a)).

Despite the large number of studies on specific aspects of MTB, we are still far from understanding why bacteria are magnetotactic. Current work on MTB largely follows two main tracks, neither of which directly addresses the question. The first involves deciphering the genetic pathway responsible for magnetite biomineralization using two cultivated magnetite-producing spirilla (Komeili et al., 2005, Scheffel et al., 2005); nothing is known about the mechanism of greigite biomineralization. The second involves EM studies of magnetosome morphology in uncultivated MTB (e.g. Bazylinski et al. (1994)) and the use of magnetosomes in paleoclimactic studies (e.g. Petersen and von Dobeneck (1986), Stolz (1992)). Because fewer than ten strains of MTB have been isolated in pure culture, all of them magnetite-producers, very little is known about the metabolic capacities of MTB in nature. Most cultivated strains are freshwater MTB in the genus Magnetospirillum in the $\alpha$-Proteobacteria. The few strains of marine MTB available in culture (Bazylinski et al., 1988, Sakaguchi et al., 2002, Spring and Bazylinski, 2000) can all grow as microaerophiles, some can grow anaerobically on $\mathrm{N}_{2} \mathrm{O}$ (Bazylinski et al., 1988), and most are capable of oxidizing but not reducing inorganic sulfur compounds (Williams et al., 2006). For one cultivated strain, a non-magnetic mutant even has a higher growth rate than the wild-type (Bazylinski et al., 2004). No strains of greigite-producing MTB have been isolated in pure culture. The available information on MTB metabolism is clearly insufficient to determine the possible role of magnetosome synthesis in cellular energy generation, despite the fact that this may be a plausible hypothesis for the existence of magnetosomes. Additionally, the possible use of magnetotaxis as a navigational tool by MTB is not well understood. Not all MTB exist as gradient organisms, and under certain conditions a large proportion of MTB in natural environments appear to swim in the "wrong" direction relative to the oxygen-sulfide gradient (Simmons et al. (2006a); Simmons, unpublished data). Very little is known about the distribution and population dynamics of MTB in the environment, which might provide valuable clues about 
the relationship of magnetotaxis to metabolism and/or behavior. In short, despite thirty years of study, we do not have enough information about MTB to construct robust testable hypotheses about the selective advantage of magnetotaxis.

The population dynamics and biogeochemical impacts of MTB are as poorly understood as the rationale for magnetotaxis, and are potentially quite significant on a global scale. To date, there has been very little work on the ecology of MTB in natural systems. MTB are found exclusively in microaerobic to anoxic conditions, probably in part due to the thermodynamics of magnetite and greigite synthesis (Chapter 6). The largest populations of MTB are typically found at or below the interface between oxygenated and reduced sediments or waters (Bazylinski et al., 1995, Flies et al., 2005, Simmons et al., 2004). Magnetite-producing MTB are found in both freshwater and marine environments, while greigite-producing MTB appear to be unique to marine environments due to the requirement for reduced sulfur species in greigite synthesis. Marine MTB are abundant in salt marsh sediments and semi-anaerobic basins worldwide (Bazylinski and Frankel, 1992, Bazylinski et al., 1995, Farina et al., 1990, Mann et al., 1990, Spring and Bazylinski, 2000) and occur in deep-sea sediments (Petermann and Bleil, 1993, Stoltz et al., 1986). These qualitative observations indicate that they should be globally more abundant than freshwater MTB, but quantitative studies of their abundances and population structure have been lacking.

The apparent ubiquity and abundance of MTB in stratified marine systems suggests that they play important roles in Fe and $\mathrm{S}$ cycling in these environments. Individual cells can accumulate large amounts of iron intracellularly: up to $2.2 \%$ of dry weight in one cultivated species (Heyen and Schüler, 2003), several orders of magnitude greater than the average iron quota of heterotrophic marine bacteria (Tortell et al., 1996). Moreover, nearly all cultivated marine magnetite-producing MTB are chemolithoautotrophic S-oxidizers (Spring and Bazylinski, 2000), and many store intermediates $\left(\mathrm{S}^{0}\right)$ intracellularly for use as electron donors (Bazylinski et al., 2004, Cox et al., 2002, Spring et al., 1993). Greigite-producing MTB, which have not yet been isolated in axenic culture, sequester large amounts of $\mathrm{Fe}$ and $\mathrm{S}$ in the greigite mineral $\left(\mathrm{Fe}_{3} \mathrm{~S}_{4}\right)$ through an unknown mechanism. Based on the identification of one greigite- 
producer in the $\delta$-Proteobacteria (DeLong et al., 1993), these have been suggested to function as sulfate reducers, but there is no data to date about their metabolic function.

Because bacteria containing magnetosomes are not a phylogenetically coherent group, the only way to study MTB communities in situ is to identify and enumerate the dominant species using molecular methods. Fortunately, their magnetotactic swimming behavior can be used to easily isolate MTB from other bacteria, which facilitates identification of their $16 \mathrm{~s}$ rDNA sequences. Very little is known about the 16s rDNA diversity of marine MTB, despite a high morphological diversity visible in most natural samples of MTB. Most published MTB sequences are from magnetiteproducing freshwater cocci in the $\alpha$-Proteobacteria (Spring and Bazylinski, 2000). Prior to this thesis, only one known greigite-producing MTB was phylogenetically identified to the species level: the many-celled magnetotactic prokaryote (MMP) in the $\delta$-Proteobacteria (DeLong et al., 1993). Morphological observations alone indicate that additional groups of greigite-producers are present in stratified marine environments in the Northeast US and presumably elsewhere as well.

Past studies of MTB in the environment have focused mainly on the morphology and mineralogy of their intracellular magnetosomes while neglecting phylogenetic identification. The overall lack of phylogenetic knowledge hinders the development of molecular probes that are required for accurate enumeration for different species of MTB in the environment, and consequently, a better understanding of the population dynamics of MTB communities. A major focus of this thesis was to identify the major MTB morphotypes in a model environment (Salt Pond) and use this information to assay their population dynamics, with the goal of acheiving an integrated understanding of the biogeochemical role of MTB.

A complete description of the geobiology of MTB would necesasrily include a description of the factors controlling MTB community structure, as well as a quantitative understanding of their biogeochemical role. It requires a perspective integrating environmental geochemistry and cellular biochemistry. For an individual cell, the surrounding water chemistry might dictate whether it precipitates intracellular crystals 
of magnetite or of greigite. For populations of cells, fluctuations in the supply of reduced iron and sulfur compounds might dictate the relative abundance of one species over another. The combination of these factors determines the amount of reduced iron and sulfur exported from the environment by the activities of the community of magnetotactic bacteria. This thesis describes an attempt to apply such a perspective to studies of marine MTB in Salt Pond, an easily sampled and characterized model system.

\section{Salt Pond as model system}

Salt Pond is a small, seasonally stratified meromictic pond (15-20 ft deep) with euxinic bottom waters adjacent to Vineyard Sound in Falmouth, MA. It shows the chemical and physical characteristics typical of much larger, more inaccessible stratified basins, making it an excellent model system for the study of marine MTB. Seasonal or permanent chemical gradients between oxic surface waters and euxinic bottom waters develop in these basins due to a combination of physically restricted water exchange, thermal heating of surface waters, and high organic matter input. The Black Sea is the largest such basin in the modern ocean, with a chemocline (defined as the region where sulfide increases from 0 to $100 \mu \mathrm{M}$ ) approximately 100 meters wide (Luther III et al., 1991). The ancient oceans are now widely thought (Anbar and Knoll, 2002, Arnold et al., 2004, Rouxel et al., 2005, Shen et al., 2003) to have contained oxic surface and iron-rich, sulfidic deep waters similar to the modern Black Sea, as originally proposed by Canfield (1998). An understanding of how environmental chemistry regulates MTB populations and subsequent deposition of their intracellular minerals therefore has strong implications for paleoenvironmental studies.

Prior to this thesis, observations of high concentrations of nanophase magnetic minerals at the oxycline of Salt Pond (Bazylinski and Moskowitz, 1997) suggested the presence of MB in significant numbers. Magnetically responsive protists were also observed at the oxycline (Bazylinski et al., 2000). These initial observations indicated the presence of a diverse and active MTB community in Salt Pond and 
provided the impetus for initial studies.

A stylized chemical profile for a stratified marine basin is shown in Figure 6-1 (page 168), based on my measurements in Salt Pond (Chapters 2 and 3). Oxygen declines gradually as depth increases, due to aerobic heterotrophic consumption of organic matter. A chemocline of varying width develops where oxygen reaches zero, produced by the continuously diffusing supply of sulfide generated by sulfate reducing bacteria in anaerobic bottom waters. Maximum sulfide concentrations in the bottom waters of Salt Pond are typically around $1 \mathrm{mM}$. The width of the Salt Pond chemocline varies seasonally and depends largely on ambient temperature and degree of insolation. The largest chemocline width observed in Salt Pond was 4-5 ft (1.2 m) in mid-late August. The change in chemocline width from the onset to breakdown of stratification is shown in a series of water column profiles from summer 2003 (Appendix B, page 200). The chemocline typically appears in mid-late June and can last through October if weather conditions are favorable.

Intermediate sulfur compounds $\left(\mathrm{S}^{0}\right.$, thiosulfate, and polysulfides) are often found at the upper boundary of the sulfide zone (Jorgensen et al., 1991, Jørgensen et al., 1979, Ramsing et al., 1996), although I did not measure these directly in Salt Pond. (Appendix A [page 181] describes the initial implementation of a voltammetric electrode system to measure these species; for additional details, see Canovas (2006)). A peak in dissolved Fe(II) is present at the base of the chemocline, where sulfide concentrations are insufficient to sequester it as solid Fe-sulfides. Typical maximum concentrations of total dissolved Fe at the chemocline in Salt Pond are 3-5 $\mu \mathrm{M}$, and occasionally reach as high as $11.5 \mu \mathrm{M}$. A peak of particulate Fe is often found immediately above the chemocline, due to the upward flux of Fe(II) into oxygenated waters (Murray et al., 1995). The presence of oxidants and reductants at the chemocline, as well as a physical density gradient between warm surface waters and cool bottom waters, results in elevated bacterial counts and dense plates of anoxic phototrophs where light is available (e.g. Tonolla et al. (2000)). These appeared in Salt Pond as a purple to brown coloration of water in the chemocline region, and usually coincided with maximum abundance of magnetotactic bacteria and protists (Fig. 1-1). 
Salt Pond has been used for previous studies on chemical cycling, particularly involving DMSO (Wakeham et al., 1984, 1987), amino acids (Lee and Jørgensen, 1995), and primary production (Lohrenz et al., 1987, Taylor et al., 1983). A facultative metal-reducing anaerobe (Pantoea agglomerans) was also discovered in sediments of Salt Pond (Francis et al., 2000). The water column chemistry described in these studies is not substantially different from measurements made in this thesis. 


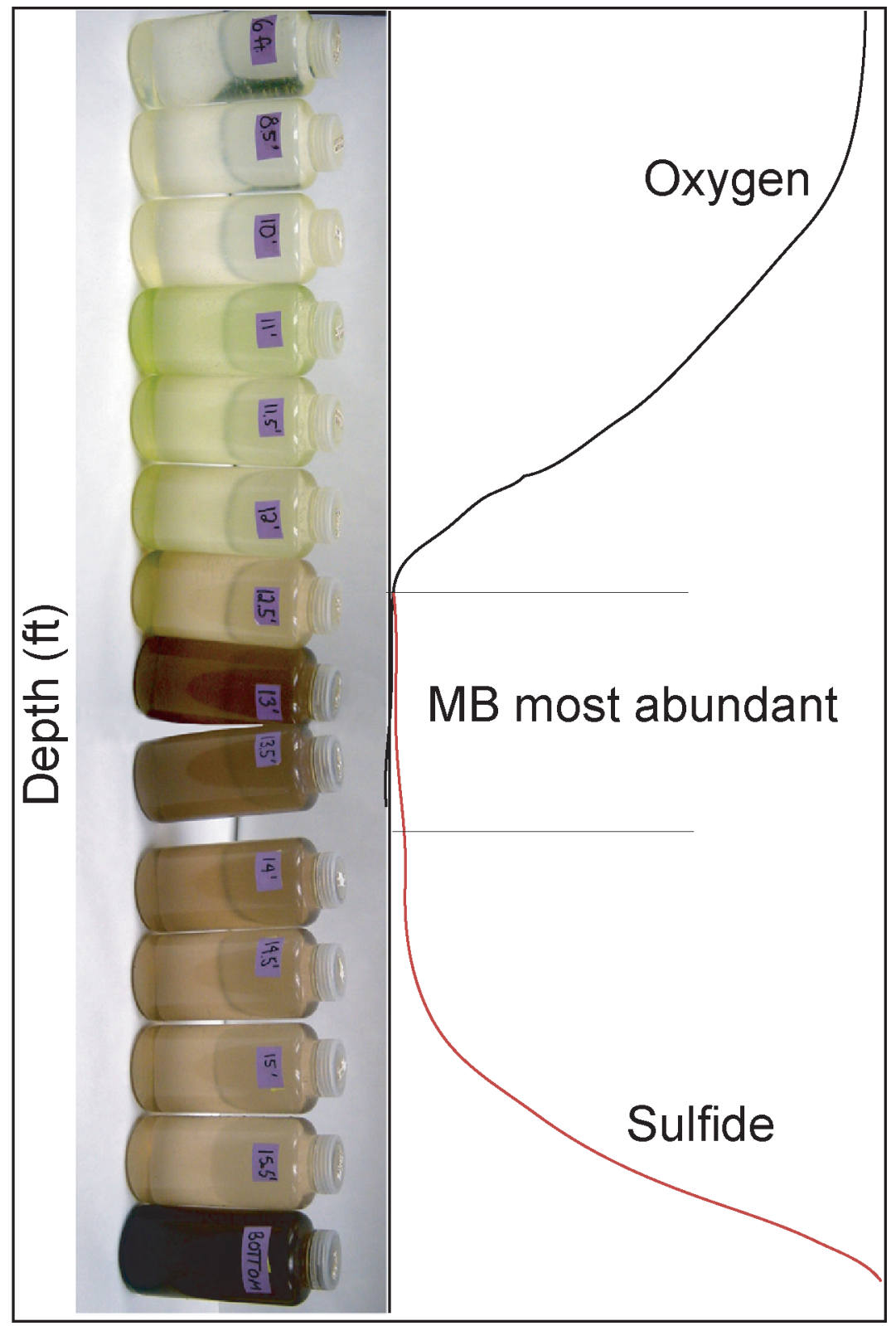

Figure 1-1: Depth profile of water samples from Salt Pond, showing the appearance of a "plate" of anaerobic photosynthetic bacteria at the oxycline. The oxycline is also the preferred habitat of MB. 


\section{Summary of chapters}

Chapter 2 presents a largely qualitative description of the magnetotactic bacterial community in Salt Pond during the summer of 2002 in conjunction with chemical measurements. The summer of 2002 was exceptionally hot and dry, which resulted in an extensive chemocline and large-scale blooms of different morphotypes of MTB. I determined the broad depth-related patterns of MTB morphotypes. Briefly, magnetiteproducing cocci occurred at the top of the chemocline, the greigite-producing "manycelled magnetotactic prokaryote" predominated in slightly sulfidic waters below the oxic-anoxic interface, and a large greigite-producing rod occurred at low abundance in the sulfidic waters of the hypolimnion. Blooms of the cocci ocurred in the early and late season when the chemocline was narrower, while the MMP predominated in mid-summer when the chemocline was widest.

I sequenced 16s rDNA from samples highly enriched in the large greigite rod, which had not been previously identified, and determined that it belonged to the $\gamma$ class of the Proteobacteria (Fig. 2-5, page 49). It is the first MTB to be identified in the $\gamma$ class. To isolate these sequences, I used a multiplex PCR technique to remove masking sequences from the Chlorobiales, which initially dominated sequence libraries. This technique also revealed extensive bacterial diversity in the chemocline (Table 2.1, page 42). DGGE analysis indicated that green sulfur bacteria (Chlorobiales) dominated in the chemocline, while unidentified Cytophaga/Bacterioides sequences dominated in the hypolimnion. DGGE proved to be an ineffective mechanism of isolating MTB sequences, however.

Chapter 2 was published in Applied and Environmental Microbiology (Simmons et al., 2004).

Chapter 3 puts the intitial observations of MTB in Salt Pond on a quantitative footing and documents the unexpected abundance in situ of the unusual "barbell"shaped MTB described in Chapter 4. I developed a quantitative PCR assay for four major groups of MTB in Salt Pond and applied it to samples collected in conjunction with chemical measurements during the summer of 2003. The development of the 
qPCR assay required the phylogenetic identification of two of the dominant MTB groups observed in Salt Pond: the greigite-producing rod and the barbell (Chapter 4). I used sequencing and catalyzed reporter deposition-fluorescent in situ hybridization (CARD-FISH) to identify these organisms. The greigite rod is distantly related (about $10 \%$ sequence divergence) to Thiomicrospira pelophila in the $\gamma$-Proteobacteria (Fig. 3-3, page 93), while the barbell is distantly related to various Desulforhopalus species in the family Desulfobulbaceae of the $\delta$-Proteobacteria (Figure 4-2, page 112).

The results from estimated cell counts obtained with qPCR broadly supported the findings presented in Chapter 1, but also revealed new patterns. Foremost among these was the dominance of the barbell MB in the late season, where it comprised $1-10 \%$ of all eubacteria. I also obtained higher resolution depth profiles which showed the cocci peaking in abundance slightly higher in the water column than the barbell (Fig. 3-6, page 94). The large greigite-producing rod occurred at low cell numbers

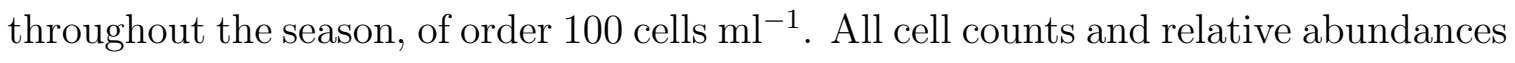
obtained with quantitative PCR are shown in appendix B (page 200). On the whole, the summer of 2003 was cooler and wetter than 2002 and the extensive blooms of MMP and cocci observed in 2002 were not present.

I also present calculations based on measurements of cellular magnetosome content in each MTB morphotype which suggest that MTB could be significant contributors to the flux of reduced Fe out of stratified marine environments (Table 3.5, page 89).

Chapter 3 was submitted to Applied and Environmental Microbiology in March 2006.

Chapter 4 describes my investigation of an unexpected phenomenon: the presence of MTB with south polarity ("south-seeking") in the northern hemisphere. Previously, it was thought that all MTB in the northern hemisphere swam to geomagnetic north when oxygen levels were higher than optimal (north polarity), because that would lead them downwards into anoxic waters or sediments. South polarity means that MTB swim towards geomagnetic south when oxygen levels are higher than optimal, a behavior that does not make sense in the context of finding an optimal position 
in a chemical gradient. I show that the newly described "barbell" MB, which I also identify in this paper, displays south polarity which appears to co-vary with environmental oxidation-reduction potential (ORP).

I first observed the barbell in high numbers in September 2003, when the population was approximately evenly divided between cells with north polarity and cells with south polarity. Katrina Edwards and Dennis Bazylinski observed extraordinarily high numbers of the barbell on July 2, 2004, when the population was comprised almost entirely of cells with south polarity (Fig. 4-1, page 111). As it later turned out, this skewed polarity distribution is unusual. My observations of the barbell in Salt Pond in 2005, when I deployed a custom-designed and built sampler (Appendix 1) in conjunction with a YSI 600QS sonde for measuring ORP, indicated more complex regulation of polarity.

Chapter 4 was published in Science (Simmons et al., 2006b).

Chapter 5 describes an unexpectedly high level of 16s rDNA diversity in populations of the many-celled magnetotactic prokaryote (MMP), an unusual packetforming greigite-producing organism abundant in slightly sulfidic sediments of the Little Sippewissett salt marsh. The MMP, previously thought to be a single species, in fact contains at least five separate clades separated by $5-10 \%$ sequence divergence in their 16s rDNA (Fig. 5-1, page 135). Rarefaction analysis and other diversity estimators show that I fully sampled diversity at that divergence level. I designed fluorescently labeled oligonucleotide probes corresponding to three of these clades, including the most abundant clone group (Table 5.1, page 122), and applied them to purified MMP collected from the marsh. The abundance of each group did not clearly correlate with sampling date, indicating that more subtle factors determine their relative abundances. It is likely that each group utilizes a slightly different carbon source and/or redox potential for optimum growth. I also show that each aggregate consists of cells that are genetically identical with respect to their 16s rDNA genes (Fig. 5-2, page 136). 
Chapter 6 is a comprehensive overview of the geobiology of magnetotactic bacteria, which I define as an integration of population dynamics and environmental geochemistry. I present an overview of molecular methods that can be used to study the ecology of MTB, including those described in this thesis. I also describe thermodynamic considerations regulating the growth and distribution of MTB, as well as the possible influence of MTB on reduced Fe cycling in stratified environments.

Chapter 6 will be included in a forthcoming book, Magnetoreception and Magnetosomes in Bacteria, edited by Dr. Dirk Schüler.

Appendix A describes the development and application of a new sampler for accurately sampling from stratified bacterial populations in Salt Pond. I present my funded proposal to the WHOI Ocean Venture fund and provide a brief overview of initial results.

Appendix C describes in situ carbon fixation experiments that I carried out in Salt Pond in fall 2003, with the goal of determining rates of light and dark carbon incorporation in the chemocline.

\section{Bibliography}

Anbar A, Knoll A (2002) Proterozoic ocean chemistry and evolution: a bioinorganic bridge? Science 297: 1137-1142.

Arnold GL, Anbar AD, Barling J, Lyons TW (2004) Molybdenum Isotope Evidence for Widespread Anoxia in Mid-Proterozoic Oceans. Science 304: 87-90.

Bazylinski DA, Dean AJ, Williams TJ, Long LK, Middleton SL, et al. (2004) Chemolithoautotrophy in the marine, magnetotactic bacterial strains MV-1 and MV-2. Archives of Microbiology 182: 373-387.

Bazylinski DA, Frankel RB (1992) Production of iron sulfide minerals by magneto- 
tactic bacteria in sulfidic environments. In: Skinner HC, Fitzpatrick RW, editors, Biomineralization Processes, Iron, Manganese, vol. 21, pp. 147-159, Catena.

Bazylinski DA, Frankel RB, Heywood BR, Mann S, King JW, et al. (1995) Controlled biomineralization of magnetite $\left(\mathrm{Fe}_{3} \mathrm{O}_{4}\right)$ and gregite $\left(\mathrm{Fe}_{3} \mathrm{~S}_{4}\right)$ in a magnetotactic bacterium. Appl Environ Microbiol 61: 3232-3239.

Bazylinski DA, Frankel RB, Jannasch HW (1988) Anaerobic magnetite production by a marine magnetotactic bacterium. Nature 334: 518-519.

Bazylinski DA, Garratt-Reed A, Frankel RB (1994) Electron-microscopic studies of magnetosomes in magnetotactic bacteria. Microscopy Res Tech 27: 389-401.

Bazylinski DA, Moskowitz BM (1997) Microbial biomineralization of magnetic iron minerals: microbiology, magnetism, and environmental significance. In: Banfield J, Nealson K, editors, Geomicrobiology: Interactions between Microbes and Minerals, vol. 35 of Reviews in Mineralogy, pp. 181-224, Washington, D.C.: Mineralogical Society of America.

Bazylinski DA, Schlezinger DR, Howes BH, Frankel RB, Epstein SS (2000) Occurrence and distribution of diverse populations of magnetic protists in a chemically stratified coastal salt pond. Chem Geol 169: 319-328.

Blakemore RP (1975) Magnetotactic bacteria. Science 190: 377-379.

Blakemore RP (1982) Magnetotactic bacteria. Ann Rev Microbiol 36: 217-238.

Canfield DE (1998) A new model for Proterozoic ocean chemistry. Nature 396: 450453.

Canovas P (2006) The redox and iron-sulfide geochemistry of Salt Pond and the thermodynamic constraints on native marine magnetotactic bacteria. M.S. Thesis, Massachusetts Institute of Technology- Woods Hole Oceanographic Institution Joint Program. 
Cox BL, Popa R, Bazylinski DA, Lanoil B, Douglas S, et al. (2002) Organization and elemental analysis of $\mathrm{P}-, \mathrm{S}-$, and Fe-rich inclusions in a population of freshwater magnetococci. Geomicrobiology Journal 19: 387-406.

DeLong EF, Frankel RB, Bazylinski DA (1993) Multiple evolutionary origins of magnetotaxis in bacteria. Science 259: 803-806.

Farina M, Esquivel D, de Barros HL (1990) Magnetic iron-sulphur crystals from a magnetotactic microorganism. Nature 383: 256-258.

Flies CB, Jonkers HM, de Beer D, Bosselmann K, Bottcher ME, et al. (2005) Diversity and vertical distribution of magnetotactic bacteria along chemical gradients in freshwater microcosms. FEMS Microbiology Ecology 52: 185-195.

Francis CA, Obraztsova AY, Tebo BM (2000) Dissimilatory Metal Reduction by the Facultative Anaerobe Pantoea agglomerans SP1. Appl Environ Microbiol 66: 543548.

Heyen U, Schüler D (2003) Growth and magnetosome formation by microaerophilic Magnetospirillum strains in an oxygen-controlled fermentor. Applied Microbiology and Biotechnology 61: 536-544.

Jorgensen BB, Fossing H, Wirsen CO, Jannasch HW (1991) Sulfide oxidation in the Black Sea chemocline. Deep-Sea Research Part A: Oceanographic Research Papers 38: S1083-S1103.

Jørgensen BB, Kuenen JG, Cohen Y (1979) Microbial transformations of sulphur compounds in a stratified lake (Solar Lake, Sinai). Limnol Oceanogr 24: 799-822.

Komeili A, Li Z, Newman DK, Jensen GJ (2005) Magnetosomes Are Cell Membrane Invaginations Organized by the Actin-Like Protein MamK. Science 311: 242-245.

Lee C, Jørgensen N (1995) Seasonal cycling of putrescine and amino acids in relation to biological production in a stratified coastal salt pond. Biogeochemistry 29: 131157. 
Lohrenz SE, Taylor CD, Howes BL (1987) Primary production of protein: II. Algal protein metabolism and its relation to particulate organic matter composition in the surface mixed layer. Mar Ecol Prog Ser 40: 175-183.

Luther III G, Church T, Powell D (1991) Sulfur speciation and sulfide oxidation in the water column of the Black Sea. Deep-Sea Res 38: S1121-S1137.

Mann S, Sparks NHC, Frankel RB, Bazylinski DA, Jannasch HW (1990) Biomineralization of ferrimagnetic greigite $\left(\mathrm{Fe}_{3} \mathrm{~S}_{4}\right)$ and iron pyrite $\left(\mathrm{FeS}_{2}\right)$ in a magnetotactic bacterium. Nature 343: 258-261.

Murray J, Codispoti L, Friedrich G (1995) Oxidation-reduction environments: the suboxic zone in the Black Sea. In: et al Huang, C, editor, Aquatic Chemistry, vol. 244 of ACS Advances in Chemistry, pp. 157-176, American Chemical Society.

Petermann H, Bleil U (1993) Detection of live magnetotactic bacteria in deep-sea sediments. Earth Planet Sci Lett 117: 223-228.

Petersen N, von Dobeneck T (1986) Fossil bacterial magnetite in deep-sea sediments from the South Atlantic Ocean. Nature 320: 611-615.

Ramsing N, Fossing H, Ferdelman T, Andersen F, Thamdrup B (1996) Distribution of bacterial populations in a stratified fjord (Mariager Fjord, Denmark) quantified by in situ hybridization and related to chemical gradients in the water column [published erratum appears in Appl Environ Microbiol 1996 Oct;62(10):3914]. Appl Environ Microbiol 62: 1391-1404.

Rouxel OJ, Bekker A, Edwards KJ (2005) Iron Isotope Constraints on the Archean and Paleoproterozoic Ocean Redox State. Science 307: 1088-1091.

Sakaguchi T, Arakaki A, Matsunaga T (2002) Desulfovibrio magneticus sp. nov., a novel sulfate-reducing bacterium that produces intracellular single-domain-sized magnetite particles. Intl J Syst Evol Microbiol 52: 215-221. 
Scheffel A, Gruska M, Faivre D, Linaroudis A, Plitzko JM, et al. (2005) An acidic protein aligns magnetosomes along a filamentous structure in magnetotactic bacteria. Nature 440: 110-114.

Schüler D (2004) Molecular analysis of a subcellular compartment: the magnetosome membrane in Magnetospirillum gryphiswaldense. Archives of Microbiology 181: 17.

Shen Y, Knoll AH, Walter MR (2003) Evidence for low sulphate and anoxia in a mid-Proterozoic marine basin. Nature 423: 632-635.

Simmons S, Bazylinski DA, Edwards KJ (2006a) Population dynamics of marine magnetotactic bacteria in a meromictic salt pond described with quantitative PCR. Submitted .

Simmons SL, Bazylinski DA, Edwards KJ (2006b) South-seeking magnetotactic bacteria in the Northern Hemisphere. Science 311: 371-374.

Simmons SL, Sievert SM, Frankel RB, Bazylinski DA, Edwards KJ (2004) Spatiotemporal Distribution of Marine Magnetotactic Bacteria in a Seasonally Stratified Coastal Salt Pond. Appl Environ Microbiol 70: 6230-6239.

Spring S, Amann R, Ludwig W, Schleifer K, van Gemerden H, et al. (1993) Dominating role of an unusual magnetotactic bacterium in the microaerobic zone of a freshwater sediment. Appl Environ Microbiol 59: 2397-2403.

Spring S, Bazylinski DA (2000) Magnetotactic Bacteria. In: Dworkin M, editor, The Prokaryotes: An Evolving Electronic Resource for the Microbiological Community, online release 3.4, Springer Verlag.

Stoltz J, Chang SBR, Kirschvink J (1986) Magnetotactic bacteria and single-domain magnetite in hemipelagic sediments. Nature 321: 849-851.

Stolz JF (1992) Magnetotactic bacteria: Biomineralization, ecology, sediment magnetism, environmental indicator. In: Skinner HC, Fitzpatrick RW, editors, Biomin- 
eralization Processes of Iron and Manganese: Modern and Ancient Environments, pp. 133-145, Cremlingen-Destedt: Catena Verlag.

Taylor C, Molongoski J, Lohrenz S (1983) Instrumentation for the measurement of phytoplankton production. Limnol Oceanogr 28: 781-787.

Tonolla M, Demarta A, Peduzzi S, Hahn D, Peduzzi R (2000) In situ analysis of sulfate-reducing bacteria related to Desulfocapsa thiozymogenes in the chemocline of meromictic Lake Cadagno (Switzerland). Appl Environ Microbiol 66: 820-824.

Tortell PD, Maldonado MT, Price NM (1996) The role of heterotrophic bacteria in iron-limited ocean ecosystems. Nature 383: 330-332.

Wakeham SG, Howes BL, Dacey JWH (1984) Dimethyl sulphide in a stratified coastal salt pond. Nature 310: 770-772.

Wakeham SG, Howes BL, Dacey JWH, Schwarzenbach RP, Zeyer J (1987) Biogeochemistry of dimethylsulfide in a seasonally stratified coastal salt pond. Geochim Cosmochim Acta 51: 1675-1684.

Williams T, Zhang C, JH S, Bazylinski DA (2006) Evidence for autotrophy via the reverse tricarboxylic acid cycle in the marine magnetotactic coccus strain MC-1. Appl Environ Microbiol 72: 1322-1329. 


\title{
Chapter 2
}

\section{Spatio-temporal distribution of}

\section{marine magnetotactic bacteria in a seasonally stratified coastal salt}

\section{pond}

Published as:

Sheri L Simmons, S.M. Sievert, R. B. Frankel, D.A. Bazylinski, K.J. Edwards. 2004. Spatio-temporal distribution of marine magnetotactic bacteria in a seasonally stratified coastal salt pond. Applied and Environmental Microbiology 70(10): 62306239

\begin{abstract}
The occurrence and distribution of magnetotactic bacteria (MB) were studied as a function of the physical and chemical conditions in meromictic Salt Pond, Falmouth, MA, USA throughout summer 2002. Three dominant MB morphotypes were observed to occur within the chemocline. Small microaerophilic magnetite producing cocci were present at the top of the chemocline, while a greigite-producing packetforming bacterium occurred at the base of the chemocline. The distributions of these groups displayed sharp changes in abundance over small length scales within the water column, as well as strong seasonal fluctuations in population abundances. We identified a novel, greigite-producing rod in the sulfidic hypolimnion that is present
\end{abstract}


in relatively constant abundance over the course of the season. This rod is the first MB that appears to belong to the $\gamma$-Proteobacteria, which may suggest an iron rather than sulfur-based respiratory metabolism. Its distribution and phylogenetic identity suggest that an alternative model for the ecological and physiological role of magnetotaxis is needed for greigite-producing MB.

\section{$2.1 \quad$ Introduction}

Magnetotactic bacteria (MB) are motile Gram-negative bacteria whose directional swimming behavior is affected by the Earth's geomagnetic and external magnetic fields. They contain highly ordered intracellular chains of magnetic iron minerals, either magnetite $\left(\mathrm{Fe}_{3} \mathrm{O}_{4}\right)$, greigite $\left(\mathrm{Fe}_{3} \mathrm{~S}_{4}\right)$ (32), or in one case, both (4). Magnetite MB (MMB) are found in both freshwater and marine environments, while greigite MB (GMB) appear to be unique to marine systems. Both MMB and GMB are present in salt marsh sediments, stratified salt ponds, estuarine basins in the eastern coastal US $(2-4,31,32,51)$, coastal marshes along the California coast (E.F. DeLong, pers comm.), and in other similar habitats worldwide, as well as deep-sea sediments (42). This widespread distribution of marine MB suggests that they are globally more abundant than freshwater MB.

All known MB share certain characteristics: motility by means of flagella, negative tactic responses to atmospheric concentrations of oxygen, optimal growth under microaerophilic or anaerobic conditions, and a respiratory metabolism (51). MB are typically found at or below the oxycline in sediments and water columns, and can reach significant population densities: the freshwater MMB "Candidatus Magnetotacticum bavaricum" reached $7 \times 10^{5}$ cells per $\mathrm{cm}^{3}$ at the oxycline in freshwater sediments (48). Many, if not most groups of MB that have been observed in the environment have not been grown in pure culture in the laboratory. Fewer than ten strains are available in pure culture, and most of those are magnetite-producing $\alpha$ Proteobacteria of the genus Magnetospirillum from freshwater environments. A few strains of marine MMB are available in culture $(5,45,51)$. These strains are all microaerophiles when growing on $\mathrm{O}_{2}$, and some can grow anaerobically on $\mathrm{N}_{2} \mathrm{O}(5)$. 
All are capable of oxidizing but not reducing inorganic sulfur compounds, with the exception of the freshwater sulfate-reducing rod Desulfovibrio magneticus (45). GMB have not yet been isolated in axenic culture.

Magnetotaxis occurs among several distinct phylogenetic lineages. Molecular analysis has shown that freshwater MMB are generally affiliated with the $\alpha$-Proteobacteria (48-50). Exceptions are D. magneticus in the $\delta$-Proteobacteria (21) and the Candidatus M. bavaricum in the Nitrospira phylum (52). The phylogeny of GMB is unknown, with the exception of one uncultivated packet-forming GMB called the "many-celled magnetotactic prokaryote" (MMP), which has been identified as a $\delta$-Proteobacterium using fluorescent in situ hybridization (FISH) (12).

The ecology of GMB remains almost completely uncharacterized. Although several studies have examined mechanisms of biomineralization in $\operatorname{GMB}(17,43)$, little information is available concerning their distribution, population structure, or geochemical significance. The composition of greigite $\left(\mathrm{Fe}_{3} \mathrm{~S}_{4}\right)$ and the abundance of magnetosomes in GMB suggest that they may play a significant role in marine iron and sulfur cycling in coastal regimes. GMB can accumulate picograms of solid Fe and $\mathrm{S}$ per cell, transforming dissolved complexes into reactive minerals. As cells die and lyse, these minerals may accumulate in the sediment and provide reactive surfaces for further microbial (47) and chemical transformations leading eventually to pyrite formation. Pyrite formation is the endpoint of the reductive portion of the sulfur cycle, suggesting a biogeochemically important role for GMB. The energy-yielding reactions used by GMB are also unknown. Phylogenetic affiliation of the MMP with the $\delta$-Proteobacteria (12) suggests a sulfate or iron-reducing metabolism. Greigite is metastable under the reducing conditions favored by MMP and should transform to pyrite (8), indicating that GMB must actively control the intracellular redox environment.

We have conducted studies on the ecology and biogeochemical role of GMB in Salt Pond, a small seasonally stratified (monomictic) coastal salt pond in Falmouth, MA (Fig. 2-1). Small saline lakes provide compact physiochemical gradients ideal for the study of microbial distributions as a function of redox chemistry. Studies 
on permanently and seasonally stratified lakes have shown characteristic changes in microbial communities across the interface between euxinic bottom waters and oxic surface waters $(10,39,40,44,54)$. The oxycline (metalimnion) of these stratified lakes typically shows elevated cell counts, peaks in dissolved and particulate iron, and large populations of anoxic phototrophs where light is available (e.g.(54)). The basic water column chemistry of Salt Pond is similar to that of larger enclosed marine systems, such as the Pettaquamscutt Estuary, RI, US (37), the Black Sea (35), and Framvaren Fjord, Norway (60). It has been used for previous studies on chemical cycling $(25,27$, $53,58)$, and is both accessible and easy to sample. The rapid changes in water column chemistry with the onset, persistence, and breakdown of water column stratification offered the opportunity to examine MB populations in relation to iron, sulfide, and oxygen levels.

Previous measurements of nanophase magnetic minerals in Salt Pond showed a peak at the oxycline (6), suggesting the presence of MB in significant numbers. $\mathrm{Nu}-$ merous unpublished observations by co-authors of this paper indicated the presence of a significant $\mathrm{MB}$ community comprised of at least four different morphotypes at and slightly below the metalimnion. Magnetically responsive protists were also observed at the oxycline (7). MB appeared to be associated with peaks in dissolved and particulate iron also present at the oxycline. Peaks of particulate Fe(III) are often observed immediately above marine chemoclines due to the upward flux of $\mathrm{Fe}(\mathrm{II})$ into oxygenated waters $(35,60)$.

Here we report the results of studies aimed at (1) describing the distribution of different MB morphotypes and phylotypes with respect to physical and chemical environmental conditions, and (2) determining how marine MB impact chemical cycling in this stratified water column. This report describes changes in marine MB population structure and water chemistry in Salt Pond during summer 2002. 


\subsection{Methods}

\section{Site description}

Salt Pond is a shallow, brackish, seasonally stratified kettle hole pond in Falmouth, MA (Fig 2-1). It is approximately 4.6-5.8 $\mathrm{m}$ deep with a surface area of $0.29 \mathrm{~km}^{2}$ (53), and is surrounded by $0.02 \mathrm{~km}^{2}$ of salt marsh (9). The pond has a permanent tidal exchange with Vineyard Sound, and freshwater input comes from runoff, rainwater, and groundwater. Average daily tidal amplitude is approximately $0.6 \mathrm{~m}$ (http://co-ops.nos.noaa.gov/data_res.html). The pond becomes stratified beginning in early summer and develops sulfidic bottom waters. As of mid-October thermal stratification begins to break down. The epilimnion of Salt Pond is highly productive: Wakeham et al (58) measured chlorophyll a concentrations of $70 \mathrm{mg} \mathrm{L}-1$ in mid-August.

\section{Physical and chemical sampling}

Salt Pond was sampled from a small aluminum rowboat. Salinity, temperature, and oxygen data were measured using an YSI 85 profiler (Yellow Springs Inc., Yellow Springs, OH, USA) in the field to determine the location of the oxycline. The YSI electrode was fixed to the modified intake of a Geopump peristaltic pump (Geotech Environmental Equipment, Inc., Denver, CO, USA), allowing simultaneous water sampling and profiling. Water samples were taken every $0.3 \mathrm{~m}$ above and below the oxycline, and every $0.15 \mathrm{~m}$ within the oxycline. Water was collected in autoclaved 1-liter Nalgene bottles. The pH was measured on board using an Orion 250A field pH meter (Orion Research Inc., Beverly, MA, USA). Water for iron and sulfide analyses was withdrawn directly from the pump tubing with $1 \mathrm{ml}$ syringes.

\section{Chemical analysis}

Iron was measured using the FerroZine method as outlined in (57). Sterile $1.5 \mathrm{ml}$ microcentrifuge tubes were pre-prepared with $100 \mu \mathrm{l}$ of $10 \mathrm{mM}$ FerroZine (FZ) in 
$100 \mathrm{mM}$ ammonium acetate. $500 \mu \mathrm{l}$ unfiltered water was placed in each tube. Tubes were stored in the dark until analysis immediately on return to the lab, 1-2 $\mathrm{h}$ after collection. Initial absorbance (A1) at $562 \mathrm{~nm}$ was measured on a UV-Vis spectrophotometer, followed by a 10 min reduction step with $150 \mu \mathrm{l} 1.4 \mathrm{M}$ hydroxylamine $\mathrm{HCl}$ in $2 \mathrm{M} \mathrm{HCl} .50 \mu \mathrm{l}$ of $10 \mathrm{M}$ ammonium acetate buffer at pH 9.5 was added, and final absorbance (A2) was measured. Standard curves were constructed from a 200 ppm ferrous iron standard in sulfuric acid (LabChem Inc., Pittsburgh, PA, USA) diluted in $2 \% \mathrm{NaCl}$ solution. A1 corresponds to [Fe(II)], and A2 to [Fe(II)+Fe(III)]. Fe(III) was calculated by difference.

Sulfide was analyzed according to the Cline method (11). In the field, $0.5 \mathrm{ml}$ water was placed into microcentrifuge tubes containing $1 \mathrm{ml} 2.6 \%$ zinc acetate solution. On return to the lab approximately 1-2 hrs later, $200 \mu \mathrm{l}$ N,N-dimethyl-pphenylenediamine sulfate (DPDS, $0.3 \%$ in $5.5 \mathrm{~N} \mathrm{HCl}$ ) and $200 \mu \mathrm{l}$ ferric chloride $(0.0115 \mathrm{M}$ in $0.6 \mathrm{~N} \mathrm{HCl})$ were added and the sample incubated for $30 \mathrm{~min}$. Absorbance was measured at $665 \mathrm{~nm}$. Standard curves were constructed using dilutions of a $100 \mathrm{mM}$ sodium sulfide solution fixed in $2.6 \%$ zinc acetate.

\section{Sample handling}

Within $2 \mathrm{~h}$ of collection, bulk water samples were withdrawn from the bottles for fixation and DNA extraction. MB were then concentrated by placing the south pole of a bar magnet against the side of the bottle. After $1 \mathrm{~h}, \mathrm{MB}$ were harvested next to the magnet with a pasteur pipette. Both bulk water and MB enriched samples for DNA extraction were concentrated by centrifugation by spinning at $10,000 \mathrm{x} g$ for 15 min. The supernatant was decanted, and the resulting pellet stored at -80C. Samples for cell counting were fixed in $4 \%$ paraformaldeyde overnight, then filtered onto $25 \mathrm{~mm}$ black Millipore Isopore polycarbonate filters (pore size $0.2 \mu \mathrm{M}$ ). Filters were rinsed with a sterile $2 \% \mathrm{NaCl}$ solution, air-dried, and stored in parafilm-sealed petri dishes at $-20{ }^{\circ} \mathrm{C}$ until further analysis. 


\section{Microscopy}

A $100 \mu \mathrm{l}$ drop from the enrichment was placed on a glass coverslip, and the south pole of a bar magnet was placed near the drop. MB accumulated at the edge of the drop closest to the bar magnet, and were examined at 40x magnification on a Zeiss Axiovert 100 inverted microscope with differential interference contrast light microscopy for evaluation of MB morphotypes present. In some cases MB were further enriched by using a $10 \mu \mathrm{l}$ glass capillary tube to remove liquid from the edge of a drop where high densities of MB had accumulated ("capillary samples"). These samples were frozen at $-20^{\circ} \mathrm{C}$ immediately.

\section{Microbiological and molecular analysis}

Based on initial chemical and microbiological data, three representative time-points (June 26, August 2, and October 9) were chosen for further analysis. To obtain total cell counts, filters were stained with a $1 \mathrm{~g} \mathrm{ml}^{-1}$ DAPI solution for 3 min, rinsed in a $2 \% \mathrm{NaCl}$ solution, and examined with an inverted Zeiss Axiovert 100 microscope equipped with a mercury arc lamp and appropriate filters. Seven fields were counted per filter based on statistical recommendations in (22). The mean and standard error of total cell numbers were calculated for each filter.

DNA from magnetically enriched and bulk water samples was extracted using a standard CTAB/isopropanol precipitation protocol (1). For denaturing gradient gel electrophoresis (DGGE), initial PCR amplification of the 16S rRNA gene was carried out using the 341F-GC clamp and 907R primer pair using a touchdown protocol (46). After quantification on an agarose gel using a low molecular weight mass standard (Invitrogen), amplification products were run on a $20-70 \%$ denaturing gradient gel for $18 \mathrm{~h}$ at $100 \mathrm{~V}$ (Bio-Rad Dcode system). Magnetically enriched and bulk water samples from the same depth were run in adjacent lanes. Gels were stained in a 1:10,000 solution of SybrGreen I (Molecular Probes) in 1x TAE for $1 \mathrm{~h}$ and visualized on a transilluminator system. Individual bands of interest were excised.

DNA was eluted by overnight incubation of the acrylamide band in sterile MilliQ 
water at $4^{\circ} \mathrm{C}$. PCR was carried out on the band DNA using the $341 \mathrm{~F}$ (non-GC) and 907R primer pair. The protocol used (46) was: (1) initial denaturation for 5 min at $94^{\circ} \mathrm{C},(2) 25$ cycles of $94^{\circ} \mathrm{C} \quad(1 \mathrm{~min}), 55^{\circ} \mathrm{C} \quad(1 \mathrm{~min})$, and $72^{\circ} \mathrm{C} \quad(3 \mathrm{~min})$, and (3) extension for $7 \mathrm{~min}$ at $72^{\circ} \mathrm{C}$. Products were cloned into the pCR2.1-TOPO vector (Invitrogen). Minipreps were performed using the Wizard SV kit (Promega), and plasmids were quantified on an agarose gel using mass ladders (Invitrogen). Alkaline lysis minipreps were also done in 96 well format on a RevPrep Orbit at the Josephine Bay Paul Center, Marine Biological Laboratory (MBL), Woods Hole, MA. Sequencing reactions were run using 1/8x reactions from the ABI v3.1 BigDye kit (Applied Biosystems) on an ABI 3730xl capillary sequencer, also at the MBL.

Clone libraries were also constructed directly from four capillary samples showing high MB levels. $1 \mu \mathrm{l}$ of sample was used directly in PCR. These samples were amplified by PCR with the bacterial primers 341F (non-GC) and 1492R. The PCR protocol used was: (1) initial denaturation at $94^{\circ} \mathrm{C}$ for 2 min, (2) 25 cycles of $94^{\circ} \mathrm{C}$ $(1 \mathrm{~min}), 47^{\circ} \mathrm{C} \quad(1 \mathrm{~min})$, and $72^{\circ} \mathrm{C} \quad(3 \mathrm{~min})$, followed by $(3)$ extension for $7 \mathrm{~min}$ at $72^{\circ} \mathrm{C}$. The products were cloned and sequenced as described above.

PCR reactions on the capillary samples were also performed using a multiplex approach with a reverse primer specific for green sulfur bacteria (GSB) and eubacterial primers $(314 \mathrm{~F}, 1492 \mathrm{R})$. These reactions were used to enrich for non-Chlorobium sequences (see below). The reaction mixture contained primers $8 \mathrm{~F}$ or $341 \mathrm{~F}$ at $0.5 \mu \mathrm{M}$, $1492 \mathrm{R}$ at $0.25 \mu \mathrm{M}$, and 1144R (GSB-specific,(1)) at $0.25 \mu \mathrm{M}$. Optimal annealing temperature for production of two bands was determined using the temperature gradient feature of the BioRad iCycler. The PCR protocol used was 30 cycles of $94^{\circ} \mathrm{C} \quad(1$ $\min ), 49^{\circ} \mathrm{C}(1 \mathrm{~min})$, and $72^{\circ} \mathrm{C}(3 \mathrm{~min})$, followed by extension for $7 \mathrm{~min}$ at $72^{\circ} \mathrm{C}$. The amplification produced two bands of different length, one from the $314 \mathrm{~F}$ and $1144 \mathrm{R}$ primer pair (specific to GSB), and the other from the 314F-1492R set (all Bacteria). Bands corresponding to $8 \mathrm{~F}-1492 \mathrm{R}$ or $341 \mathrm{~F}-1492 \mathrm{R}$ sequences were excised from $1 \%$ agarose gels in TAE and DNA was isolated using Qiagen gel purification kits. The products were cloned and sequenced as described above. Several samples of interest were sequenced from both directions using the universal M13F and M13R primers. 
Chromatograms were edited and contigs assembled using the Staden software package (http://www.mrc-lmb.cam.ac.uk/pubseq/). Sequences were imported into a pre-existing 16S rRNA database provided with ARB (30) and aligned using the ARB editor. Bootstrap parsimony and maximum likelihood trees were constructed using the Phylip package (http://evolution.genetics.washington.edu/phylip.html).

Fluorescent in situ hybridization (FISH) was carried out on 10-well slides coated with a gelatin solution $(0.075 \%$ gelatin, $0.01 \%$ chromium potassium sulfate dodecahydrate). $5 \mu \mathrm{l}$ of paraformaldehyde-fixed sample stored in 1:1 PBS:EtOH was spotted into each well, air-dried, and dehydrated in an ethanol series $(50 \%, 80 \%$, and 98\%, 3 min each). A dual stain was performed using probe GAM42A (Cy3) targeting 23S RNA (33) and the nonsense probe NON338 (flourescein)(59) as a control for nonspecific uptake of labelled probe. Fixed cells of Vibrio parahemolyticus were used as a positive control for probe GAM42A and cells of the $\alpha$-Proteobacterium MV-1 as a negative control. Hybridization with $35 \%$ formamide and a subsequent wash were carried out following protocols described in (41). Images were captured from an inverted Zeiss Axiovert 100 with a digital camera and processed in Adobe Photoshop.

\section{Electron microscopy}

Transmission electron microscopy (TEM) was carried out at the MBL Central Microscope Facility with a Zeiss 10CA microscope operating at 80kV. Selected area electron diffraction (SAED) measurements were carried out at the MIT Center for Materials Research with a JEOL Model 200CX microscope operating at 200kV. The microscope camera length was calibrated with a sample of thallous chloride.

\section{Nucleotide sequence accession numbers}

Sequences obtained in this study were deposited under the following accession numbers: AY587877-AY587881 (putative magnetic cocci cluster), AY587194-AY587198 (Thiomicrospira-related cluster), AY587199-AY587207 (Stentrophomonas-related cluster), and AY589474- AY589488 (individual clones, shown in Fig. 2-6). 


\subsection{Results}

\section{Water chemistry}

Figure 2 shows the compiled data for water column chemistry in June, August, and October. Density profiles through the water column show that stratification was most pronounced in June and August. The chemocline of Salt Pond occurred between 1.5 and 3.4 meters on all sampling dates. The chemocline reached $0.6 \mathrm{~m}$ wide, and particulate iron was highest at the base of the oxycline, where MB were most abundant. Total precipitation was $7.8 \mathrm{~cm}$ in June, with freshwater input likely resulting in low density and high oxygen in the epilimnion. July was hot and dry, with solar radiation $5 \%$ above average and total precipitation only $1.7 \mathrm{~cm}$, the lowest in 36 years (http://www.whoi.edu/climate/2002). Solar heating, low freshwater input, and biological oxygen consumption likely resulted in the warm, dense, low oxygen epilimnion observed in early August. The chemocline was widest on August 2nd, when oxygen and sulfide were below detection limits between 1.5 and $2.4 \mathrm{~m}$. A warm, less saline epilimnion overlay a cool, saline hypolimnion on all sampling dates. The $\mathrm{pH}$ declined from highs of 8.5-9 in the oxic epilimnion to approximately 7 in the sulfidic hypolimnion. Peaks in $\mathrm{pH}$ and oxygen measurements at approximately $0.9 \mathrm{~m}$ depth corresponded to blooms of oxygenic phototrophs in the epilimnion. Total iron (partic-

ulate + dissolved) peaked at the oxycline on all sampling dates. Hypolimnion sulfide remained steady at 400-500 $\mu \mathrm{M}$ between August and October. The rise in sulfide was typically steep below the oxycline, with increases from 0 to $500 \mu \mathrm{M}$ in little over 1 meter.

\section{Microscopic analysis of MB}

The number of total DAPI-stained cells closely tracked the oxycline. Cell numbers peaked at the oxycline on all sampling dates (Fig. 2-3), corresponding with visual observations of increased turbidity and a change in water color to purple-brown. Cell numbers immediately above and below the oxycline were similar. Maximum cell 
numbers were observed in June, and October counts were about an order of magnitude less.

The abundance, distribution, and type of MB present shifted with the degree of stratification and total cell number. MB were observed in highest density immediately above, within, and immediately below the oxycline. Microscope observations suggested that they were most abundant when stratification was greatest (August). Three readily distinguished morphologies (morphotypes) of MB were dominant: magnetite-producing cocci, greigite- producing MMP, and a large slow moving rod. A small $\operatorname{rod}(0.5 \times 1 \mu \mathrm{M})$ was observed at similar depths as the MMB cocci, and a chain-forming organism (each cell about $2 \mu \mathrm{M}$ ) was observed in the lower part of the oxycline at similar depths to the GMB MMP. Light micrographs and TEM images of the three dominant morphotypes are shown in Fig. 2-4 and Fig. 2-5. Each MB morphotype showed tactic and motile responses unique to the morphotype.

\section{Cocci and MMP}

The cocci (MMB) occurred at the top of the oxycline. They exhibited a rapid bouncing motion back and forth at the drop edge. The MMP (GMB) were found at the bottom of or slightly below the oxycline in areas of low sulfide, and swam by spinning counterclockwise when moving away from the drop edge, and clockwise when moving towards it. MMP and cocci were found at significantly different mean sulfide levels ( $p<0.05$, t-test, unequal variances). The cocci were most abundant at sulfide levels of 0-10 $\mu \mathrm{M}$. MMP were most abundant at sulfide concentrations less than $40 \mu \mathrm{M}$, but occurred in samples with sulfide levels up to $1 \mathrm{mM}$. MMP and cocci fluctuated in abundance throughout the season. Cocci were most abundant early and late in the season, while MMP were most abundant during periods of intense stratification in mid-summer. MMP abundance reached an estimated $103 \mathrm{ml}^{-1}$ at the oxycline in August, the highest number of MMP observed in the water column during the entire summer. 


\section{Novel rod-shaped GMB}

We observed a morphologically distinct, large, slow moving magnetotactic rod in sulfidic regions of Salt Pond, approximately $5 \mu \mathrm{M}$ long and $3 \mu \mathrm{M}$ wide (Fig. 2-5). These organisms swam very slowly to the drop edge where they accumulated without exhibiting the back and forth swimming behavior displayed by both the cocci and MMP. Sulfide concentrations in samples with abundant rods averaged $327 \mu \mathrm{M}$, as compared with $116 \mu \mathrm{M}$ for MMP and $19.2 \mu \mathrm{M}$ for cocci, and the rods were never found in water with sulfide less than $100 \mu \mathrm{M}$. Unlike the cocci and MMP, the rods did not show sharp changes in abundance with depth or season, although they were most abundant in mid to late summer. We further characterized the slow-moving rod using TEM (Fig. 2-5), sequencing of the 16S rDNA, and FISH (see below). TEM analysis revealed that the rod contained numerous mineral crystals similar to magnetosomes observed in other organisms (21). The crystals appear as irregularly shaped black dots in Fig. 2-5b. A single crystal electron diffraction pattern obtained from the crystals corresponded to greigite (data not shown).

\section{Sequencing results}

DGGE profiling (data not shown) showed a marked decrease in bacterial diversity for the mid-season sampling as compared to the early and late seasons. Based on microscopy, MMP were by far the most abundant MB type during the period of low diversity, while cocci were the most abundant morphotype present in the early and late seasons. Sequencing results confirmed that the dominant amplicon in both bulk and magnetically enriched samples were related to various Chlorobiales. We then used the multiplex PCR approach described above to eliminate this dominant amplicon from the cloning and sequencing steps, thereby increasing the probability of obtaining MB sequences from magnetically enriched samples. A diverse set of sequences were obtained from "capillary" samples highly enriched in the MMP (Table 2.1, Fig. 2-6). A group of five novel sequences was closely related to a marine magnetotactic coccus in the a-Proteobacteria, and one is closely related to the marine magnetotactic vibrio 
MV-1 (12). Several $\delta$-proteobacterial sequences were also identified in the MMP-rich sample, but no sequences identical to the MMP clones sequenced by (12) were found. GenBank accession numbers for individual clones are shown in Fig. 2-6.

We obtained several 16S rDNA sequences clustering in the $\gamma$-Proteobacteria from samples highly enriched in the slow-moving rod (Fig. 2-6) and amplified using multiplex PCR. These separated into two major groups: the first contains clones with 90\% similarity to Thiomicrospira sp., and the second contains clones with $99 \%$ similarity to Stenotrophomonas maltophilia. Combined, these two groups accounted for $42 \%$ of clones obtained from the samples highly enriched in large magnetotactic rods. Additionally, the sequence of a DGGE band obtained from a magnetically enriched sample clustered with Thiomicrospira spp. (Fig. 2-6). The remaining clones were widely distributed among the Bacteria (Table 2.1).

\section{Fluorescence in-situ hybridization}

To confirm that the above identified large GMB rod is associated with the g-subclass of the Proteobacteria, FISH was performed on samples that were highly enriched in this morphotype using the $\gamma$-Proteobacteria-specific GAM42a probe (33). The large GMB rod FISH results are shown in Figure 2-5c.

\subsection{Discussion}

We observed a marked stratification in the distribution of three different types of MB at and below the chemocline in meromictic Salt Pond, which we hypothesize is due to their as yet unknown respiratory requirements. A schematic cartoon which summarizes these distributions within Salt Pond is shown in Figure 2-7. Small, fastmoving MMB cocci were found at the top of the oxycline, the GMB many-celled magnetotactic prokaryote (MMP) at the base of and slightly below the oxycline, and a novel GMB rod in the sulfidic hypolimnion (Fig. 2-4 and Fig. 2-5). This distribution remained constant throughout the summer, although numbers of cocci and MMP fluctuated widely. Peaks in abundance of the cocci coincided with peaks 


\begin{tabular}{llll}
\hline Sample set & $\begin{array}{l}\text { Enriched in large } \\
\text { GMB rods } \\
\text { plex) }\end{array}$ & $\begin{array}{l}\text { Enriched in } \\
\text { (Multiplex) }\end{array}$ & $\begin{array}{l}\text { Enriched in MMP } \\
\text { (Non multiplex) }\end{array}$ \\
\hline Phylogenetic grouping & & & 13 \\
Alpha proteobacteria & 0 & 14 & 0 \\
Gamma proteobacteria & 55 & 9 & 0 \\
Beta proteobacteria & 6.5 & 0 & 10 \\
Delta proteobacteria & 6.5 & 9 & 0 \\
Epsilon proteobacteria & 6.5 & 0 & 3.2 \\
CFB & 10 & 9 & 74 \\
Chlorobiales & 13 & 23 & 0 \\
Chloroflexi & 0 & 4.5 & 0 \\
Cyanobacteria & 0 & 4.5 & 0 \\
CV & 3.2 & 14 & 0 \\
OP11 & 0 & 9 & 0 \\
Planctomycetales & 0 & 4.5 & \\
\hline
\end{tabular}

Table 2.1: Distribution of clones obtained from sequencing of "capillary" samples highly enriched in different types of MB (values in \% of total). Multiplex PCR was used to screen out Chlorobiales sequences in columns 1 and 2.

in total cell numbers, while peaks in MMP abundance coincided with low total cell numbers below the oxycline (Fig. 2-3).

Major factors determining the distribution of bacteria in a stratified salt pond include the location and width of the chemocline, as well as the proximity and concentrations of electron donors and acceptors. Motile microbial populations are often finely layered around the chemocline with respect to these properties (e.g. (54)). In particular, many known colorless sulfur bacteria can closely track shifting oxygensulfide gradients (39) without the need for magnetotaxis. Populations of magnetotactic cocci were strongly layered in a similar fashion, with orders of magnitude changes in abundance over 30 centimeters depth.

It is likely that the small magnetotactic cocci we observed are microaerophilic sulfide-oxidizers. Their position on top of the chemocline, coinciding with maximum total cell counts, suggests that they prefer the oxygen-sulfide interface. They were most abundant in the early and late season sampling, when oxygen was higher in the epilimnion and the chemocline was narrowest (Fig. 2-2). Additionally, the few cultivated marine MMB are all autotrophic sulfide-oxidizing microaerophiles (51). We recovered several sequences from Salt Pond closely related to these strains (Fig. 2-6). 
The MMP also appears to be a gradient organism, but of a different type. The MMP always occurred at the base of the chemocline, and never at depths with detectable oxygen. It was most abundant in midsummer, when the chemocline was widest (Fig. 2-2), but also occurred in small numbers in the early and late season. In August, MMP concentration reached an estimated $10^{3}$ per ml within in a $50 \mathrm{~cm}$ window directly below the chemocline and dropped off abruptly outside it (Fig. 23b). Within that window an order of magnitude shift in MMP abundance occurred within $15 \mathrm{~cm}$.

It is not certain which environmental stimuli the MMP may use to position itself within the chemocline. The MMP may be chemotactic to an iron or sulfur compound, since it precipitates an iron sulfur mineral and appears to be most closely related to the sulfate reducer Desulfosarcina variabilis (12). Fe(III) concentrations peaked at the depth of greatest MMP abundance and sulfide was less than $1 \mu \mathrm{M}$. We did not measure intermediate sulfur compounds, but studies on other euxinic water bodies show that they typically peak at the oxygen-sulfide interface (summarized in (60)). It is possible that the MMP responded to gradients in one of these compounds. Interestingly, while $\delta$-proteobacterial clones were identified in MMP-rich samples (Fig. $2-6)$, the sequences we recovered are distinct from the one previously reported for this organism (12). Recently, however, we have identified sequences similar to those previously reported (12) from an MMP rich sample obtained from a salt marsh (Simmons \& Edwards, unpublished data). This recent result suggests that the absence of MMP sequences from the Salt Pond samples may be due to preferential amplification of other sequences, or some phylogenetic differences between salt marsh and pond MMPs. The clones identified in the present study also support the suggestion of an active chemocline sulfur cycle typical of meromictic salt lakes (reviewed in (38)). We identified clones from organisms capable of sulfate and iron reduction (Desulfobacteraceae), sulfur disproportionation (Desulfocapsa sulfoexigens, (14)), and reduction of either elemental sulfur or iron (Desulfuromusa succinoxidans, $(26,28)$ ).

DGGE analysis suggests that the chemocline population was dominated by various species of green sulfur bacteria, mainly nonmotile Chlorobiales, while various $\mathrm{Cy}$ - 
tophaga/Bacteroides were the dominant hypolimnion population detected by DGGE. Both DGGE and PCR with general primers were an ineffective means of identifying MB; Chlorobiales were the dominant amplicon even in the samples that were extracted by capillary from the microscope stage, where we could verify that the template was dominated by MB. Often in molecular studies, when a specific group of microorganisms is targeted such as we are doing here with the MB, specific rather than general primers targeting the group of interest will be used (e.g., $\delta$-proteobacterial primers for sulfate reducing bacteria). However, studies on MB to date indicate that they are not a phylogenetically or physiologically coherent group, precluding the use of primers that target specific phylotypes. The multiplex PCR approach we used here allowed us to eliminate the masking amplicons (see Table 2.1) and obtain MB sequences.

The rod-shaped GMB identified in this study in part through this multiplex method is the first magnetotactic bacterium that appears to be a member of the $\gamma$-Proteobacteria (Fig. 2-6). It is clearly not a gradient organism, as it was found in low densities in the sulfidic hypolimnion on multiple sampling dates. Previous studies have shown TEM images of organisms similar to the rod (20), but its phylogeny was not known. Placement of this new GMB in the $\gamma$ sub-class of the Proteobacteria could suggest it involved primarily in iron cycling. Respiration using metals, particularly iron, is widespread among the $\gamma$-Proteobacteria. Emerson \& Moyer (13) identified two strains of freshwater microaerobic Fe oxidizing bacteria and several environmental clones with $95 \%$ similarity to Stentrophomonas maltophila. Stentrophomonas is a diverse genus with isolates from soil, water, and medical sources (19). The ironoxidizing strain ES-1 from (13) is closely related to one cluster of clones from the rodshaped GMB identified in this study (Fig. 2-6). Additionally, several $\gamma$-Proteobacteria isolated from anoxic soils and marine sediments are capable of dissimilatory metal reduction $(15,29,34,36)$.

The second cluster of putative GMB clones has about $90 \% 16 \mathrm{~S}$ rRNA similarity to Thiomicrospira crunogena and Thiomicrospira pelophila. A DGGE band from a sample enriched in GMB also clustered with the Thiomicrospira, providing additional support for the presence of the rod GMB in the $\gamma$-Proteobacteria. Both 
Thiomicrospira species are obligate sulfur chemolithotrophs using oxygen as an electron acceptor (23). Notably, Thiomicrospira pelophila was isolated from sulfide-rich muds and has a high tolerance for sulfide (24). The novel GMB was also found in water with high sulfide concentrations. However, the spiral cells of T. pelophila are quite a bit smaller than the greigite rods.

The in situ hybridization of samples that were highly enriched in greigite rods with the GAM42 probe targeting $\gamma$-Proteobacteria (33) shows positive hybridization to cells of the right size and shape (Fig. 2-5). Further work with probes designed from these two clusters is necessary to determine the phylogenetic position of the rod shaped GMB.

It remains unclear why cells in highly sulfidic waters should be magnetotactic. Frankel et al (16) proposed that magnetotactic cocci and other microaerophilic MMB found at the chemocline in Salt Pond use magnetotaxis to more rapidly locate optimal levels of $\mathrm{O}_{2}$. If the rod-shaped GMB are using magnetotaxis to optimize their position with respect to some physical or chemical gradient, we have not yet identified it. Unlike the magnetic cocci and the MMP, the rod GMB were never observed near the chemocline and were not concentrated in layers of high cell density. They did not appear to be most abundant at a specific iron concentration. Measurements taken the following summer (unpublished data) show that the hypolimnion light level is around 0.01 microEinsteins, suggesting that the GMB are not responding to light gradients. It is possible that they are responding to gradients of some as yet unidentified electron acceptor or donor.

Magnetotaxis may also be the relatively rare consequence of a more common form of prokaryotic iron metabolism. Metal inclusions of various kinds have been found in non-magnetotactic $\gamma$-Proteobacteria. Glasauer et al (18) identified membrane-bound crystalline Fe inclusions in Shewanella putrefaciens grown with ferrihydrite as the electron acceptor. Vainshtein et al (56) identified "magnet-sensitive" particles in Ectothiorhodospira shaposhnikovii, which were rich in Fe but did not contain sulfur. In a separate study, Vainshtein et al (55) found "magnet sensitive" inclusions of various types in prokaryotic cells of diverse phylogeny when grown in media containing 
$1 \mathrm{mM}$ iron, suggesting some kind of detoxification function. The inclusions were not ordered crystals and incorporated various other unspecified organic compounds. Further studies are necessary to determine whether GMB utilize ferrous or ferric iron in dissimilatory metabolism, as well as how such a metabolism might be linked to intracellular greigite precipitation.

The clear stratification in populations of marine MB with respect to the chemocline suggest that each type of MB is adapted to different chemical and physical gradients within the water column. It is likely that iron and sulfur compounds play a key role in determining the population dynamics of GMB. We have sampled Salt Pond in a subsequent summer in an attempt to better determine these gradients. While the phylogeny and geochemical environment of MB provide clues as to their ecological role, additional studies are needed to better define the predominant electron donors and acceptors used by MB, as well as the relationship between respiration and intracellular mineral formation.

\section{Acknowledgements}

We thank L. Hirt, S. Selgrade, D. Rogers, and C. Santelli for assistance. The manuscript was greatly improved with input from E. Webb and three anonymous reviewers. This work was partially funded by a grant from the Woods Hole Oceanographic Institution Reinhart Coastal Research Center to S.L.S. and K.J.E. S.L.S. was supported by a National Defense Science and Engineering Graduate Fellowship. DAB is supported by National Science Foundation grant EAR-0311950 and National Aeronautics

and Space Administration (NASA) Johnson Space Center grant NAG 9-1115. This is WHOI contribution \#11168. 

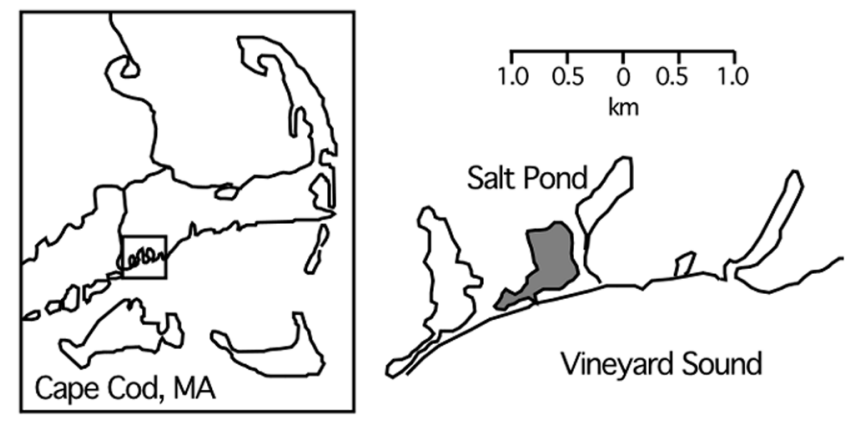

Figure 2-1: Sample site, Salt Pond, Falmouth, Massachusetts, USA. The location of Salt Pond is shown relative to other coastal features.
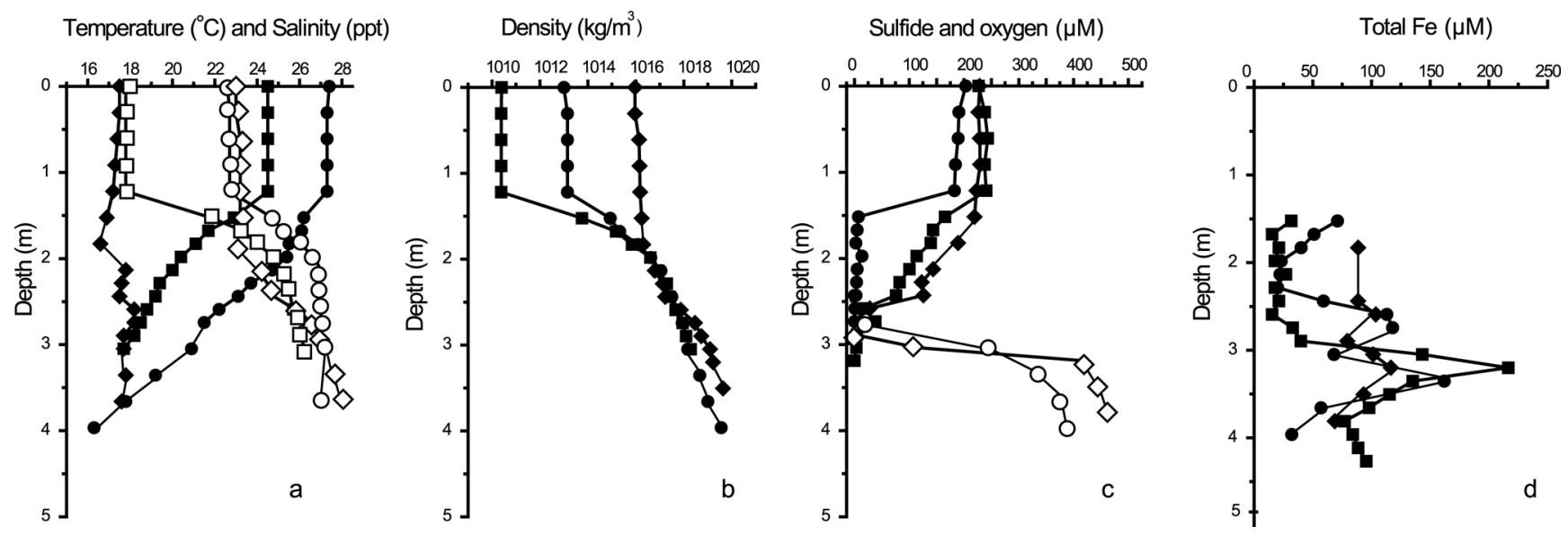

Figure 2-2: Chemistry of stratified Salt Pond water column. Shown are chemical profiles from early (squares), mid (circles), and late (diamonds) season sampling dates. Early season $=$ June 26, mid season $=$ August 2, late season $=$ October 9. (a) temperature (closed symbols) and salinity (open symbols);(b) water column density; (c) oxygen (closed symbols) and sulfide (open symbols); (d) dissolved + particulate iron. June 26 sulfide measurements are not shown due to possible sampling error. 

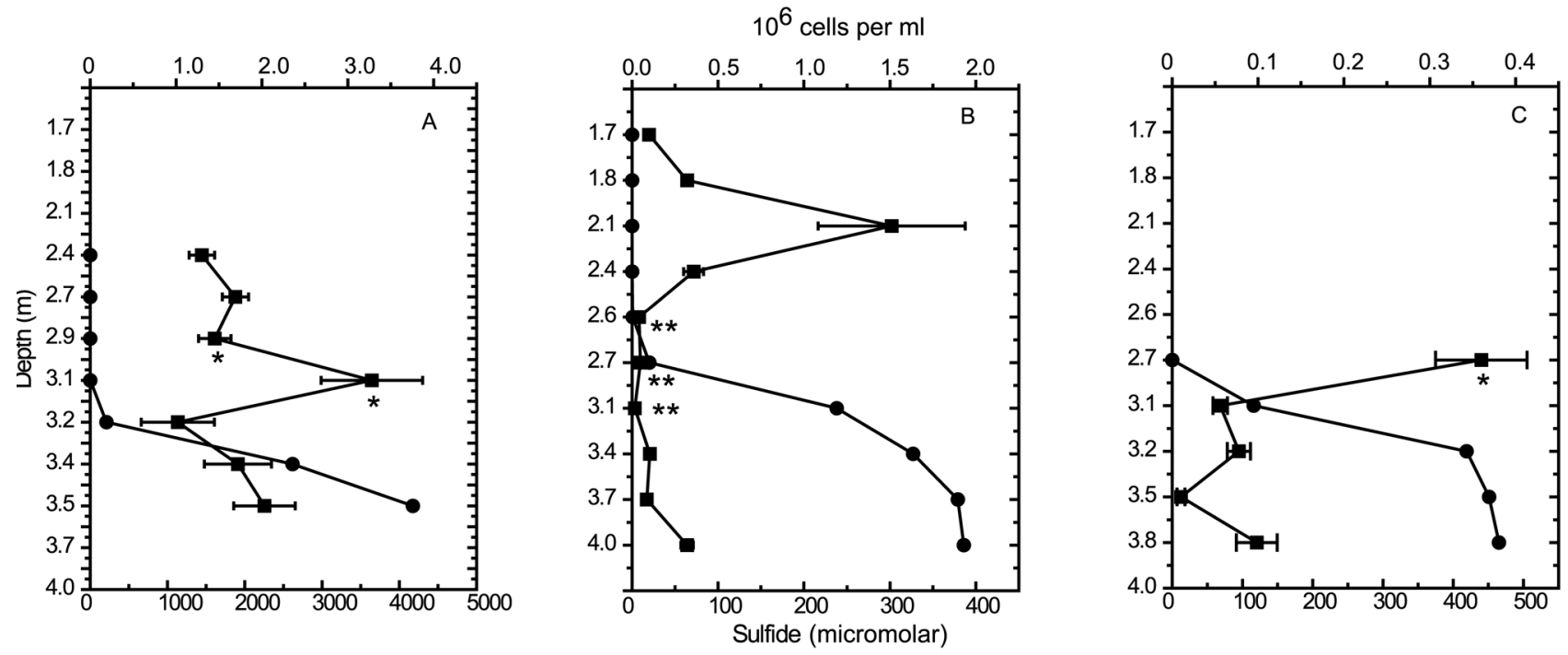

Figure 2-3: Total cell numbers for each sampling date obtained using DAPI staining and epiflourescence microscopy. (A) June 26, (B) August 2, (C) October 9. Counts are shown as squares, and sulfide profiles as circles. Error bars: plus minus one standard error of the mean. Cell numbers peaked at the oxycline. The location of the largest MB population for each sampling date is marked with $*$ (cocci) or ** (MMP). MMP were most numerous at $2.7 \mathrm{~m}$ on August 2 (b). Note the differences in scales between graphs. 


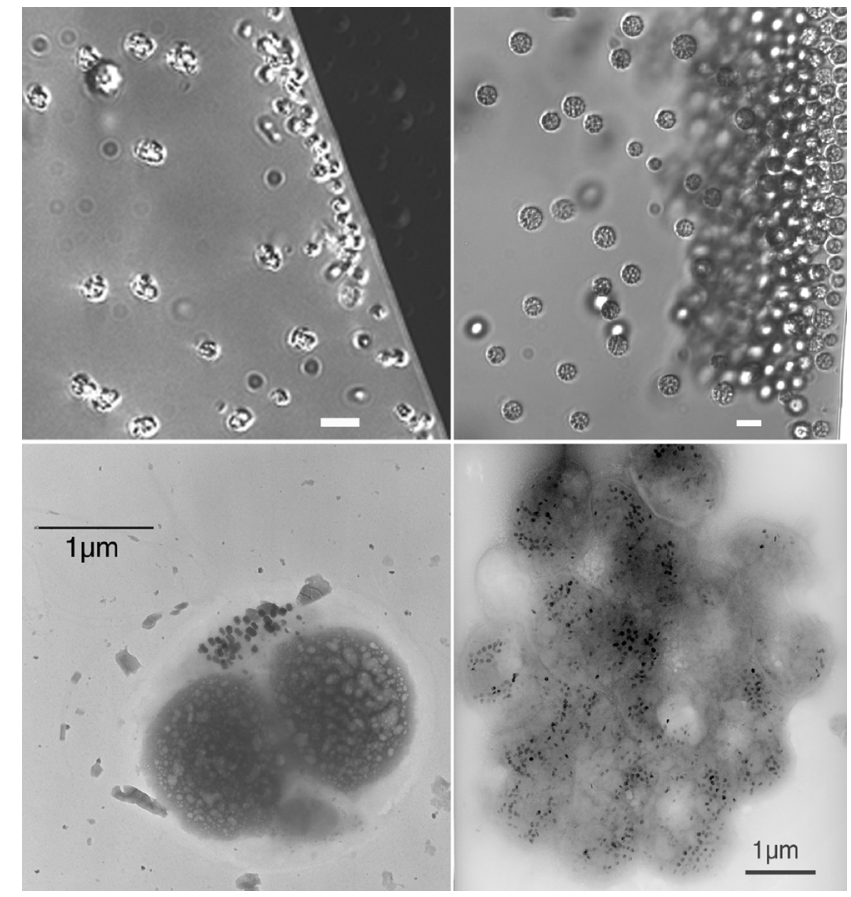

Figure 2-4: Depth stratification of MB in Salt Pond. Top and bottom images correspond to the same cell type, by differential contrast light microscopy (top) and TEM (bottom). Left, magnetite-producing cocci collected from the top of the oxycline. Right, greigite-producing MMP collected from the bottom of the OATZ. Scale bars are shown for each image. DIC scalebars are all 5 microns, lower right of each image.

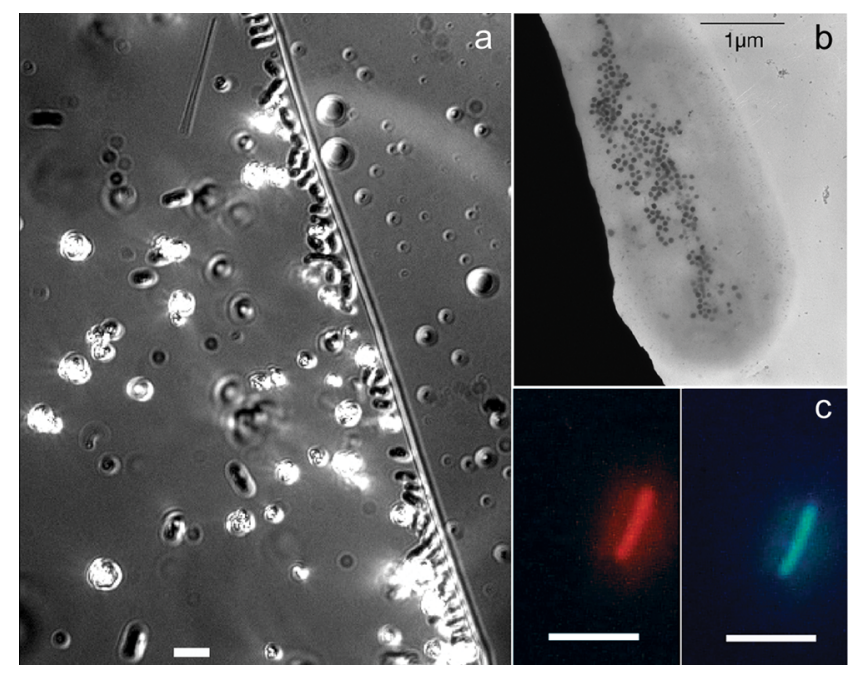

Figure 2-5: Greigite-producing rod found in sulfidic bottom waters of Salt Pond. (a) DIC with scale bar 5 microns. The diagonal line is the edge of the drop. (b) TEM showing intracellular greigite crystals (black dots). (c) FISH with GAM42A probe (Cy3, left) and DAPI stain of the same cell. Scale bar 5 microns. 


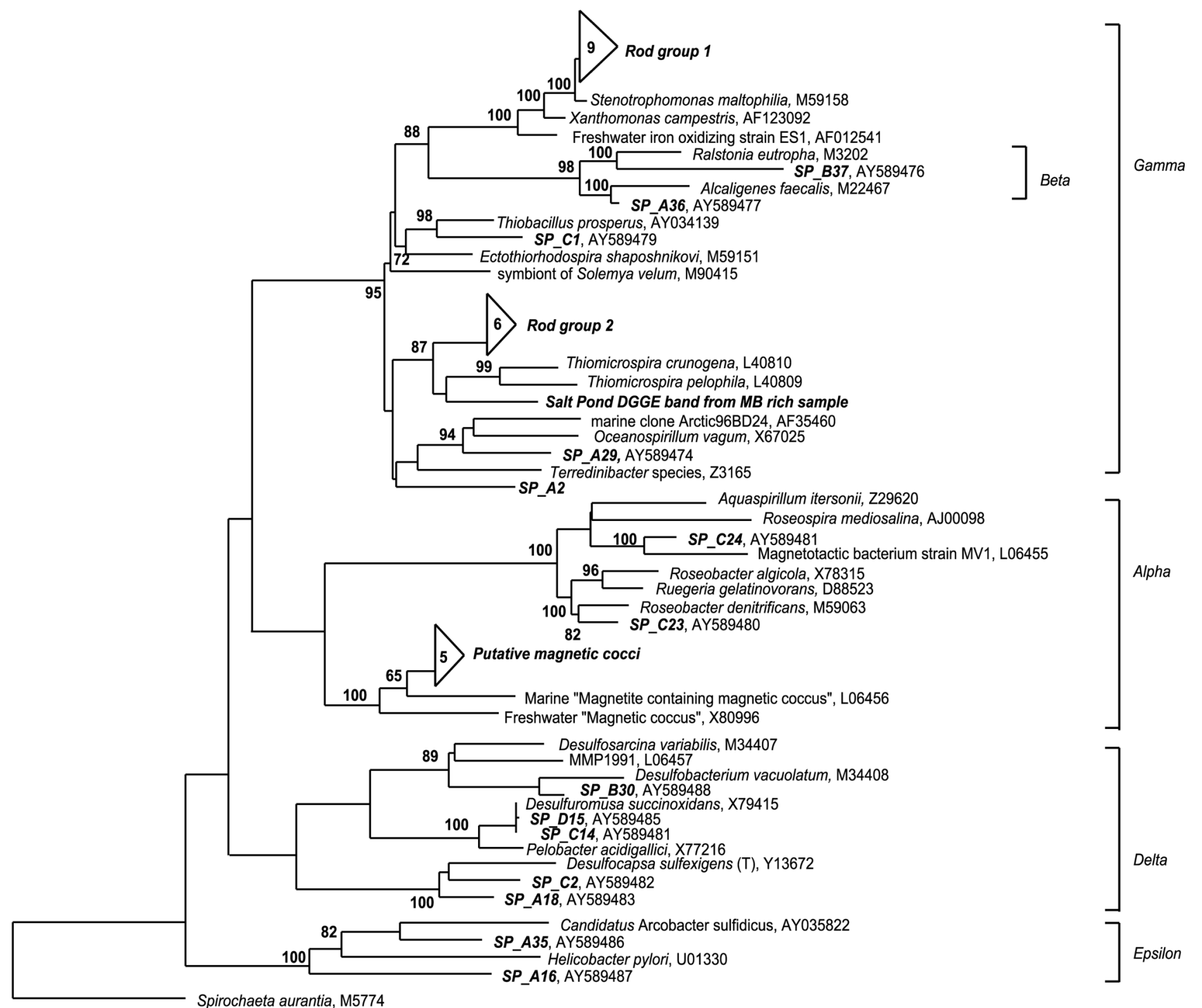

0.1

Figure 2-6: Phylogenetic relationship of several novel 16S rRNA sequences in the Proteobacteria obtained from Salt Pond samples highly enriched in different types of magnetotactic bacteria. The tree was obtained with a maximum parsimony analysis of sequences $>1000$ bp with 200 bootstrap replicates in Phylip. Short sequences were added to the tree using the "interactive parsimony" tool in ARB, maintaining previous topology. Spirochaeta aurantia was used as the outgroup. Nodes with greater than $60 \%$ bootstrap support are marked. Tree topology was also supported by maximum likelihood and distance analyses. The two groups of clones in the gamma proteobacteria ("Rod group 1" and "Rod group 2"), as well as sequences labelled SP_A and SP_B, were obtained from capillary samples highly enriched in the large greigite rod. An additional cluster of sequences ("putative magnetic cocci") was obtained from capillary samples highly enriched in magnetococci. Sequences labelled SP_C and SP_D were obtained from capillary samples highly enriched in MMP. 


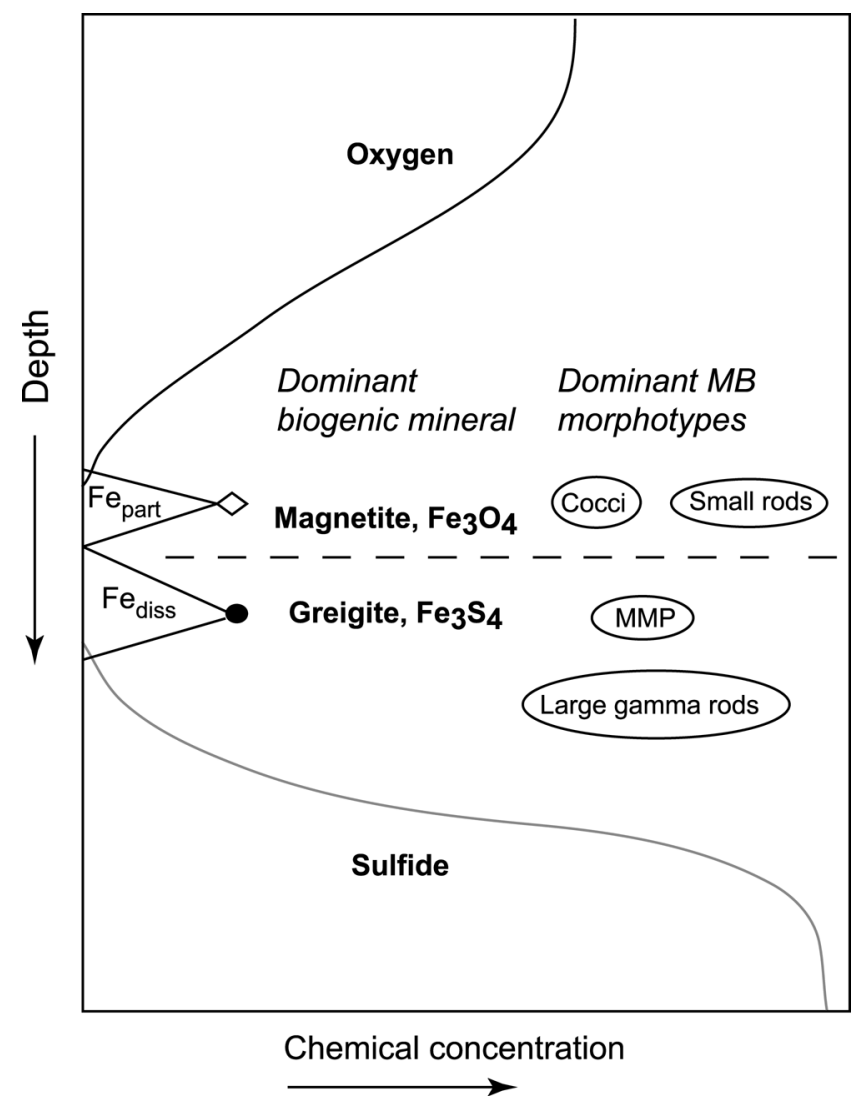

Figure 2-7: Schematic of MB distribution observed in Salt Pond, showing approximate locations of magnetite and greigite producing $\mathrm{MB}$ relative to a typical stratified water column chemical profile. $\mathrm{Fe}_{\text {part }}=$ total particulate iron and $\mathrm{Fe}_{\text {diss }}=$ total dissolved iron. 


\section{Bibliography}

[1] Achenbach, L. A., J. Carey, and M. T. Madigan. 2001. Photosynthetic and phylogenetic primers for detection of anoxygenic phototrophs in natural environments. Appl. Environ. Microbiol., 67:2922-2926.

[2] Bazylinski, D. A. and R. B. Frankel. 1992. Production of iron sulfide minerals by magnetotactic bacteria in sulfidic environments. In H. C. Skinner and R. W. Fitzpatrick, eds., Biomineralization Processes, Iron, Manganese, vol. 21, pp. 147159, Catena.

[3] Bazylinski, D. A. and R. B. Frankel. 2004. Magnetosome formation in prokaryotes. Nature Reviews Microbiology, 2:217-230.

[4] Bazylinski, D. A., R. B. Frankel, B. R. Heywood, S. Mann, J. W. King, P. L. Donaghay, and A. K. Hanson. 1995. Controlled biomineralization of magnetite $\left(\mathrm{Fe}_{3} \mathrm{O}_{4}\right)$ and gregite $\left(\mathrm{Fe}_{3} \mathrm{~S}_{4}\right)$ in a magnetotactic bacterium. Appl. Environ. Microbiol., 61:3232-3239.

[5] Bazylinski, D. A., R. B. Frankel, and H. W. Jannasch. 1988. Anaerobic magnetite production by a marine magnetotactic bacterium. Nature, 334:518519.

[6] Bazylinski, D. A. and B. M. Moskowitz. 1997. Microbial biomineralization of magnetic iron minerals: microbiology, magnetism, and environmental significance. In J. Banfield and K. Nealson, eds., Geomicrobiology: Interactions between Microbes and Minerals, Reviews in Mineralogy, vol. 35, pp. 181-224, Mineralogical Society of America, Washington, D.C.

[7] Bazylinski, D. A., D. R. Schlezinger, B. H. Howes, R. B. Frankel, and S. S. Epstein. 2000. Occurrence and distribution of diverse populations of magnetic protists in a chemically stratified coastal salt pond. Chem. Geol., 169:319328. 
[8] Berner, R. 1967. Thermodynamic stability of sedimentary iron sulfides. Am. J. Sci., 265:773-785.

[9] Cape Cod Commission. 2001, Cape Cod Atlas of Tidally Restricted Salt Marshes.

[10] Casamayor, E. O., H. Schafer, L. Baneras, C. Pedros-Alió, and G. Muyzer. 2000. Identification of and spatio-temporal Differences between microbial assemblages from two neighboring sulfurous lakes: comparison by microscopy and denaturing gradient gel electrophoresis. Appl. Environ. Microbiol., 66:499-508.

[11] Cline, J. D. 1969. Spectrophotometric determination of hydrogen sulfide in natural waters. Limnol. Oceanogr., 14:454-458.

[12] DeLong, E. F., R. B. Frankel, and D. A. Bazylinski. 1993. Multiple evolutionary origins of magnetotaxis in bacteria. Science, 259:803-806.

[13] Emerson, D. and C. L. Moyer. 1997. Isolation and characterization of novel iron-oxidizing bacteria that grow at circumneutral pH. Appl. Environ. Microbiol., 63:4784-4792.

[14] Finster, K., W. Liesack, and B. Thamdrup. 1998. Elemental sulfur and thiosulfate disproportionation by Desulfocapsa sulfoexigens sp. nov., a new anaerobic bacterium isolated from marine surface sediment. Appl. Environ. Microbiol., 64:119-125.

[15] Francis, C. A., A. Y. Obraztsova, and B. M. Tebo. 2000. Dissimilatory Metal Reduction by the Facultative Anaerobe Pantoea agglomerans SP1. Appl. Environ. Microbiol., 66:543-548.

[16] Frankel, R. B., D. A. Bazylinski, M. S. Johnson, and B. L. Taylor. 1997. Magneto-aerotaxis in marine coccoid bacteria. Biophys. J., 73:994-1000. 
[17] Frankel, R. B., D. A. Bazylinski, and D. Schüler. 1998. Biomineralization of magnetic iron minerals in magnetotactic bacteria. J. Supramolecular Sci., 5:388390.

[18] Glasauer, S., S. Langley, and T. J. Beveridge. 2002. Intracellular iron minerals in a dissimilatory iron-reducing bacterium. Science, 295:117-119.

[19] Hauben, L., L. Vauterin, E. Moore, B. Hoste, and J. Swings. 1999. Genomic diversity of the genus Stenotrophomonas. Int J Syst Bacteriol, 49:17491760.

[20] Heywood, B. R., D. A. Bazylinski, A. J. Garrett-Reed, S. Mann, and R. B. Frankel. 1990. Controlled biosynthesis of greigite $\left(\mathrm{Fe}_{3} \mathrm{~S}_{4}\right)$ in magnetotactic bacteria. Naturwissenschaften, 77:536-538.

[21] Kawaguchi, R., J. Burgess, T. Sakaguchi, H. Takeyama, R. Thornhill, and T. Matsunaga. 1995. Phylogenetic analysis of a novel sulfate-reducing bacterium, RS-1, demonstrates its membership of the delta-Proteobacteria. FEMS Microbiol. Lett., 126:277-282.

[22] Kirchman, D., J. Sigda, R. Kapuscinski, and R. Mitchell. 1982. Statistical analysis of the direct count method for enumerating bacteria. Appl. Environ. Microbiol., 44:376-382.

[23] Kuenen, J. G., L. A. Robertson, and O. H. Tuovinen. 2003. The Genera Thiobacillus, Thiomicrospira, and Thiosphaera. In M. Dworkin, ed., The Prokaryotes: An Evolving Electronic Resource for the Microbiological Community, 3rd ed., Springer-Verlag, New York.

[24] Kuenen, J. G. and H. Veldkamp. 1972. Thiomicrospira pelophila, gen. n., sp. n., a new obligately chemolithotrophic colourless sulfur bacterium. Antonie Van Leeuwenhoek, 38:241-56.

[25] Lee, C. and N. Jørgensen. 1995. Seasonal cycling of putrescine and amino 
acids in relation to biological production in a stratified coastal salt pond. Biogeochemistry, 29:131-157.

[26] Liesack, W. and K. Finster. 1994. Phylogenetic analysis of 5 strains of gramnegative, obligately anaerobic, sulfur-reducing bacteria and description of Desulfuromusa Gen-Nov, including Desulfuromusa-Kysingii Sp-Nov, DesulfuromusaBakii Sp-Nov, and Desulfuromusa-Succinoxidans Sp-Nov. Int. J. Syst. Bacteriol., 44:753-758.

[27] Lohrenz, S. E., C. D. Taylor, and B. L. Howes. 1987. Primary production of protein: II. Algal protein metabolism and its relation to particulate organic matter composition in the surface mixed layer. Mar. Ecol. Prog. Ser., 40:175-183.

[28] Lonergan, D. J., H. L. Jenter, J. D. Coates, E. J. Phillips, T. M. Schmidt, and D. R. Lovley. 1996. Phylogenetic analysis of dissimilatory Fe (III)-reducing bacteria. J. Bacteriol., 178:2402-2408.

[29] Lovley, D. R. 2003. Dissimilatory Fe(III)- and Mn(IV)-reducing prokaryotes. In M. Dworkin, ed., The Prokaryotes: An Evolving Electronic Resource for the Microbiological Community, 3rd ed., Springer-Verlag, New York.

[30] Ludwig, W., O. Strunk, R. Westram, L. Richter, H. Meier, Yadhukumar, A. Buchner, T. Lai, S. Steppi, G. Jobb, W. Forster, I. Brettske, S. Gerber, A. W. Ginhart, O. Gross, S. Grumann, S. Hermann, R. Jost, A. Konig, T. Liss, R. Lussmann, M. May, B. Nonhoff, B. Reichel, R. Strehlow, A. Stamatakis, N. Stuckmann, A. Vilbig, M. Lenke, T. Ludwig, A. Bode, and K.-H. Schleifer. 2004. ARB: a software environment for sequence data. Nucl. Acids. Res., 32:1363-1371.

[31] Mann, S., N. H. C. Sparks, and R. G. Board. 1990. Magnetotactic bacteria: Microbiology, biomineralization, paleomagnetism and biotechnology. Adv Microbial Physiol, 31:125-181. 
[32] Mann, S., N. H. C. Sparks, R. B. Frankel, D. A. Bazylinski, and H. W. Jannasch. 1990. Biomineralization of ferrimagnetic greigite $\left(\mathrm{Fe}_{3} \mathrm{~S}_{4}\right)$ and iron pyrite $\left(\mathrm{FeS}_{2}\right)$ in a magnetotactic bacterium. Nature, 343:258-261.

[33] Manz, W., R. Amann, W. Ludwig, M. Wagner, and K.-H. Scheifer. 1992. Phylogenetic oligodeoxynucleotide probes for the major subclasses of proteobacteria: problems and solutions. System Appl Microbiol, 15:593-600.

[34] McLean, J. and T. J. Beveridge. 2001. Chromate reduction by a pseudomonad isolated from a site contaminated with chromated copper arsenate. Appl. Environ. Microbiol., 67:1076-1084.

[35] Murray, J., L. Codispoti, and G. Friedrich. 1995. Oxidation-reduction environments: the suboxic zone in the Black Sea. In et al. Huang, C, ed., Aquatic Chemistry, ACS Advances in Chemistry, vol. 244, pp. 157-176, American Chemical Society.

[36] Nevin, K. P., K. T. Finneran, and D. R. Lovley. 2003. Microorganisms associated with uranium bioremediation in a high-salinity subsurface sediment. Appl. Environ. Microbiol., 69:3672-3675.

[37] O'Sullivan, D. W., A. K. Hanson Jr., and D. R. Kester. 1997. The distribution and redox chemistry of iron in the Pettaquamscutt Estuary. Estuar. Coast. Shelf Sci., 45:769-788.

[38] Overmann, J. and H. van Gemerden. 2000. Microbial interactions involving sulfur bacteria: implications for the ecology and evolution of bacterial communities. FEMS Microbiol. Rev., 24:591-599.

[39] Peduzzi, S., M. Tonolla, and D. Hahn. 2003. Isolation and characterization of aggregate-forming sulfate-reducing and purple sulfur bacteria from the chemocline of meromictic Lake Cadagno, Switzerland. FEMS Microbiol. Ecol., 45:29-37. 
[40] Peduzzi, S., M. Tonolla, and D. Hahn. 2003. Vertical distribution of sulfatereducing bacteria in the chemocline of Lake Cadagno, Switzerland, over an annual cycle. Aquat. Microb. Ecol., 30:295-302.

[41] Pernthaler, J., F. Glöckner, W. Schönhuber, and R. Amann. 2001. Flourescence in situ hybridization with rRNA-targeted oligonucleotide probes. In J. Paul, ed., Methods in Microbiology, vol. 30, pp. 207-226, Academic Press, San Diego.

[42] Petermann, H. and U. Bleil. 1993. Detection of live magnetotactic bacteria in deep-sea sediments. Earth Planet. Sci. Lett., 117:223-228.

[43] Pósfai, M., P. R. Buseck, D. A. Bazylinski, and R. B. Frankel. 1998. Reaction sequence of iron sulfide minerals in bacteria and their use as biomarkers. Science, 280:880-883.

[44] Rickard, D. 1997. Kinetics of pyrite formation by the H2S oxidation of iron (II) monosulfide in aqueous solutions between 25 and 125C: The rate equation. Geochim Cosmochim Acta, 61:115-134.

[45] Sakaguchi, T., A. Arakaki, and T. Matsunaga. 2002. Desulfovibrio magneticus sp. nov., a novel sulfate-reducing bacterium that produces intracellular single-domain-sized magnetite particles. Intl. J. Syst. Evol. Microbiol., 52:215221.

[46] Schafer, H. and G. Muyzer. 2001. Denaturing gradient gel electrophoresis in marine microbial ecology. In Methods in Microbiology, Methods in Microbiology, vol. 30, pp. 425-468, Academic Press, San Diego.

[47] Schippers, A. and B. Jørgensen. 2002. Biogeochemistry of pyrite and iron sulfide oxidation in marine sediments. Geochem. Cosmochim. Acta, 66:85-92.

[48] Spring, S., R. Amann, W. Ludwig, K. Schleifer, H. van Gemerden, and N. Petersen. 1993. Dominating role of an unusual magnetotactic bacterium 
in the microaerobic zone of a freshwater sediment. Appl. Environ. Microbiol., 59:2397-2403.

[49] Spring, S., R. Amann, W. Ludwig, K.-H. Schleifer, and N. Petersen. 1992. Phylogenetic diversity and identification of nonculturable magnetotactic bacteria. System. Appl. Microbiol., 15:116-122.

[50] Spring, S., R. Amann, W. Ludwig, K.-H. Schleifer, D. Schüler, K. Poralla, and N. Petersen. 1994. Phylogenetic analysis of uncultured magnetotactic bacteria from the alpha-subclass of Proteobacteria. System. Appl. Microbiol., 17:501-508.

[51] Spring, S. and D. A. Bazylinski. 2000. Magnetotactic Bacteria. In M. Dworkin, ed., The Prokaryotes: An Evolving Electronic Resource for the Microbiological Community, online release 3.4, Springer Verlag.

[52] Spring, S. and K. H. Schleifer. 1995. Diversity of Magnetotactic Bacteria. System. Appl. Microbiol., 18:147-153.

[53] Taylor, C., J. Molongoski, and S. Lohrenz. 1983. Instrumentation for the measurement of phytoplankton production. Limnol. Oceanogr., 28:781-787.

[54] Tonolla, M., S. Peduzzi, D. Hahn, and R. Peduzzi. 2003. Spatio-temporal distribution of phototrophic sulfur bacteria in the chemocline of meromictic Lake Cadagno (Switzerland). FEMS Microbiol. Ecol., 43:89-98.

[55] Vainshtein, M., N. Suzina, E. Kudryashova, and E. Ariskina. 2002. New magnet-sensitive structures in bacterial and archaeal cells. Biol. Cell., 94:29-35.

[56] Vainshtein, M., N. Suzina, and V. Sorokin. 1997. A new type of magnetsensitive inclusions in cells of photosynthetic purple bacteria. System. Appl. Microbiol., 20:182-186.

[57] Viollier, E., P. W. Inglett, K. Hunter, A. N. Roychoudhury, and P. V. Cappellen. 2000. The ferrozine method revisited: Fe (II)/Fe (III) determination in natural waters. Appl. Geochem., 15:785-790. 
[58] Wakeham, S. G., B. L. Howes, J. W. H. Dacey, R. P. Schwarzenbach, and J. Zeyer. 1987. Biogeochemistry of dimethylsulfide in a seasonally stratified coastal salt pond. Geochim. Cosmochim. Acta, 51:1675-1684.

[59] Wallner, G., R. Amann, and W. Beisker. 1993. Optimizing fluorescent in situ hybridization with rRNA-targeted oligonucleotide probes for flow cytometric identification of microorganisms. Cytometry, 14:136-143.

[60] Zopfi, J., T. G. Ferdelman, B. B. Jørgensen, A. Teske, and B. Thamdrup. 2001. Influence of water column dynamics on sulfide oxidation and other major biogeochemical processes in the chemocline of Mariager Fjord (Denmark). Mar. Chem., 74:29-51. 


\title{
Chapter 3
}

\section{Population dynamics of marine}

\section{magnetotactic bacteria in a}

\section{meromictic salt pond described}

\section{with quantitative PCR}

\author{
Sheri L. Simmons, Dennis A. Bazylinski, and Katrina J. Edwards \\ Submitted to Applied and Environmental Microbiology, March 2006
}

\begin{abstract}
Magnetotactic bacteria (MTB) contain membrane-bound magnetic iron minerals and are globally abundant in the suboxic/anoxic portions of chemically stratified marine and freshwater environments, but their population dynamics and potential contribution to iron sequestration to sediments have not been previously quantified. We developed a quantitative PCR assay to enumerate four major groups of marine MTB during summer 2003 in seasonally stratified Salt Pond, MA, with respect to environmental chemistry. Using CARD-FISH, we also show that a large greigite-producing bacterium is distantly related to Thiomicrospira pelophila in the gamma-Proteobacteria. QPCR cell abundances indicate that MTB occur at up to $10 \%$ of total eubacteria and that each organism has a characteristic distributional profile with respect to the chemocline. Cell abundances obtained with qPCR allowed us to obtain the first estimate of Fe sequestered by a natural population of MTB. We show that MTB sequester as much as $10^{-9} \mathrm{~g} \mathrm{Fe} \mathrm{cm}^{-3}$ in Salt Pond and can contribute up to 2 kilograms of mineralized Fe to the sediments of Salt Pond during summer stratification. We propose
\end{abstract}


a model of the "MTB iron pump" to help quantify the contribution of MTB to Fe cycling in stratified environments, where our calculations suggest they constitute a significant percentage of total Fe flux.

\subsection{Introduction}

Magnetotactic bacteria (MTB) biomineralize membrane-bound intracellular single domain iron oxides (magnetite, $\mathrm{Fe}_{3} \mathrm{O}_{4}$ ) and/or iron sulfides (greigite, $\mathrm{Fe}_{3} \mathrm{~S}_{4}$ ). Each cell typically contains one or more chains of magnetosomes, which produces a net dipole moment sufficient to align the cell with local geomagnetic fields. The largest populations of MTB are typically found at or below the interface between oxygenated and reduced sediments or waters $(4,21,59)$. Magnetotaxis is thought to allow MTB to more rapidly locate these optimal micro-aerobic or anaerobic habitats, although recent findings challenge this hypothesis (58). Magnetite-producing MTB are found in both freshwater and marine environments, while greigite-producing MTB appear to be unique to marine environments. In stratified marine systems where magnetite and greigite producers co-exist, magnetite producers are found at the top to middle of the chemocline while greigite producers occur at the base of and below the chemocline in sulfidic waters $(4,59)$. Marine MTB are abundant in salt marsh sediments and semi-anaerobic basins worldwide $(3,4,18,40,68)$ and occur in deep-sea sediments $(48,71)$. These qualitative observations indicate that they should be globally more abundant than freshwater MTB, but quantitative studies of their abundances and population structure are thus far lacking.

The apparent ubiquity and abundance of MTB in stratified marine systems suggests that they play important roles in Fe and $\mathrm{S}$ cycling in these environments. Individual cells can accumulate large amounts of iron intracellularly: up to $2.2 \%$ of dry weight in one cultivated species (24), several orders of magnitude greater than the average iron quota of heterotrophic marine bacteria (76). Moreover, nearly all cultivated marine magnetite-producing MTB are chemolithoautotrophic S-oxidizers (68), and many store intermediates $\left(\mathrm{S}^{0}\right)$ intracellularly for use as electron donors $(2,14,65)$. Greigite-producing MTB, which have not yet been isolated in axenic 
culture, sequester large amounts of $\mathrm{Fe}$ and $\mathrm{S}$ in the greigite mineral $\left(\mathrm{Fe}_{3} \mathrm{~S}_{4}\right)$ through an unknown mechanism. Based on the identification of one greigite-producer in the $\delta$-Proteobacteria (16), these have been suggested to function as sulfate reducers, but there is no data to date about their metabolic function.

In spite of their potential environmental and geochemical significance in both present and past $(62,64)$ environments, very little quantitative information exists about the abundance and distribution of extant populations of MTB. Present-day stratified environments where MTB are abundant are strong analogues for the ancient oceans, now widely thought to have contained oxic surface and iron-rich, sulfidic deep waters. The few previous studies of MTB in the environment have been almost entirely qualitative $(4,59,66)$, and none have tracked quantitative changes in the abundance of magnetite- and greigite- producers in the natural environment over time with respect to environmental geochemistry. In the only MTB study of its kind, Spring et al. (65) found that the uncultivated "Magnetotacticum bavaricum" occurred at $7 \times 10^{5}$ cells $\mathrm{cm}^{-3}$ in freshwater sediments and comprised $30 \%$ of the microbial biovolume. Flies et al. (21, 22) established MTB microcosms from freshwater and marine sediments to track changes in MTB abundance and diversity with geochemical parameters. The maximum number of MTB were found at and below the oxic-anoxic transition zone (OATZ), but exhibited little correlation with the specific parameters monitored. Diversity in these microcosms is quite low compared to natural systems, however; most freshwater and marine microcosms eventually became dominated by magnetite-producing magnetotactic cocci in the $\alpha$-Proteobacteria after an incubation of several days to months (22). The dominance of a single morphotype in microcosms contrasts with the large morphological diversity of magnetotactic bacteria visible in water samples from stratified marine systems $(4,59)$, and indicates the need for molecular identification of marine MTB in the environment.

Quantitative studies of MTB in natural environments have been hampered by limited knowledge of their phylogeny and diversity, particularly for the greigite- producers. Only a few strains of magnetite-producers have been isolated in pure culture, and all except two (70) fall within the $\alpha$ class of the Proteobacteria $(2,68,80)$. Un- 
cultivated freshwater and marine magnetite producing MTB also appear to belong largely to the $\alpha$-Proteobacteria $(16,21,22,66,67,70)$. The "many-celled magnetotactic prokaryote" (MMP) is the only greigite producer previously identified to the species level, and is closely related to Desulfosarcina variabilis in the $\delta$-Proteobacteria (16). In earlier work, we identified a large greigite-producing magnetotactic rod as a member of the $\gamma$-Proteobacteria (59). We also identified a "barbell" shaped magnetotactic organism displaying south polarity (swimming behavior); this bacterium is related to Desulforhopalus sp. in the $\delta$-Proteobacteria (58).

Our aim was to develop a quantitative PCR assay to determine the abundance of key magnetite- and greigite-producing MTB with respect to geochemistry in the natural environment. In particular, we sought to identify magnetite- and greigiteproducers at the species level so that cell counts obtained with molecular methods could be used to estimate the production of each mineral in situ. Salt Pond, a small seasonally stratified marine basin in Falmouth, MA, is an excellent natural laboratory for the study of marine MTB. Water column chemistry and structure changes dramatically in Salt Pond from the onset of stratification in early summer (June) through its breakdown in fall (October), allowing different groups of MTB to dominate $(58,59)$. In previous work, we described the qualitative distribution of magnetite- and greigiteproducing MTB with respect to water chemistry and obtained several novel 16s rRNA sequences from samples highly enriched in different morphotypes of MTB (59).

We selected four major groups of MTB in Salt Pond for the development and application of a quantitative PCR assay using SybrGreen, which we then applied to samples collected in summer 2003. The groups were selected based on their apparent abundance in time-course observations over several sampling seasons in Salt Pond, as gauged by light microscopy. These are magnetite-producing cocci in the $\alpha$-Proteobacteria (sequences described in (59)), the "barbell"-shaped organism (58), the greigite-producing MMP (16), and a large greigite rod (59). This group contains both magnetite- and greigite-producing MTB, and allows us to track the production of each mineral over changing water column chemistry. The magnetic swimming behavior of MTB makes separation of cells for molecular analysis relatively straight- 
forward, and has been used before to obtain 16s rRNA sequences from uncultivated MTB $(65,66)$.We used catalyzed reporter deposition-in situ hybridization (CARDFISH; (46)) to identify both the barbell (58) and greigite rod to the species level prior to qPCR primer design. While FISH and CARD-FISH are powerful techniques for identification and enumeration of microbial groups, for our system the use of qPCR allowed for rapid analysis of many more environmental samples than could be analyzed by FISH. Additionally, qPCR allowed us to track cell numbers for different MTB groups over the course of population blooms and crashes, where small fluctuations could have eluded accurate enumeration with FISH. We also combine cell counts with estimates of the number and size of magnetosomes in each group of MTB to estimate for the first time the volume of iron sequestered and potentially exported by a natural population of magnetotactic bacteria.

\subsection{Methods}

\subsubsection{Water collection and chemistry}

The physical characteristics of Salt Pond are described elsewhere (59). The approximate surface area of the deeper portion of Salt Pond (4-6 m deep) is $7.9 \times 10^{4} \mathrm{~m}^{2}$ as estimated using Google Earth satellite maps. Water samples were collected from discrete depths in Salt Pond on several dates in summer 2001, 2003, and 2004 in conjunction with physical and chemical measurements (sulfide, iron, oxygen, temperature, conductivity) largely using previously described methods (59) with the exception of an improved assay for iron in 2003 and 2004. We used a scaled-up version of the ferrozine assay described in (78) to obtain iron concentrations. We collected water samples directly from the pump line using a plastic syringe, and then separated dissolved and particulate fractions by sequential filtration in the field using coupled $\mathrm{GF} / \mathrm{F}$ glass fiber prefilters $(0.7 \mu \mathrm{m}$ pore size) and $0.4 \mu \mathrm{m}$ membrane filters. Four samples of $5 \mathrm{ml}$ each were collected for each depth and placed in acid-washed plastic bottles. Two bottles contained $500 \mu \mathrm{l}$ FerroZine solution (10 mM FerroZine in 100 
mM ammonium acetate) for analysis of $\mathrm{Fe}(\mathrm{II})$ and two bottles contained $10 \mu \mathrm{l} 1 \mathrm{~N}$ $\mathrm{HCl}$ for analysis of total Fe. One set of samples was filtered for determination of dissolved Fe, while the other set was unfiltered for determination of total Fe. Particulate Fe was calculated as the difference. Samples were stored on ice in the dark until analysis. FerroZine, hydroxylamine hydrochloride, and buffer were added to total Fe bottles in the lab as described in (78). It was important to fully mix the samples after reagents were added for complete color development.

For nutrient analysis, three sets of samples were collected on each sampling date: one from the upper mixed layer, one from the chemocline, and one from the sulfidic bottom layer. Four samples of $40 \mathrm{ml}$ each were withdrawn directly from the pump line with a $50 \mathrm{ml}$ plastic syringe and filtered using a $\mathrm{GF} / \mathrm{F}+0.4 \mu \mathrm{M}$ filter couple into acid-washed Nalgene bottles. Samples were placed on ice for transport to the lab. In the lab, one set of samples was frozen at $-20^{\circ} \mathrm{C} .80 \mu \mathrm{l}$ of $8 \mathrm{~N}$ sulfuric acid was added to the other set, which was stored at $4{ }^{\circ} \mathrm{C}$. Colorimetric analysis for phosphate, ammonium, silicate, and nitrate+nitrite was performed using standard protocols (23) on a Lachat nutrient autoanalyzer.

\subsubsection{Sample preservation}

Duplicate samples of $2 \mathrm{ml}$ were withdrawn from each untreated water sample and centrifuged at $4^{\circ} \mathrm{C}$ for $20 \mathrm{~min}$ at $14000 \mathrm{rpm}$. The supernatant was siphoned off and the tubes frozen at $-80^{\circ} \mathrm{C}$. To obtain concentrated samples of MTB, droplets of water were placed on a glass coverslip on a light microscope with the south pole of a small bar magnet adjacent to one side. This process selected for magnetotactic bacteria with north polarity. Magnetotactic bacteria accumulated in high densities near the magnet, where they were removed with a $10 \mu$ l glass capillary tube ("capillary samples"). These samples were frozen at $-20^{\circ} \mathrm{C}$ immediately.

For in situ hybridization, capillary samples of different MTB morphotypes were placed directly on a gelatin-coated welled slide. The slide was air-dried, fixed in $2 \%$ paraformaldehyde in PBS, pH 7.2, for 20-30 minutes, and subsequently dehydrated in $50 \%, 80 \%$, and $98 \%$ EtOH for three minutes at each concentration prior to hy- 


\begin{tabular}{llcc}
\hline Primer & Sequence $^{1}$ & Target & Ref \\
\hline Barb452F & GTGTATGGCAGCTAATATCTG & Barbell & 2 \\
Barb644R & CCTCCAATACTCAAGTCTTAC & Barbell & 2 \\
Eub341F & CCTACGGGAGGCAGCAG & Bacteria & $(43)$ \\
Eub515R & TACCGCGGCKGCTGGCA & Bacteria & 2 \\
Grod1267F & GAGGTGGTGCGAATCTCAA & Greigite rod & 2 \\
Grod1426R & ATGAACCACACCGTGGGCGA & Greigite rod & 2 \\
Mcoc984F & CCTGCTTTTGACATCCTTCGG & Mag cocci & 2 \\
Mcoc1249R & ACCCTTTCGCTGCCCTTTG & Mag cocci & 2 \\
MMP86F & GCAGGAGATAGTAAAGTGGCG & MMP & 2 \\
MMP227R & CTAATGGTACGCGGACTCAC & MMP & 2 \\
\hline
\end{tabular}

Table 3.1: Primers used to enumerate magnetotactic bacteria in this study.

${ }^{1}$ Sequences in the 5' to 3' direction. ${ }^{2}$ This study.

bridization. The unhybridized slides were stored at $-20^{\circ} \mathrm{C}$ for several months with no loss of hybridization signal.

\subsubsection{DNA extraction}

Two different extraction methods were used on the Salt Pond samples: a standard CTAB method with phenol and chloroform (81) and the MoBio UltraClean kit. The concentration of DNA was measured in duplicate for each sample using a Nanodrop ND-1000 spectrophotometer. In general the CTAB method resulted in much higher yields of DNA, up to two orders of magnitude. However, extraction blanks from the CTAB method also gave high concentration readings on the Nanodrop even when they did not show significant amplification in qPCR.

\subsubsection{Sequencing and probe/primer design}

Capillary samples of a large greigite-producing rod and a magnetotactic organism ("barbell") with unique morphology and behavior (58) were used directly in PCR without extraction; amplification products were cloned and sequenced as previously reported $(58,59)$. Sequences obtained from capillary samples were imported into ARB (36), which was used to design both CARD-FISH probes and qPCR primers. Identification of the barbell using CARD-FISH is in (58). The greigite rod sample 
produced two sequence clusters of four to nine sequences each ((59), Fig. 3-1) with the remaining sequences falling in diverse phylogenetic groups. Probes were designed to target each of these clusters (Table 3.3).

For qPCR primer design, we targeted four groups of MTB often observed in Salt Pond: magnetotatic cocci (see Fig. 6 in (59)), barbells (58), greigite rods, and MMP. We also prepared a new primer set to quantify eubacteria, using the forward primer $341 \mathrm{~F}$ (43) and reverse complementing the standard 515F primer, as existing eubacterial qPCR primer sets $(55,73)$ had annealing temperatures lower than our other primers. Following identification of the rod with CARD-FISH (see Results), we used the relevant sequence clusters to design qPCR primers. A cluster of sequences in the $\alpha$-Proteobacteria obtained from samples highly enriched in magnetotactic cocci from Salt Pond (59) was used to design primers targeting that group. MMP sequences obtained from our work in Sippewisett salt marsh (57) were used for primer design. Primers were checked against the RDP database (13) to verify specificity. The free online utility NetPrimer (Premier Biosoft) was used to check for dimers and hairpins in each primer. The NetPrimer score was a good predictor of a primer's performance in qPCR. Primers used in this study are listed in Table 3.1.

Optimal annealing temperatures were determined by non-quantitative gradient PCR with linearized plasmid standards (described below). The reaction mix included $5 \mu \mathrm{l}$ GoTaq clear buffer, $5 \mu \mathrm{l}$ GoTaq green buffer, $1 \mu \mathrm{l} 10$ mM dNTP mix, $33.9 \mu \mathrm{l}$ nuclease-free water, forward and reverse primers at 400 nM, $0.1 \mu \mathrm{l}$ GoTaq (Promega), and approximately $1 \mathrm{ng}$ plasmid. Each primer pair was applied to a target and nontarget plasmid simultaneously. The optimal annealing temperature selected for each set was the lowest temperature yielding good amplification of the target plasmid while showing minimal or no amplification from the non-target plasmid. Gel electrophoresis was also used to check that the amplicons produced were the correct size.

\subsubsection{CARD-FISH}

We previously described the application of catalyzed reporter deposition-in situ hybridization (CARD-FISH) for identification of the barbell MTB (58). In this study, 
one oligonucleotide probe was designed as described above for each sequence cluster in the greigite rod sample (Fig. 3-1). The probes were first synthesized with Cy3 tags for use in standard fluorescent in situ hybridization (FISH), following the protocol of Pernthaler et al (47). Optimal stringency (\% formamide) was determined using clone-FISH (53). Briefly, pCR2.1 TOPOC plasmids containing target and non-target 16s rDNA PCR products were transformed (56) into E.coli JM109(DE3) (Promega), which contains phage T7 RNA polymerase to increase the copy number of non-native ribosomes. Transformants were diluted 1:1000 into LB media with $50 \mu \mathrm{g} \mathrm{ml}^{-1}$ ampicillin and grown to an OD600 of 0.3-0.4 at $37^{\circ} \mathrm{C}$. Cells were then incubated $1 \mathrm{~h}$ with $1 \mathrm{mM}$ IPTG, followed by a $4 \mathrm{~h}$ incubation with $170 \mathrm{mg} \mathrm{L}^{-1}$ chloramphenicol, and then fixed in $4 \%$ paraformaldehyde in PBS for $30 \mathrm{~min}$ and stored in 1:1 PBS:EtOH at $20^{\circ} \mathrm{C}$. Cells were spotted on Teflon-coated welled slides as described (47). FISH was performed according to published protocols (47). Each probe was tested against two classes of clone-FISH cells: one containing an insert from the targeted sequence cluster and one containing an insert from the other sequence cluster obtained from that sample. We determined the minimum stringency required to reliably discriminate between these while preserving fluorescence. Clone-FISH cells were also hybridized with GAM42A (41), which targets the native ribosomes of Escherichia coli host cells, to control for variability in fluorescence induced by assay conditions. Image analysis was done with Adobe Photoshop and Kodak 1D software.

Probe fluorescence was very low when regular FISH was applied to these samples, so we used CARD-FISH (46) to amplify the signal. The probes were synthesized with HRP conjugated to the 5' end by Biomers (Ulm, Germany) and used in CARDFISH on capillary samples of MTB following a slightly modified version of published protocols (46) with Cy3-tyramides for visualization. Cells were counterstained with DAPI following CARD-FISH. Cells produced in clone-FISH were used as positive and negative controls in CARD-FISH. Probes GROD-1-824 and GROD-2-470, targeting the greigite-producing rod, were applied to capillary samples of MTB taken from Salt Pond in three different years (2001, 2003, and 2004) using $40 \%$ formamide in the hybridization buffer. These samples were observed to contain large numbers of 
slow moving rod-shaped MTB with the light microscope at the time of collection. Each sample was divided into several parts and hybridized with each GROD probe in isolation, as well as with the general eubacterial probes EUBI, II, and III (15) as a positive hybridization control. The number, shape, and fluorescence intensity of cells hybridizing with each probe was compared to determine which probe preferentially bound the target cells.

\subsubsection{Quantitative PCR standards}

We constructed standard curves with plasmids containing inserts for the desired species for direct quantification of copy number in environmental samples. 16s rDNA PCR products obtained from highly enriched samples of MTB were cloned into the pCR2.1-TOPOC vector (Invitrogen) and sequenced as previously described (59). Selected plasmids containing inserts used for primer design were grown in E. coli and miniprepped using a Promega kit. The plasmids were linearized with a single-cutter enzyme (HindIII or XbaI, New England Biolabs) prior to qPCR. Linearized plasmids produce qPCR standard curves that more closely approximate genomic DNA standards curves than do supercoiled plasmids (73). The concentration of each plasmid was measured with a Nanodrop ND-1000 spectrophotometer and translated into units of copy number per ml with the following formula from Zhu et al. (82):

$$
\text { molecules } / \mu l=(a /[p l * 660]) \times 6.022 \times 10^{23},
$$

where $a$ is the plasmid DNA concentration in $\mathrm{g} / \mu \mathrm{l}, p l$ is the length of the plasmid + the length of the insert (in bp), $660 \mathrm{~g} / \mathrm{mol}$ is the average molecular weight of one base pair, and $6.022 \times 10^{23}$ molecules $/ \mathrm{mol}$ is the molar constant. The length of the vector used was $3931 \mathrm{bp}$. The formula can also be used for PCR product standards by simply setting $p l=$ amplicon length.

Standard curves were run in duplicate or triplicate for each primer set using reaction conditions identical to those used for samples (described below). A PCR product was used instead of linearized plasmid for the Mcoc primer set. The reac- 
tion master mix was prepared first without template, then divided into four separate tubes to which appropriate amounts of each standard were added. The mixes were then aliquoted into a 96 well plate and run on a Bio-Rad iCycler using protocols described below. The efficiency of each reaction was calculated using the formula $E=$ $\left[10^{(-1 / \text { slope })}-1\right]$, where the slope was determined by a linear regression of log copy number versus threshold cycle $\left(\mathrm{C}_{t}\right)$. The detection range of each plasmid was determined as the linear range of semi-log plots of $\mathrm{C}_{t}$ versus $\log$ [copy number] (see Table 3.1). A slope of -3.32 is equivalent to $100 \%$ efficiency, or one doubling per cycle. The $\mathrm{C}_{t}$ of samples was translated directly to copy number via comparison with these standard curves.

For all primer sets except Eub341F/515R, 5 ng of Marinobacter aqualeoli (26) genomic DNA was added per standard reaction. We determined that the addition of background DNA with no target site for the tested primers improved the reaction efficiency of each primer set (data not shown). It also more closely approximated the amplification of a small amount of target against a large background of other environmental DNA. Background DNA at $10 \mathrm{ng}$ per reaction showed reduced efficiency and higher detection limits than $5 \mathrm{ng}$ per reaction. The type of background DNA used did not change this effect (data not shown).

\subsubsection{Quantitative PCR optimization}

Optimization of qPCR reactions was largely performed on plasmid standards, because they were both readily quantifiable and available in large quantities. We tested both two- and three-step reaction protocols. The two-step protocol included an enzyme hotstart at $95^{\circ} \mathrm{C}$ for $3 \mathrm{~min}$, followed by 40 cycles of $95^{\circ} \mathrm{C}$ for $15 \mathrm{~s}$ and $1 \mathrm{~min}$ at the optimal annealing temperature. A melt curve was run for every reaction as follows: 1 cycle of $1 \mathrm{~min}$ at $95^{\circ} \mathrm{C}, 1$ cycle of $1 \mathrm{~min}$ at the annealing temperature, and $0.5^{\circ} \mathrm{C}$ increases of annealing temperature at $10 \mathrm{~s}$ intervals up to $95^{\circ} \mathrm{C}$. The three step protocol included an enzyme hotstart at $95^{\circ} \mathrm{C}$ for $3 \mathrm{~min}$, followed by 40 cycles of $95^{\circ} \mathrm{C}$ for $15 \mathrm{~s}$, annealing temperature (Table 3.2) for $30 \mathrm{~s}$, and $72^{\circ} \mathrm{C}$ for $30 \mathrm{~s}$. Melt curves were run identically to the two-step reaction. The purpose of the melt curves 
was to detect primer-dimers and/or nonspecific PCR products.

Each reaction included $25 \mu \mathrm{l}$ SybrGreen supermix with fluorescein (BioRad), 2

$\mu \mathrm{l}$ acetylated BSA at $10 \mathrm{mg} \mathrm{m}^{-1}$ (Promega), forward and reverse primers (Sigma Genosys) at 200, 400 or $500 \mathrm{nM}$, template, and nuclease free water (Promega) to a total volume of $50 \mu \mathrm{l}$. Primer concentrations of 200 to $500 \mathrm{nM}$ were tested for each primer set with the aim of maximizing efficiency while minimizing primer-dimers (Table 3.2). Acetylated BSA was required for the amplification of some environmental samples. It either improved or did not affect the efficiency of each assay (data not shown). The amount of template required depended on DNA concentration, and was varied between 1-10 $\mu \mathrm{l}$ in order to obtain a value of $\mathrm{C}_{t}$ within the linear detection range of the standard curves. The threshold value for determination of $\mathrm{C}_{t}$ was changed to equal the threshold value of the applicable standard curve. This is a requirement for direct quantification with standard curves. For quantification to be valid, the amplification efficiency of samples and standards should be identical $(42,49)$. We tested the amplification efficiency using tenfold dilutions of selected samples for all primer sets. A qPCR result was counted if the no template control showed a $\mathrm{C}_{t}$ at least 3.3 cycles lower than the no-template control (a tenfold difference).

Two qPCR reactions were run per primer set per depth sampled, with a few exceptions. We chose to amplify replicates taken at the water sampling stage rather than run replicate qPCR reactions using the same source of template. Using duplicate samples from each depth incorporates variation in sample collection and DNA extraction, in addition to well to well variation in qPCR. This results in higher error estimates but more accurately reflects true error in the analysis because variation between identical reactions in different wells was very low. Cell counts for each group were normalized to eubacterial cell counts, also obtained with qPCR.

\subsubsection{Electron microscopy and magnetosome analysis}

We collected MTB from Salt Pond on formvar/carbon coated copper grids for additional TEM analysis. Images were taken with a Zeiss 10CA TEM at the Marine Biological Laboratory in Woods Hole, MA, the JEOL 2000FX and 200CX TEMs at 
MIT, and the HB603 STEM at MIT with assistance from Anthony Garratt-Reed (Fig. 3-4). Additional unpublished TEM images of magnetotactic bacteria from Salt Pond were kindly provided by Richard Frankel. An image of the MMP was taken from Pósfai et al (50). The number of magnetosomes per cell was counted manually. Data on the average diameter of greigite magnetosomes was taken from Pósfai et al (51), and the average diameter of several types of magnetite magnetosomes was obtained from Devouard et al (17). Richard Frankel provided unpublished data on crystal diameters in cells which appeared morphologically similar to the barbell. Each magnetosome was approximated as a sphere in order to estimate the volume. The amount of Fe and S per magnetosome was calculated using the density of magnetite and greigite and the theoretical percent of each element (data obtained from webmineral.com). The average amount of each element per cell contained in magnetosomes was calculated by multiplying the average number of magnetosomes per cell by the amount of each element per magnetosome. Cell counts obtained with quantitative PCR for each morphotype were integrated with respect to depth to obtain estimates of the total number of magnetotactic cells in Salt Pond. These counts were multiplied by the amounts of Fe and S per cell to calculate the estimated total sequestration of these elements by MTB in Salt Pond.

\subsection{Results}

\subsubsection{Water chemistry}

The water chemistry of Salt Pond is summarized in Fig. 3-2. In the early stages of stratification the chemocline was both narrower and deeper, occurring at $4 \mathrm{~m}$. During July it moved up slowly to $3.5 \mathrm{~m}$, and during August it rose to $2.5-3 \mathrm{~m}$ and widened. In late September it was present as a narrow band around $3 \mathrm{~m}$. A peak in particulate Fe was typically observed above the peak in dissolved Fe. It was not possible to separate total dissolved iron from dissolved Fe(II) with our technique, as samples oxidized in the field prior to analysis. The maximum amount of dissolved total iron 
observed during water column stratification was $11.5 \mu \mathrm{M}$, and the maximum amount of sulfide was approximately $1 \mathrm{mM}$ in the bottom waters. Ammonium was present at $0-1 \mu \mathrm{M}$ in surface waters and at levels up to $400 \mu \mathrm{M}$ in bottom waters (Fig. 32a). Nitrate+nitrite was present at $<0.5 \mu \mathrm{M}$ in surface waters and up to $1.8 \mu \mathrm{M}$ in bottom waters (Fig. 3-2a) while phosphate was largely below detection limits in surface waters and present at up to $38 \mu \mathrm{M}$ in bottom waters (Fig. 3-2b). A peak in nitrate+nitrite at lower sulfide levels (Fig. 3-2a) suggests a zone of denitrification. Nitrite is an intermediate in the denitrification process, and similar nitrite peaks have been observed in other stratified water bodies such as the Black Sea (33). The surface layer nutrient concentrations are similar to 1987 data collected by Lohrenz et al (35), but the bottom water concentrations of ammonium and phosphate are several times higher, possibly indicating increased nutrient loading of Salt Pond in intervening years or high interannual variability.

\subsubsection{FISH and CARD-FISH}

The number of fluorescent cells as well as the fluorescence per cell was extremely variable in clone-FISH cells hybridized with standard FISH probes, perhaps due to low expression of non-native ribosomes. Less than half the target cells successfully bound the probe, but there was still sufficient data to optimize hybridization stringency. It was necessary to use E.coli JM109(DE3) (Promega) cells for clone-FISH as TOP10F cells provided with the TOPO TAC) (Invitrogen) cloning kit yielded extremely weak fluorescence. All probes successfully bound control cells in clone-FISH. The fluorescence signal for probe GROD-1-824 was low compared to probe GROD-2-470 in clone-FISH cells, perhaps due to its placement in a region of the 16 s ribosome that typically produces low hybridization signals (6). Probe GROD-1-824 did not produce a sufficient fluorescent signal when applied to environmental samples in regular FISH to be visible with our microscope setup.

However, the signal amplification of CARD-FISH made HRP-labeled probe GROD1-824 clearly visible in natural samples. This probe, corresponding to clones distantly related to Thiomicrospira crunogena (Fig. 3-1), preferentially bound cells taken from 


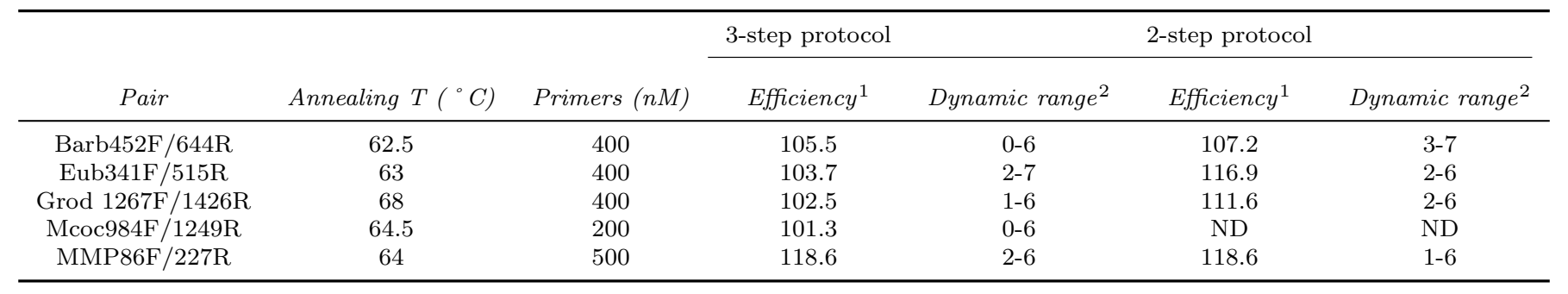

Table 3.2: Properties of quantitative PCR primer pairs used in this study. ${ }^{1} \%$ Efficiency calculated as $10^{(-1 / \text { slope })}-1 .{ }^{2}$ Dynamic range calculated as the log copy number of an external plasmid standard detected with the given primer set. A PCR product was used for the Mcoc primer set. See Methods section. ND, not determined.

samples highly enriched in large rods. Comparison of GROD-1-824 and GROD-2-470 applied to samples from three different years showed that GROD-1-824 bound multiple small rods with approximate length 2.5-3 $\mu \mathrm{m}$ and width $1 \mu \mathrm{m}$ (Fig. 3-3), while GROD-2-470 either bound cells of different morphology or did not bind any cells. The similarity of GROD-1-824 positive cell morphology in samples highly enriched in the large magnetotactic rod from three different years strongly supports the phylogenetic identification.

\subsubsection{QPCR reaction efficiencies}

Our aims were to achieve optimal efficiency and maximize the linear detection range of the assay for each primer set while minimizing non-specific products and primerdimers. We were able to achieve reaction efficiencies very close to the optimum value of $100 \%$ for all primer sets except MMP86F/227R (Table 3.2). Primer-dimers were not visible in the melt curves for standards or samples in all primer sets. Melt curves showed a single amplification product for each primer set in environmental samples, with the exception of the MMP primer set (see below).

All primer pairs had an optimal annealing temperature between 60 and $68^{\circ} \mathrm{C}$ (Table 3.2). Reaction efficiencies of environmental samples were nearly identical to those of plasmid standard curves for Barb, Eub, and Grod primers. The MMP primer set showed a higher efficiency and the Mcoc primer set a lower efficiency when applied to environmental samples than when used to construct standard curves. Previous qPCR studies using SybrGreen methods have used both two-step (82) and three-step 


\begin{tabular}{|c|c|c|c|c|}
\hline Probe name & Sequence ${ }^{1}$ & Target & $\%$ Formamide $^{2}$ & Closest cultivated relative \\
\hline GROD-1-824 & ACAGTCCCAACAGCTAGT & GR cluster 1 & 40 & Thiomicrospira crunogena \\
\hline GROD-2-470 & GTACCGTCATCCCAACCG & GR cluster 2 & $40(55)$ & Stentrophomonas maltophila \\
\hline BARB-1-834 & GAGAAGATTAACCTCCC & Barbell cluster 1 & 35 & $\begin{array}{l}\text { Desulforhopalus singaporen- } \\
\text { sis }\end{array}$ \\
\hline BARB-2-1250 & CGCGAAGTGGCTGCCTTT & Barbell cluster 2 & $35(55)$ & Desulfocapsa sulfoexigens \\
\hline
\end{tabular}

Table 3.3: CARD-FISH probes designed for identification of uncultivated magnetotactic bacteria in this study. The use of the BARB probes, though not the sequences, is described in Simmons et al. (58). ${ }^{1}$ Sequences in the 5 ' to 3' direction. ${ }^{2}$ Formamide $\%$ in parenthesis is the highest stringency possible for use of the probe in isolation. We applied both probes to the same slide in the experiments described here at the lower stringency.

cycling protocols $(60,61,72,83)$. The three-step protocol is generally recommended for use with SybrGreen while the two-step protocol is used for qPCR chemistries with internal hydrolysis probes (45). We achieved better efficiencies and detection ranges using a three-step reaction protocol (Table 3.2).

\subsubsection{QPCR results for MTB and Eubacteria}

The eubacterial primer set that we used in this study (341F and 515R, Table 3.1) yielded $\mathrm{C}_{t}$ values of 13-19 when applied to $1 \mu \mathrm{l}$ template. However, no template controls with this primer set routinely produced $\mathrm{C}_{t}$ values in the mid to upper $20 \mathrm{~s}$, even with new out of the box reagents. Negative controls with no template added did not routinely produce a detectable signal with our other primer sets. Because of this, eubacterial qPCR counts were only considered valid if $\mathrm{C}_{t}$ (sample) exceeded $\mathrm{C}_{t}$ (no template control) by 10, approximately a thousandfold difference in starting template concentration. In practice this threshold was almost always met. Eubacterial qPCR counts were then used to normalize counts obtained for each MTB group to eliminate sample-specific differences in extraction or amplification efficiency. The standard deviation to mean ratio was lower for eubacteria than the specific MTB groups.

Due to some sequence diversity within the MMP group (57), we designed the MMP primer set to cover as many sequences as possible. This rendered it less specific and probably contributed to its relatively poor efficiency and detection range (119\%) relative to the other primer sets (Table 3.2). Most samples did not contain MMP DNA in sufficient quantities to be detected within the limits of our assay (about 
500 cells per $\mathrm{ml}$ ). The MMP is an aggregate containing an average of $17.4 \pm 3.59$ cells (69). Each cell is counted separately in qPCR, requiring this correction factor to be applied to estimate the total number of aggregates. Samples with detectable product indicated that total MMP cells (counting each cell within an aggregate) were present in a range of $0.13 \pm 0.10 \%$ to $1.9 \pm 1.4 \%$ of total eubacteria (Fig. 3-5), with maximum counts of $6.3 \pm 4.4 \times 10^{3}$ aggregates $\mathrm{ml}^{-1}$ in sediments from the early season. MMP typically occurred at an order of magnitude estimate of 500 aggregates $\mathrm{ml}^{-1}$. MMP PCR products from natural samples showed two distinct melt curves, possibly indicating the presence of multiple sequence types. Of 36 samples with detectable product from MMP primers, $75 \%$ had a melt curve peak at $86^{\circ} \mathrm{C}, 22 \%$ had a peak at $83{ }^{\circ} \mathrm{C}$, and $3 \%$ had peaks at both temperatures. The standard used peaked at $83^{\circ} \mathrm{C}$ and belonged to the most abundant clone type in a MMP 16 s rDNA library constructed from salt marsh samples (57).

It was not possible to design primer sets encompassing both sequences from Salt Pond cocci and previously identified MTB in the $\alpha$-Proteobacteria due to sequence divergence at appropriate primer sites. This diverse group includes both cultivated and uncultivated magnetite-producing bacteria $(22,66,67)$, mostly from freshwater environments, as well as the marine coccus MC-1 (80). Sequences in this cluster have secondary structure elements typical of $\alpha$-Proteobacteria (16), but the cluster is grouped with the $\alpha$-Proteobacteria at bootstrap values less than $50 \%$ (data not shown). The primer set used here only targets sequences obtained from Salt Pond.

We obtained cell counts of magnetotactic cocci from almost all samples analyzed, indicating both their abundance in the environment and the efficacy of the primer set. The cocci showed a distributional pattern with depth similar to previous qualitative observations (59), peaking immediately above the peak in dissolved iron. This pattern held for both high and low total cell numbers of cocci. The cocci were most abundant in July (Figs. 3-5 and 3-6) when the chemocline of Salt Pond was both deeper and narrower than later observations. The range of abundance observed was $0.020 \pm 0.016 \%$ to $2.2 \pm 0.6 \%$ of total bacteria (Fig. 3-5), and the range of cell counts was $23 \pm 18$ to $6.2 \pm 2.4 \times 10^{3}$ cells $\mathrm{ml}^{-1}$. To a degree, the abundance of the cocci varied 
inversely with the abundance of the barbell MTB (Fig. 3-6). It is possible that we underestimated the abundance of the cocci when they occurred at very low numbers due to differences in amplification efficiency between samples and standard (see above).

The barbell MTB increased steadily in abundance throughout the summer, with concentrations peaking in August and September (Figs. 3-5 and 3-6). The variance in counts of the barbell was higher than for other MTB groups, equaling or exceeding the mean for half of all counts. The highest abundances with acceptable variances were $23 \pm 16 \%$ and $9.1 \pm 5.7 \%$ of total bacteria (Fig. 3-5), and the lowest $0.07 \pm 0.1 \%$. Maximum cell counts reached $10^{5}$ cells $\mathrm{ml}^{-1}$ on one occasion, although more typical

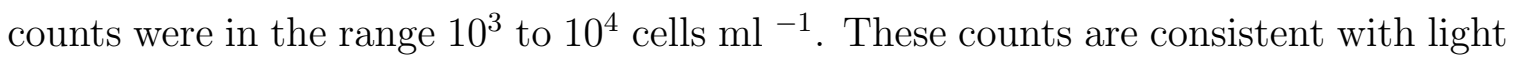
microscopic observations of barbells in the late season. Depth profiles from 7/22 and 8/7 (Fig. 3-6) indicate that numbers of the barbell peaked slightly lower in the water column than the peak abundance of cocci. There was a significant difference (paired t-test, $\mathrm{p}<0.05$ ) between the mean abundance of barbells and the mean abundance of cocci, even when barbell abundances over $10 \%$ were excluded from the analysis.

The greigite rod occurred in low numbers throughout the season (Fig. 3-5), comprising $0.01-0.1 \%$ of total eubacteria, or tens to hundreds of cells per ml. The lower

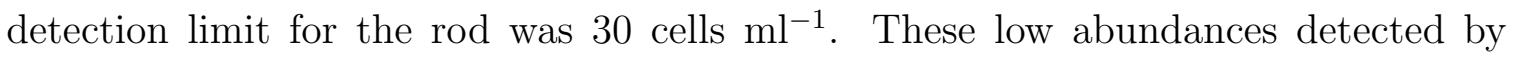
qPCR are consistent with light microscopic observation of the samples on which the qPCR was performed.

\subsubsection{Fe sequestration by MTB}

The average number of magnetosomes was higher in greigite-producing MTB than magnetite-producing MTB (Table 3.4). There appeared to be two classes of greigite rod sampled from Salt Pond based on magnetosome counts, indicating either enormous plasticity in magnetosome production or the presence of an additional rod phylogenetically distinct from the one identified here. Most greigite rods, presumably the one identified here and shown in Figs. 3-3 and 3-4, contained 66 \pm 19 magnetosomes/cell. However, one rod (pictured in (59)) contained 224 magnetosomes. 
Heywood et al. (25) also observed two classes of greigite rod from New England salt marshes, separated by the average number of magnetosomes per cell (57 for "large," and 26 for "small" rods). The MMP contains 491 195 magnetosomes per aggregate, although the sample size used for counts was low due to the difficulty of preserving intact aggregates on the TEM grid. The density of organic matter in the MMP also makes accurate counting of magnetosomes difficult. We do not yet know what type of mineral is produced by the barbell, but the magnetosome morphology in images possibly corresponding to the barbell suggests magnetite (R.B. Frankel, pers. comm.). Unpublished data on crystal sizes from possible barbells imaged with TEM was provided by R.B. Frankel. The cells in these TEM images were not phylogenetically confirmed as the barbell. From magnetosome sizes and numbers per cell, we obtained estimates of the average iron content of each MTB type, approximately $10^{-14} \mathrm{~g} \mathrm{Fe}$ per cell with the exception of the MMP at $10^{-13} \mathrm{~g}$ Fe per aggregate (Table 3.4).

We integrated cell counts obtained with our qPCR assay with respect to depth for each sampling date and multiplied these by the estimated surface area of Salt Pond to obtain the total number of MTB cells in Salt Pond. Depth integration showed that MTB in Salt Pond are present at an average concentration of $10^{2}-10^{4}$ cells $\mathrm{ml}^{-1}$ within the 0.5-2 $\mathrm{m}$ depth lens where they were measured by qPCR (Table 3.5). This result should be considered an underestimate of the total MTB population since our qPCR assay targeted only four major groups of MTB, and we did not enumerate MTB at every depth in the sulfidic hypolimnion. We multiplied the Fe content per cell by total cell counts to obtain an estimate of total Fe contained in MTB cells in Salt Pond. Depending on the degree of stratification, we estimate that the instantaneous sequestration by measured MTB populations is between 1 and $11 \mathrm{~g}$ of Fe in the deeper portions of Salt Pond. The total amount of iron sequestered by MTB on each date was then divided by the volume of the lens containing MTB to obtain an estimate of Fe sequestered by MTB per cubic centimeter of pond water. Depending on the date, this number ranged from $2.3 \times 10^{-10}$ to $9.6 \times 10^{-12} \mathrm{~g} \mathrm{Fe} \mathrm{cm}^{-3}$ (Table 3.5).

We also calculated the amount of Fe that would be sequestered by MTB populations in Salt Pond averaging $10^{4}$ or $10^{5}$ cells $\mathrm{ml}^{-1}$ over a one meter depth range 


\begin{tabular}{|c|c|c|c|c|c|c|}
\hline Morphotype & cells & msomes/cell & mineral & source & $\begin{array}{l}* 10^{-14} \mathrm{~g} F e \\
\text { per cell }\end{array}$ & $\begin{array}{l}* 10^{-14} g \quad S \\
\text { per cell }\end{array}$ \\
\hline $\begin{array}{l}\text { Large greigite rod, includ- } \\
\text { ing outlier }\end{array}$ & 18 & $75 \pm 42$ & greigite & Salt Pond* & $1.8 \pm 1.0$ & $0.067 \pm 0.038$ \\
\hline $\begin{array}{l}\text { Large greigite rod, not in- } \\
\text { cluding outlier }\end{array}$ & 17 & $66 \pm 19$ & greigite & Salt Pond* & & \\
\hline "Barbell" & 7 & $37 \pm 15$ & unknown $^{2}$ & Salt Pond* & $1.2 \pm 0.37$ & na \\
\hline Coccus & 32 & $13 \pm 6$ & magnetite & Salt Pond* & $2.5 \pm 0.22$ & na \\
\hline MMP & 5 & $491 \pm 195$ & greigite & Salt Pond*; (50) & $12 \pm 5^{5}$ & $0.43 \pm 0.17^{5}$ \\
\hline Little rod & 4 & $14 \pm 2.2$ & magnetite & Salt Pond* & na & na \\
\hline Large greigite rod & na & $57 \pm$ na & greigite & $\begin{array}{ll}\text { Salt } & \text { marshes }^{1} \\
(25) & \end{array}$ & na & na \\
\hline Small gregite rod & na & $26 \pm$ na & greigite & $\begin{array}{ll}\text { Salt } & \text { marshes }^{1} \\
(25) & \end{array}$ & na & na \\
\hline
\end{tabular}

Table 3.4: Average numbers of magnetosomes for several types of uncultivated MTB observed in Salt Pond. * indicates images were collected for this study or obtained from previous unpublished images from in Salt Pond taken by R.B. Frankel and D.A. Bazylinski. ${ }^{1}$ Cells collected from Neponset salt marsh, Woods Hole, and Morro Bay; see (25) for details. ${ }^{2}$ Calculations assume unknown mineral is magnetite, based on morphology (data not shown). ${ }^{3}$ Estimates taken from depth integrated cell counts on 8/15/2003. ${ }^{4}$ Greigite rod data from $8 / 21 / 2003$. ${ }^{5}$ Number indicates Fe and $\mathrm{S}$ per aggregate, not in each individual cell.

(Table 3.5). These numbers are intended to estimate the effect of MTB blooms on Fe flux. While these blooms were infrequently observed in 2003, they were common in

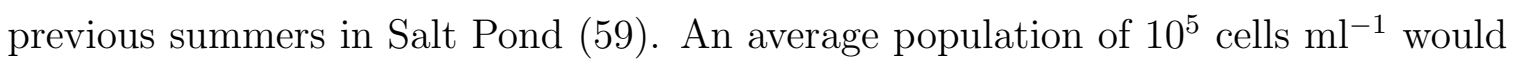

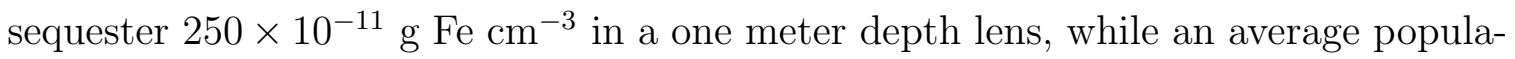
tion of $10^{4}$ cells $\mathrm{ml}^{-1}$ would sequester ten times less. An estimate of the turnover time for natural populations of MTB is required to introduce a time element into these numbers. The turnover time of MTB populations in nature is not known, but we can use estimated turnover times for heterotrophic marine bacterial assemblages (1-4 days in one study (44)) as a boundary condition. We used an estimated turnover time of 2 days in our calculations. Over the course of summer stratification (approximately 100 days), using a value of $2.3 \times 10^{-10} \mathrm{~g}$ MTB-specific Fe $\mathrm{cm}^{-3}$ in a one meter depth lens, approximately $1.9 \times 10^{3} \mathrm{~g}$ of Fe are sequestered by MTB in the deeper portions of Salt Pond.

The contribution of MTB to Fe flux was also estimated for populations in the Lower Basin of the Pettaquamscutt Estuary, RI, a stably stratified euxinic basin (4). MTB in the Pettaquamscutt are found in a depth range of $4.25 \mathrm{~m}$ and reach estimated concentrations of $10^{5}$ cells $\mathrm{ml}^{-1}$ in a $1.2 \mathrm{~m}$ band (4). We estimated MTB 


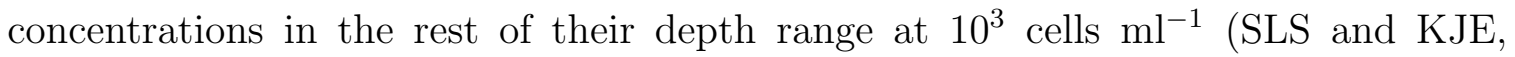
unpublished observations). The volume of water contained in this lens in the Lower Basin is approximately $1.6 \times 10^{12} \mathrm{~cm}^{3}(77)$. If we use the same value of $10^{-14} \mathrm{~g} \mathrm{Fe}$

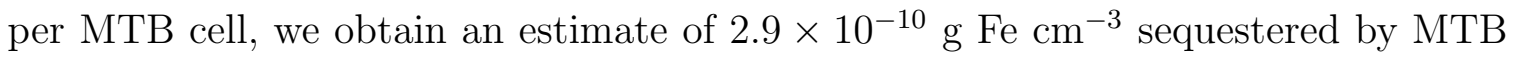
in the Pettaquamscutt, a value comparable to Salt Pond.

\subsection{Discussion}

We applied the classical full cycle 16s rRNA method to several groups of MTB in a chemically stratified environment with the goal of obtaining a quantitative understanding of their ecology. The wide variation in abundances and often low cell densities of certain groups makes them difficult to consistently count accurately using FISH, so qPCR offered a more sensitive, high-throughput solution. Our goal was not necessarily to obtain exact cell numbers, but rather to quantify the relative abundance of different MTB species with respect to changing water chemistry.

\subsubsection{Technical issues with SybrGreen quantitative PCR}

The first step was to design specific primers for each MTB group and verify that they bound to the correct target site. Here, we first validated the phylogenetic identity of uncultivated MTB using physical separation of cells, 16s rRNA sequencing, and CARD-FISH prior to primer design. Our primers were checked against existing 16s databases and tested on plasmid standards to determine the size and specificity of the product. We determined whether the product produced a single peak in the melt curve, indicating the absence of nonspecific products and primer-dimers. Because SybrGreen binds to any dsDNA, not just the product of interest, the presence of excessive primer-dimers can affect the overall efficiency of the reaction (10). Our primer sets did not produce noticeable primer-dimers or multiple products when applied to standards.

Maximizing primer efficiency is also important for accurate quantification. The presence of primer-dimers or nonspecific products can cause a SybrGreen reaction 
to show efficiency greater than $100 \%$, which is theoretically impossible (10). While direct quantification is occasionally used with primer sets that have poor efficiency, this is not optimal. The factors causing poor efficiency may vary between reactions with the same primer set, resulting in inaccurate quantification as reaction efficiencies vary unpredictably from the standard curve. Poor efficiency also reduces the dynamic range of the assay. At low starting template concentrations, primer-dimers and nonspecific products can produce a larger component of the measured fluorescence, resulting in a non-linear relationship between template amount and $\mathrm{C}_{t}$. We were able to achieve a dynamic range of 1 or 10 to $10^{6}$ copies for several of our primer sets with efficiencies close to $100 \%$ (Table 3.2).

For accurate quantification, amplification efficiency should be close to identical for standards and samples. If the efficiencies are unequal, the relationship between template concentration and $\mathrm{C}_{t}$ determined for a plasmid standard curve is not equivalent to the same relationship for a sample; a greater difference in efficiencies results in larger quantification errors. The magnitude of the error is directly proportional to the value of $\mathrm{C}_{t}$, meaning that this effect is most significant at low initial template concentration. A ten-fold difference in efficiency between samples and standards results in a two-fold error in quantification if $\mathrm{C}_{t}=15$, but a 4.3 -fold error if $\mathrm{C}_{t}=30$. A twenty-fold difference in efficiency results in a four-fold error if $\mathrm{C}_{t}=15$, but almost a twenty-fold error if $\mathrm{C}_{t}=30$. This problem is often ignored in qPCR studies of marine microorganisms and makes it difficult to gauge the accuracy of cell quantifications. Our primer sets behaved similarly for standards and samples, with two exceptions. The MMP primer set showed a higher efficiency and the Mcoc primer set a lower efficiency when applied to environmental samples than when used to construct standard curves. If these differences held for all samples, it would result in an overestimate of MMP concentration and an underestimate of Mcoc concentration in environmental samples. We found that using acetylated BSA in our reactions improved amplification efficiency for samples, possibly due to sequestration of contaminants.

Variation in sample collection and extraction is another obvious source of quantification error. In general, spiking experiments have shown a linear relationship between 
the number of cells added prior to extraction and the numbers recovered by qPCR $(19,56)$. A large collection of environmental samples may, however, contain factors influencing extraction efficiency (metal content, for example) in different directions. We chose to use a relative abundance method for quantification to control for this between-sample variation. Cell numbers for each MTB group were normalized to total cell counts retrieved with a eubacterial primer set (Table 3.1). This also controls for the two different extraction methods we used (CTAB/phenol/chloroform and spin column kit). The spin column kit resulted in lower total yields of DNA and lower total eubacterial cell counts than the CTAB method. Because we did not use both extraction methods in parallel on a single sample, we cannot make a direct comparison. MTB/Eub ratios for all MTB groups do not vary systematically with extraction method, however. The variance to mean ratio was higher for our relative abundance qPCR counts than in other qPCR studies using a similar method $(19,54,60)$ probably due to two factors: collection of samples with centrifugation rather than filtration and the magnetic swimming behavior of MTB resulting in an uneven distribution of MTB in the sample bottle.

Our standards curves gave a direct relationship between copy number and $\mathrm{C}_{t}$. Because many microbes contain more than one copy of the rRNA operon per genome, copy number does not necessarily equal cell number. The average number of rRNA operons in all bacteria is 4.1, 2.2 in the $\alpha$-Proteobacteria, 2.5 in $\delta$-Proteobacteria, and 2.5 in the Thiobacillus group of the $\gamma$-Proteobacteria (31), the most relevant for the greigite rod described here. If we applied a correction of 0.25 (4 copies equal to 1 cell) to the eubacterial standard curve and 0.5 (2 copies equal to 1 cell) to the MTB standard curves, the ratio of MTB to Eub would be twice the value presented here. Because we do not know the number of operons per cell in Salt Pond MTB, we did not apply this correction to the data shown in Figs. 3-5 and 3-6.

\subsubsection{MTB ecology in Salt Pond}

Our results broadly confirm prevous qualitative observations of the MTB community in Salt Pond (59). In that work, we described the presence of magnetite-producing 
MTB (cocci) at the top of the chemocline with greigite-producers (MMP and rods) layered below in more sulfidic waters. The distribution of magnetite-producing cocci observed with qPCR coincides with qualitative observations. These cocci are closely related to marine coccus strain MC-1, which is a microaerophilic, chemolithoautotrophic sulfide-oxidizer (80). They have always been observed directly above the peak in ferrous iron (Fig. 3-6), a typical distributional pattern for sulfide-oxidizers. We might have expected higher cell counts than the $10^{3}$ cells $\mathrm{ml}^{-1}$ observed here based on the dramatic blooms observed in 2002. On the whole, however, the summer of 2003 was much cooler than 2002 and the MTB dynamics appeared qualitatively different. We do not know why the cocci were more abundant in the early season than the mid to late season when the chemocline widened; possibly the presence of intermediate sulfur compounds during extensive stratification favored the dominance of other chemotrophs.

It is unlikely that we dramatically underestimated the abundance of magnetiteproducing cocci. There was a $10 \%$ difference in $\mathrm{qPCR}$ reaction efficiency between our standards and one set of samples, but we do not know if that difference held for all samples. Even if it did, that would result in at most a four-fold error in estimation. The cocci contained a remarkably steady number of magnetosomes $(13 \pm 6)$ with a distinctive square shape in TEM images, consistent with previous observations of strain-specific magnetosome morphology in magnetite-producing MTB (5). The relatively low cell numbers coupled with the low magnetosome counts mean that the cocci are not the primary MTB contributors to iron sequestration at the chemocline (Table 3.4).

The major surprise in our findings was the high abundance of the "barbell," the first magnetotactic organism described to demonstrate south polarity in the Northern Hemisphere, the opposite of all previously observed magnetotactic behavior (58). Despite the high variances in estimates of barbell relative abundance, it is clear that the barbell appeared in higher numbers than all other MTB groups and in the late

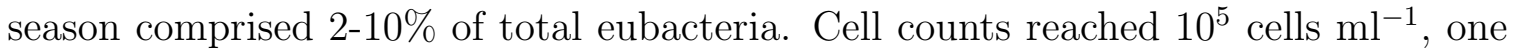
of the highest observed for MTB in nature. We have observed comparable counts of 
MTB in the stably stratified Pettaquamscutt Estuary, RI (unpublished data). Abundance of the barbell also appeared to vary inversely with that of the cocci, suggesting different chemical requirements for the two groups. The Salt Pond chemocline was narrow (approximately one-third of a meter) when the abundance of cocci reached a maximum in the early season; oxygen and sulfide appeared to overlap within the limits of our analytical measurements (7/22 on Fig. 3-6). With the exception of $9 / 24$, increased abundance of the barbell coincided with increased chemocline width (over $1 \mathrm{~m}$ on 8/15). An intense bloom of the barbell occurred on 9/24, especially in samples taken during a night sampling. QPCR and light microscopic counts both suggest that the barbell reached $10^{5}$ cells $\mathrm{ml}^{-1}$, so chemocline width cannot be the only factor. Peak concentrations of dissolved iron were much higher on 9/24 (10.5 $\mu \mathrm{M})$ than on $7 / 22(3 \mu \mathrm{M})$, which may also have played a role.

The distributional pattern of the barbell with depth as well as the metabolism of closely related species offer some clues to its role in chemocline ecology. The barbell is most closely related to Desulforhopalus singaporensis (58), an unusual organism in the family Desulfobulbaceae that reduces sulfate, ferments taurine, and grows in chains of cells similar to the barbell (34). Maximum abundances of the barbell occurred immediately below the peak in dissolved iron when the chemocline was widest (Fig. $3-6)$, and below the peak in relative abundance of the cocci. The distributional patterns of the barbell are generally similar to other closely related organisms in the Desulfobulbaceae, although few studies exist on the distribution of this family of organisms with respect to environmental chemistry. Studies of $d s r A$ phylotypes in the water column of Lake Fryxell, Antarctica (29) and SRB in cold seep sediments (32) both show that organisms related to Desulforhopalus sp. are most abundant in the upper part of sulfidic transition zones, where sulfide concentrations are approximately the same as those observed in this study.

Several 16s rRNA clones nearly identical to Desulfocapsa sulfexigens were also identified in a barbell-rich sample (58). D. sulfexigens is not capable of sulfate reduction and grows by disproportionation of elemental sulfur, thiosulfate, or sulfite in the presence of ferrihydrite as a sulfide scavenger (20). The co-existence of the 
barbell with $D$. sulfexigens and their position in the chemocline suggests the likely presence of intermediate sulfur compounds at the same depths as the barbell. A peak of elemental sulfur is often found at the upper boundary of the sulfide zone in stratified marine environments (e.g. the Black Sea (27) and Mariager Fjord (52)), along with other intermediate sulfur compounds such as thiosulfate (28). These clues suggest that the barbell is either a sulfate reducer with a low tolerance for sulfide or is capable of growth on intermediate sulfur compounds. The presence or absence of genes involved in sulfate reduction in the barbell would provide important additional information. It is uncertain what role, if any, the south polarity of the barbell plays in its environmental distribution.

The distribution of the many-celled magnetotactic prokaryote (MMP), a large greigite-producer, was not as well defined with qPCR as the barbells and cocci. This was largely due to a higher detection limit with the MMP primer set, which resulted from the attempt to design primers encompassing most of the high diversity within this group (57). Tracking species-level sub-populations of this group is needed for a more accurate estimate of total MMP. The few depth profiles obtained indicated that MMP cell numbers peak below the chemocline, as previously observed (59), and that MMP typically occurred at of order 500 aggregates cells $\mathrm{ml}^{-1}$. We did not observe any large blooms of MMP comparable to 2002. High numbers of MMP observed in Salt Pond sediments in late June $(1.9 \pm 1.4 \%$ of all bacteria) suggest that MTB survive the winter mixed water column of Salt Pond by retreating to reduced sediments, forming a seed population for colonization of the stratified water column in summer. The large number of magnetosomes in MMP aggregates (491士195) indicates that their impact on Fe and S sequestration is out of proportion to their abundance (Table 3.4).

QPCR counts of the large greigite rod identified in this work confirm the relative invariance of cell numbers over time based on previous qualitative observations (59). The rod is found from the base of the chemocline into the hypolimnion, where sulfide concentrations do not change much during seasonal stratification. The rod did not show bloom dynamics either in these samples or qualitatively in 2002, and low cell counts (100 cells $\mathrm{ml}^{-1}$ on average) suggest a slow growth rate. Its distribution also 
indicates that it is not a gradient organism like the other three groups of MTB described here. Despite the high average number of magnetosomes per cell, low cell numbers of the rod mean that it does not contribute to iron and sulfur sequestration at the same level as the MMP.

\subsubsection{The contribution of MTB to Fe flux in euxinic basins}

Our data suggest that MTB are potentially important, previously neglected, contributors to the flux of particulate Fe out of the chemocline of stratified marine basins. We propose a simple model of the "MTB iron pump" (Fig. 3-7) as a conceptual guide to understanding and quantifying the effects of MTB on iron cycling. Chemoclines above marine euxinic waters typically show a peak of particulate Fe in the form of Fe-oxyhydroxides directly above a peak in dissolved Fe(II). MTB grow in the chemocline with turnover time $t$. A fraction of Fe concentrated by MTB in magnetosomes is recycled in the chemocline, either through lysis and dissolution or grazing by protists $(g)$. Magnetically responsive protists are occasionally present in the Salt Pond chemocline at concentrations of up to $10^{3}$ per ml (D. Bazylinski, unpublished observations), suggesting an active grazing population. Fe in magnetosomes is exported from the chemocline through death and settling of individual MTB and magnetic protists. Individual magnetosomes fall very slowly to the sediments due to their small size. A few simple calculations using Stokes' law applied to small particles show that a magnetosome with diameter $100 \mathrm{~nm}$ settles at a rate of $9 \times 10^{-3} \mathrm{~cm}$ per hour. If magnetosomes are packaged into a bacterial cell or protist of diameter $3 \mu \mathrm{m}$, they settle at $8.3 \mathrm{~cm}$ per hour. Clearly, the form in which magnetosomes settle to the sediments determines the time they are exposed to sulfidic bottom waters and hence the probability of dissolution or alteration. Magnetite dissolves easily in sulfidic waters and sediments, but approximately $10-20 \%$ of the input flux can be preserved by the formation of pyrite coatings (11).

The overall contribution of MTB to Fe flux can be determined with a fairly limited set of parameters: cell density, Fe content per cell, chemocline width, and population turnover times. The first three parameters were measured directly in Salt Pond 
and can be approximated for other stratified water columns known to contain MTB. The population turnover time is not known, but we use an estimate of 2 days here based on observations of marine heterotrophic bacteria (44). The highest MTB cell concentrations observed in stratified marine basins are approximately $10^{5}$ cells $\mathrm{ml}^{-1}$ (this study, (4)). MTB in freshwater sediments occurred at $10^{5}$ cells cm $\mathrm{cm}^{-3}$ (65), while MTB in freshwater microcosms showed a maximum of $10^{6}$ cells $\mathrm{cm}^{-3}$ (21). After storage of months to years, MTB in marine sediments increased to $10^{5}$ cells $\mathrm{cm}^{-3}$ (8). MTB in marine sediments in New England average $10^{3}-10^{4}$ cells $\mathrm{ml}^{-1}$ (9). It seems reasonable to assume, therefore, that $10^{5}$ cells $\mathrm{cm}^{-3}$ is an upper bound for the density of MTB in the environment. Using qPCR, we have shown in this study that integration of MTB cell counts with depth in Salt Pond results in an average MTB concentration of $10^{2}-10^{4}$ cells $\mathrm{ml}^{-1}$ in their preferred habitat at and below the chemocline (Table 3.5). We estimated Fe content per cell at about $10^{-14} \mathrm{~g}$, less than a previously published figure of $10^{-13} \mathrm{~g}$ Fe/cell for MTB in carbonate sediments with larger magnetosomes (12) and for Magnetospirillum in laboratory culture (74). MTB Fe contents probably differ slightly between environments, but could be easily determined using TEM to determine magnetosome sizes for a representative set of samples.

With this information we can calculate the contribution of MTB to the total flux of reduced Fe out of euxinic basins $\left(\mu \mathrm{g} \mathrm{Fe} \mathrm{cm}^{-2} \mathrm{yr}^{-1}\right)$, as follows: (the depth-integrated concentration of MTB $) \times($ Fe content per cell $) \times($ chemocline width $) \times($ number of MTB populations per year). The results for five stratified basins are presented in Table 3.5. Live MTB have been observed directly in three of these (Lake Ely (30), the Pettaquamscutt (4), and Salt Pond) and magnetosomes in another (Swedish lake sediment (63)). MTB have not been described in the Black Sea chemocline, but it is probable they are present given the similarity between iron and sulfide profiles in the Black Sea and smaller basins where MTB occur. In addition, dead cells of MTB are present in Black Sea sediment (unpublished observations). The maximum microbial biomass observed in the Black Sea is approximately $10^{6}$ cells $\mathrm{ml}^{-1}$ (7). If MTB constitute $1 \%$ of this biomass, as described here for Salt Pond, their concentration 
would be $10^{4}$ cells $\mathrm{ml}^{-1}$. The Black Sea chemocline (defined as the region where sulfide increases from 0 to $100 \mu \mathrm{M})$ is approximately 100 meters wide (37). If the Fe content of MTB in the Black Sea is $10^{-14} \mathrm{~g} \mathrm{cell}^{-1}$, the total flux of Fe contained in MTB minerals is $0.2 \mu \mathrm{g} \mathrm{Fe} \mathrm{cm}{ }^{-2} \mathrm{yr}^{-1}$. For a slightly larger Fe content of $10^{-13} \mathrm{~g}$ cell ${ }^{-1}$, the flux would be $2 \mu \mathrm{g} \mathrm{Fe} \mathrm{cm}^{-2} \mathrm{yr}^{-1}$.

To put this in perspective, the total flux of reduced Fe in the form of Fe-sulfides to sediments of the Black Sea deep euxinic basin is $38 \pm 28 \mu \mathrm{g} \mathrm{Fe} \mathrm{cm}^{-2} \mathrm{yr}^{-1}$ (1). The primary Fe source for this flux is the transport of dissolved Fe remobilized from the continental shelf into anoxic waters (39). Fe-sulfides are formed almost entirely in a narrow zone directly below the oxic-anoxic interface and then sink to the sediments through 2000 meters of euxinic waters (38). If our estimates are accurate, precipitation of Fe in intracellular minerals by MTB accounts for 0.5 to $5 \%$ of the total Fe flux in the deep basin of the Black Sea. The total flux of Fe in pyrite out of the chemocline in the Pettaquamscutt Lower Basin is $0.6 \mu \mathrm{g} \mathrm{cm}^{2} \mathrm{yr}^{-1}$ (79). If MTB are present at concentrations of $10^{4}$ cells ml ${ }^{-1}$ in the chemocline (4), a conservative estimate, they would account for 1.3-13\% of the total pyrite flux. For both these systems, some fraction of magnetite from MTB would be lost to dissolution (11), but greigite from MTB would be preserved via transformation to pyrite. Because we do not have estimates of total Fe-sulfide flux for Salt Pond, it is not possible to calculate the percentage of total flux due to MTB. Our calculations for the Black Sea, the world's largest stratified basin, and the Pettaquamscutt Estuary suggest that MTB could be major unrecognized contributors to geochemically important fluxes of reduced Fe.

Several additional parameters need to be measured to determine the magnitude of MTB Fe sequestration relative to other organic and inorganic processes in Salt Pond. The total amount of particulate Fe flux out of the chemocline should be measured with sediment traps suspended in the sulfidic hypolimnion, in conjunction with measurements of dissolved and particulate Fe at the chemocline. The distinctive morphology of MTB magnetosomes means that their abundance relative to other forms of particulate $\mathrm{Fe}$ (oxides and/or sulfides) could be easily determined. A depth series of such traps would reveal the dissolution rates of magnetosomes relative to other 


\begin{tabular}{|c|c|c|c|c|c|c|c|}
\hline & Environment & $\begin{array}{l}\text { Chemocline } \\
\text { width } \\
(\mathrm{cm})\end{array}$ & Populations/yr & $\begin{array}{l}\text { Average } \\
M T B \\
m l^{-1}\end{array}$ & $\begin{array}{l}\text { Fe flux } \\
\text { from } \\
M T B\end{array}$ & $\begin{array}{l}\text { Estimated } \\
\% \text { of in- } \\
\text { organic } \\
\text { flux }\end{array}$ & $\begin{array}{l}\text { Source } \\
\text { for } \\
\text { parame- } \\
\text { ters }\end{array}$ \\
\hline Lake Ely & $\begin{array}{l}\text { Freshwater } \\
\text { lake }\end{array}$ & 500 & 183 & $2.1^{*} 10^{4}$ & $1.9^{*} 10^{-2}$ & $\mathrm{n} / \mathrm{a}$ & $(30)$ \\
\hline $\begin{array}{l}\text { Pettaquamscutt } \\
\text { Lower Basin }\end{array}$ & $\begin{array}{l}\text { Brackish } \\
\text { river }\end{array}$ & 425 & 183 & $2.9^{*} 10^{4}$ & $0.2-0.02$ & $1.3-13 \%$ & $(4,79)$ \\
\hline Salt Pond & $\begin{array}{l}\text { Brackish } \\
\text { pond }\end{array}$ & 100 & 60 & $10^{2}-10^{4}$ & $2.5^{*} 10^{-4}$ & $\mathrm{n} / \mathrm{a}$ & $\begin{array}{l}\text { This } \\
\text { study }\end{array}$ \\
\hline Black Sea & Marine & 10,000 & 183 & $\begin{array}{l}10^{4} \\
\text { (est) }\end{array}$ & $0.2-2$ & $0.5-5 \%$ & $(37)$ \\
\hline Swedish lakes ${ }^{1}$ & Freshwater & & & & $1.2^{*} 10^{-3}$ & $\mathrm{n} / \mathrm{a}$ & (63) \\
\hline
\end{tabular}

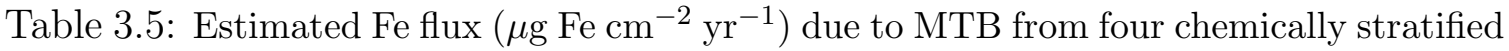
basins (see text). Populations per year were calculated using an estimated turnover time of 2 days. For Salt Pond, we assumed a 2 day turnover time and a 4 month period of stratification. The Black Sea chemocline was defined as the region where sulfide increases from 0 to $100 \mu \mathrm{M}$ as shown in Luther et al. (37). A value of $10^{-14} \mathrm{~g} \mathrm{Fe} /$ cell was used for all flux calculations. Where a range is given, $10^{-13} \mathrm{~g} \mathrm{Fe} /$ cell was also used.

${ }^{1}$ Flux estimate includes both biogenic and inorganic magnetite.

particle types. The concentration of magnetosomes in sediment samples collected before, during, and after the summer stratification would provide a relationship between MTB concentrations in the water column and magnetosome preservation in sediments. This information is required to determine the overall quantitative significance of the MTB iron pump in stratified environments.

\subsubsection{Conclusions and future work}

One season of observations of a complex bacterial community is an ecological snapshot. Our observations at Salt Pond over several summers demonstrate that the MTB community is dynamic, changing in response to narrow gradients potentially too fine to be captured with our instruments. To document natural perturbations in the Salt Pond system and their effect on the MTB community, a time series of finer-scale chemical measurements coupled with qPCR counts will be required. We have taken steps in this direction with the construction of a fine-layer sampler (58) and the use of voltammetric microelectrodes to collect in situ chemical data (Simmons, Canovas, and Edwards, unpublished). Longitudinal studies of bacterial populations indicate the importance of time-series measurements for a better understanding of microbial ecology. In a similar environment to Salt Pond, Tonolla et al (75) observed large fluc- 
tuations in populations of purple and green sulfur bacteria correlated with changes in the chemocline over a ten-year period.

Our observations in Salt Pond nonetheless provide significant insights into MTB ecology in stratified marine basins. Numbers of magnetite-producing MTB (cocci and possibly the barbell) generally exceed numbers of greigite-producing MTB (the MMP and the greigite rod), but the higher number of magnetosomes in greigite MTB make them nearly as important in iron cycling. The barbell MTB occurred in unexpectedly high numbers, and further work is needed to understand the factors regulating its distribution. Clone libraries and TEM images (unpublished data) suggest additional diversity among greigite-producers, meaning that the cell counts and sequestration data presented here are likely underestimates. A more exhaustive effort to identify greigite MTB using 16s RNA full cycle analysis is required. The steps are reasonably straightforward: isolation of MTB using their magnetic swimming behavior, 16s rRNA sequencing, and identification with FISH or CARD-FISH. These identifications can then be used to design qPCR primers for additional groups of MTB.

It is feasible to determine the parameters required for estimates of Fe export by MTB (MTB concentration and Fe content per cell) for any stratified environment using the qPCR techniques described here in combination with electron microscopy. More accurate understanding of Fe export, however, requires studies that include understanding export mechanisms (i.e. grazing vs. settling) in greater detail. The combination of qPCR counts of MTB, magnetosome counts obtained with TEM imaging, and measurements of environmental chemistry is a powerful tool to obtain quantitative information about the impact of MTB on iron and sulfur cycling in the environment. The application of these techniques to other stratified marine basins, in conjunction with measurements of inorganic Fe precipitation, can provide significant insight into the operation of the MTB iron pump. 


\subsection{Acknowledgments}

S.L.S. was partially supported by a National Defense Science and Engineering Graduate fellowship. Funding for the research described here was provided by the Reinhart Coastal Research Center and the Ocean Life Institute, both part of the Woods Hole Oceanographic Institution. We thank Ronnie Yoo, Cara Santelli, and Dan Rogers for sampling assistance. We also thank Eric Webb for help with quantitative PCR and access to equipment, Richard Frankel for unpublished TEM images from Salt Pond, Anthony Garratt-Reed for assistance with STEM analysis, and Matt Charette for providing equipment and technical advice for the nutrient analysis. D.A.B. is supported by U.S. National Science Foundation grant EAR-0311950. 


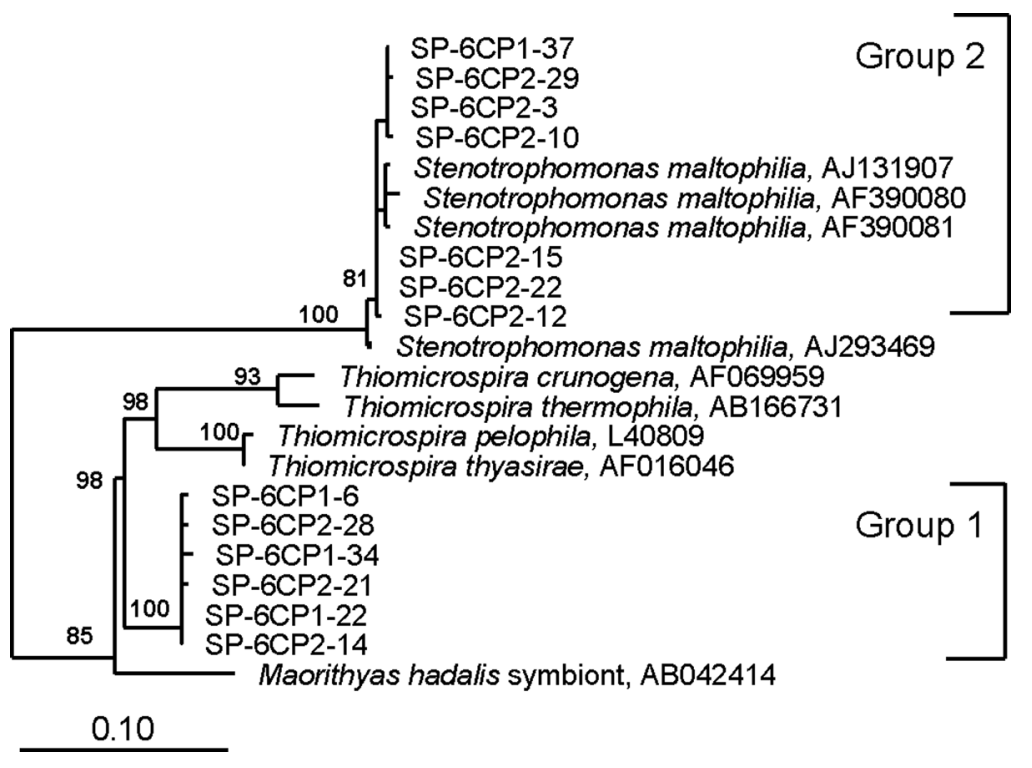

Figure 3-1: Sequences (59) used for probe design for probes targeting the greigite rod. Two clusters of sequences in the $\gamma$-Proteobacteria obtained from samples of the greigite rod are shown in an unrooted tree. Sequences (labeled with "SP-") were aligned in ARB, and 969 bp of each was exported using the mask "beta_gamma_rr5_dec04." The tree was produced using maximum likelihood analysis in PAUP* with 1000 bootstrap replicates. Bootstrap support is shown in bold for each node. Genbank accession numbers are AY587194-AY587198 for group 1 and AY587199-AY587207 for group 2.

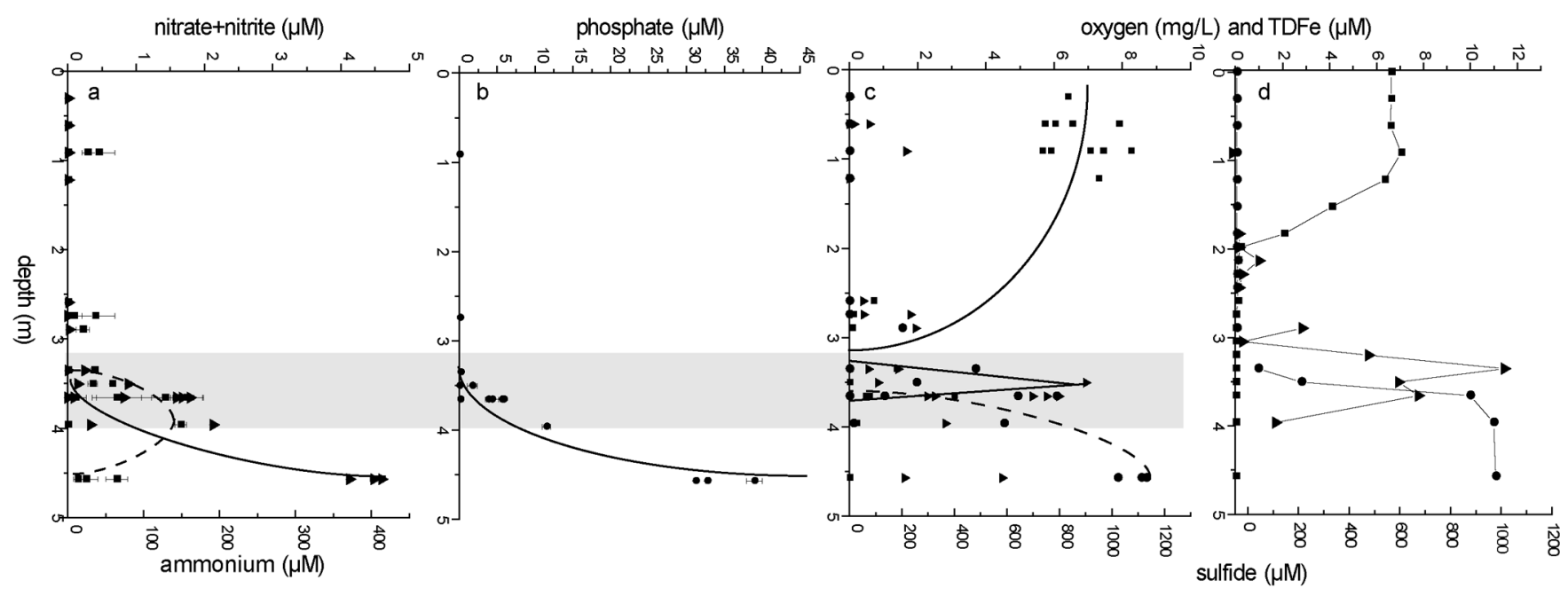

Figure 3-2: Chemical profiles of Salt Pond showing aggregated data for summer 2003. a) Nitrate + nitrite (squares, dotted line) and ammonium (triangles, solid line); (b) phosphate; (c) oxygen (squares, solid line), total dissolved iron (triangles, solid line), sulfide (circles, dotted line); (d) a complete profile for one sampling date, 8/15/2003. The grey band shows the approximate location of the chemocline throughout the season. 


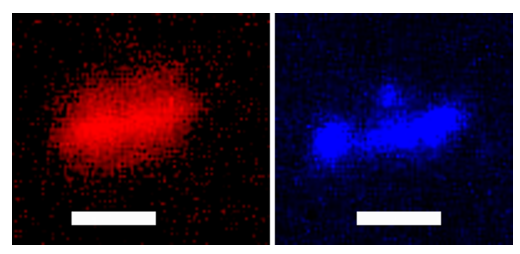

Figure 3-3: CARD-FISH shows that probe GROD-1-824 binds to multiple cells that display morphologies consistent with MTB rods observed in environmental samples. Sample collected on 8/10/2004 from Salt Pond. Left, Cy3-tyramides were used to visualize probe GROD-1-824. Right, DAPI stain of the same cell. Scale bars $2.5 \mu \mathrm{m}$. Images were processed to reduce background fluorescence using Adobe Photoshop.

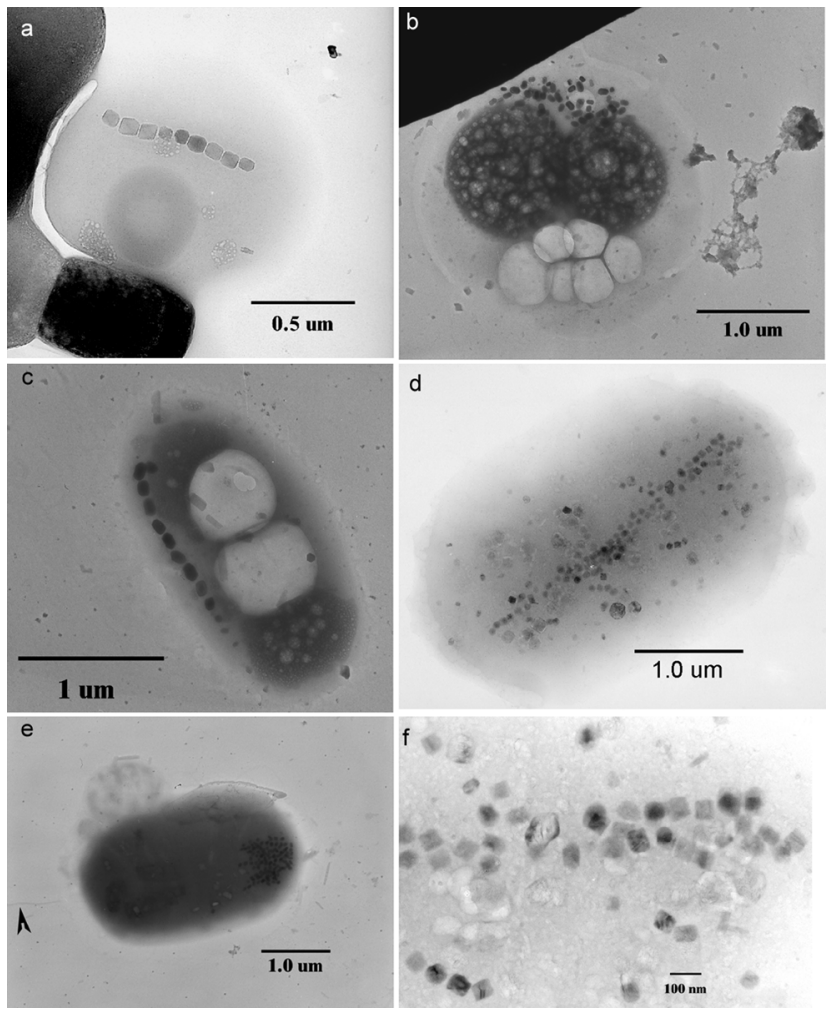

Figure 3-4: Transmission electron micrographs of MTB from Salt Pond. (a) and (b), magnetite-producing cocci with inclusions; large electron dense inclusions in (b) are polyphosphate (holes are from electron beam damage) while others are of unknown composition but probably sulfur and/or polyphosphate; (c), small magnetiteproducing rod; (d) and (e), uncultivated greigite-producing rods, arrow denotes single polar flagellum; (f) individual greigite magnetosomes from cell shown in (d). 


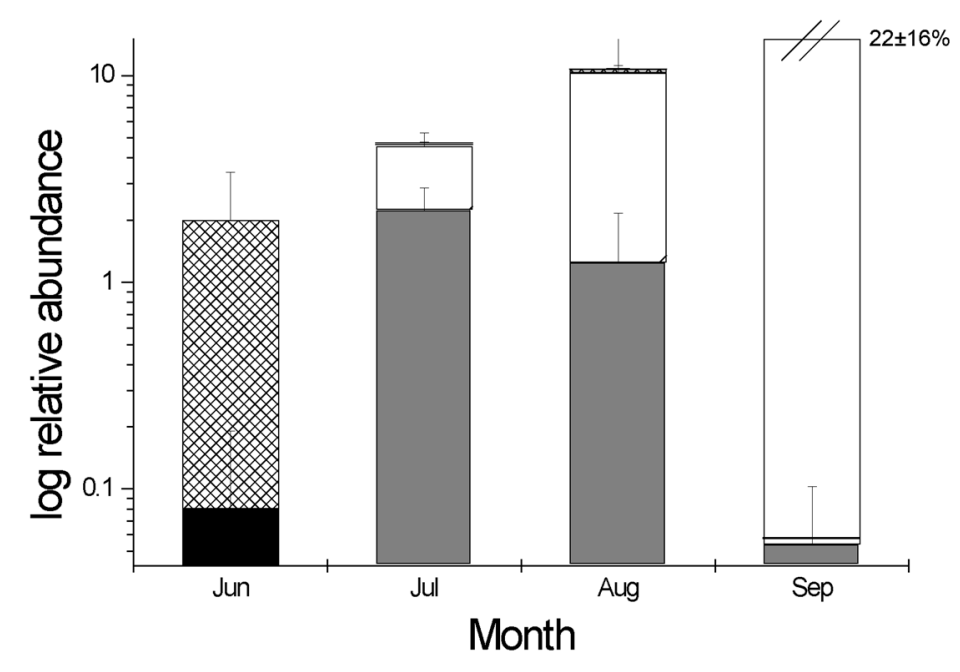

Figure 3-5: Trends in the abundance of each group throughout summer 2003. Abundance was measured as a percentage of total eubacterial counts obtained with qPCR. The highest abundance observed for each group during the month on the $\mathrm{x}$-axis is plotted. Dark grey, cocci; white, barbells; black, MMP; slashes, greigite rod.

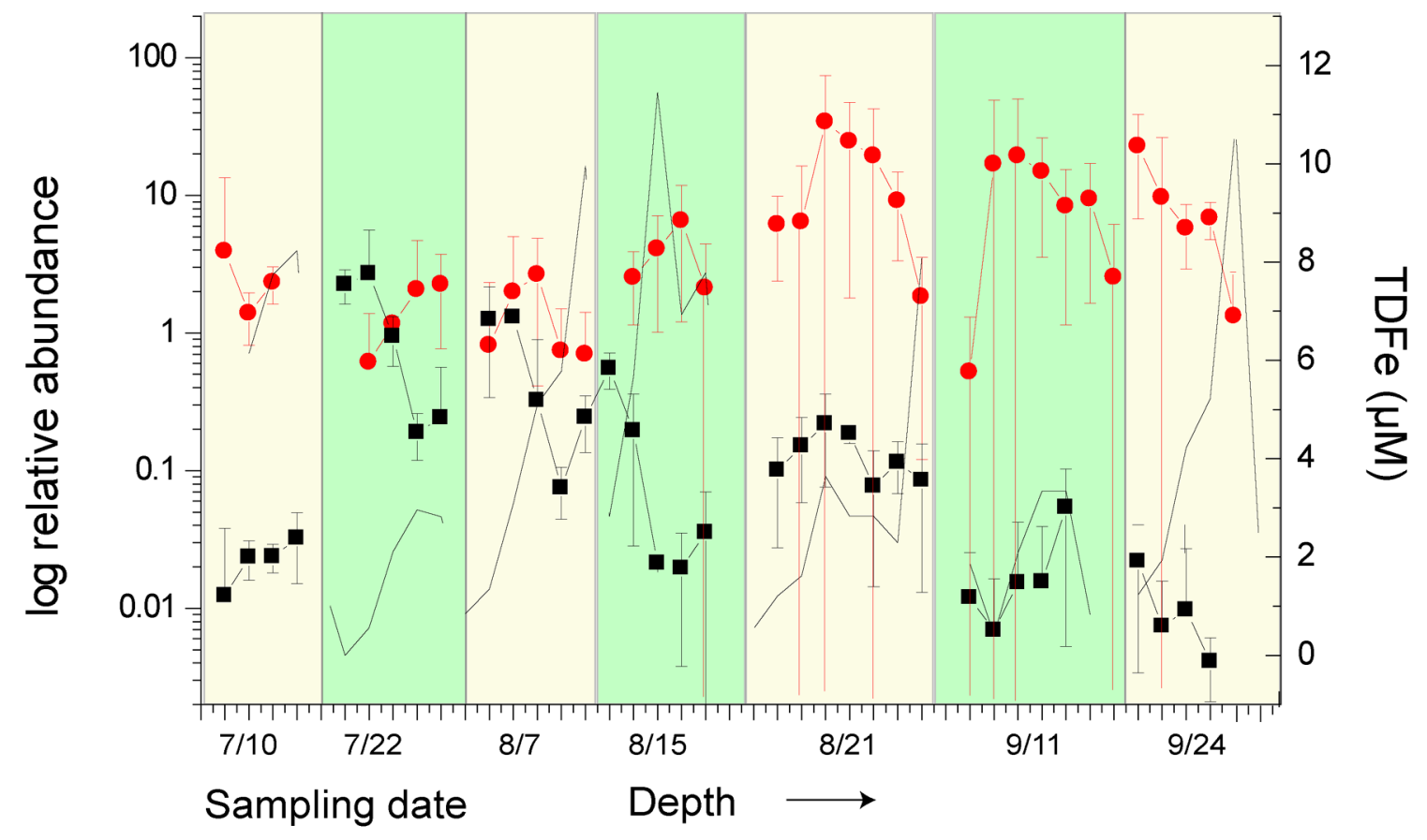

Figure 3-6: The log abundances of magnetotactic barbells and cocci tracked over summer 2003. Barbells are shown with red circles, cocci with black squares (left axis). Each stripe marks a different sampling date, and depth increases from left to right within each date. The dissolved iron concentration profile for each date (right axis) is shown as a black line. 


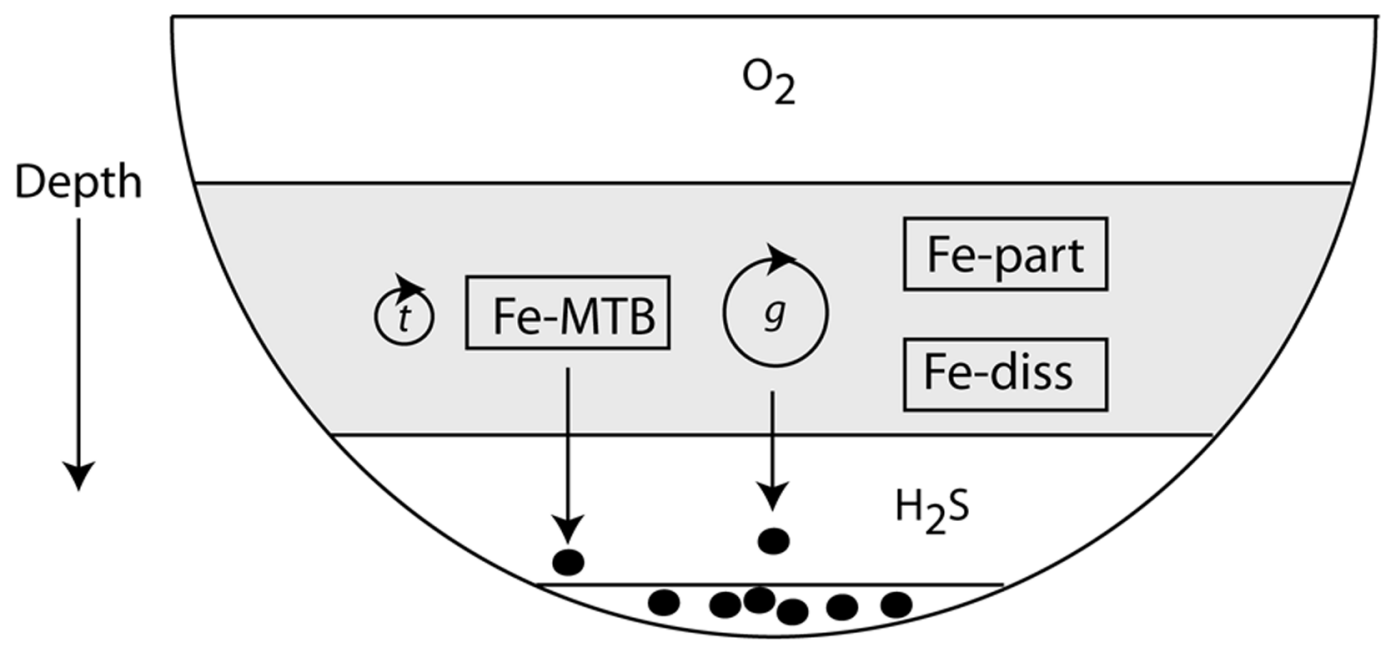

Figure 3-7: A model of the "MTB iron pump" in a stratified marine basin. MTB are present in the chemocline (shaded in grey) and export magnetite and greigite to the sediments via two mechanisms: cell death and subsequent settling of magnetosomes, and grazing of MTB followed by excretion of magnetosomes. The magnitude of these two processes is unknown. $t$, turnover time; $g$, grazing by protists. Fe-MTB: Fe in intracellular magnetite and greigite. Fe-diss: dissolved Fe. Fe-part: particulate Fe. 


\section{Bibliography}

[1] Anderson, T. and R. Raiswell. 2004. Sources and mechanisms for the enrichment of highly reactive iron in euxinic Black Sea sediments. Am. J. Sci., 304:203-233.

[2] Bazylinski, D. A., A. J. Dean, T. J. Williams, L. K. Long, S. L. Middleton, and B. L. Dubbels. 2004. Chemolithoautotrophy in the marine, magnetotactic bacterial strains MV-1 and MV-2. Archives of Microbiology, 182:373-387.

[3] Bazylinski, D. A. and R. B. Frankel. 1992. Production of iron sulfide minerals by magnetotactic bacteria in sulfidic environments. In H. C. Skinner and R. W. Fitzpatrick, eds., Biomineralization Processes, Iron, Manganese, vol. 21, pp. $147-$ 159, Catena.

[4] Bazylinski, D. A., R. B. Frankel, B. R. Heywood, S. Mann, J. W. King, P. L. Donaghay, and A. K. Hanson. 1995. Controlled biomineralization of magnetite $\left(\mathrm{Fe}_{3} \mathrm{O}_{4}\right)$ and gregite $\left(\mathrm{Fe}_{3} \mathrm{~S}_{4}\right)$ in a magnetotactic bacterium. Appl. Environ. Microbiol., 61:3232-3239.

[5] Bazylinski, D. A., A. Garratt-Reed, and R. B. Frankel. 1994. Electronmicroscopic studies of magnetosomes in magnetotactic bacteria. Microscopy Res. Tech., 27:389-401.

[6] Behrens, S., C. Ruhland, J. Inacio, H. Huber, A. Fonseca, I. SpencerMartins, B. M. Fuchs, and R. Amann. 2003. In Situ Accessibility of SmallSubunit rRNA of Members of the Domains Bacteria, Archaea, and Eucarya to Cy3-Labeled Oligonucleotide Probes. Appl. Environ. Microbiol., 69:1748-1758.

[7] Bird, D. and D. M. Karl. 1991. Microbial biomass and population diversity in the upper water column of the Black Sea. Deep-Sea Res., 38:S1069-S1082.

[8] Blakemore, R. P. 1975. Magnetotactic bacteria. Science, 190:377-379. 
[9] Blakemore, R. P. 1982. Magnetotactic bacteria. Ann Rev Microbiol, 36:217238.

[10] Bustin, S. A. and T. Nolan. 2004. The qPCR does not work. In S. A. Bustin, ed., A-Z of Quantitative PCR, pp. 493-524, International University Line, La Jolla, CA.

[11] Canfield, D. E. and R. Berner. 1987. Dissolution and pyritization of magnetite in anoxic marine sediments. Geochem. Cosmochim. Acta, 51:645-659.

[12] Chang, S.-B., J. L. Kirschvink, and J. Stolz. 1987. Biogenic magnetite as a primary remanence carrier in limestone deposits. Physics of the Earth and Planetary Interiors, 46:289-303.

[13] Cole, J. R., B. Chai, R. J. Farris, Q. Wang, S. A. Kulam, D. M. McGarrell, G. M. Garrity, and J. M. Tiedje. 2005. The Ribosomal Database Project (RDP-II): sequences and tools for high-throughput rRNA analysis. Nucl. Acids Res., 33:D294-296.

[14] Cox, B. L., R. Popa, D. A. Bazylinski, B. Lanoil, S. Douglas, A. Belz, D. L. Engler, and K. H. Nealson. 2002. Organization and elemental analysis of $\mathrm{P}-$, S-, and Fe-rich inclusions in a population of freshwater magnetococci. Geomicrobiology Journal, 19:387-406.

[15] Daims, R., H. Bruhl, K.-H. Amann, Schleifer, and M. Wagner. 1999. The Domain-specific probe EUB338 is insufficient for the detection of all Bacteria: Development and Evaluation of a more comprehensive probe set. Syst. Appl. Microbiol., 22:434-444.

[16] DeLong, E. F., R. B. Frankel, and D. A. Bazylinski. 1993. Multiple evolutionary origins of magnetotaxis in bacteria. Science, 259:803-806.

[17] Devouard, B., M. Pósfai, X. Hua, D. A. Bazylinski, R. B. Frankel, and P. R. Buseck. 1998. Magnetite from magnetotactic bacteria; size distributions and twinning. American Mineralogist, 83:1387-1398. 
[18] Farina, M., D. Esquivel, and H. L. de Barros. 1990. Magnetic iron-sulphur crystals from a magnetotactic microorganism. Nature, 383:256-258.

[19] Fierer, N., J. A. Jackson, R. Vilgalys, and R. B. Jackson. 2005. Assessment of soil microbial community structure by use of taxon-specific quantitative PCR assays. Applied and Environmental Microbiology, 71:4117-4120.

[20] Finster, K., W. Liesack, and B. Thamdrup. 1998. Elemental sulfur and thiosulfate disproportionation by Desulfocapsa sulfoexigens sp. nov., a new anaerobic bacterium isolated from marine surface sediment. Appl. Environ. Microbiol., 64:119-125.

[21] Flies, C. B., H. M. Jonkers, D. de Beer, K. Bosselmann, M. E. Bottcher, and D. Schüler. 2005. Diversity and vertical distribution of magnetotactic bacteria along chemical gradients in freshwater microcosms. FEMS Microbiology Ecology, 52:185-195.

[22] Flies, C. B., J. Peplies, and D. Schüler. 2005. Combined Approach for Characterization of Uncultivated Magnetotactic Bacteria from Various Aquatic Environments. Appl. Environ. Microbiol., 71:2723-2731.

[23] Hansen, H. and F. Koroleff. 1999. Determination of nutrients. In K. Grasshoff, K. Kremling, and M. Ehrhardt, eds., Methods of Seawater Analysis, 3rd ed., pp. 159-228, Wiley-VCH, New York.

[24] Heyen, U. and D. Schüler. 2003. Growth and magnetosome formation by microaerophilic Magnetospirillum strains in an oxygen-controlled fermentor. Applied Microbiology and Biotechnology, 61:536-544.

[25] Heywood, B. R., D. A. Bazylinski, A. J. Garrett-Reed, S. Mann, and R. B. Frankel. 1990. Controlled biosynthesis of greigite $\left(\mathrm{Fe}_{3} \mathrm{~S}_{4}\right)$ in magnetotactic bacteria. Naturwissenschaften, 77:536-538.

[26] Huu, N. B., E. B. Denner, D. T. Ha, G. Wanner, and H. Stan-Lotter. 
1999. Marinobacter aquaeolei sp. nov., a halophilic bacterium isolated from a Vietnamese oil-producing well. Intl J Syst Bacteriol, 49:367-375.

[27] Jorgensen, B. B., H. Fossing, C. O. Wirsen, and H. W. Jannasch. 1991. Sulfide oxidation in the Black Sea chemocline. Deep-Sea Research Part A: Oceanographic Research Papers, 38:S1083-S1103.

[28] Jørgensen, B. B., J. G. Kuenen, and Y. Cohen. 1979. Microbial transformations of sulphur compounds in a stratified lake (Solar Lake, Sinai). Limnol. Oceanogr., 24:799-822.

[29] Karr, E. A., W. M. Sattley, M. R. Rice, D. O. Jung, M. T. Madigan, and L. A. Achenbach. 2005. Diversity and Distribution of Sulfate-Reducing Bacteria in Permanently Frozen Lake Fryxell, McMurdo Dry Valleys, Antarctica. Appl. Environ. Microbiol., 71:6353-6359.

[30] Kim, B. Y., K. P. Kodama, and R. E. Moeller. 2005. Bacterial magnetite produced in water column dominates lake sediment mineral magnetism: Lake Ely, USA. Geophys. J. Int., 163:26-37.

[31] Klappenbach, J., P. Saxman, J. Cole, and T. Schmidt. 2001. rrndb: The Ribosomal RNA Operon Copy Number Database. Nucl. Acids Res., 29:181-184.

[32] Knittel, K., A. Boetius, A. Lemke, H. Eilers, K. Lochte, O. Pfannkuche, P. Linke, and R. Amann. 2003. Activity, Distribution, and Diversity of Sulfate Reducers and Other Bacteria in Sediments above Gas Hydrate (Cascadia Margin, Oregon). Geomicrobiology Journal, 20:269-294.

[33] Kuypers, M. M. M., A. O. Sliekers, G. Lavik, M. Schmid, B. B. Jorgensen, J. G. Kuenen, J. S. Sinninghe Damste, M. Strous, and M. S. M. Jetten. 2003. Anaerobic ammonium oxidation by anammox bacteria in the Black Sea. Nature, 422:608-611.

[34] Lie, T. J., M. L. Clawson, W. Godchaux, and E. R. Leadbetter. 1999. Sulfidogenesis from 2-Aminoethanesulfonate (Taurine) Fermentation by a Mor- 
phologically Unusual Sulfate-Reducing Bacterium, Desulforhopalus singaporensis sp. nov. Appl. Environ. Microbiol., 65:3328-3334.

[35] Lohrenz, S. E., C. D. Taylor, and B. L. Howes. 1987. Primary production of protein: II. Algal protein metabolism and its relation to particulate organic matter composition in the surface mixed layer. Mar. Ecol. Prog. Ser., 40:175-183.

[36] Ludwig, W., O. Strunk, R. Westram, L. Richter, H. Meier, Yadhukumar, A. Buchner, T. Lai, S. Steppi, G. Jobb, W. Forster, I. Brettske, S. Gerber, A. W. Ginhart, O. Gross, S. Grumann, S. Hermann, R. Jost, A. Konig, T. Liss, R. Lussmann, M. May, B. Nonhoff, B. Reichel, R. Strehlow, A. Stamatakis, N. Stuckmann, A. Vilbig, M. Lenke, T. Ludwig, A. Bode, and K.-H. Schleifer. 2004. ARB: a software environment for sequence data. Nucl. Acids. Res., 32:1363-1371.

[37] Luther III, G., T. Church, and D. Powell. 1991. Sulfur speciation and sulfide oxidation in the water column of the Black Sea. Deep-Sea Res., 38:S1121-S1137.

[38] Lyons, T. W. 1997. Sulfur isotopic trends and pathways of iron sulfide formation in upper Holocene sediments of the anoxic Black Sea. Geochem. Cosmochim. Acta, 61:3367-3382.

[39] Lyons, T. W. and S. Severmann. 2006. A critical look at iron paleoredox proxies based on new insights from modern euxinic basins. Geochem. Cosmochim. Acta, Accepted.

[40] Mann, S., N. H. C. Sparks, R. B. Frankel, D. A. Bazylinski, and H. W. Jannasch. 1990. Biomineralization of ferrimagnetic greigite $\left(\mathrm{Fe}_{3} \mathrm{~S}_{4}\right)$ and iron pyrite $\left(\mathrm{FeS}_{2}\right)$ in a magnetotactic bacterium. Nature, 343:258-261.

[41] Manz, W., R. Amann, W. Ludwig, M. Wagner, and K.-H. Scheifer. 1992. Phylogenetic oligodeoxynucleotide probes for the major subclasses of proteobacteria: problems and solutions. System Appl Microbiol, 15:593-600. 
[42] Mueller, R., G. Padmabandu, and R. H. Taylor. 2004. Standardization of qPCR and RT-qPCR Assays. In S. A. Bustin, ed., A-Z of Quantitative PCR, pp. 578-590, International University Line, La Jolla, CA.

[43] Muyzer, G., E. D. Waal, and A. Uitterlinden. 1993. Profiling of complex microbial populations by denaturaing gradient gel electrophoresis analysis of polymerase chain reaction-amplified genes coding for 16s rRNA. Appl. Env. Microbiol., 59:695-700.

[44] Noble, R. T. and J. A. Fuhrman. 2000. Rapid Virus Production and Removal as Measured with Fluorescently Labeled Viruses as Tracers. Appl Environ Microbiol, 66:3790-3797.

[45] Nolan, T. 2004. Getting Started- The Basics of Setting up a qPCR Assay. In S. A. Bustin, ed., A-Z of Quantitative PCR, pp. 529-543, International University Line, La Jolla, CA.

[46] Pernthaler, A., J. Pernthaler, and R. Amann. 2002. Fluorescence In Situ Hybridization and Catalyzed Reporter Deposition for the Identification of Marine Bacteria. Appl. Environ. Microbiol., 68:3094-3101.

[47] Pernthaler, J., F. Glöckner, W. Schönhuber, and R. Amann. 2001. Flourescence in situ hybridization with rRNA-targeted oligonucleotide probes. In J. Paul, ed., Methods in Microbiology, vol. 30, pp. 207-226, Academic Press, San Diego.

[48] Petermann, H. and U. Bleil. 1993. Detection of live magnetotactic bacteria in deep-sea sediments. Earth Planet. Sci. Lett., 117:223-228.

[49] Pfaffl, M. W. 2001. A new mathematical model for relative quantification in real-time RT-PCR. Nucl. Acids Res., 29:e45-.

[50] Pósfai, M., P. R. Buseck, D. A. Bazylinski, and R. B. Frankel. 1998. Reaction sequence of iron sulfide minerals in bacteria and their use as biomarkers. Science, 280:880-883. 
[51] Pósfai, M., K. Cziner, E. Marton, P. Marton, P. R. Buseck, R. B. Frankel, and D. A. Bazylinski. 2001. Crystal-size distributions and possible biogenic origin of Fe sulfides. European Journal of Mineralogy, 13:691-703.

[52] Ramsing, N., H. Fossing, T. Ferdelman, F. Andersen, and B. Thamdrup. 1996. Distribution of bacterial populations in a stratified fjord (Mariager Fjord, Denmark) quantified by in situ hybridization and related to chemical gradients in the water column [published erratum appears in Appl Environ Microbiol 1996 Oct;62(10):3914]. Appl. Environ. Microbiol., 62:1391-1404.

[53] Schramm, A., B. M. Fuchs, J. L. Nielsen, M. Tonolla, and D. A. Stahl. 2002. Fluorescence in situ hybridization of $16 \mathrm{~S}$ rRNA gene clones (Clone-FISH) for probe validation and screening of clone libraries. Environmental Microbiology, 4:713-720.

[54] Schwalbach, M. S. and J. A. Fuhrman. 2005. Wide-ranging abundances of aerobic anoxygenic phototrophic bacteria in the world ocean revealed by epifluorescence microscopy and quantitative PCR. Limnology and Oceanography, 50:620-628.

[55] Schwieger, F. and C. C. Tebbe. 1998. A New Approach To Utilize PCRSingle-Strand-Conformation Polymorphism for 16S rRNA Gene-Based Microbial Community Analysis. Appl. Environ. Microbiol., 64:4870-4876.

[56] Seidman, C. E., K. Struhl, J. Sheen, and T. Jessen. 2003. Introduction of plasmid DNA into cells. In F. M. Ausubel, R. Brent, R. E. Kingston, D. D. Moore, J. G. Seidman, J. A. Smith, and K. Struhl, eds., Current Protocols in Molecular Biology, John Wiley and Sons.

[57] Simmons, S. and K. J. Edwards. 2006. Unexpected diversity in populations of the many-celled magnetotactic bacterium. In prep.

[58] Simmons, S. L., D. A. Bazylinski, and K. J. Edwards. 2006. South-seeking magnetotactic bacteria in the Northern Hemisphere. Science, 311:371-374. 
[59] Simmons, S. L., S. M. Sievert, R. B. Frankel, D. A. Bazylinski, and K. J. Edwards. 2004. Spatiotemporal Distribution of Marine Magnetotactic Bacteria in a Seasonally Stratified Coastal Salt Pond. Appl. Environ. Microbiol., 70:6230-6239.

[60] Skovhus, T. L., N. B. Ramsing, C. Holmstrom, S. Kjelleberg, and I. Dahllof. 2004. Real-Time Quantitative PCR for Assessment of Abundance of Pseudoalteromonas Species in Marine Samples. Appl. Environ. Microbiol., 70:2373-2382.

[61] Smits, T. H. M., C. Devenoges, K. Szynalski, J. Maillard, and C. Holliger. 2004. Development of a real-time PCR method for quantification of the three genera Dehalobacter, Dehalococcoides, and Desulfitobacterium in microbial communities. Journal of Microbiological Methods, 57:369-378.

[62] Snowball, I., L. Zillen, and P. Sandgren. 2002. Bacterial magnetite in Swedish varved lake-sediments: a potential bio-marker of environmental change. Quaternary International, 88:13-19.

[63] Snowball, I., L. Zillen, and P. Sandgren. 2005. How Much Magnetite Have Magnetic Bacteria Made? A Multiple Case Study of Swedish Varved Lake Sediments. Eos Trans. AGU, 86:B24A-08.

[64] Snowball, I. F., P. Sandgren, and G. Petterson. 1999. The mineral magnetic properties of an annually laminated Holocene lake-sediment sequence in northern Sweden. Holocene, 9:353-362.

[65] Spring, S., R. Amann, W. Ludwig, K. Schleifer, H. van Gemerden, and N. Petersen. 1993. Dominating role of an unusual magnetotactic bacterium in the microaerobic zone of a freshwater sediment. Appl. Environ. Microbiol., 59:2397-2403.

[66] Spring, S., R. Amann, W. Ludwig, K.-H. Schleifer, and N. Petersen. 
1992. Phylogenetic diversity and identification of nonculturable magnetotactic bacteria. System. Appl. Microbiol., 15:116-122.

[67] Spring, S., R. Amann, W. Ludwig, K.-H. Schleifer, D. Schüler, K. Poralla, and N. Petersen. 1994. Phylogenetic analysis of uncultured magnetotactic bacteria from the alpha-subclass of Proteobacteria. System. Appl. Microbiol., 17:501-508.

[68] Spring, S. and D. A. Bazylinski. 2000. Magnetotactic Bacteria. In M. Dworkin, ed., The Prokaryotes: An Evolving Electronic Resource for the Microbiological Community, online release 3.4, Springer Verlag.

[69] Spring, S., U. Lins, R. Amann, K.-H. Schleifer, L. C. S. Ferreira, D. M. S. Esquivel, and M. Farina. 1998. Phylogenetic affiliation and ultrastructure of uncultured magnetic bacteria with unusually large magnetosomes. Archives of Microbiology, 169:136-147.

[70] Spring, S. and K. H. Schleifer. 1995. Diversity of Magnetotactic Bacteria. System. Appl. Microbiol., 18:147-153.

[71] Stoltz, J., S.-B. R. Chang, and J. Kirschvink. 1986. Magnetotactic bacteria and single-domain magnetite in hemipelagic sediments. Nature, 321:849-851.

[72] Stubner, S. 2004. Quantification of Gram-negative sulphate-reducing bacteria in rice field soil by $16 \mathrm{~S}$ rRNA gene-targeted real-time PCR. Journal of Microbiological Methods, 57:219-230.

[73] Suzuki, M. T., L. T. Taylor, and E. F. DeLong. 2000. Quantitative Analysis of Small-Subunit rRNA Genes in Mixed Microbial Populations via 5'-Nuclease Assays. Appl. Environ. Microbiol., 66:4605-4614.

[74] Suzuki, T., Y. Okamura, R. J. Calugay, H. Takeyama, and T. Matsunaga. 2006. Global Gene Expression Analysis of Iron-Inducible Genes in Magnetospirillum magneticum AMB-1. J. Bacteriol., 188:2275-2279. 
[75] Tonolla, M., R. Peduzzi, and D. Hahn. 2005. Long-Term Population Dynamics of Phototrophic Sulfur Bacteria in the Chemocline of Lake Cadagno, Switzerland. Appl. Environ. Microbiol., 71:3544-3550.

[76] Tortell, P. D., M. T. Maldonado, and N. M. Price. 1996. The role of heterotrophic bacteria in iron-limited ocean ecosystems. Nature, 383:330-332.

[77] Unknown. 2001. Fecal Coliform TDML for the Pettaquamscutt (Narrow) River Watershed, Rhode Island. Tech. rep., Office of Water Resources, Rhode Island Department of Environmental Management.

[78] Viollier, E., P. W. Inglett, K. Hunter, A. N. Roychoudhury, and P. V. Cappellen. 2000. The ferrozine method revisited: Fe (II)/Fe (III) determination in natural waters. Appl. Geochem., 15:785-790.

[79] Wilkin, R. T. and H. L. Barnes. 1997. Pyrite formation in an anoxic estuarine basin. American Journal of Science, 297:620-650.

[80] Williams, T., C. Zhang, S. J.H., and D. A. Bazylinski. 2006. Evidence for autotrophy via the reverse tricarboxylic acid cycle in the marine magnetotactic coccus strain MC-1. Appl Environ Microbiol, 72:1322-1329.

[81] Wilson, K. 2001. Preparation of Genomic DNA from Bacteria. In F. M. Ausubel, R. Brent, R. E. Kingston, D. D. Moore, J. G. Seidman, J. A. Smith, and K. Struhl, eds., Current Protocols in Molecular Biology, pp. 15.7.1-15.7.8, John Wiley and Sons.

[82] Zhu, F., R. Massana, F. Not, D. Marie, and D. Vaulot. 2005. Mapping of picoeucaryotes in marine ecosystems with quantitative PCR of the 18S rRNA gene. FEMS Microbiology Ecology, 52:79-92.

[83] Zinser, E. R., A. Coe, Z. I. Johnson, A. C. Martiny, N. J. Fuller, D. J. Scanlan, and S. W. Chisholm. 2006. Prochlorococcus Ecotype Abundances in the North Atlantic Ocean As Revealed by an Improved Quantitative PCR Method. Appl. Environ. Microbiol., 72:723-732. 


\title{
Chapter 4
}

\section{South seeking magnetotactic bacteria in the Northern \\ Hemisphere}

Published as: Simmons, S. L., D. A. Bazylinski, and K. J. Edwards. 2006. Southseeking magnetotactic bacteria in the Northern Hemisphere. Science 311(5759):371374 .

\begin{abstract}
Magnetotactic bacteria biomineralize membrane-bound intracellular iron minerals (magnetosomes) and respond to magnetic fields. Polar magnetotactic bacteria in vertical chemical gradients are thought to respond to high oxygen levels by swimming downwards into areas with low or no oxygen (towards geomagnetic north in the northern hemisphere and geomagnetic south in the southern hemisphere). We identified populations of polar magnetotactic bacteria in the northern hemisphere that respond to high oxygen levels by swimming towards geomagnetic south, the opposite of all previously reported magnetotactic behavior. The percentage of magnetotactic bacteria with south polarity in the environment is positively correlated with higher redox potential. The co-existence of magnetotactic bacteria with opposing polarities in the same redox environment conflicts with current models of the adaptive value of magnetotaxis.
\end{abstract}


Magnetotactic bacteria form intracellular single domain ferrimagnetic iron oxide (magnetite, $\mathrm{Fe}_{3} \mathrm{O}_{4}$ ) or iron sulfide (greigite, $\mathrm{Fe}_{3} \mathrm{~S}_{4}$ ) crystals. The torque produced by these chains causes the cells to align and swim with respect to local or induced magnetic fields (1-3). Magnetotactic bacteria are globally distributed at and below the oxic-anoxic interface in chemically stratified freshwater (4-6) and marine environments (7-10), where they can reach significant population densities $\left(10^{5}\right.$ cells $\left.\mathrm{ml}^{-1}\right)$ $(5,11)$. Magnetotaxis is currently thought to enable these bacteria to more rapidly locate habitats with low or no oxygen in a vertical chemical and/or redox gradient (12). Here we describe observations which call into question this explanation for the adaptive value of magnetotaxis.

There are two predominant types of magnetotaxis in magnetotactic bacteria: polar and axial (12). When observed microscopically in an applied magnetic field, a polar magnetotactic bacterium swims in a preferred direction relative to the local field, while an axial bacterium swims back and forth in both directions (12). When the direction of an applied field is reversed, a polar bacterium reverses swimming direction while an axial bacterium rotates $180^{\circ}$ but continues to swim back and forth (12). Axial behavior has only been observed in cultivated strains of the genus Magnetospirillum (12-14), while polar behavior is exhibited far more commonly by magnetotactic bacteria in marine samples (15). The polarity of polar magnetotactic bacteria is defined as their swimming direction under atmospheric oxygen levels. Here we explore the environmental cues that influence polarity among magnetotactic bacteria.

Previous work asserted that virtually all polar magnetotactic bacteria $(\geq 99 \%)$ in the northern hemisphere have north polarity $(1,16,17)$, meaning that they swim towards geomagnetic north when exposed to higher than optimal oxygen levels. In the northern hemisphere, owing to the vertical component of the Earth's geomagnetic field, swimming towards geomagnetic north would direct bacteria downwards into anoxic sediments or waters in a vertical chemical gradient. In the southern hemisphere polar magnetotactic bacteria swim towards geomagnetic south, presumably for the same reason $(2,3)$. Here we report observing significant numbers of magnetotactic bacteria in the northern hemisphere which swim towards geomagnetic south when 
exposed to high oxygen (south polarity), the opposite of all previously described magnetotactic behavior. We also show that south polarity in magnetotactic bacteria is statistically correlated with environmental redox chemistry.

A morphologically unusual bacterium with south polarity was found at high density in Salt Pond (Falmouth, MA), a small seasonally stratified marine basin, in July 2004 (18). This bacterium ("barbell") formed chains of 2-5 cocci which appeared refractive with DIC microscopy (Fig.4-1c). The barbell occurred in narrow layers immediately below the oxygen/sulfide interface in Salt Pond and co-occurred with previously described magnetite- and greigite-producing bacteria (9) (Fig.4-1c). Magnetotactic bacteria were not present at depths above and below those shown in Fig. $4-1$.

Because of the high cell density ( $4.6 \pm 1.1 \times 10^{4}$ cells $\mathrm{ml}^{-1}$, based on direct counts), we were able to observe the polarity of the barbell without potential interference from prior magnetic enrichment (18). Over $90 \%$ of the barbells from bulk water samples showed south polarity in the standard drop assay (18) (Fig.4-1b). Morphologically distinct populations with north polarity co-occurred with the barbell, suggesting that south polarity was not universal among all magnetotactic bacterial taxa in a given environment (Fig.4-1c).

We identified the barbell as a member of the Desulfobulbaceae family of the delta Proteobacteria (Fig.4-2), using sequencing of 16s rDNA and catalyzed reporter deposition-in situ hybridization (CARDFISH) with custom-designed probes (18). It is closely related to Desulforhopalus singaporensis, which also has an unusual chain morphology (19). The barbell is the third magnetotactic bacterium identified in the delta Proteobacteria; of the other two, one produces magnetite (20) and the other greigite (21).

We also observed a population of small magnetotactic rods with south polarity in Salt Pond on July 1, 2004 (Fig.4-1a). These appeared at high density (1.5 $\pm 0.47 \times 10^{4}$ cells $\mathrm{ml}^{-1}$ ) at and below the narrow chemocline, and had nearly $100 \%$ south polarity at every depth at which they occurred. South polarity is not an artifact of our assay; we did not directly observe polarity reversal caused by the small magnets we used, 
and past experiments have required far higher field strengths $(2,22)$.

We only observed these dense populations of magnetotactic bacteria with overwhelmingly south polarity on one occasion. Further observations indicated that magnetotactic bacteria more frequently occurred at lower abundance and showed a mixture of north and south polarities, with occasional blooms dominated by specific taxa. Quantitative PCR on samples taken from Salt Pond in summer 2003 (11) showed that abundances of the barbell fluctuate greatly during the seasonal stratification of Salt Pond. The barbell is most abundant when the pond is less stratified, in the early and late season $\left(10^{4}-10^{5}\right.$ cells $\left.\mathrm{ml}^{-1}\right)$. This is consistent with our observations of dense populations of the barbell and an unidentified small rod early in summer 2004, when the chemocline was very narrow. The sharp chemocline may have contributed to the high abundance of bacteria with south polarity.

To determine whether water chemistry is correlated with the presence of magnetotactic bacteria with south polarity, we determined the total numbers of magnetotactic bacteria with north and south polarity across the Salt Pond chemocline in summer 2005 in conjunction with fine-scale physical and chemical profiling (18). The oxidation-reduction potential (ORP), collected in situ, provided a bulk descriptor of water chemistry; more negative values indicate a more reducing environment. Total numbers of magnetotactic bacteria peaked between ORP values of -50 to -200 .

We found a significant relationship between ORP and the percentage of magnetotactic bacteria with south polarity (Fig.4-3). In more reducing conditions (ORP < -200), the average percentage of bacteria with south polarity was $1.3 \pm 3$. Greigiteproducing organisms predominated in this group. In more oxidizing conditions (ORP $>-200$ ), the average percentage of bacteria with south polarity was $12 \pm 14$. The barbell and small magnetite-producing cocci predominated in this group, and most organisms with south polarity were barbells. The high variance is due to the dominance of cocci with north polarity in some samples. The means of the two groups were significantly different at the $\mathrm{p}=0.01$ level (independent t-test). There was no correlation between polarity and the total numbers of magnetotactic bacteria observed. Our results suggest that either the polarity of a single bacterium is affected by ORP 
(or a redox active chemical species correlated with ORP), or that south polarity is characteristic of a particular species that occurs at a specific ORP.

The coexistence of magnetotactic bacteria with north and south polarity in the same chemical environment contradicts the current accepted model of magnetotaxis, which states that all magnetotactic bacteria in the Northern Hemisphere swim north (downwards in situ) when exposed to oxidized conditions to reach their preferred microaerobic or anaerobic habitat. We observed that barbells with south polarity and cocci with north polarity co-exist in microaerobic conditions in the water column. Based on this distributional pattern, south polarity is clearly not used to direct the barbell upwards in the water column towards higher oxygen levels. The current model does not, therefore, provide any explanation that can account for the existence of south polarity.

This model implicitly assumes that polarity observed in the laboratory under atmospheric oxygen levels is equivalent to polarity in situ. Our results suggest that this assumption might be incorrect. While the benefit of north polarity in situ is clear for microaerophilic magnetotactic bacteria, south polarity would have a clearly deleterious effect by directing the bacteria away from their preferred chemical environment. There are reasons to believe the behavior of magnetotactic bacteria in situ could differ from behavior in the laboratory. Magnetotactic bacteria at the chemocline of a stratified water column rarely, if ever, experience atmospheric oxygen levels like those in the standard laboratory assay for polarity. They also experience chemical gradients (particularly of iron and sulfur species) not present in a drop of water exposed to air in the laboratory assay. It is also possible that bacteria with north and south polarity possess different chemo- or redox-sensors that have opposite responses to chemical concentrations out of the range they typically experience. Based on these results, new models are clearly needed to explain the adaptive significance of magnetotaxis by magnetotactic bacteria in the environment. 

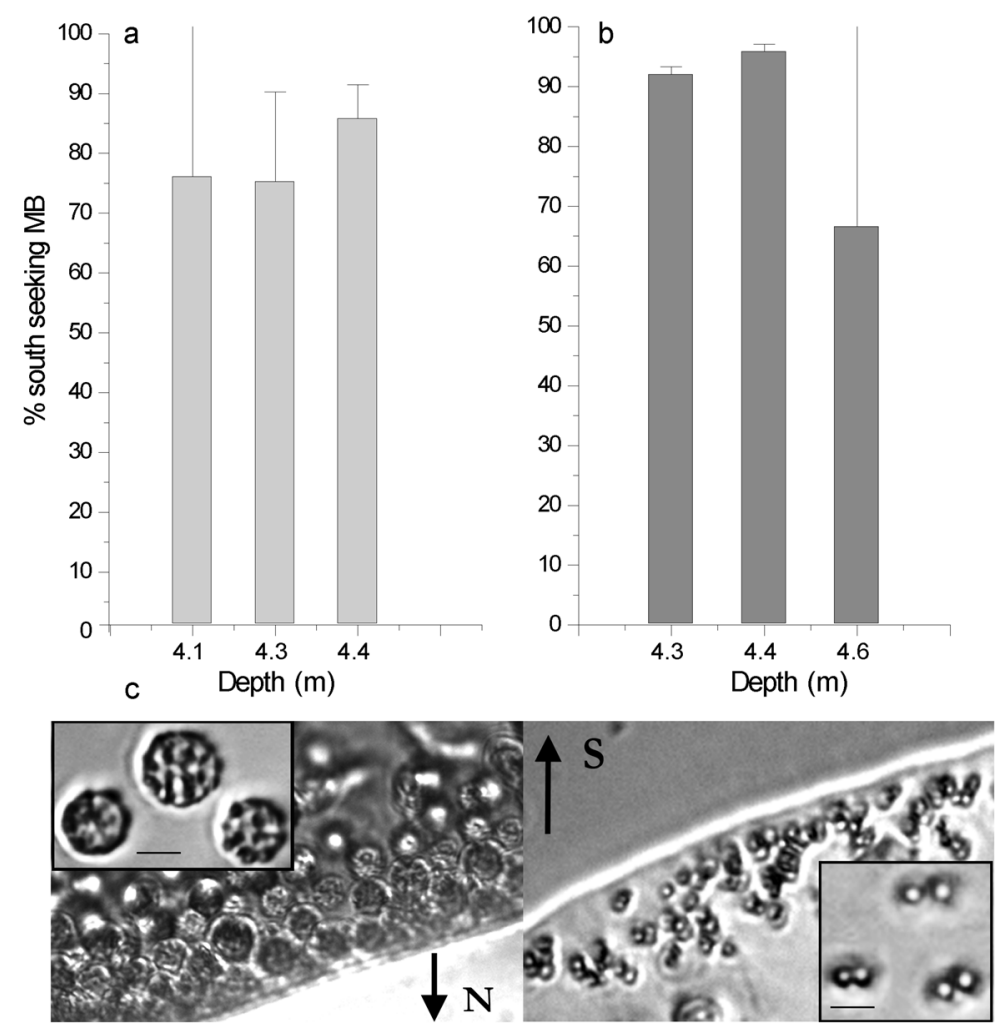

Figure 4-1: The barbell and small rod shaped cells (not shown) have primarily south polarity at discrete depths in Salt Pond. \% S seekers $=100 *$ ratio of MB with south polarity to total MB. The mean and standard deviation were calculated from microscopic counts of two drops from the same sample. In both samples higher standard deviation was associated with low total cell counts. (a) A small rod shaped magnetotactic bacterium had south polarity in Salt Pond on 7/1/04. (b) Barbells had south polarity in Salt Pond on $7 / 2 / 04$. (c) MMP with north polarity (left) and barbells with south polarity (right) co-occuring in water from Salt Pond on $7 / 2 / 04$. Insets show cell morphology. All scale bars 5 microns. 
a
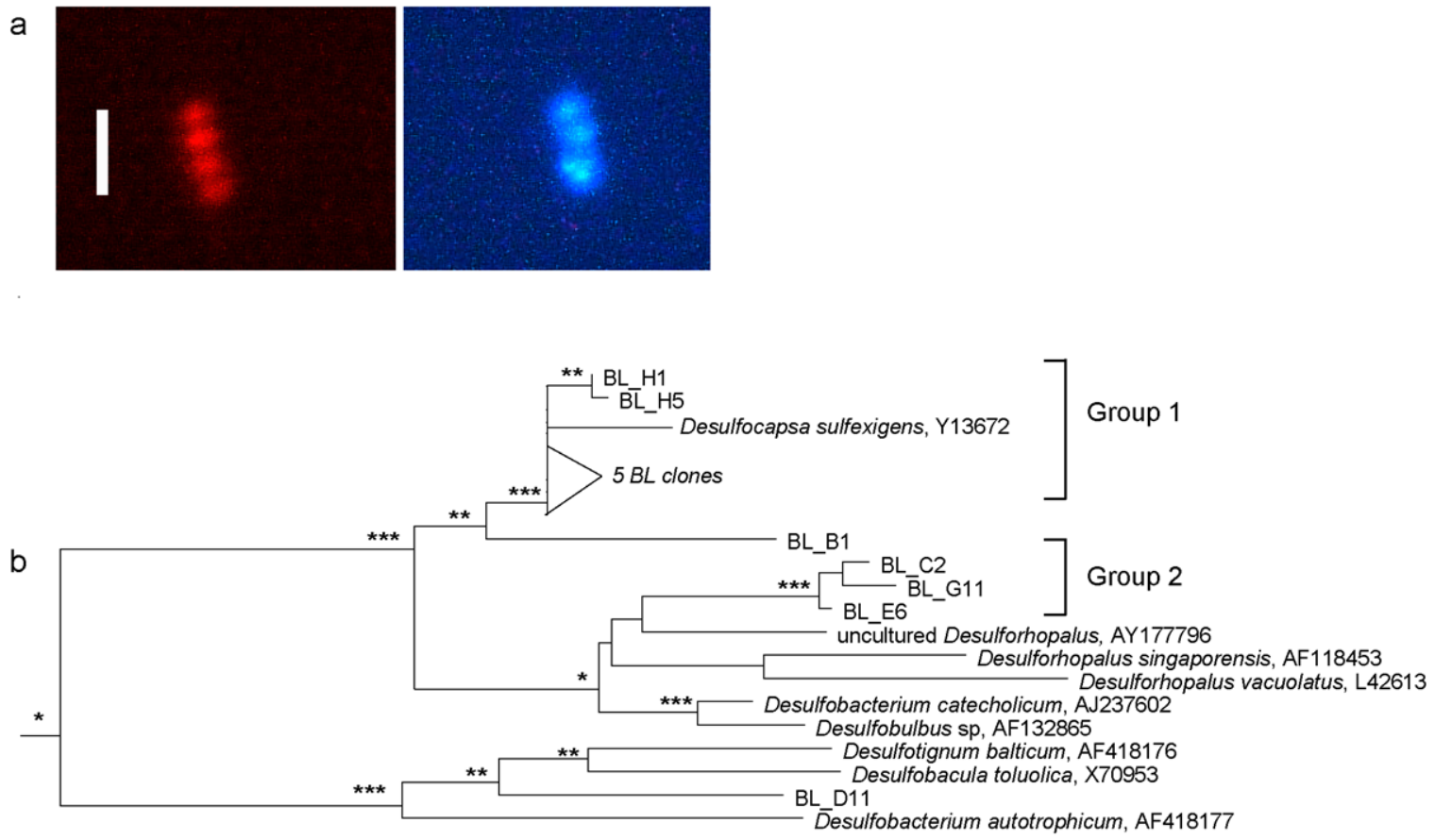

0.10

Figure 4-2: The barbell was identified as a $\delta$-proteobacterium using CARDFISH. (a) Left, the barbell with south polarity hybridizes with a HRP-labeled probe (visualized with Cy3-tyramides) targeting Group 2 sequences (related to Desulforhopalus spp.). Right, a DAPI stain of the same cell. Scale bar 5 microns. (b) Two clusters of $16 \mathrm{~s}$ rDNA sequences (marked with "BL_*") were obtained from samples highly enriched in the barbell bacterium. The tree was constructed using maximum likelihood analysis and 1000 bootstrap replicates in Phylip. Nodes with greater than 90\% bootstrap support are marked with ${ }^{* * *}, 60-90 \%$ with ${ }^{* *}$, and 50-60\% with *. A mask was used to allow for inclusion of partial sequences (700-800 bp)and sequences were exported from ARB with a $25 \%$ homology filter based on a complete alignment of $\delta$-Proteobacteria. Desulfovibrio desulfuricans was used as an outgroup to root the tree (not shown). Short sequences were added using the ARB Parsimony tool without changing tree topology. Parsimony analysis also supported the tree topology. 


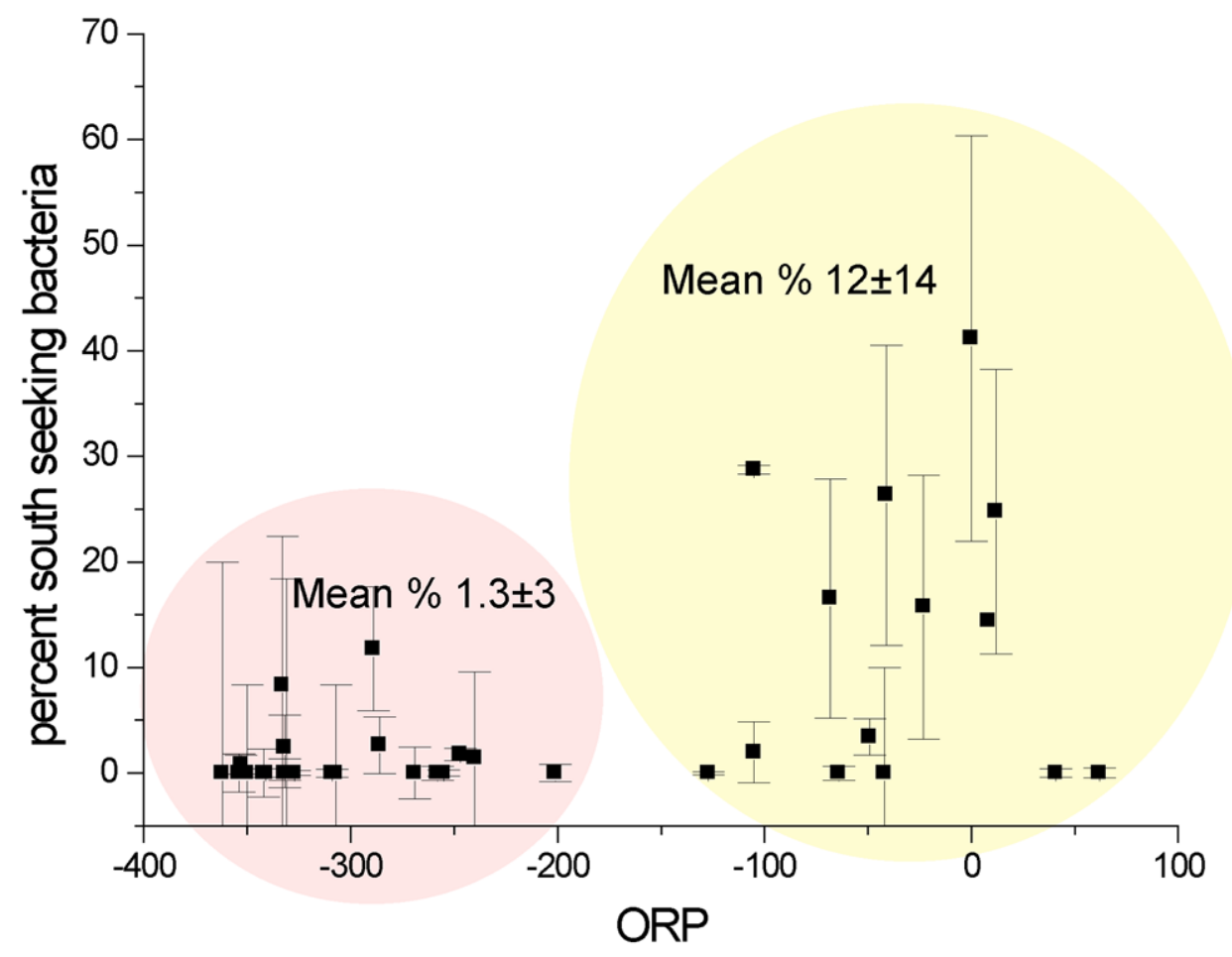

Figure 4-3: South polarity is related to environmental oxidation-reduction potential (ORP). The percentage of bacteria with south polarity is shown versus the oxidationreduction potential of Salt Pond in situ water for all magnetotactic bacteria present in the water column for each of five dates in August and September 2005. Percentages were calculated as the total number of bacteria with south polarity divided by the total number of bacteria in three separate drops. The mean is shown \pm one standard deviation. Experimental error (the variation from three separate drops) and statistical error (1/total number of cells counted) were calculated for all points, and the larger value is shown. The yellow oval denotes data points with $\mathrm{ORP} \geq-200$, and the pink oval denotes data points with $\mathrm{ORP} \leq-200$. As a general trend, most of the counts at $\mathrm{ORP} \geq-200$ are for magnetotactic cocci and barbells. In 2005, the barbell did not occur at high levels comparable to our observation in 2004. 


\subsection{Supplementary Online Material}

\section{Materials and Methods}

Observations made on bulk samples. Duplicate one liter bottles were collected from discrete depths in Salt Pond in 2004 and 2005 as described in Simmons et al (9) and were examined within a few hours of sampling. Collections in 2005 were taken with a custom-built sampler designed to sample closely spaced stratified layers in the water column. The sampler was built after the design of Jørgensen et al (23) with assistance from Craig Taylor (WHOI Biology). Measurements of in situ water conditions were taken with a YSI 85 sonde (Yellow Springs Incorporated, Yellow Springs, OH, USA) in 2004 and a YSI 600QS sonde in 2005. The 600QS allowed for measurements of ORP (oxidation-reduction potential) and depth in addition to the oxygen, temperature, and conductivity measured with the YSI 85.

For observation of polarity, a small drop of water was placed on a microscope coverslip and the south pole of a small laboratory bar magnet was placed about 1-2 $\mathrm{cm}$ away from the drop. The south pole of a bar magnet corresponds to geomagnetic North, hence cells swimming toward the south pole have "north polarity" and cells on the opposite side of the drop have "south polarity." The number of cells with north and south polarity was determined by direct count using light microscopy on an inverted microscope (Zeiss Axiovert). Triplicate drops of $50 \mu \mathrm{l}$ each were counted for each depth sampled. Measurements of the field strength of the magnet with a magnetometer in the lab of K. Canter (Brandeis University) showed that bacteria in a small drop $1 \mathrm{~cm}$ from the magnet experienced a field of approximately $70 \mathrm{G}$.

16s rDNA sequences and fluorescent in situ hybridization. 16s rDNA sequences from samples highly enriched in the barbell bacterium were obtained using methods described in Simmons et al (9) and analyzed using the software package ARB (24). For fluorescent in situ hybridization (FISH), cells with south polarity were removed from a drop of environmental water on a microscope slide with a glass capillary and placed directly on a gelatin-coated welled slide. The slide was air-dried, 
fixed in 2\% paraformaldehyde in PBS for 20-30 minutes, and subsequently dehydrated in 50\%, 80\%, and 98\% EtOH for three minutes at each concentration prior to hybridization. Fluorescent in situ hybridization with the probe SRB 385 (25) to confirm membership in the $\delta$-Proteobacteria was performed using protocols described by Pernthaler et al (26).

Two specific oligonucleotide probes for sequence clusters potentially representing the barbell MB (Fig. 4-2) were designed in ARB. Optimal stringency was determined using clone-FISH (27). HRP-linked probes for catalyzed reporter depositionin situ hybridization (CARD-FISH) were synthesized by Biomers (Ulm, Germany). The probes were applied to samples of the barbell bacterium fixed on slides as described above, following the CARD-FISH protocol of Pernthaler et al (28) with Cy3tyramides. Cells were counterstained with DAPI following CARD-FISH. 


\section{Bibliography}

[1] R. P. Blakemore, Ann Rev Microbiol 36, 217 (1982).

[2] R. P. Blakemore, R. B. Frankel, A. J. Kalmijn, Nature 286, 384 (1980).

[3] J. L. Kirschvink, J. Exp. Biol. 86, 345 (1980).

[4] T. Sakaguchi, A. Arakaki, T. Matsunaga, Intl. J. Syst. Evol. Microbiol. 52, 215 (2002).

[5] S. Spring, et al., Appl. Environ. Microbiol. 59, 2397 (1993).

[6] S. Spring, R. Amann, W. Ludwig, K.-H. Schleifer, N. Petersen, System. Appl. Microbiol. 15, 116 (1992).

[7] D. A. Bazylinski, et al., Appl. Environ. Microbiol. 61, 3232 (1995).

[8] H. Petermann, U. Bleil, Earth Planet. Sci. Lett. 117, 223 (1993).

[9] S. L. Simmons, S. M. Sievert, R. B. Frankel, D. A. Bazylinski, K. J. Edwards, Appl. Environ. Microbiol. 70, 6230 (2004).

[10] J. Stoltz, S.-B. R. Chang, J. Kirschvink, Nature 321, 849 (1986).

[11] SLS, KJE (2005). Manuscript in prep.

[12] R. B. Frankel, D. A. Bazylinski, M. S. Johnson, B. L. Taylor, Biophys. J. 73, 994 (1997).

[13] R. Blakemore, D. Maratea, R. S. Wolfe, J. Bacteriol. 140, 720 (1979).

[14] A. M. Spormann, R. S. Wolfe, Fems Microbiology Letters 22, 171 (1984).

[15] SLS, KJE (2005). Unpublished observations.

[16] R. P. Blakemore, Science 190, 377 (1975).

[17] T. Moench, W. Konetzka, Arch. Microbiol. 119, 203 (1978). 
[18] Materials and methods are available as supporting material on Science Online.

[19] T. J. Lie, M. L. Clawson, W. Godchaux, E. R. Leadbetter, Appl. Environ. Microbiol. 65, 3328 (1999).

[20] R. Kawaguchi, et al., FEMS Microbiol. Lett. 126, 277 (1995).

[21] E. F. DeLong, R. B. Frankel, D. A. Bazylinski, Science 259, 803 (1993).

[22] A. J. Kalmijn, R. P. Blakemore, Animal Migration, Navigation, and Homing, K. Schmidt-Koenig, W. Keeton, eds. (Springer-Verlag, Berlin, 1978), pp. 354355.

[23] B. B. Jørgensen, J. G. Kuenen, Y. Cohen, Limnol. Oceanogr. 24, 799 (1979).

[24] W. Ludwig, et al., Nucl. Acids. Res. 32, 1363 (2004).

[25] R. Amann, et al., Appl. Environ. Microbiol. 56, 1919 (1990).

[26] J. Pernthaler, F. Glöckner, W. Schönhuber, R. Amann, Methods in Microbiology, J. Paul, ed. (Academic Press, San Diego, 2001), vol. 30, pp. 207-226.

[27] A. Schramm, B. M. Fuchs, J. L. Nielsen, M. Tonolla, D. A. Stahl, Environmental Microbiology 4, 713 (2002).

[28] A. Pernthaler, J. Pernthaler, R. Amann, Appl. Environ. Microbiol. 68, 3094 (2002). 


\title{
Chapter 5
}

\section{Unexpected diversity in}

\section{populations of the many-celled magnetotactic prokaryote}

\begin{abstract}
The many-celled magnetotactic prokaryote (MMP) is an uncultivated, highly motile aggregate of 10-30 cells containing numerous chains of greigite $\left(\mathrm{Fe}_{3} \mathrm{~S}_{4}\right)$ magnetosomes. It is unique to marine environments and is abundant in slightly sulfidic sediments of the Little Sippewissettt salt marsh (Falmouth, MA). We sequenced 16s rDNA genes from a natural population of MMP and found five clades separated by at least $5 \%$ sequence divergence. We designed in situ hybridization probes for three of these clades and found significant variation in their relative abundances across a seasonal cycle in marsh productivity. The MMP should therefore be considered a separate genus in the $\delta$-Proteobacteria rather than a single species as previously thought. Additionally, we show that all cells in each aggregate are genetically identical with respect to their 16s rDNA genes, supporting a model of the MMP as comprised of clonal cells which reproduce by binary fission of the aggregate.
\end{abstract}

\subsection{Introduction}

Magnetotactic bacteria (MTB) biomineralize membrane-bound intracellular iron minerals (magnetosomes), comprised either of magnetite $\left(\mathrm{Fe}_{3} \mathrm{O}_{4}\right)$ or greigite $\left(\mathrm{Fe}_{3} \mathrm{~S}_{4}\right)$ depending on the species. Chains of magnetosomes produce a torque which causes the 
cells to align in magnetic fields. These organisms are distributed in microaerobic to anaerobic habitats worldwide, including freshwater (Spring et al., 1993) and marine (Petermann and Bleil, 1993) sediments, methane-oxidizing microbial mats (Reitner et al., 2005), salt marshes (Blakemore, 1975, DeLong et al., 1993, Heywood et al., 1990), and stratified marine basins (Bazylinski et al., 1995, Simmons et al., 2006a, 2004). Their density is highest at the interface between oxic and anoxic environments (Bazylinski et al., 1995, Flies et al., 2005, Simmons et al., 2004). These qualitative observations suggest that marine MTB are globally more abundant than freshwater MTB, and quantitative studies of MTB in a stratified marine basin indicate that they may have a significant impact on the flux of reduced iron out of these environments (Simmons et al., 2006a). While some cultivated species of MTB are autotrophs (Bazylinski et al., 2004, Williams et al., 2006), the identification of uncultivated MTB in the $\delta$ - (DeLong et al., 1993, Simmons et al., 2006b) and $\gamma-$ (Simmons et al., 2006a) Proteobacteria suggests that some may be anaerobic heterotrophs using sulfate or iron reduction.

The many-celled magnetotactic prokaryote (MMP) is a greigite-producing magnetotactic bacterium (Farina et al., 1990, Mann et al., 1990) unique to marine environments, with a sarcina-like morphology rare among bacteria. It is a roughly spherical to ovoid aggregate containing 10-30 cells (Rodgers et al., 1990) arranged in a helix around a hollow core, with the entire structure coated in a polysaccharide capsule (Keim et al., 2004a). Cells appear trapezoidal in thin sections (Keim et al., 2004a) and may contain small membrane junctions joining individual cells (Rodgers et al., 1990). Aggregate diameter usually ranges from 5-10 $\mu \mathrm{m}$. MMP are highly motile and show a unique swimming behavior when exposed to magnetic fields in the laboratory. Aggregates rotate clockwise when swimming towards the edge of a water drop and counterclockwise when swimming away. They exhibit a "ping-pong" motion towards and away from the drop edge that appears to vary with the strength of the applied magnetic field (Greenberg et al., 2005), suggesting that it may not be relevant to their motility in the environment. Individual cells of the aggregate are not motile and do not show a magnetotactic response. Flagella are apparent on the outer sur- 
face of each cell in the aggregate; it is not understood how the aggregate coordinates flagellar motion to achieve its unusual swimming behavior (Rodgers et al., 1990).

Each aggregate contains numerous chains of greigite $\left(\mathrm{Fe}_{3} \mathrm{~S}_{4}\right)$ magnetosomes, most of which are 60-90 nm in diameter (Pósfai et al., 1998), within the magnetic singledomain size for greigite (Bazylinski and Moskowitz, 1997). Each cell contains several chains, and the aggregate as a whole contains $491 \pm 195$ magnetosomes or about $10^{-13} \mathrm{~g}$ Fe per aggregate (Simmons et al., 2006a). Magnetosomes have an irregular, elongated morphology (Pósfai et al., 1998) and can contain up to 10 percent $\mathrm{Cu}$, depending on the concentration of $\mathrm{Cu}$ in the external environment (Bazylinski et al., 1993, Pósfai et al., 1998). The chemical synthesis pathway for greigite in MMP can be inferred from studies of their intracellular mineral content and known pathways for inorganic low temperature greigite formation. Inorganic greigite synthesis proceeds through the solid state conversion of mackinawite (FeS) to greigite (and eventually pyrite), via loss of $\mathrm{Fe}^{2+}$ from the crystal structure (Wilkin and Barnes, 1996). Cubic FeS and mackinawite were identified within MMP from a stratified coastal pond and salt marshes (Pósfai et al., 1998). Moreover, mackinawite was only found in crystals on the end of the growing chain, suggesting that new magnetosomes are synthesized using this pathway (Pósfai et al., 1998). Because the conversion of greigite to pyrite is thermodynamically favorable in the reducing environments favored by MMP, it is possible to infer that cells are actively controlling the intracellular redox potential.

MMP are globally distributed in stratified marine environments, including meromictic basins (Bazylinski et al., 1995, Simmons et al., 2006a), salt marshes, marine sediments, and hypersaline lagoons (Keim et al., 2004b). Typical concentrations of MMP in Salt Pond, a meromictic coastal pond, were around 500 aggregates $\mathrm{ml}^{-1}$, with a maximum abundance of $6.3 \pm 4.4 \times 10^{3}$ aggregates $\mathrm{ml}^{-1}$ in pond sediments (Simmons et al., 2006a). The MMP is a gradient organism preferring low sulfide concentrations $(<100 \mu \mathrm{M})$ and reaches maximum abundance slightly below the interface between oxic and euxinic waters (Simmons et al., 2006a). It was previously identified as a $\delta$ proteobacterium most closely related to Desulfosarcina variabilis (0.91 16s rDNA sequence similarity; (DeLong et al., 1993)). D. variabilis is a sulfate-reducing anaerobe 
capable of both heterotrophic growth on a variety of carbon sources and autotrophic growth with $\mathrm{H}_{2}$ as an electron donor (Kendall and Boone, 2000). The metabolic pathways used by the MMP are unknown, as the organism has not yet been isolated in axenic culture, but its phylogenetic placement and environmental distribution suggest that it could be a sulfate reducer.

The MMP is abundant in sediments and small pools of the Little Sippewissett salt marsh (Falmouth, MA). It is present in the surface layers of sulfidic sediments and co-occurs with photo- and chemo-synthetic sulfide oxidizing bacteria (unpublished observations). The marsh is an area of extremely high productivity (Howarth and Teal, 1979). Sulfate reduction is the primary respiratory pathway in the Sippewissett marsh, accounting for the consumption of $1.8 \mathrm{~kg}$ organic $\mathrm{C} \mathrm{m}^{-2} \mathrm{yr}^{-1}$ (Howarth and Teal, 1979). The sulfate reduction rate in New England marshes varies seasonally with the growth of the marsh grass Spartina alterniflora (Hines et al., 1999, 1989, Howarth and Teal, 1979), probably due to utilization of plant exudates by sulfatereducing bacteria (SRB) (Hines et al., 1989). SRB of the family Desulfobacteraceae, which includes the MMP and D. variabilis, are the most abundant SRB in salt marshes (Devereux et al., 1996, Klepac-Ceraj et al., 2004, Rooney-Varga et al., 1997) and can comprise up to $40 \%$ of bacterial rRNA associated with Spartina roots (Hines et al., 1999). The likely explanation is that many members of the Desulfobacteraceae are complete oxidizers with high substrate diversity (Klepac-Ceraj et al., 2004).

Here we report the results of $16 \mathrm{~s}$ rDNA sequencing and fluorescent in situ hybridization on MMP collected from Sippewissett salt marsh over the course of an annual cycle in marsh productivity.

\subsection{Results}

Sequencing of 45 clones containing full-length PCR-amplified 16s rDNA genes from several natural samples of MMP showed the presence of five clades defined by at least $5 \%$ sequence divergence (Fig. 5-1). Some sequence clusters within these clades also had high bootstrap support (>90\%; marked with ** in Fig. 5-1). These clades can be 


\begin{tabular}{lccl}
\hline $\begin{array}{l}\text { Probe } \\
\text { target }\end{array}$ & Probe name & Target site & Probe sequence \\
\hline Group 1 & MMPG1-190 & 190 & GAGGCCACCTTTAATAAGCTCTCT \\
Group 4 & MMPG4-95 & 95 & CCCGTACGCCACTTTACTATC \\
Group 4 & MMPG4-COMP95 & 95 & CCCGTGCGCCACTTTACTATC \\
Group 6 & MMPG6-199 & 199 & GCTTAATTAGAGGCCCCT \\
\hline
\end{tabular}

Table 5.1: Probes designed in this study to target different groups of MMP as shown in Fig.5-1.

${ }^{1}$ Unlabeled competitor, used at tenfold the amount of labeled probe. The one-base difference between the two probes is underlined.

considered new species by the commonly accepted empirical definition of microbial species as organisms separated by more than $3 \%$ sequence divergence in the $16 \mathrm{~s}$ rDNA gene (Gevers et al., 2005). Organisms with less than 3\% 16s rDNA divergence can also be defined as separate species depending on their phenotypic properties and distributions (Gevers et al., 2005). Groups 2 and 6 showed 8-10\% sequence divergence from groups 1 and 4, while groups 1 and 4 were approximately 5\% divergent from each other. The two previously available MMP sequences (DeLong et al., 1993) fell within group 4. The MMP sequences diverged by 8-11\% from Desulfosarcina variabilis. Group 4 sequences comprised $56 \%$ of all clones, Group 1 comprised 29\%, and Groups 2 and 6 each comprised $7 \%$.

Rarefaction, Chao1, and ACE estimators (Hughes et al., 2001) show that diversity was fully sampled at the $5 \%$ sequence divergence level, indicating that it was a good dividing line between groups for probe design. Rarefaction, Chao1, and ACE curves also indicate that we did not fully sample microdiverse MMP sequences within the main clades (sequence divergence less than 1\%). Both nonparametric estimators gave a value of 4 distinct OTUs at the $5 \%$ level. This is a slight underestimate, as clone mmp2_22 appears to represent a 5th distinct, undersampled, OTU in addition to the four groups used for probe design (Fig. 5-1). Existing probes targeting the Desulfosarcina-Desulfococcus group have limited coverage of the new MMP genus (Table 5.2). The probe DSS658 (Manz et al., 1998) has the best coverage, with an exact match to 43 of 45 clones.

Fluorescent in situ hybridization (FISH) probes were designed to target groups 


\begin{tabular}{|c|c|c|c|c|c|}
\hline Probe & Sequence & Source & Exact match & Single mismatch & Double mismatch \\
\hline DSS138 & CGG GTT ATC CCC GAT TCG & (Mussmann et al., 2005) & 0 & 0 & 0 \\
\hline DSS225 & TGG TAC GCG GGC TCA TCT & (Ravenschlag et al., 2000) & 0 & Group 1 MMP & Group 6 MMP \\
\hline DSS449 & TTA GCA TAC TGC AGG TTC & (Mussmann et al., 2005) & 0 & 0 & 0 \\
\hline DSS658 & TCC ACT TCC CTC TCC CAT & (Manz et al., 1998) & 43 & 2 & 0 \\
\hline C181-644 & CCC ATA CTC AAG TCC CTT & (Ravenschlag et al., 2000) & 0 & 0 & Group 1 MMP \\
\hline DSC193 & AGG CCA CCC TTG ATC CAA & (Ravenschlag et al., 2000) & 0 & 0 & 0 \\
\hline
\end{tabular}

Table 5.2: Existing probes for Desulfosarcina and closely related organisms and their coverage of the new MMP genus. The number of MMP clones matching the probe is shown.

1, 4, and 6 (Table 5.1). It was not possible to design a unique probe for Group 2 that fell in a sufficiently high fluorescence class (Behrens et al., 2003) for good detection. Because the Group 4 probe (G4-95) had only a single mismatch with some other MMP clones and 99 other delta proteobacteria in the ARB database, an unlabeled competitor probe (G4-COMP95) with one mismatch was designed to block hybridization to these nonspecific targets (Table 5.1). The competitor probe was used at tenfold excess. Probe MMPG4-95 was an exact match to two clones listed in the RDP database (Cole et al., 2005), one from sediments below Beggiatoa mats (Mills et al., 2004) and the other from the interior of gas hydrates (Mills et al., 2005) in the Gulf of Mexico. It is possible that these sequences correspond to MMP, but they were too short $(<600 \mathrm{bp})$ to determine a definitive match. The Group 1 probe (G1-190) had no single mismatches and one double mismatch to another MMP clone, and the Group 6 probe (G6-199) had single mismatches to two other MMP clones and two double mismatches to MMP clones. The Group 1 and Group 6 probes did not match any other sequence in the RDP database. All hybridizations were done with $30 \%$ formamide concentration in the hybridzation buffer due to decreased fluorescence at higher stringencies. Background Cy3 fluorescence of aggregates was occasionally visible, but aggregates with correctly hybridized probe were considerably brighter and could easily be distinguished by eye. Filters from sediment samples purified with the magnetic technique described in Methods contained nearly 100\% aggregates.

Probes bound to all cells within an aggregate, demonstrating that the aggregate is comprised of cells that are genetically identical with respect to their 16s rDNA genes. Simultaneous staining by DAPI and probes labeled with Cy3 confirmed that all DAPI- 
positive cells within each aggregate were also labeled by Cy3. Confocal micrographs show that Cy3-labeled probes bound to individual cells within each aggregate (Fig. 5-2). This was the case for all three probes examined. In some confocal images, what appeared to be a radial arrangement of cells around a central core was apparent (Fig. 5-2c), similar to the arrangement of individual cells in MMP described by electron microscopy (Keim et al., 2004a). A few apparently dividing cells were also present (Fig. 5-2c).

The relative abundance of each group to the total number of DAPI-stained aggregates was not clearly correlated with the sampling date or air temperature (Fig. 5-3a), suggesting that another factor is the primary determinant of relative abundances. MMP in Group 4 were the most abundant overall, always comprising at least $25 \%$ of total MMP. This observation is congruent with the dominance of Group 4 sequences in the clone library. Group $1 \mathrm{MMP}$ were the least abundant, while the relative abundance of group 6 varied from 0 to $45 \pm 17 \%$. Group 1 cells appeared to be most abundant on the coldest sampling date (March 30). Aggregates counted with these three probes did not account for all DAPI-stained MMP. The relative abundance of probe-stained aggregates to total DAPI-stained MMP ranged from a low of $32 \pm 17 \%$ on April 5 to a high of $72 \pm 23 \%$ on August 17 .

The average diameter of aggregates from all groups combined was similar between sampling dates (Fig.5-3b), ranging from $5.8 \pm 1.8 \mu \mathrm{m}$ on $1 / 20 / 06$ to $7.2 \pm 1.3$ $\mu \mathrm{m}$ on $7 / 29 / 05$. Group 1 and Group 6 aggregates were smaller overall than Group 4 aggregates on 8/17/05 and 1/20/06 (Fig. 5-2 and Fig. 5-3).

\subsection{Discussion}

The magnetotactic organism known as the many-celled magnetotactic prokaryote (MMP) contains at least five clades whose $16 \mathrm{~s}$ rDNA sequences diverge sufficiently (5\%) to be considered species (Fig. 5-1). Additionally, two clades (Groups 1 and 4) contain clusters with high bootstrap support that may also represent additional species (Fig. 5-1). The MMP is therefore best considered a genus rather than a 
single species as previously thought (DeLong et al., 1993). Since each clone was bidirectionally sequenced as well as sequenced with an internal primer, this divergence is highly unlikely to be due to sequencing errors. Errors introduced by Taq polymerase affect diversity estimates at and above the $99 \%$ sequence similarity level (Acinas et al., 2005), indicating that PCR error is highly unlikely to account for our results. Commonly used diversity estimators indicate that we achieved close to full coverage of the species-level diversity, although they appear to underestimate the number of separate species. The observation that the combination of probes used in this study (Groups 1, 4, and 6) accounted for as little as $32 \pm 17 \%$ of all DAPI-stained MMP indicates that additional separate clades (including Group 2 and clone mmp2_2 in Fig. 5-1) are likely to be numerically significant in the environment.

This level of diversity is unexpected, considering that the different subgroups of MMP cannot be distinguished under a light microscope by morphology or swimming behavior. Aggregates in some of the MMP clades appear to differ by size, but this is not consistent between different dates (Fig. 5-3). Numerous light microscopic observations also suggest a range in aggregate size (unpublished data), but this does not appear to be a reliable marker of the different MMP clades. All MMP examined to date by electron microscopy contain greigite magnetosomes, as predicted by thermodynamic calculations based on their distribution in a meromictic coastal pond (Simmons and Edwards, 2006). The samples analyzed in this study were all selected by their capacity to swim to the north pole of a bar magnet, so it is possible to infer that the magnetotactic behavior of each clade is not significantly different. Nonetheless, variation in the relative abundance of different MMP clades over the course of a year (Fig. 5-3) suggests that this diversity is quantitatively significant in the natural environment.

\subsubsection{Diversity and the concept of a microbial niche}

There are two possibilities to explain the extent of observed diversity in the MMP genus. Either it arises from the accumulation of neutral mutations that have not been eliminated by a selective sweep, or it is adaptive, indicating that each clade 
has a particular selective advantage. The extent of $16 \mathrm{~s}$ rDNA sequence divergence between groups (up to 10\% between Groups 2 and 6 and all other groups) supports the latter hypothesis; studies of related microbes that diverge by less the amounts observed in this study have shown that each clade occupies a distinct environmental niche (reviewed in (Giovannoni and Stingl, 2005)). Microdiversity (clusters of 16s rDNA sequences with divergence $<1 \%$ ) appears to be extensive among some natural bacterial populations (Acinas et al., 2004). It has been suggested that bacterial populations evolve by the accumulation of multiple closely related strains with very little adaptive differentiation, followed by periodic selective sweeps which eliminate all but one type (Cohan, 2001). The effect of these sweeps is to produce divergent sequence clusters with very little microdiversity that occupy distinct ecological niches. Because we did not sequence enough clones to fully sample microdiversity among the MMP, we cannot determine the current operation of this mechanism for differentiation within the MMP genus.

The concept of a "niche" is not well defined theoretically. Operationally, a microbial niche is defined as a set of resources used uniquely by a particular microbe coexisting with other microbes using slightly different resource sets, all within a habitat set by the experimenter. The habitat is defined as an area constrained by physical parameters relevant to the system under study; examples could include the euphotic zone of the upper ocean (Johnson et al., 2006), a mineral surface, or a microbial mat a few millimeters thick. Perhaps the best-studied example of niche differentiation among microbes is the open-ocean cyanobacterium Prochlorococcus. Ecotypes of this species differ by less than 3\% in their SSU rRNA, yet are stratified by depth in the water column and have distinct physiologies corresponding to their environmental distribution (Johnson et al., 2006). The large uncultivated sulfur bacterium Achromatium, whose habitat in freshwater and brackish sediments is somewhat similar to the MMP, also consists of a complex of closely related species which show different distributions with respect to depth in the sediment (Gray et al., 1999).

The diversity apparent in the MMP genus should be viewed in the context of the high diversity among closely related SRB of the family Desulfobacteraceae, which con- 
tains the MMP. Molecular studies show that uncultivated bacteria related to Desulfosarcina/Desulfococcus are among the most diverse of all SRB groups, with high diversity observed in salt marshes (Klepac-Ceraj et al., 2004, Rooney-Varga et al., 1997), shallow intertidal sediments (Mussmann et al., 2005), and deep arctic sediments (Ravenschlag et al., 2000). This group also numerically dominates the SRB community in the same environments (Mussmann et al., 2005, Ravenschlag et al., 2000, Rooney-Varga et al., 1997). Part of the explanation for this diversity could be the wide variety of substrates used by members of this group of completely-oxidizing $\mathrm{SRB}$, including $\mathrm{H}_{2}$, aromatic compounds, alcohols, fatty acids, formate, lactate, and acetate; D. variabilis is also capable of autotrophic growth (Rabus et al., 2000).

\subsubsection{Possible environmental niches for the MMP}

The most likely explanation for the high diversity within the MMP genus is that each clade occupies a distinct niche within the surface layers of salt marsh sediments, defined by differences in substrate utilization and/or preferences for particular redox potentials. The environments in which MMP are found are characterized by both a high organic matter content and a sharp oxygen-sulfide redox gradient, producing a wide variety of possible niches for each clade. In salt marshes dominated by the grass Spartina alterniflora, a large proportion of bacterial growth is due to exudation of organic carbon from plant roots (Boschker et al., 1999), which varies seasonally with plant production, peaking in late summer (Howarth and Teal, 1979). Little information is available on the types of exudates produced by estuarine plants in situ. In general, plant roots contain numerous organic acids (e.g. lactate, acetate, oxalate, succinate, fumarate, malate, and citrate) which are continually transported into the soil, in part due to the large concentration gradient between plant cells and bulk soil (Jones, 1998). These are all substrates utilized by SRB in the family Desulfobacteraceae (Rabus et al., 2000). The rhizosphere and adjacent sediments where MMP are found are therefore areas rich in organic matter with a diversity of carbon sources.

Since MMP are found largely in surface marsh sediments, as well as just below the 
oxic-anoxic interface in stratified euxinic basins (Simmons et al., 2006a, 2004), they also have access to intermediate sulfur compounds produced by the abiotic reaction of sulfide and oxygen (e.g. thiosulfate, polysulfides, and elemental sulfur (Jørgensen et al., 1979)). MMP co-occur with anaerobic photosynthetic bacteria in both these environments. Our experiments show that MMP have a low tolerance for sulfide, with the percentage of MMP surviving exposure to $100 \mu \mathrm{M}$ or higher sulfide significantly lower than the percentage surviving exposure to $50 \mu \mathrm{M}$ or less sulfide over a $3 \mathrm{hr}$ period (unpublished data). MMP appear to survive extended exposure to atmospheric oxygen when observed on a light microscope, consistent with $\mathrm{O}_{2}$ tolerance observed in other SRB (Rabus et al., 2000). These results suggest that the multiple clades of MMP observed in this study are compressed within a fairly narrow depth horizon with respect to the oxic-anoxic interface. It is plausible that different clades of MMP could occur at slightly different points in an oxygen-sulfide redox gradient, as we have observed with different species of marine magnetotactic bacteria in Salt Pond, a stratified euxinic basin (Simmons et al., 2006a). We observed multiple sequence types of MMP in Salt Pond with quantitative PCR (Simmons et al., 2006a), with one type consistently occuring higher in the water column than the other. Closely related co-occurring species of the large sulfur bacterium Achromatium showed different tolerances to changes in redox conditions (Gray et al., 2004), supporting redox potential as a mechanism to separate niches of closely related species.

The particular niches occupied by MMP are not defined by the seasonal abundance data (Fig. 5-3). Group 4 MMP appear to be the dominant clade in the genus, as reflected both by their abundance in the clone library (Fig. 5-1) and their abundance in situ, which never fell below $26 \pm 15 \%$ of total MMP. Group 4 aggregates appear larger than Groups 1 and 6, but not consistently by date. Their relatively constant abundance compared to the wide fluctuations in the abundances of Groups 1 and 6 suggests a broader tolerance to environmental variability. The lack of a consistent correlation between group abundances and ambient temperature (Fig. 5-3) indicates that our method of collecting bulk sediment erased variability due to more subtle environmental parameters. To better determine possible niches for each MMP clade, 
a method of detecting depth stratification of the different MMP clades is required in conjunction with measurement of relevant geochemical parameters. The flocculent sediment in Sippewissett marsh makes traditional coring difficult and requires a resin-embedding method (Bernhard et al., 2003) to accurately preserve organismal positions.

\subsubsection{Aggregates are clonal}

The frequency of dividing aggregates in natural populations observed with light microscopy ((Rodgers et al., 1990); unpublished data) and in situ hybridization (this study) is very low, suggesting that the MMP has a slow growth rate. Electron and light microscopic observations indicate that the MMP probably divides as follows. First, each cell grows in size, then divides synchronously; the aggregate then elongates into an elliptical shape, becomes "eight-shaped" by a torsional motion of the two halves, then splits into two new aggregates of equal size (Keim et al., 2004b). Our observations indicate that all cells within each aggregate are genetically identical with respect to their 16s rDNA genes (Fig. 5-2), supporting the hypothesis that the aggregate divides as a unit rather than forming from the assembly of individual cells. The lack of probe-positive individual cells in our samples also indicates that these cells, as previously observed (Rodgers et al., 1990), do not retain the magnetotactic swimming behavior of the aggregate.

\subsubsection{Conclusions}

Our results show that near-identical morphology and swimming behavior in an unusual microbial group can hide a surprising amount of genetic diversity. The uncultivated "many-celled magnetotactic prokaryote" is sufficiently diverse to be considered a separate genus in the family Desulfobacteraceae. The variation in abundance of each clade across a seasonal cycle suggests that each clade occupies a distinct niche defined by substrate utilization and redox potential. While the metabolism of the MMP is not known, its phylogenetic placement in a diverse family of sulfate-reducing $\delta$ - 
Proteobacteria makes sulfate reduction a likely possibility. Additional work is needed to determine the fine-scale distribution of each clade as well as possible differences in their metabolism.

The high diversity of this group should be taken into account when using in situ hybridization or quantitative PCR (qPCR) to enumerate the MMP in the environment. We previously designed broad-spectrum qPCR primers to the MMP, but these did not target all groups (Simmons et al., 2006a). For the most accurate enumeration of MMP, all three probes or primer sets based on these probes should be used. Better estimates of MMP abundance in will also lead to more accurate estimates of its impact on the flux of reduced iron out of stratified environments.

\subsection{Materials and Methods}

\subsubsection{Sample site and collection}

Sediments were collected from a shallow saltwater pool in the Little Sippewissett salt marsh (Falmouth, MA) close to a tidal inlet and an extensive microbial mat on six dates in 2005 and 2006. MMP from these samples were used for in situ hybridzation. Sediments used for PCR amplification of MMP 16s rRNA sequences were collected on four dates in October and November 2003. Surface sediments were flocculent, while roots of marsh grass were abundant slightly below the surface. The odor of sulfide was readily apparent when sediments were disturbed. White filaments, presumably sulfur extruded by sulfide-oxidizing bacteria, were visible near the water edge on some dates. Purple "berries" containing photosynthetic purple sulfur bacteria (Seitz et al., 1993) were abundant on the sediment surface, especially during mid-summer sampling. Historical air temperature data for Otis Air Force Base, approximately ten miles away from the collection site, was obtained from http://www.wunderground.com. The pool is shallow (less than $0.5 \mathrm{~m}$ at the deepest point) and quickly heats or cools depending on air temperature and insolation. Surface sediments were scooped with a

chisel into autoclaved 1 liter Nalgene bottles, which were filled one-third to one-half 
of the way with sediments; water from the pool was added to exclude oxygen. Six bottles of sediment and water were collected per sampling date.

In the laboratory, the south pole of a bar magnet was placed slightly above the sediment-water interface for each bottle to attract north-seeking MMP (the south pole of a bar magnet is equivalent to geomagnetic north, hence cells swimming towards the south pole are "north-seekers"). Cells were allowed to collect for 1-2 hrs until a large black streak was visible on the side of the bottle. Magnetotactic bacteria were removed from the bottle with a glass Pasteur pipette. Seawater collected from the marsh was filtered through a 0.4 micron membrane filter (Millipore), amended with resazurin as an oxygen indicator, and gently heated while bubbled with $\mathrm{N}_{2}$ to remove oxygen. $100 \mu \mathrm{M}$ sulfide was added from a $1 \mathrm{mM} \mathrm{Na}_{2} \mathrm{~S}$ stock solution. Approximately $20 \mathrm{ml}$ of reduced seawater was dispensed into glass culture tubes, sealed with rubber

plugs, and allowed to cool. Combined MMP collected from 3 bottles were added to each tube of reduced seawater. As with the bottles, a bar magnet was placed near the side of each tube and MMP were allowed to collect on the glass wall for 20-30 min. Pellets were removed with a glass Pasteur pipette and placed in fresh tubes of reduced seawater for magnetic enrichment. This procedure was repeated one more time to isolate MMP from nonmagnetic cells and inorganic contaminants.

After magnetic purification, cells were briefly fixed with 2-4\% paraformaldehyde $\left(30 \mathrm{~min}\right.$ at $4^{\circ} \mathrm{C}$ ) and filtered onto white $25 \mathrm{~mm}$ membrane filters using a sterile syringe and Swinnex filter cartridge. The filters were rinsed twice with 1x PBS, airdried, and stored at $-20^{\circ} \mathrm{C}$ in sealed petri dishes for later in situ hybridization. For DNA extraction and amplification, cells were filtered onto $13 \mathrm{~mm}$ membrane filters (Millipore) using a bleach-sterilized Swinnex filter cartridge and sterile syringe. The filters were frozen at $-80^{\circ} \mathrm{C}$ immediately.

\subsubsection{Amplification and sequencing}

Genomic DNA from MMP collected on filters from Sippewissett salt marsh in October and November 2003 was amplifed with the GenomiPhi kit (Amersham Biosciences); the GenomiPhi product was subsequently used in PCR for amplification of bacterial 
16s rRNA genes. The GenomiPhi kit uses random hexamer primers and Phi29 polymerase to amplify genomic DNA several thousand-fold in a nonbiased manner (Dean et al., 2001). The GenomiPhi technique has been used previously to amplify genomic DNA from low concentrations of bacteria in the environment prior to standard PCR (Gonzalez et al., 2005).

Each 13 mm filter containing MMP was immersed in sterile $500 \mu \mathrm{l} 10 \mathrm{mM}$ Tris$\mathrm{HCl}(\mathrm{pH}$ ) in a $1.5 \mathrm{ml}$ microcentrifuge tube. Cells were resuspended off the filters by brief sonication $(2 \mathrm{~min})$ in a water bath. This procedure was verified to remove the vast majority of MMP from filters by pre- and post-sonication DAPI staining (data not shown). Filters were not removed from the tubes following sonication. Cells were then lysed by a 5 minute incubation at $95^{\circ} \mathrm{C}$ per manufacturer's recommendations. Tubes were spun for 1 minute at $6000 \mathrm{rpm}$ in a microcentrifuge to pellet cell debris. 1 $\mu \mathrm{l}$ of the lysate was added to $9 \mu \mathrm{l}$ sample buffer in PCR reaction tubes. This solution was incubated at $95^{\circ} \mathrm{C}$ for 3 minutes to denature DNA and cooled to $4^{\circ} \mathrm{C}$ on ice. A master mix containing $9 \mu \mathrm{l}$ reaction buffer and $1 \mu \mathrm{l}$ Phi29 polymerase per tube was prepared on ice and added to the denatured lysate. The reaction was incubated at $30^{\circ} \mathrm{C}$ for 18 hours, then heated to $65^{\circ} \mathrm{C}$ for ten minutes and cooled to $4^{\circ} \mathrm{C}$ on ice. $5 \mu \mathrm{l}$ of a log-phase Vibrio parahemolyticus culture was used as a positive control, and Tris buffer was used as a negative control. Products were analyzed by field inversion gel electrophoresis (FIGE) using a FIGE Mapper Field Inversion System (Bio-Rad) with a $5 \mathrm{~kb}$ ladder (Bio-Rad). The majority of product fell within the 20-35 kb size range. The negative control product, comprised of amplification from the random hexamer primers only (GenomiPhi documentation) was less than $20 \mathrm{~kb}$. GenomiPhi products were combined and diluted 1:100 for use in PCR.

PCR was performed twice with the bacterial primers $8 \mathrm{~F}$ and $1492 \mathrm{R}$ on the diluted GenomiPhi products as well as the GenomiPhi negative control product and a PCR negative control (no template). Each reaction contained $10 \mu \mathrm{l}$ GoTaq buffer, $1 \mu \mathrm{l} 10$ mM dNTP mix, $2.5 \mu \mathrm{l}$ each primer at $10 \mu \mathrm{M}, 32.9 \mu \mathrm{l}$ nuclease-free $\mathrm{H}_{2} \mathrm{O}$, and $0.1 \mu \mathrm{l}$ GoTaq. Cycling conditions were (1) initial denaturation at $94^{\circ} \mathrm{C}$ for $2 \mathrm{~min}$, (2) 25 cycles of $94^{\circ} \mathrm{C}(1 \mathrm{~min}), 49^{\circ} \mathrm{C}(1 \mathrm{~min})$, and $72^{\circ} \mathrm{C}(3 \mathrm{~min})$, followed by (3) extension 
for $7 \mathrm{~min}$ at $72^{\circ} \mathrm{C}$. PCR products were cloned into the pCR2.1-TOPO ${ }^{\circledR}$ vector (Invitrogen). Alkaline lysis minipreps were done in 96 well format on a RevPrep Orbit at the Josephine Bay Paul Center, Marine Biological Laboratory (MBL), Woods Hole, MA. Sequencing reactions were run using $1 / 8 \mathrm{x}$ reactions from the ABI v3.1 BigDye kit (Applied Biosystems) on an ABI 3730xl capillary sequencer, also at the MBL. Each clone was sequenced separately with the universal primers M13F, M13R, and 515R to ensure complete high-quality coverage.

\subsubsection{Phylogenetic analysis}

Vector trimming and sequence assembly was done using the trev, pregap 4 , and gap 4 programs in the Staden package (http://staden.sourceforge.net/). Mismatches between the three separate traces were checked by reference to the trace files. Sequences were imported into the tree-building and database management program ARB (Ludwig et al., 2004) and aligned. Sequences were checked for the presence of chimeras with Bellerophon (Huber et al., 2004), and chimeric sequences were removed from the database. Sequences trimmed to $1277 \mathrm{bp}$ were exported from ARB using the filter "delta_proteo_rr5_dec04," a delta-proteobacterial specific filter which retains sequence positions conserved in at least $50 \%$ of input sequences. Maximum likelihood phylogenetic analysis with 100 bootstrap replicates was performed with PAUP*.

Rarefaction curves and the nonparametric diversity estimators Chao1 and ACE (Hughes et al., 2001) were calculated for several sequence divergence levels (0 to 12\%) using the program DOTUR (Schloss and Handelsman, 2005). The distance matrix for input into DOTUR contained all 45 full length sequences obtained in this study as well as the two previously identified MMP clones MMP1990 and MMP1991 (DeLong et al., 1993), and was calculated without applying any sequence filter. Gaps and missing data were excluded from the distance calculation. The distance between sequences from each group was calculated with ARB. 


\subsubsection{Probe design and use}

Only sequence groupings with at least $5 \%$ distance from each other and containing at least 3 sequences were used for probe design (Groups 1, 2, 4, and 6) in ARB. Clone mmp2_2 appears to form part of a distinct sequence group but was not used for probe design due to the lack of other similar sequences. Probes were designed using only sequences with greater than $1400 \mathrm{bp}$ to maximize the chance of finding an appropriate region. Probe specificity was checked using ARB and the RDP database (Cole et al., 2005). Fluorescence classes for in situ hybridization (Behrens et al., 2003) were checked using probeBase (Loy et al., 2003). The original MMP probe (MMP218) designed by DeLong et al (DeLong et al., 1993) is located in a region with very low fluorescence (classes 4-6). Probes were tested at hybridization stringencies from $0-50 \%$ formamide following previously published protocols (Pernthaler et al., 2001). The Cy3-tagged probes (Sigma Genosys) were tested on filters containing highly purified MMP collected as described above. The highest stringency producing sufficient fluorescence was used.

Filters from each sampling date were cut into small pieces and immersed in $400 \mu \mathrm{l}$ hybridization buffer (Pernthaler et al., 2001) containing $5 \mathrm{ng} \mu \mathrm{l}^{-1}$ Cy3-labeled probe, then incubated for 2 hours at $46^{\circ} \mathrm{C}$ followed by a 15 minute wash at $48^{\circ} \mathrm{C}$. Each probe was used separately, and a no-probe negative control was included in every hybridization. Dual staining with Cy3- and Alexa 488-labeled probes was attempted, but did not produce clearly distinguishable signals. Sections were washed briefly in DI water, then immersed in $80 \% \mathrm{EtOH}$ for 1 min to reduce background staining. Air-dried sections were placed on glass slides. A mountant mix containing 5.5 parts Citiflour, 1 part VectaShield, 0.5 parts $1 \mathrm{x}$ PBS, and $1 \mu \mathrm{g} \mathrm{ml}^{-1}$ DAPI was applied to the sections, as previously described (Pernthaler et al., 2002). Sections were viewed on a Zeiss Axiovert microscope equipped with epifluoresence and on a Zeiss inverted LSM-510 META laser scanning confocal system at the Marine Biological Laboratory,

Woods Hole. For each field viewed, the number of DAPI-stained aggregates and the number of $\mathrm{Cy} 3$-stained aggregates were counted. Aggregates were easily distinguished 
from other cells due to their unique morphology. At least 10 fields were counted per filter section.

\subsubsection{Image analysis}

Images were taken with Nikon Capture software on the epiflurorescence microscope and the Zeiss LSM 510 software on the confocal microscope. Color images were converted to greyscale using Adobe Photoshop software. The diameter of aggregates was determined using the public domain program ImageJ (http://rsb.info.nih. gov/ij/) with scaling derived from imaging a Petroff-Hauser counter. Automatic thresholds were checked by eye prior to particle analysis. 


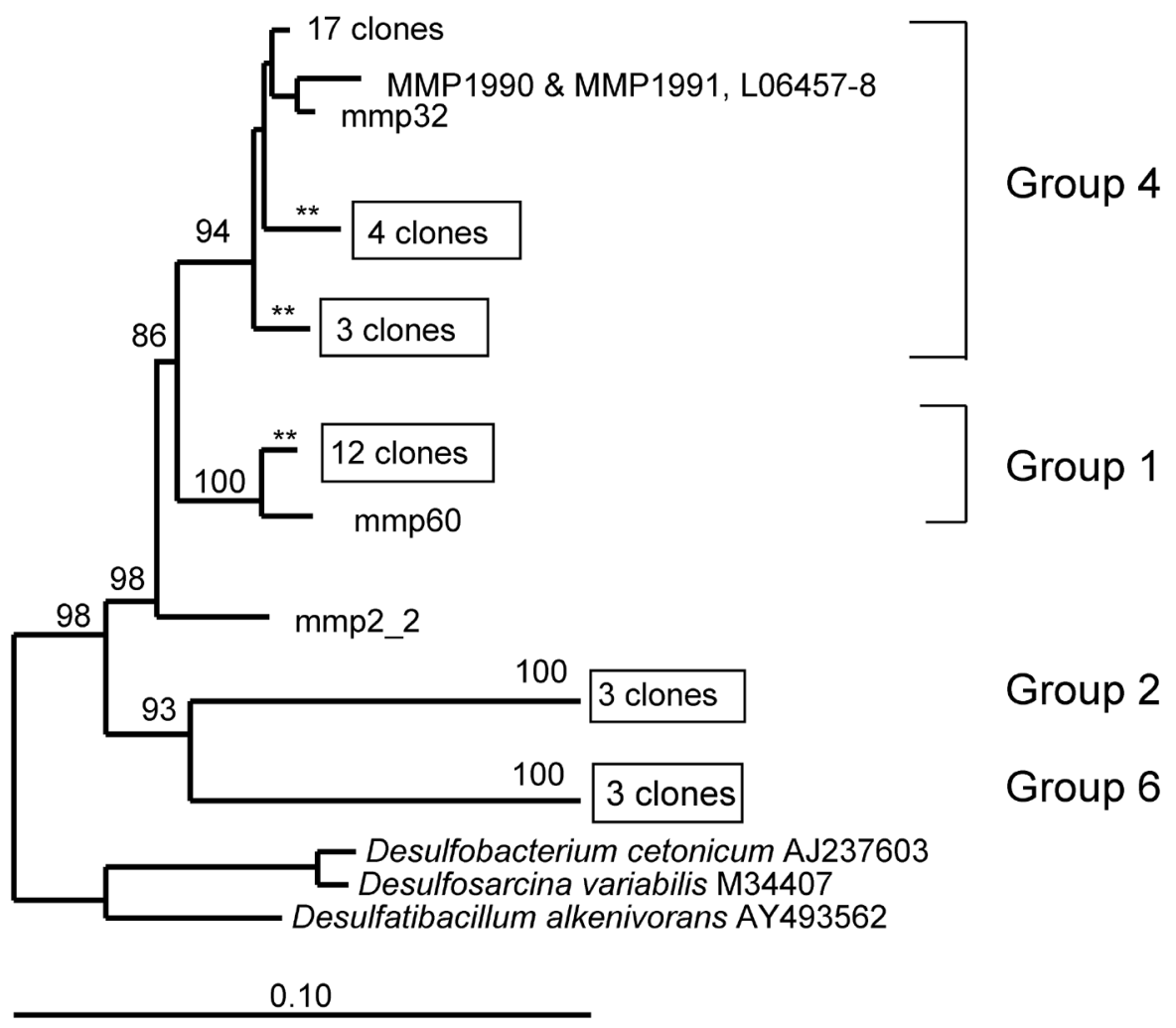

Figure 5-1: Phylogenetic tree based on sequences of the 16s rDNA gene from Sippewissett marsh MMP showing sequence groupings used for probe design. Sequences were aligned in ARB, trimmed to 1277bp, and exported using the "delta_proteo_rr5_dec04" filter. The tree was constructed using maximum likelihood analysis with 100 bootstrap replicates in PAUP*. ${ }^{* *}$ signifies $>90 \%$ bootstrap support. Accession numbers for the sequences are **. The tree was rooted using **. Clones labeled "mmp2*" are from a second round of PCR on the same set of lysates as clones labeled "mmp*." The clone mmp2 2 appears to be the only member of an additional sequence cluster (Group 5) as it diverged by at least $5 \%$ from all other sequences. 

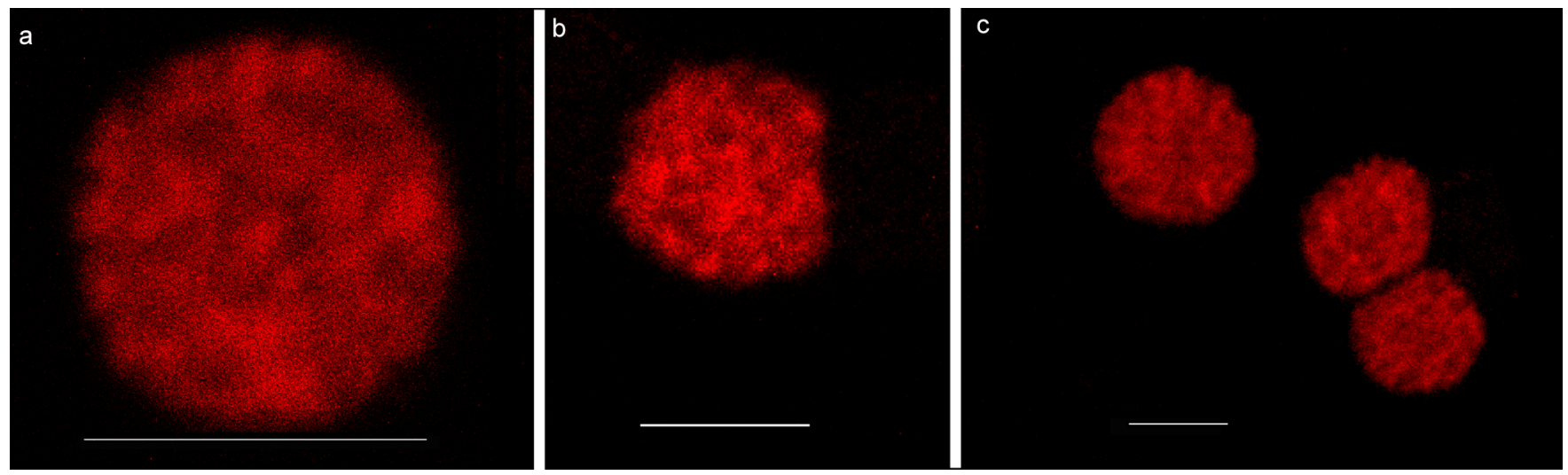

Figure 5-2: All cells within each aggregate are genetically identical. Confocal micrograph showing MMP collected on 17 August 2005 hybridizing with the (a) MMPG4-95 and (b) MMPG1-190 oligonucleotide probes. (c) An apparent radial arrangement of cells around a central core is visible in these aggregates hybridized with the MMPG495 probe. The pair of cells on the right appears to be dividing. Both probes are tagged with Cy3. All scale bars $5 \mu \mathrm{m}$. 

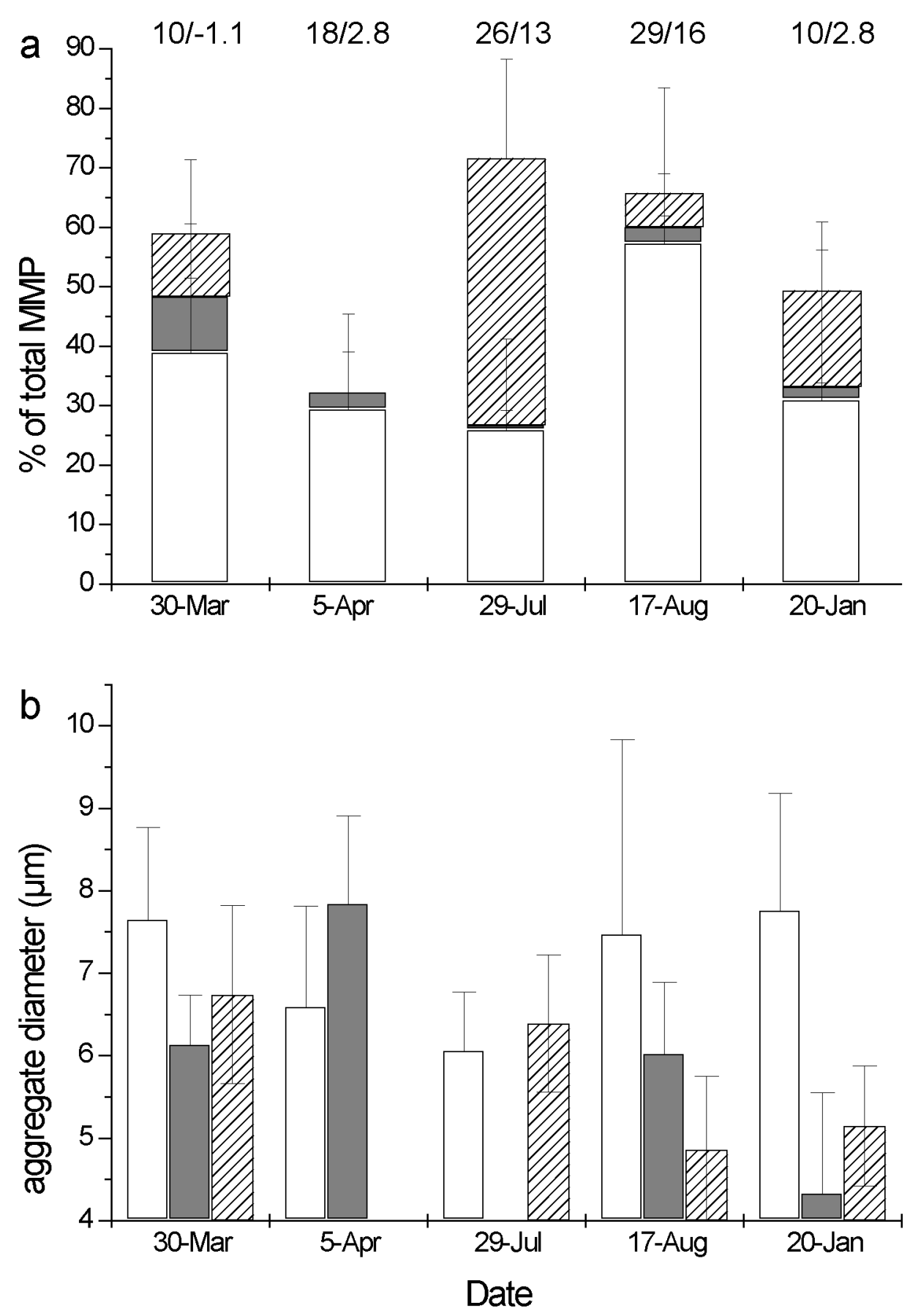

Figure 5-3: (a) The fractional abundance of each MMP probe group by date. The number of probe-positive cells was divided by the total number of MMP and multiplied by 100 . White, Group 4; dark grey, Group 1; hatched, Group 6. The high/low air temperatures for each date are shown on the top $\left({ }^{\circ} \mathrm{C}\right)$. (b) The average diameter of aggregates hybridized with each probe on each date. Same colors as in (a). 


\section{Bibliography}

Acinas SG, Klepac-Ceraj V, Hunt DE, Pharino C, Ceraj I, et al. (2004) Fine-scale phylogenetic architecture of a complex bacterial community. Nature 430: 551-554.

Acinas SG, Sarma-Rupavtarm R, Klepac-Ceraj V, Polz M (2005) PCR-Induced Sequence Artifacts and Bias: Insights from Comparison of Two 16S. Appl Env Microbiol 71: 8966-8969.

Bazylinski DA, Dean AJ, Williams TJ, Long LK, Middleton SL, et al. (2004) Chemolithoautotrophy in the marine, magnetotactic bacterial strains MV-1 and MV-2. Archives of Microbiology 182: 373-387.

Bazylinski DA, Frankel RB, Heywood BR, Mann S, King JW, et al. (1995) Controlled biomineralization of magnetite $\left(\mathrm{Fe}_{3} \mathrm{O}_{4}\right)$ and gregite $\left(\mathrm{Fe}_{3} \mathrm{~S}_{4}\right)$ in a magnetotactic bacterium. Appl Environ Microbiol 61: 3232-3239.

Bazylinski DA, Garratt-Reed AJ, Abedi A, Frankel RB (1993) Copper Association with Iron Sulfide Magnetosomes in a Magnetotactic Bacterium. Archives of Microbiology 160: 35-42.

Bazylinski DA, Moskowitz BM (1997) Microbial biomineralization of magnetic iron minerals: microbiology, magnetism, and environmental significance. In: Banfield J, Nealson K, editors, Geomicrobiology: Interactions between Microbes and Minerals, vol. 35 of Reviews in Mineralogy, pp. 181-224, Washington, D.C.: Mineralogical Society of America.

Behrens S, Ruhland C, Inacio J, Huber H, Fonseca A, et al. (2003) In Situ Accessibility of Small-Subunit rRNA of Members of the Domains Bacteria, Archaea, and Eucarya to Cy3-Labeled Oligonucleotide Probes. Appl Environ Microbiol 69: 1748-1758.

Bernhard JM, Visscher PT, Bowser SS (2003) Submillimeter life positions of bacteria, protists, and metazoans in laminated sediments of the Santa Barbara Basin. Limnology and Oceanography 48: 813-828. 
Blakemore RP (1975) Magnetotactic bacteria. Science 190: 377-379.

Boschker HTS, de Brouwer JFC, Cappenberg TE (1999) The contribution of macrophyte-derived organic matter to microbial biomass in salt-marsh sediments: Stable carbon isotope analysis of microbial biomarkers. Limnology and Oceanography 44: 309-319.

Cohan F (2001) Bacterial Species and Speciation. Syst Biol 50: 513-524.

Cole JR, Chai B, Farris RJ, Wang Q, Kulam SA, et al. (2005) The Ribosomal Database Project (RDP-II): sequences and tools for high-throughput rRNA analysis. Nucl Acids Res 33: D294-296.

Dean FB, Nelson JR, Giesler TL, Lasken RS (2001) Rapid Amplification of Plasmid and Phage DNA Using Phi29 DNA Polymerase and Multiply-Primed Rolling Circle Amplification. Genome Res 11: 1095-1099.

DeLong EF, Frankel RB, Bazylinski DA (1993) Multiple evolutionary origins of magnetotaxis in bacteria. Science 259: 803-806.

Devereux R, Hines ME, Stahl DA (1996) S cycling: Characterization of natural communities of sulfate-reducing bacteria by 165 rRNA sequence comparisons. Microbial Ecology 32: 283-292.

Farina M, Esquivel D, de Barros HL (1990) Magnetic iron-sulphur crystals from a magnetotactic microorganism. Nature 383: 256-258.

Flies CB, Jonkers HM, de Beer D, Bosselmann K, Bottcher ME, et al. (2005) Diversity and vertical distribution of magnetotactic bacteria along chemical gradients in freshwater microcosms. FEMS Microbiology Ecology 52: 185-195.

Gevers D, Cohan FM, Lawrence JG, Spratt BG, Coenye T, et al. (2005) Re-evaluating prokaryotic species. Nat Rev Micro 3: 733-739.

Giovannoni SJ, Stingl U (2005) Molecular diversity and ecology of microbial plankton. Nature 437: 343-348. 
Gonzalez JM, Portillo MC, Saiz-Jimenez C (2005) Multiple displacement amplification as a pre-polymerase chain reaction (pre-PCR) to process difficult to amplify samples and low copy number sequences from natural environments. Environmental Microbiology 7: 1024-1028.

Gray ND, Comaskey D, Miskin IP, Pickup RW, Suzuki K, et al. (2004) Adaptation of sympatric Achromatium spp. to different redox conditions as a mechanism for coexistence of functionally similar sulphur bacteria. Environmental Microbiology 6: 669-677.

Gray ND, Howarth R, Rowan A, Pickup RW, Jones JG, et al. (1999) Natural Communities of Achromatium oxaliferum Comprise Genetically, Morphologically, and Ecologically Distinct Subpopulations. Appl Environ Microbiol 65: 5089-5099.

Greenberg M, Canter K, Mahler I, Tornheim A (2005) Observation of magnetoreceptive behavior in a multicellular magnetotactic prokaryote in higher than geomagnetic fields. Biophysical Journal 88: 1496-1499.

Heywood BR, Bazylinski DA, Garrett-Reed AJ, Mann S, Frankel RB (1990) Controlled biosynthesis of greigite $\left(\mathrm{Fe}_{3} \mathrm{~S}_{4}\right)$ in magnetotactic bacteria. Naturwissenschaften 77: 536-538.

Hines M, Evens R, Genthner BS, Willis S, Friedman S, et al. (1999) Molecular phylogenetic and biogeochemical studies of sulfate-reducing bacteria in the rhizosphere of Spartina alterniflora. Appl Env Microbiol 65: 2209-2216.

Hines M, Knollmeyer SL, Tugel J (1989) Sulfate Reduction and Other Sedimentary Biogeochemistry in a Northern New England Salt Marsh. Limnol Oceanogr 34: $578-590$.

Howarth R, Teal J (1979) Sulfate Reduction in a New England Salt Marsh. Limnol Oceanogr 24: 999-1013.

Huber T, Faulkner G, Hugenholtz P (2004) Bellerophon; a program to detect chimeric sequences in multiple sequence alignments. Bioinformatics 20: 2317-2319. 
Hughes J, Hellmann J, Ricketts T, Bohannan B (2001) Counting the uncountable: statistical approaches to estimating microbial diversity. Appl Environ Microbiol 67: 4399-4406.

Johnson ZI, Zinser ER, Coe A, McNulty NP, Woodward EMS, et al. (2006) Niche Partitioning Among Prochlorococcus Ecotypes Along Ocean-Scale Environmental Gradients 10.1126/science.1118052. Science 311: 1737-1740.

Jones DL (1998) Organic acids in the rhizosphere: a critical review. Plant and Soil 205: $25-44$.

Jørgensen BB, Kuenen JG, Cohen Y (1979) Microbial transformations of sulphur compounds in a stratified lake (Solar Lake, Sinai). Limnol Oceanogr 24: 799-822.

Keim CN, Abreu F, Lins U, de Barros HL, Farina M (2004a) Cell organization and ultrastructure of a magnetotactic multicellular organism. Journal of Structural Biology 145: 254-262.

Keim CN, Martins JL, Abreu F, Rosado AS, de Barros HL, et al. (2004b) Multicellular life cycle of magnetotactic prokaryotes. FEMS Microbiology Letters 240: 203-208.

Kendall MM, Boone DR (2000) The Order Methanosarcinales. In: Dworkin M, editor, The Prokaryotes: An Evolving Electronic Resource for the Microbiological Community, release 3.3, New York: Springer Verlag.

Klepac-Ceraj V, Bahr M, Crump BC, Teske AP, Hobbie JE, et al. (2004) High overall diversity and dominance of microdiverse relationships in salt marsh sulphatereducing bacteria. Environ Microbiol 6: 686-698.

Loy A, Horn M, Wagner M (2003) probeBase: an online resource for rRNA-targeted oligonucleotide probes. Nucl Acids Res 31: 514-516.

Ludwig W, Strunk O, Westram R, Richter L, Meier H, et al. (2004) ARB: a software environment for sequence data. Nucl Acids Res 32: 1363-1371. 
Mann S, Sparks NHC, Frankel RB, Bazylinski DA, Jannasch HW (1990) Biomineralization of ferrimagnetic greigite $\left(\mathrm{Fe}_{3} \mathrm{~S}_{4}\right)$ and iron pyrite $\left(\mathrm{FeS}_{2}\right)$ in a magnetotactic bacterium. Nature 343: 258-261.

Manz W, Eisenbrecher M, Neu TR, Szewzyk U (1998) Abundance and spatial organization of Gram-negative sulfate-reducing bacteria in activated sludge investigated by in situ probing with specific 16S rRNA targeted oligonucleotides. FEMS Microbiology Ecology 25: 43-61.

Mills HJ, Martinez RJ, Story S, Sobecky PA (2004) Identification of Members of the Metabolically Active Microbial Populations Associated with Beggiatoa Species Mat Communities from Gulf of Mexico Cold-Seep Sediments. Appl Environ Microbiol 70: $5447-5458$.

Mills HJ, Martinez RJ, Story S, Sobecky PA (2005) Characterization of Microbial Community Structure in Gulf of Mexico Gas Hydrates: Comparative Analysis of DNA- and RNA-Derived Clone Libraries. Appl Environ Microbiol 71: 3235-3247.

Mussmann M, Ishii K, Rabus R, Amann R (2005) Diversity and vertical distribution of cultured and uncultured Deltaproteobacteria in an intertidal mud flat of the Wadden Sea. Environmental Microbiology 7: 405-418.

Pernthaler A, Pernthaler J, Amann R (2002) Fluorescence In Situ Hybridization and Catalyzed Reporter Deposition for the Identification of Marine Bacteria. Appl Environ Microbiol 68: 3094-3101.

Pernthaler J, Glöckner F, Schönhuber W, Amann R (2001) Flourescence in situ hybridization with rRNA-targeted oligonucleotide probes. In: Paul J, editor, Methods in Microbiology, vol. 30, pp. 207-226, San Diego: Academic Press.

Petermann H, Bleil U (1993) Detection of live magnetotactic bacteria in deep-sea sediments. Earth Planet Sci Lett 117: 223-228. 
Pósfai M, Buseck PR, Bazylinski DA, Frankel RB (1998) Iron sulfides from magnetotactic bacteria: Structure, composition, and phase transitions. American Mineralogist 83: 1469-1481.

Rabus R, Hansen T, Widdel F (2000) Dissimilatory Sulfate- and Sulfur-Reducing Prokaryotes. In: Dworkin M, editor, The Prokaryotes: An Evolving Electronic Resource for the Microbiological Community, release 3.3, New York: Springer Verlag.

Ravenschlag K, Sahm K, Knoblauch C, Jorgensen BB, Amann R (2000) Community structure, cellular rRNA content, and activity of sulfate-reducing bacteria in marine Arctic sediments. Applied and Environmental Microbiology 66: 3592-3602.

Reitner J, Peckmann J, Blumenberg M, Michaelis W, Reimer A, et al. (2005) Concretionary methane-seep carbonates and associated microbial communities in Black Sea sediments. Palaeogeography Palaeoclimatology Palaeoecology 227: 18-30.

Rodgers FG, Blakemore RP, Blakemore NA, Frankel RB, Bazylinski DA, et al. (1990) Intercellular Structure in a Many-Celled Magnetotactic Prokaryote. Archives of Microbiology 154: 18-22.

Rooney-Varga J, Devereux R, Evans R, Hines M (1997) Seasonal changes in the relative abundance of uncultivated sulfate- reducing bacteria in a salt marsh sediment and in the rhizosphere of Spartina alterniflora. Appl Environ Microbiol 63: 3895-3901.

Schloss PD, Handelsman J (2005) Introducing DOTUR, a Computer Program for Defining Operational Taxonomic Units and Estimating Species Richness. Appl Environ Microbiol 71: 1501-1506.

Seitz AP, Nielsen TH, Overmann J (1993) Physiology of Purple Sulfur Bacteria Forming Macroscopic Aggregates in Great Sippewissett Salt-Marsh, Massachusetts. FEMS Microbiol Ecol 12: 225-236.

Simmons S, Bazylinski DA, Edwards KJ (2006a) Population dynamics of marine 
magnetotactic bacteria in a meromictic salt pond described with quantitative PCR. Submitted .

Simmons SL, Bazylinski DA, Edwards KJ (2006b) South-seeking magnetotactic bacteria in the Northern Hemisphere. Science 311: 371-374.

Simmons SL, Edwards KJ (2006) Geobiology of magnetotactic bacteria. In: Schler D, editor, Magnetoreception and magnetosomes in bacteria, vol. Forthcoming, Elsevier.

Simmons SL, Sievert SM, Frankel RB, Bazylinski DA, Edwards KJ (2004) Spatiotemporal Distribution of Marine Magnetotactic Bacteria in a Seasonally Stratified Coastal Salt Pond. Appl Environ Microbiol 70: 6230-6239.

Spring S, Amann R, Ludwig W, Schleifer K, van Gemerden H, et al. (1993) Dominating role of an unusual magnetotactic bacterium in the microaerobic zone of a freshwater sediment. Appl Environ Microbiol 59: 2397-2403.

Wilkin RT, Barnes HL (1996) Pyrite formation by reactions of iron monosulfides with dissolved inorganic and organic sulfur species. Geochim Cosmochim Acta 60: $4167-4179$

Williams T, Zhang C, JH S, Bazylinski DA (2006) Evidence for autotrophy via the reverse tricarboxylic acid cycle in the marine magnetotactic coccus strain MC-1. Appl Environ Microbiol 72: 1322-1329. 


\title{
Chapter 6
}

\section{Conclusion}

A modified version of this chapter will appear as: Sheri L. Simmons and Katrina J. Edwards, "Geobiology of magnetotactic bacteria," in Magnetoreception and Magnetosomes in Bacteria, edited by Dr. Dirk Schüler.

\begin{abstract}
MTB population dynamics and their contribution to iron cycling in modern chemically stratified environments have not been previously evaluated in a systematic fashion. Using the tools of modern molecular microbial ecology and mineralogy, it is possible to determine the population dynamics of magnetite and greigite producing MTB with respect to environmental geochemistry. This integrated approach can help provide an understanding of the contribution of MTB to iron and sulfur cycling and export to sediments. Additionally, understanding the coupled biology and geochemistry of MTB in modern environments can help interpret the significance of magnetofossils present in the rock record.
\end{abstract}

\subsection{Introduction}

The ecology of magnetotactic bacteria (MTB) and their potentially substantial role in iron cycling are largely unexplored questions amidst the extensive literature on MTB behavior, phylogeny, and magnetofossil morphology. Quantitative microbial ecology seeks, in part, to define how the population density of different species varies over both time and space in conjunction with relevant environmental parameters. It 
requires species-level identification of uncultivated organisms and the development and application of tools to enumerate them in the environment, in conjunction with appropriate geochemical measurements. These tools have been applied to individual species of MTB, but not to track the population dynamics of MTB communities over time. Such an integrated approach is required to understand both the impacts of MTB on their environment and the biosignatures they leave behind. MTB communities in chemically stratified coastal ponds provide ideal model systems for this approach. They are analogues of much larger stratified basins (e.g. the Black Sea and the Cariaco Basin) where the contribution of MTB to iron flux could be quantitatively significant, but which are far less accessible and more difficult to sample.

The widespread prevalence of such chemically stratified marine environments (water columns and sediments) suggests that marine MTB are globally more abundant than freshwater MTB, the focus of the limited previous work on MTB ecology in natural environments (e.g. Spring et al. (1993)). Mostly qualitative observations of marine MTB show that they are abundant in the suboxic to anoxic zones of salt marsh sediments and semi-anaerobic basins worldwide (Bazylinski and Frankel, 1992, Bazylinski et al., 1995, Farina et al., 1990, Mann et al., 1990a,b, Simmons et al., 2006a, 2004, Spring and Bazylinski, 2000) and occur in deep-sea sediments (Petermann and Bleil, 1993, Stoltz et al., 1986). Marine MTB can reach population densities of $10^{5}$ cells $\mathrm{ml}^{-1}$ (Simmons et al., 2006a). The large amounts of Fe concentrated by MTB in intracellular magnetosomes $\left(10^{-13}\right.$ to $10^{-15} \mathrm{~g}$ Fe per cell), considering their estimated population density, indicate that nanomolar concentrations of Fe may be sequestered in biomass (Simmons et al., 2006a, Stolz, 1992). These observations suggest a significant MTB contribution to iron cycling in the environment that has not been quantitatively addressed.

The potential contribution of MTB to sulfur cycling and deposition is also significant. Nearly all cultivated marine magnetite-producing MTB are chemolithoautotrophic S-oxidizers (Spring and Bazylinski, 2000), and many store intermediates $\left(\mathrm{S}^{0}\right)$ intracellularly for use as electron donors (Bazylinski et al., 2004, Cox et al., 2002, Spring et al., 1993). Greigite-producing MTB, which have not yet been isolated 
in axenic culture, sequester large amounts of $\mathrm{Fe}$ and $\mathrm{S}$ in the greigite mineral $\left(\mathrm{Fe}_{3} \mathrm{~S}_{4}\right)$ by an unknown mechanism. Based on the identification of one greigite-producer in the $\delta$-Proteobacteria (DeLong et al., 1993), these have been suggested to function as sulfate reducers, but there is no data to date about their metabolic function.

The general characteristics of environments where MTB are found are fairly well defined by numerous observations (Blakemore, 1982, Mann et al., 1990a). These include a neutral to slightly alkaline $\mathrm{pH}$, suboxic to anoxic conditions, the presence of dissolved iron, and the presence of sulfide for greigite-producing MTB. The minimum concentration of dissolved iron required for the presence of MTB is not known. Observations in Salt Pond, a small stratified marine basin, suggest that MTB are most abundant in slightly reducing conditions (Simmons and Edwards, unpublished data). MTB also appear to be most abundant in organic-rich environments such as salt marshes (Blakemore, 1975), the water column of stratified eutrophic freshwater (Kim et al., 2005) and salt ponds (e.g. Simmons et al. (2004)), and freshwater sediments (Cox et al., 2002, Spring et al., 1993). Heterotrophic consumption of organic matter in these environments leads to the depletion of oxygen and the establishment of oxicanoxic gradients favorable to the growth of MTB. At least some MTB are autotrophs (Bazylinski et al., 2004, Williams et al., 2006), but it is possible that others make use of high organic content by anaerobic heterotrophy (sulfate or iron reduction).

A complete description of the geobiology of MTB would necessarily include a comprehensive description of the microbial ecology of MTB and the governing factors controlling their population dynamics, as well as a quantitative understanding of the biogeochemical role they play in Fe and S cycling. A more complete understanding of the geobiology of MTB would enable the development of, for example, a predictive model for the amount of magnetite and greigite deposition by MTB given certain environmental parameters. Such a model has two potential benefits: it would enable us to quantify the impact of MTB on iron and sulfur cycling in modern environments, as well as better interpret magnetofossils as paleoenvironmental indicators. Clearly, the best way to develop this model is to study modern MTB populations in situ. The key parameters to measure are the relative abundances of magnetite- and greigite- 
producing MTB, their turnover time, and cellular iron and sulfur content with respect to environmental chemistry. The standard tools of modern molecular ecology can be used to identify individual species of MTB and track their population dynamics over time. In combination with analysis of MTB mineral content and post-depositional modification, it will be possible to obtain estimates of how fluctuations in MTB populations regulate the amount of iron and sulfur deposited as magnetofossils in sediments.

\subsubsection{Magnetofossils as paleoindicators}

Fossilized magnetosomes produced by MTB have been previously suggested as useful paleoenvironmental indicators (Stolz, 1992), both in the sedimentary and rock records (see also chapter by Winklhofer and Petersen, this volume). Magnetosomes have characteristic morphologies that are distinct from inorganic minerals, and are important carriers of remanent magnetism in the sedimentary rock record (Petersen and von Dobeneck, 1986, Stolz, 1992). Magnetite magnetofossils have been identified in rocks as old as 700 Mya (Chang, 1989). Fossil magnetite from MTB appears to be well preserved in suboxic freshwater sedimentary environments (Snowball et al., 2002). Magnetite dissolves easily in highly sulfidic environments, but $10-20 \%$ can be preserved by formation of a pyrite coating (Canfield and Berner, 1987). Greigite is also abundant and well-preserved in the rock record (Kao et al., 2004, Pósfai et al., 2001, Roberts et al., 1996). The distinctive morphology of magnetofossil gregite has not yet been used to distinguish it from inorganic greigite, although biogenic greigite crystals have been shown to display different size distributions than inorganic greigite (Pósfai et al., 2001).

It is much less clear, however, exactly what the presence of fossilized magnetite and/or greigite reveals about the original depositional environment. Magnetite formed by MTB was once thought to indicate the presence of oxygen, due to the microaerophilic habitat of most of these species, but subsequent observations showed that MTB can also produce magnetite under anaerobic conditions (Bazylinski et al., 1988, Sakaguchi et al., 2002) and are found in anaerobic zones in nature (Simmons et al., 2006a). 
Greigite-producing MTB require the presence of sulfide. Some greigite-producers appear to require an oxygen-sulfide gradient, while others are found at low abundance in highly sulfidic waters (up to $1 \mathrm{mM}$ sulfide) (Simmons et al., 2006a). These observations indicate that the presence of particular types of magnetofossils in the rock record could be a strong indicator of a particular redox environment existing at the time of deposition. The key factor limiting the use of magnetofossils as reliable paleoindicators, however, is the lack of quantitative constraints on the redox environments favoring magnetite vs. greigite production by MTB.

Studies of magnetosomes preserved in lacustrine and marine sediments show broad correlations between the concentration and/or type of magnetosome and bulk chemical properties of the sediment, suggesting that environmental chemistry regulates both the total number of MTB and the relative abundance of different species. A positive linear relationship between total organic carbon and sediment magnetism, dominated by single domain magnetite and greigite of probable bacterial origin (Snowball et al., 2002, 1999), appeared in varved lake cores from Swedish freshwater lakes covering 9000 years of sediment deposition. A similar positive relationship between organic carbon content and magnetosome concentration was found in recent sediments from freshwater Lake Ely (Kim et al., 2005). The magnetic properties of magnetosomes were correlated with redox potential in sediment cores from a Swiss freshwater lake (Egli, 2004a). Two groups of magnetosomes with distinct morphology and magnetic properties were present, which were interpreted as originating from two or more species of MTB (Egli, 2004a,b). The first group of magnetosomes, characterized by greater morphological diversity, was associated with more oxygenated sediments. The second group was characterized by magnetosomes with less morphological diversity that were either magnetite with an elongated morphology or greigite. The organic carbon content of Pacific deep-sea sediments was also strongly correlated with magnetosome crystal morphology (Yamazaki and Kawahata, 1998), again suggesting a habitat preference by distinct species of MTB with species-specific magnetosome morphologies.

These observations hint at a more precise governance of the population dynamics of individual MTB species by environmental chemistry. The study of modern strat- 
ified environments where MTB are abundant can provide some of the information required to intepret these magnetofossils, by linking the quantitative population dynamics of magnetite- and greigite- producing MTB to environmental geochemistry and mineralogy. Modern stratified marine environments are good analogues for the ancient oceans, now widely thought (Anbar and Knoll, 2002, Arnold et al., 2004, Rouxel et al., 2005, Shen et al., 2003) to have contained oxic surface and iron-rich, sulfidic deep waters, as originally proposed by Canfield (1998). Moreover, stratified water columns with euxinic bottom waters provide expanded chemical gradients that are easily sampled for simultaneous microbiological and chemical analysis. The lessons learned from MTB dynamics in small ponds could have widespread implications for larger such systems in the modern Earth environment, as well as for the ancient stratified oceans.

\subsection{The ecology of MTB in stratified marine envi- ronments}

\subsubsection{Salt marshes and salt ponds}

Magnetotactic bacteria were first reported by Richard Blakemore from sediments of Eel Pond in Woods Hole, MA (Blakemore, 1975), and since then, the salt marshes and salt ponds of New England have played a key role in our understanding of MTB ecology. A wide variety of MTB are abundant in salt marshes, particularly in the surface layers of sulfidic sediments where they co-occur with photo- and chemo-synthetic sulfide oxidizing bacteria (unpublished observations). The many-celled magnetotactic prokaryote (MMP), a greigite-producer, was identified as a $\delta$-proteobacterium with samples from Sippewissett salt marsh (Falmouth, MA) (DeLong et al., 1993). Large numbers of morphologically diverse, phylogenetically unidentified greigite rods were found in the Neponset, MA salt marsh (Bazylinski and Frankel, 1992, Heywood et al., 1990). The chemical gradients in salt marsh sediments are steep, however, and it is difficult to match chemistry and microbiology on such small scales. 
Glacially formed kettle ponds and basins such as Salt Pond and Siders Pond (Falmouth, MA) and the Lower Basin of the Pettaquamscutt River (Narragansett, RI) develop seasonal or permanent chemical gradients between oxic surface waters and euxinic bottom waters, due to a combination of restricted water exchange, thermal heating of surface waters, and high organic matter input. The chemical and biological gradients in salt ponds are expanded versions of the surface layers of salt marsh sediments. They are compact, easily sampled analogues of large stratified basins like the Black Sea, and are the only natural environments where the distribution of MTB has been studied with respect to chemical gradients (Bazylinski et al., 1995, Simmons et al., 2006a, 2004, Stolz, 1992).

Microcosms have been used to examine the distribution of freshwater MTB with respect to chemical gradients (Flies et al., 2005a,b). In these studies, sediments from various nutrient-rich freshwater environments were incubated at room temperature in bottles or small aquaria (0.1-5 L). MTB were sampled and counted in conjunction with detailed measurement of several chemical parameters. MTB were most abundant in suboxic conditions immediately below the oxic-anoxic transition zone (about $1 \%$ of total cell numbers), consistent with MTB distributions in stratified marine environments (Simmons et al., 2006a, 2004). The main drawback of MTB microcosms is that ecological succession in such a restricted environment inevitably leads to the dominance of one organism (typically a magnetite-producing coccus), eliminating much of the natural diversity. Additionally, sulfide tends to accumulate to high levels in marine microcosms, poisoning some sulfide-sensitive MTB (unpublished data). Microcosms provide valuable information due to the high resolution of sampling possible, but cannot replace detailed studies of natural MTB communities.

A stylized chemical profile for a stratified marine basin is shown in Figure 6-1, based on measurements in Salt Pond, MA (Simmons et al., 2006a, 2004). Oxygen declines gradually as depth increases, due to aerobic heterotrophic consumption of organic matter. A chemocline of varying width develops where oxygen reaches zero, produced by the continuously diffusing supply of sulfide generated by sulfate reducing bacteria in anaerobic bottom waters. Intermediate sulfur compounds $\left(\mathrm{S}^{0}\right.$, thiosulfate, 
and polysulfides) are often often found at the upper boundary of the sulfide zone (Jorgensen et al., 1991, Jørgensen et al., 1979, Ramsing et al., 1996). A peak in dissolved $\mathrm{Fe}(\mathrm{II})$ is present at the base of the chemocline, where sulfide concentrations are insufficient to sequester it as solid Fe-sulfides. A peak of particulate Fe is often found immediately above the chemocline, due to the upward flux of Fe(II) into oxygenated waters (Murray et al., 1995). The presence of oxidants and reductants at the chemocline, as well as a physical density gradient between warm surface waters and cool bottom waters, results in elevated bacterial counts and dense plates of anoxic

phototrophs where light is available (e.g. Tonolla et al. (2000)). MTB and magnetic protists (Bazylinski et al., 2000) are most abundant within and below the chemocline (Bazylinski et al., 1995, Simmons et al., 2004).

\subsubsection{Methods for studying MTB population dynamics}

Microscopic observations of MTB in the environment generally show a high morphological diversity (Bazylinski et al., 1995, Kim et al., 2005, Stolz, 1992), particularly of greigite-producing MTB, that as yet is not completely accounted for in studies of the diversity of their 16s ribosomal RNA genes. Most published MTB sequences are from magnetite-producing freshwater cocci in the $\alpha$-Proteobacteria (Spring and Bazylinski, 2000). Only two known greigite-producing MTB have been phylogenetically identified to the species level: the many-celled magnetotactic prokaryote (MMP) in the $\delta$-Proteobacteria (DeLong et al., 1993) and a large rod in the $\gamma$-Proteobacteria (Simmons et al., 2006a). The overall lack of phylogenetic knowledge hinders the development of molecular probes that are required for accurate enumeration for different species of MTB in the environment, and consequently, a better understanding of the population dynamics of MTB communities. Here we briefly review previous work on the molecular identification of MTB, current methods that can be applied to newly discovered MTB, and their application to enumerating MTB in the environment.

Most previous observations of uncultivated MTB have been based on light microscopy. It is straightforward to collect sediments or waters known to contain MTB, place a drop of water on a microscope coverslip, put a bar magnet next to the drop, 
and observe MTB accumulating on the north or south side of the drop. For inverted microscopes, the drop can be viewed directly; for upright microscopes, the widely used "hanging drop" method is necessary. In this method, a small rubber O-ring is placed on a coverslip and a drop of water put inside. The O-ring is covered with an additional coverslip and the sandwich is gently inverted. The disadvantage of direct observation for quantitative cell counts is that it relies on cells being abundant enough in the natural sample to observe without prior magnetic enrichment. In our experience, natural waters often contain low abundances of MTB, which can make accurate direct counts difficult. Past direct counts in the literature also did not take into account the presence of MTB with south polarity in the Northern Hemisphere (Simmons et al., 2006b), as it was assumed that all Northern Hemisphere MTB possessed north polarity. The degree of undercount depends on the environment; in our recent experience, the majority of marine MTB usually appear to show north polarity, but we have observed up to $100 \%$ south polarity in natural samples (Simmons et al., 2006b). MTB with especially slow or axial swimming behavior that do not accumulate rapidly at a drop edge can also be undercounted.

Molecular identification methods make no prior assumptions about the abundance or swimming behavior of MTB. Full-cycle 16s ribosomal RNA analysis, a widely used technique in microbial ecology for the identification and quantification of microorganisms (reviewed by Amann and Ludwig (2000)), can easily be applied to MTB. This method requires separation of MTB from the bulk matrix, PCR and sequencing of their 16s ribosomal DNA genes, design of oligonucleotide probes based on those sequences, and subsequent verification of probes on environmental samples. Once a probe is verified to correspond to a particular species of MTB, it can then be applied to water column or sediment samples to count cells of that species. There are multiple methods available for physically isolating MTB from other microbes. These include the classic "racetrack" technique (Wolfe et al., 1987), in which a glass Pasteur pipette is flame-sealed at the tip and a sterile cotton plug is placed at the base of the wide end. Sterile, chemically reduced medium or environmental water is injected through the plug into the tip, while water containing MTB is placed in the wide end. A 
magnet is placed near the tip, and over a short period (10-30 min) MTB migrate through the cotton plug into the tip, which can be broken off to collect cells. A dissecting scope can be used to observe cells accumulating in a black pellet at the tip. It is recommended not to incubate the racetrack for excessive periods, as other small, fast-swimming non-magnetotactic bacteria can swim through the cotton plug. Flies et al. (2005a) described a novel racetrack-like method for MTB isolation using a separation chamber constructed on a microscope slide with cellulose strips separating slurry containing MTB from sterile water under a coverslip. As in the large-scale racetrack, application of a magnetic field causes MTB to swim out of the slurry into sterile water. Using an inverted microscope, it is also possible to directly isolate particular morphotypes of MTB using a small drop of water placed on a microscope slide in conjunction with a small bar magnet. MTB accumulating on either side of the drop can be gently removed with a small-volume (5-10 $\mu \mathrm{l})$ glass capillary pipettor (Simmons et al., 2004). This method has the advantage that particular morphotypes of MTB can be observed microscopically prior to isolation, and samples collected in this fashion can be used directly for PCR or fixed on slides for in situ hybridization. Flow cytometry has also been used on chemically fixed samples containing MTB to separate them based on size and magnetosome content (Spring et al., 1993, Wallner et al., 1997).

Once samples are isolated, they can be used directly in PCR with universal bacterial primers without further DNA extraction. A subsample of cells should also be preserved for in situ hybridization (ISH) by fixation with 2-4\% paraformaldehyde. Because often only small numbers of MTB are available, it is best to immobilize live cells directly on a gelatin- or agarose-spotted welled slide, followed by immersion of the slide in paraformaldehyde and subsequent washing (see Simmons et al. (2006b) for details). In the ideal case, sequencing of the PCR product reveals one or two clusters of closely related sequences that can be used for probe design (as in Simmons et al. (2006a)). If a wide variety of unrelated sequences are obtained, it is better (and less expensive) to optimize the physical isolation step and repeat PCR rather than designing multiple probes. Alternatively, denaturing gradient gel electrophore- 
sis (DGGE) can be used prior to sequencing to identify the most abundant sequence. Flies et al. (2005a) used this method, followed by gel extraction and sequencing, to identify a freshwater coccus in MTB microcosms. The drawbacks of DGGE are that it is primarily used with relatively short amplicons (Muyzer et al., 1993), limiting the amount of available phylogenetic information, and requires a high abundance of the target population.

Once sequences are obtained, tools in the free software program ARB (Ludwig et al., 2004) are useful for sequence alignment, tree-building, and probe design. A variety of detection methods can be used with labeled oligonucleotide probes, with the goal of connecting a particular sequence to a particular morphotype of MTB. Probes should be tested on a suite of positive and negative control cells, either from cultures or manufactured using the clone-FISH method (Schramm et al., 2002). The most common technique is direct labeling of a probe with a fluorescent dye, usually fluorescein or Cy3. Spring et al. (1993) used flow cytometry, PCR, sequencing, and detection with this method to identify and enumerate cells of "Magnetobacterium bavaricum" in eutrophic freshwater sediment. Spring et al. (1992, 1994) also used fluorescently labeled probes to identify uncultivated freshwater magnetotactic cocci. Secondary detection methods such as catalyzed reporter deposition- in situ hybridization (CARD-FISH; Pernthaler et al. (2002)) and gold-antibody conjugation can be used to increase the sensitivity of ISH. We used CARD-FISH with fluorescent tyramides to identify two uncultivated marine MTB (Simmons et al., 2006a,b), based on morphology and relative abundance in fixed enriched samples (Fig. 6-2).

The gold-labeling method has the advantage of combining TEM visualization with phylogenetic identification. Spring et al. (1998) designed polyribonucleotide probes labeled with fluorescein or dioxygenin to target MTB with unusually large magnetosomes. Anti-FITC and anti-dioxygenin antibodies labeled with nanometer-size gold particles visible in TEM were applied to thin sections of resin-embedded cells. This is probably the only method that can definitively connect a particular phylogenetic probes with cells that are unquestionably magnetotactic, but it is technically challenging and time-consuming. It may be sufficient in many cases to apply fluorescent 
probes to highly enriched samples of a particular morphotype and make arguments based on the relative abundance of probe-positive cells in enriched and non-enriched samples, as well as any unique morphological characteristics.

Once the phylogenetic identity of cells is known, FISH probes can be used to count cells in the environment. Using FISH probes, Spring et al. (1993) found that "Magnetobacterium bavaricum" occurred in the microaerobic zone of freshwater sediments at $7 \times 10^{5}$ cells $\mathrm{cm}^{3}$ and constituted approximately $30 \%$ of the microbial biovolume in that layer. FISH is not necessarily the best technique for counting extremely lowabundance microbes in the environment, however, as it requires a minimum number of cells per filter or slide and is time-consuming to apply to multiple species in multiple samples. Quantitative PCR (qPCR) is a more sensitive, high-throughput method to count multiple species in a microbial community over a time series. Species-specific primers are designed to amplify short segments of the 16s rRNA gene, and amplification is quantitatively tracked by the incorporation of a DNA-binding dye (SybrGreen) or a fluorescently labeled probe (TaqMan) (see Nolan (2004) for an introduction). The SybrGreen method is widely used in marine microbial ecology. We have developed a SybrGreen assay for several species of MTB in Salt Pond (Simmons et al., 2006a), and strongly recommend qPCR as a method for describing MTB communities.

Key genes involved in magnetosome biomineralization (Komeili et al., 2005, Scheffel et al., 2005, Schüler, 2004) are also potential targets for quantitative PCR to enumerate MTB in the environment. At present, this is limited by the very few sequences of such genes available, all of them from magnetite-producers in the $\alpha$-Proteobacteria, and many with no experimentally determined function. Degenerate primers designed from the amino acid sequences of proteins identified as biomineralization-related (Grünberg et al., 2001) were not successful in amplifying potential biomineralization genes from purified DNA of the greigite-producing many-celled magnetotactic prokaryote (Simmons and Edwards, unpublished data), suggesting significant differences between genes responsible for magnetite and greigite biomineralization. Much more work is needed to determine what, if any, relationship exists between biomineralization pathways in magnetite-producers and greigite-producers before functional 
genes can be used as molecular probes for MTB in the environment.

\subsubsection{Layered populations of MTB}

Most MTB are gradient organisms, meaning both that they derive energy for growth from the proximity of reductants and oxidants at a chemical interface, and occur in thin layers at particular locations relative to this interface. We frequently observe blooms of different species of MTB in Salt Pond as the chemocline expands during summer stratification, implying the transient presence of optimal conditions for their growth. It is often possible to infer possible metabolic pathways based on the depth profile of the organism with respect to water chemistry, particularly reduced sulfur and iron compounds. Qualitative observations in the Pettaquamscutt (Sieburth, unpublished; cited by Stolz (1992)) and stratified Lake Ely (Kim et al., 2005) both showed a transition in MTB morphotypes across the redoxcline. Bazylinski et al. (1995) showed that this transition corresponds to a boundary between magnetite and greigite producing MTB, with magnetite-producers occurring higher in the water column than greigite-producers. A similar transition occurs in Salt Pond (Simmons et al., 2006a, 2004) and presumably in other stratified marine systems (Fig. 6-1). An organism capable of co-precipitating magnetite and greigite was found in high numbers in the Pettaquamscutt (Bazylinski et al., 1993), but due to the lack of phylogenetic identification we do not know if it occurs elsewhere. Thus far, there have been no other reports of simultaneous magnetite and greigite precipitation in a single bacterium.

Most observations of MTB in stratified systems have been qualitative. In an attempt to understand the quantitative contributions of MTB to iron and sulfur cycling, we developed and applied a quantitative PCR assay for four major groups of MTB in Salt Pond (Simmons et al., 2006a) (see below for description of methods). Each group was previously known to produce magnetite or greigite. We tracked population densities and distributions across the chemocline in Salt Pond during summer

2003 (Simmons et al., 2006a). The results broadly confirmed previous qualitative observations (Fig. 6-1). Magnetite-producing MTB are most abundant at the the 
top of the chemocline. The dominant magnetite-producers in Salt Pond and the Pettaquamscutt are uncultivated cocci closely related to the isolate MC-1, a microaerophilic sulfide-oxidizer with the capacity for autotrophy (Williams et al., 2006). They peaked directly above the peak in ferrous iron, a typical distributional pattern for sulfide-oxidizers. We have observed $10^{5}$ cocci $\mathrm{ml}^{-1}$ in the Pettaquamscutt (unpublished data) and $10^{3}$ cocci $\mathrm{ml}^{-1}$ in Salt Pond (Simmons et al., 2006a). Smaller populations of magnetite-producing vibrios have been observed but not counted at similar depths in the Pettaquamscutt (Stolz, 1992), and occasionally in Salt Pond.

We discovered, identified, and quantified a new MTB with a unique barbell-shaped morphology and unknown mineral content in Salt Pond (Fig. 6-2). This organism is the first known MTB to exhibit south polarity (Simmons et al., 2006b), though the significance of this behavior, if any, is not known for its ecological niche. It appeared in higher numbers than all other MTB groups and in the late season comprised 2$10 \%$ of total eubacteria (Simmons et al., 2006a). Cell counts of the barbell varied inversely with that of the magnetite-producing cocci, and it typically occurred slightly lower in the water column. The distributional patterns of the barbell, along with the metabolic capabilities of co-existing species, suggest that the barbell is either a sulfate reducer with a low tolerance for sulfide or is capable of growth on intermediate sulfur compounds.

Known greigite-producing MTB tended to occur at lower cell densities than the magnetite-producers, though the reasons are unknown. None of these organisms have yet been cultivated in the laboratory. The many-celled magnetotactic prokaryote (MMP) typically occurred at around 500 cells $\mathrm{ml}^{-1}$ as determined by qPCR in 2003 (Simmons et al., 2006a), but we have observed higher abundances during blooms in other years. Its depth distribution was not as well-defined with qPCR as the other groups due to a higher detection limit with the MMP primer set, which was necessary due to the high diversity within this group (Simmons and Edwards, 2006). Interestingly, the MMP comprised $1.9 \pm 1.4 \%$ of all bacteria in Salt Pond sediments during early stratification in June, suggesting that MTB survive the oxic mixed water column during winter by retreating to the sediments. A large greigite-producing 
rod distantly related to Thiomicrospira crunogena is found from the base of the chemocline into the hypolimnion, where sulfide concentrations do not change much during seasonal stratification (Simmons et al., 2006a). The lack of bloom dynamics as revealed by qPCR and numerous qualitative observations and the low cell abundances (100 cells $\mathrm{ml}^{-1}$ on average) suggest a slow growth rate. Its distribution also indicates that it is not a gradient organism like the other three groups of MTB described here. Higher concentrations of unidentified large rods $\left(10^{5}\right.$ cells $\left.\mathrm{ml}^{-1}\right)$ were observed in sulfidic waters of the Pettaquamscutt (Stolz, 1992), suggesting that greigite producers can occasionally reach higher concentrations.

The phylogenetic diversity of the greigite producers has barely been tapped, and our observations are almost certainly an underestimate of their total concentration. Further work is needed to develop suites of $\mathrm{qPCR}$ primers for more groups of magnetite- and greigite-producers to achieve more accurate counts of their true abundance and distribution.

\subsubsection{Protist grazing of MTB}

Grazing of bacteria by heterotrophic nanoflagellates (HNF) and ciliates can be an important regulator of bacterial populations in aquatic environments, although this coupling is less strong under eutrophic conditions (Pernthaler, 2005). Abundances of $\mathrm{HNF}$ and bacteria show typical predator/prey dynamics in experimental microcosms, with maximum populations of HNF appearing shortly after maximum populations of bacteria. These dynamics also appear to be applicable to blooms of individual species in natural waters (Pernthaler, 2005). We and others (Bazylinski et al., 2000) have observed magnetically responsive protists in Salt Pond on numerous occasions (Fig. 6-3). These consist of flagellates, biflagellates, dinoflagellates, and ciliates (Bazylinski et al., 2000). TEM analysis showed that the protist cells contained magnetosomes with morphologies and dimensions identical to those of magnetite-producing MTB (Bazylinski et al., 2000), suggesting that they accumulate within protists as a result of consumption and digestion of MTB. The magnetosomes are also occasionally visible on a light microscope (Fig. 6-3). 
The magnetically responsive protists appear to be most abundant in the early and late season of stratification in Salt Pond, when the chemocline narrows and MTB are concentrated within a smaller volume. We have observed up to $2.9 \pm 0.59 \times 10^{3}$ magnetotactic protists $\mathrm{ml}^{-1}$ of diverse morphologies in the chemocline of Salt Pond during late September (unpublished data). About half of these showed north polarity and the other half south polarity. They exhibited a slow looping swimming motion near the drop edge, unlike the swimming behavior of individual MTB.

The possible correlation between MTB blooms and protist abundance suggests that protists could play a role in mediating the flux of magnetosomes out of the chemocline. Protists could increase Fe flux in three ways: by packaging large quantities of magnetosomes into a single cell, which sinks faster than individual magnetosomes by Stokes' law, consuming MTB and subsequently egesting magnetosomes, and stimulating the growth of MTB. The observations of Bazylinski et al. (2000) show that protists can accumulate large numbers of magnetosomes. During blooms of protists, we have observed that direct feeding on MTB and subsequent egestion of magnetosomes appears qualitatively to be an important mechanism. This behavior is consistent with experiments on cultivated protists, which have shown that different species egest non-optimal food particles with a passage time ranging from a few seconds when prey abundance is high to several minutes when prey abundance is low (Boenigk et al., 2001). If magnetosome egestion rates are higher during blooms of MTB, protist grazing could be an important driver of Fe export from the system.

These possible connections between protists, MTB, and Fe flux are poorly understood. Coupled measurements of protist and MTB abundance in the environment are needed to determine the degree to which MTB populations are regulated by grazing. Culture-based experiments are needed to indicate whether grazing stimulates MTB population growth, the rates of MTB consumption, as well as whether protists mostly internalize or expel magnetosomes from digested MTB. 


\subsection{Thermodynamic constraints on MTB}

A consideration of the energetics of intracellular mineral synthesis by MTB can inform ecological observations. Our chemical data from Salt Pond, collected in conjunction with observations of MTB, provides a basis for some simple thermodynamic calculations on the energetics of magnetotaxis. These calculations can help elucidate the observed layering of magnetite- and greigite-producers and whether MTB can derive sufficient energy from magnetite or greigite synthesis to meet their metabolic requirements. Magnetite has been proposed to serve as an intracellular electrochemical "battery" powered by MTB cycling across the redoxcline (Kopp et al., 2004, Vali and Kirschvink, 1990). We consider the energy available from this mechanism for MTB observed in Salt Pond.

\subsubsection{Thermodynamics of mineral synthesis helps regulate MTB distribution}

The layering of magnetite-producing MTB higher in the chemocline than greigiteproducing MTB (Fig. 6-1) suggests an external control on their distribution. We hypothesized that the presence of magnetite- or greigite-producers is strongly influenced by the thermodynamic stability of their intracellular minerals in a given chemical environment and conducted a preliminary test of this idea by a comparison of thermodynamic calculations and MTB abundance in Salt Pond. Data were collected in the stratified water column of Salt Pond on 11 August 2004, when chemical and physical conditions were characteristic of mid-summer stratification. Magnetite was the most oversaturated metastable mineral phase at the top of the chemocline (Canovas, 2006), where sulfide was not detectable. The corresponding stable phase is hematite $\left(\mathrm{Fe}_{2} \mathrm{O}_{3}\right)$. Magnetite-producing cocci were the most abundant MTB at $1.4 \pm 0.24 \times 10^{4}$ cells $\mathrm{ml}^{-1}$, while greigite-producing MMP were only present at about 100 cells $\mathrm{ml}^{-1}$. Just $15 \mathrm{~cm}$ deeper in the water column, greigite was the most thermodynamically stable intermediate mineral phase due to the abrupt appearance of dissolved sulfide (Canovas, 2006). Pyrite is the corresponding stable mineral phase. 
The abundance of greigite-producing MMP rose to $8.7 \pm 0.71 \times 10^{3}$ aggregates $\mathrm{ml}^{-1}$, while the abundance of the cocci fell an order of magnitude to $2.5 \pm 0.42 \times 10^{3}$ cells $\mathrm{ml}^{-1}$.

At this location in the top of the sulfide zone, pyrite formation is favored by the simultaneous presence of reduced sulfur species and a weak oxidant such as $\mathrm{S}^{0}$, polysulfides, trace dissolved oxygen, $\mathrm{Fe}^{3+}$, or organics (Wilkin and Barnes, 1997b). Most pyrite formation in stratified euxinic water columns occurs in this narrow zone directly below the oxic-anoxic transition (Lyons, 1997, Wilkin and Barnes, 1997b), while pyrite is generally supersaturated in deeper, more sulfidic waters. The very low abundance of greigite-producing MTB in these highly sulfidic regions (Simmons et al., 2006a) suggests that conditions in the top of the sulfide zone are more favorable for their growth. Further determinations of cell abundances, chemical measurements, and thermodynamic modeling are required to substantiate these initial observations, which suggest that MTB generally seek to minimize the redox differential between their intracellular minerals and the external environment.

\subsubsection{The energetic yield of mineral synthesis}

Blakemore (1982) calculated that the magnetite synthesis reaction

$$
3 \mathrm{Fe}^{2+}+0.5 \mathrm{O}_{2}+3 \mathrm{H}_{2} \mathrm{O} \quad \rightarrow \quad \mathrm{Fe}_{3} \mathrm{O}_{4}+6 \mathrm{H}^{+}
$$

is energetically favorable, with a $\Delta \mathrm{G}_{\text {reaction }}$ of $-0.85 \mathrm{~kJ}$ per gram of magnetite produced under reactant concentrations which maximized the growth of Aquaspirillum magnetotacticum (now called Magnetospirillum magnetotacticum). He then estimated that this reaction could only account for less than $1 \%$ of the observed growth yield. This relatively simple thermodynamic calculation showed that the amount of energy produced by one possible reaction pathway for magnetite synthesis was insufficient for biomass synthesis by two orders of magnitude. Since Blakemore's calculation was based on growth yields in culture, however, its applicability to MTB in the environment is not immediately apparent. 
We used concomitant estimates of MTB density, dissolved iron, and oxygen concentrations in Salt Pond collected over three summers (Simmons et al., 2006a, 2004), as well as newer thermodynamic data (Robie and Hemmingway, 1995), to calculate the $\Delta \mathrm{G}$ for magnetite synthesis in the environment. Using the same equation as above, the maximum $\Delta \mathrm{G}$ we observed at depths where magnetite-producing MTB were observed was $-0.17 \mathrm{~kJ}$ per gram of magnetite. For comparison, the iron and oxygen concentrations used by Blakemore give a $\Delta \mathrm{G}$ of $-0.20 \mathrm{~kJ}_{\text {gram }}{ }^{-1}$ under temperatures typical of Salt Pond. Magnetite synthesis in the environment is less energetically favorable than under $M$. magnetotacticum culture conditions, primarily due to about ten-fold lower concentrations of dissolved iron.

Using the concept of Gibbs energy dissipation (Heijnen, 1993), it is possible to calculate the amount of biomass that could theoretically be produced from the energetic yield of magnetite synthesis. Approximately $2900 \mathrm{~kJ}$ are required to produce one mole of biomass carbon for iron-oxidizing micro-organisms (Heijnen, 1993). Aquatic bacteria contain about 5-20 fg C per cell (Whitman et al., 1998), or $1.7 \times 10^{-15} \mathrm{~mol}$ $\mathrm{C}$ per cell at the upper end of the range. It therefore requires $4.8 \times 10^{-12} \mathrm{~kJ}$ to manufacture the carbon biomass of one cell using ferrous iron oxidation. Magnetotactic bacteria contain $10^{-13}$ to $10^{-14} \mathrm{~g}$ of Fe per cell sequestered in magnetite (Chang et al., 1987, Simmons et al., 2006a, Suzuki et al., 2006). Multiplied by a $\Delta \mathrm{G}_{\text {reaction }}$ of $-0.2 \mathrm{~kJ}$ per gram of magnetite, the value for optimal growth conditions for MTB, the synthesis of this amount of magnetite yields from $2 \times 10^{-14}$ to $2 \times 10^{-15} \mathrm{~kJ}$. These values are two to three orders of magnitude lower than the amount of energy required for biosynthesis of a single cell. From these simple calculations, it is obvious that magnetite synthesis cannot provide enough energy for growth - the same conclusion reached by Blakemore in his culture experiments.

Inorganic low temperature greigite $\left(\mathrm{Fe}_{3} \mathrm{~S}_{4}\right)$ synthesis proceeds through the solid state conversion of mackinawite (FeS) to greigite (and eventually pyrite), via loss of $\mathrm{Fe}^{2+}$ from the crystal structure (Wilkin and Barnes, 1996). The presence of oxidants is required, either sulfur species of intermediate oxidation state (Benning et al., 2000) or other non-sulfur oxidants such as $\mathrm{Fe}^{3+}$ or bicarbonate (Wilkin and Barnes, 1996). 
Greigite formation by MTB appears to follow this pathway (Pósfai et al., 1998). The $\mathrm{Fe}^{2+}$ lost from mackinawite in this process is oxidized to form amorphous Feoxyhydroxides, which have been observed to surround greigite magnetosomes in one study (Farina et al., 1990) but not in another (Pósfai et al., 1998). Wilkin and Barnes (1997a) give a balanced equation for greigite formation from mackinawite via this "iron loss" pathway:

$$
4 \mathrm{FeS}_{(s)}+0.5 \mathrm{O}_{2}+2 \mathrm{H}^{+} \rightarrow \mathrm{Fe}_{3} \mathrm{~S}_{4(s)}+\mathrm{Fe}^{2+}+\mathrm{H}_{2} \mathrm{O}
$$

other oxidants are likely substituted for oxygen under the mildly reducing conditions where greigite-producing MTB are typically found. $\Delta \mathrm{G}_{r}^{0}$ for this reaction is $-130.2 \mathrm{~kJ}$ $\mathrm{mol}^{-1}$, or $0.5 \mathrm{~kJ}$ per gram of greigite, with $\Delta \mathrm{G}_{f}^{0}$ values for greigite and mackinawite from Benning et al. (2000) and all other values from Stumm and Morgan (1996). As with magnetite formation, the energy yielded by greigite synthesis appears insufficient for biomass production.

\subsubsection{The magnetite/maghemite battery hypothesis}

Magnetite in MTB has been proposed to serve as an "electrochemical storage battery" (Kopp et al., 2004, Vali and Kirschvink, 1990): cells migrating across a redoxcline could access additional energy for growth by oxidizing magnetite to maghemite in oxidizing conditions and reversing the reaction in reducing conditions. The transformation of magnetite $\left(\mathrm{Fe}^{2+} \mathrm{Fe}_{2}^{3+} \mathrm{O}_{4}\right)$ to maghemite $\left(\mathrm{Fe}_{2}^{3+} \mathrm{O}_{3}\right)$ releases an atom of ferrous iron while maintaining the same crystal structure and magnetic properties. The abiotic reaction kinetics of this transformation in aqueous solution are very slow on the time scale of a bacterium (months to years; ), so it is a good candidate for active catalysis by the cell. Kopp et al. (2004) observed that cells of Magnetospirillum magnetotacticum in the high-oxygen zone of oxygen gradient media contained more oxidized magnetosomes than cells in the reduced zone, but it is unknown whether MTB are actively mediating this process, or whether they are actually cycling back and forth across a redoxcline on relevant timescales. 
A plausible set of reactions for each "half-cell" of the battery is:

$$
\begin{gathered}
4 \mathrm{Fe}_{3} \mathrm{O}_{4(s)}+\mathrm{O}_{2(a q)} \rightarrow 6 \mathrm{Fe}_{2} \mathrm{O}_{3(s)} \Delta G^{0}=-333 \mathrm{~kJ} \mathrm{~mol}^{-1} \\
12 \mathrm{Fe}_{2} \mathrm{O}_{3(s)}+H S^{-} \rightarrow 8 \mathrm{Fe}_{3} O_{4(s)}+S O_{4}^{2-}+H^{+} \Delta G^{0}=-123.5 \mathrm{~kJ} \mathrm{~mol}^{-1}
\end{gathered}
$$

These assume complete conversion of magnetite to maghemite in the oxic zone with no formation of other ferric oxyhydroxides (Tang et al., 2003). The conversion is unlikely to be complete (Cornell and Schwertmann, 1996), in which case this equation gives a maximum value. Sulfide is the most abundant reductant in the reducing zone; at circumneutral $\mathrm{pH}$ about half is $\mathrm{HS}^{-}$and the other half $\mathrm{H}_{2} \mathrm{~S}$. It is unlikely that this reaction proceeds directly as written because the reaction of maghemite and sulfide would be likely to produce pyrite. Another possibility is that cells use $\mathrm{H}_{2}$ as a reductant for maghemite, similar to known iron reducers in the Geobacteraceae (Lovley, 2003). The $\Delta \mathrm{G}_{f}$ for maghemite is from Majzlan et al. (2003), the $\Delta \mathrm{G}_{f}$ for magnetite is from Robie and Hemmingway (1995), and all other values are from Stumm and Morgan (1996).

We calculated the expected $\Delta \mathrm{G}_{r}$ for each reaction using measured oxygen, sulfide, and $\mathrm{pH}$ values from Salt Pond during its 2003 summer stratification. The per-cell $\Delta \mathrm{G}_{r}$ available from the aerobic reaction was about $1.3 \times 10^{-14} \mathrm{~kJ}$ for oxygen concentrations typical of depths where magnetite-producers are found. The $\Delta \mathrm{G}_{r}$ available per cell for the reducing reaction (normalized to $4 \times 10^{-14} \mathrm{~g}$ magnetite/cell) was $3.9-4.2 \times 10^{-15}$ $\mathrm{kJ}$, with the smaller values corresponding to lower sulfide concentrations found at the top of the sulfide zone. Since magnetite-producing MTB are primarily located at the top of the chemocline, if they are cycling back and forth over a $10 \mathrm{~cm}$ scale they are not likely to encounter sulfide concentrations higher than $0.1 \mathrm{mM}$. The maximum total energy available from a single cycle is about $1.7 \times 10^{-14} \mathrm{~kJ}$. To produce enough energy to synthesize a cell's worth of biomass as calculated above, a magnetotactic bacterium would have to cycle through the redoxcline 282 times.

If cells were continually cycling up and down, we might expect to see a diffuse band of MTB in Salt Pond bounded by oxygen concentrations at the top and sulfide 
at the bottom. Instead, we see fairly distinct peaks in MTB abundance with a resolution of 10-15 cm (Simmons et al., 2006a). This sampling resolution is not high enough to conclusively resolve the question, however. The number of cycles required suggests that the cell might use this method for maintenance energy, but is unlikely to rely on it exclusively to fill its energy requirements. Culture-based measurements of the magnetite-producers MV-1 and MV-2 indicate that those strains primarily oxidize reduced sulfur compounds in gradient media to obtain energy for growth (Bazylinski et al., 2004). The observation that a non-magnetotactic mutant strain of MV-1 showed higher growth rates than wild-type MV-1 under Fe concentrations typical of Salt Pond (Dubbels et al., 2004) also suggests that the "battery" is not a primary energy source in the environment. Since MV-1 was grown in anaerobic conditions, however, there is the possibility that results would have differed in gradient media. The presence of greigite-producing MTB in highly sulfidic waters, away from a redox gradient, also argues against the universality of this mechanism among MTB. It seems unlikely to be a major driving force for the evolution and maintenance of magnetotaxis.

\subsection{The influence of MTB on reduced Fe cycling}

\subsubsection{The contribution of MTB to reactive Fe flux}

The abundance of MTB in chemically stratified marine environments with high concentrations of dissolved iron indicates that they could substantially contribute to the flux of reduced Fe to sediments. The presence of MTB in stratified ponds like Salt Pond suggests that they could also be present in much larger but chemically similar stratified environments, such as the Cariaco Basin and the Black Sea. Since detailed geochemical data on reduced iron fluxes is available for these environments, it is possible to constrain the total potential contribution of MTB to Fe flux with measurements from Salt Pond and the Pettaquamscutt. A fairly limited set of parameters is required: cell density, Fe content per cell, chemocline width, and population 
turnover times. The first three parameters were measured directly in Salt Pond, and can be approximated for other environments based on published data. The population turnover time of MTB is not known, but an estimate of 2 days is reasonable based on observations of marine heterotrophic bacteria (Noble and Fuhrman, 2000). With this information we can calculate the contribution of MTB to the total flux of reduced Fe out of euxinic basins $\left(\mu \mathrm{g} \mathrm{Fe} \mathrm{cm}^{-2} \mathrm{yr}^{-1}\right)$, as follows: (the depth-integrated concentration of MTB $) \times($ Fe content per cell $) \times($ chemocline width $) \times($ number of MTB populations per year).

Our counts of MTB, as well as numerous other observations, provide a bound on the abundance of MTB in stratified marine environments. The highest MTB concentrations observed in stratified marine basins are approximately $10^{5}$ cells $\mathrm{ml}^{-1}$ (Bazylinski et al., 1995, Simmons et al., 2006a). MTB in marine sediments in New England average $10^{3}-10^{4}$ cells $\mathrm{ml}^{-1}$ (Blakemore, 1982), and integration of MTB cell counts with depth in Salt Pond results in an average MTB concentration of $10^{2}-10^{4}$ cells $\mathrm{ml}^{-1}$ at and below the chemocline. Estimates for Fe content per cell are in the range of $10^{-13}$ to $10^{-14} \mathrm{~g}$ (Chang et al., 1987, Simmons et al., 2006a). It is possible to estimate this value for novel MTB by TEM analysis of magnetosome size and numbers per cell. Chemocline width is environment-dependent and simple to measure using analytical techniques for determining oxygen, sulfide, and dissolved iron.

If we estimate that MTB constitute $1 \%$ of the microbial biomass in the Black Sea chemocline, a reasonable number given their proportion of total bacteria in Salt Pond (Simmons et al., 2006a), precipitation of Fe in intracellular minerals by MTB accounts for 0.5 to $5 \%$ of the total reduced Fe flux in the deep basin. The total flux of reduced Fe in the form of Fe-sulfides to sediments of the Black Sea deep euxinic basin is $38 \pm 28 \mu \mathrm{g} \mathrm{Fe} \mathrm{cm}^{-2} \mathrm{yr}^{-1}$ (Anderson and Raiswell, 2004), almost all of which forms in a narrow zone directly below the oxic-anoxic interface (Lyons, 1997), the location where MTB would be most likely to occur. Further work is needed to determine the abundance and distribution of MTB in the Black Sea chemocline. This estimate is supported by observed concentrations of MTB (Bazylinski et al., 1995) and measured Fe-sulfide flux (Wilkin and Barnes, 1997b) in the Pettaquamscutt 
estuary. MTB constitute an estimated $1.3-13 \%$ of the total Fe-sulfide flux out of the chemocline in the Pettaqamscutt, consistent with our estimates for the Black Sea. These numbers suggest that MTB could be major unrecognized contributors to geochemically important fluxes of reduced Fe.

\subsubsection{Integrated studies}

The combination of traditional molecular microbial ecological techniques and geochemical measurements provides a powerful tool for determining the contribution of MTB to iron cycling in the environment, as well as the energetic factors dictating their distribution. We now have a fairly good understanding of the type of work necessary to fill in the many gaps in our knowledge of MTB. It is important to track the changing abundances of MTB over time in a single environment to obtain an integrated picture of population dynamics, as MTB can occur in sudden blooms and in narrow layers driven by the formation of particular favorable chemical conditions.

Ideally, the study of MTB in a novel stratified environment would proceed as follows. First, light microscopy can be used to identify the major species of MTB present. These can be isolated for molecular identification as described above, as well as placed on TEM grids for elemental analysis of their mineral contents. The goal should be to link molecular phylogenetic probes with organisms known to produce magnetite or greigite. Next, samples should be collected over a time series using a fine-scale sampler, such as the inverted cone described by (Jørgensen et al., 1979) or a multi-syringe instrument (Tonolla et al., 2000). Fine-scale chemical sampling should be conducted in conjunction with sample collection, perhaps with voltammetric microelectrodes to obtain information on intermediate sulfur species (Luther III et al., 2001). Fluorescently labeled probes or qPCR primers can be applied to the samples to count magnetite- and greigite-producing MTB. Sediment traps could be placed to obtain information on both the total flux of particulate Fe and the percentage of that comprised by magnetosomes, perhaps using the sediment-trap design recommended by Kim et al. (2005). This information can be compared with the estimated flux due to MTB obtained from cell counts and Fe content per cell. 
With sufficient observations of this type, it may be possible to develop a predictive model for the amount of magnetite and greigite deposition by MTB given certain environmental parameters. Such a model would also greatly aid in the development of magnetofossils as paleoenvironmental indicators. To date, little is known about the diversity, ecology, and geochemistry of MTB communities in the environment. The tools we have described already exist; all that is needed is their application to this fascinating group of organisms in new environments. 


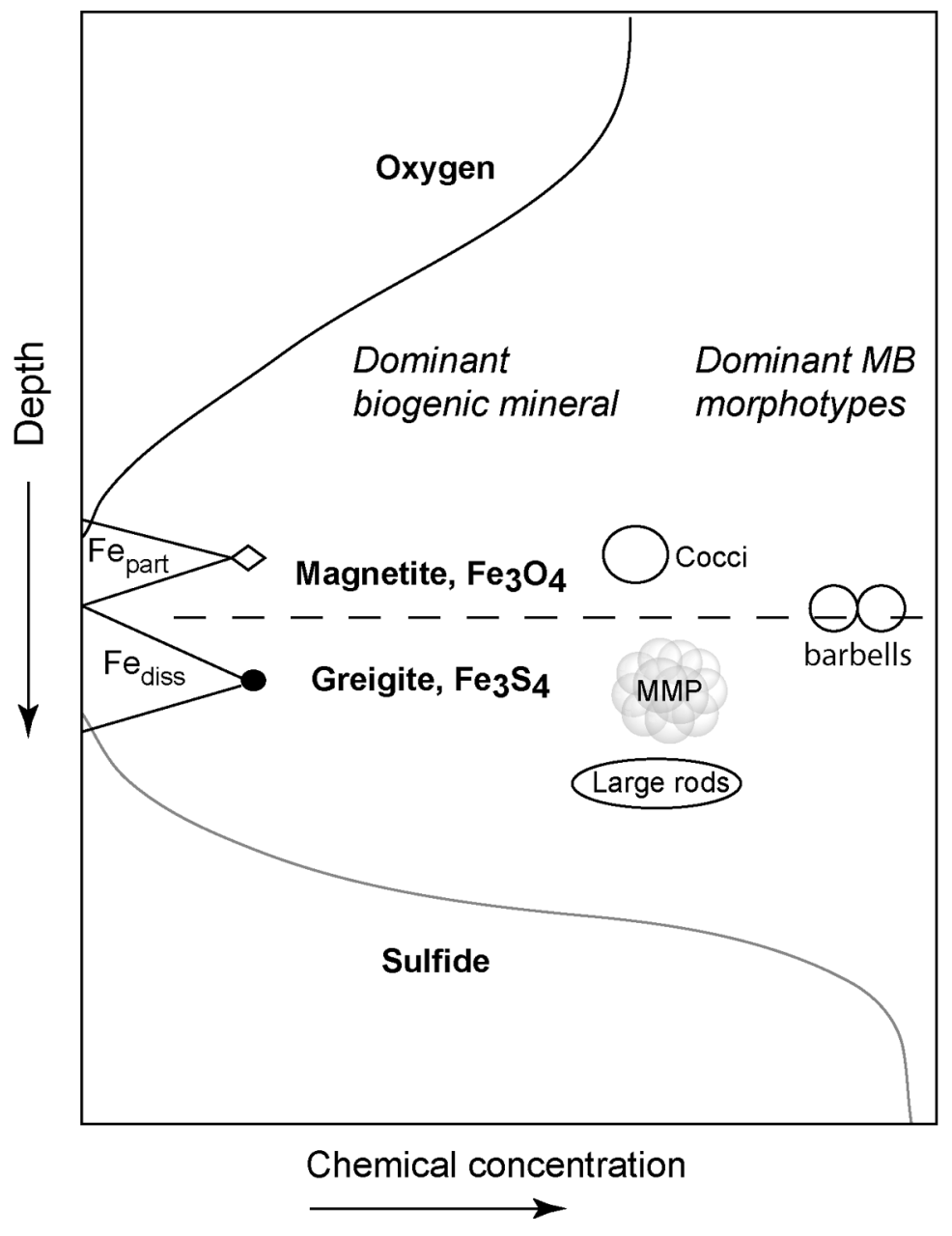

Figure 6-1: Schematic of MB distribution observed in Salt Pond, showing approximate locations of magnetite and greigite producing $\mathrm{MB}$ relative to a typical stratified water column chemical profile. $\mathrm{Fe}_{\text {part }}=$ total particulate iron and $\mathrm{Fe}_{\text {diss }}=$ total dissolved iron. Figure and legend reprinted from (Simmons et al., 2004) with slight modifications. 

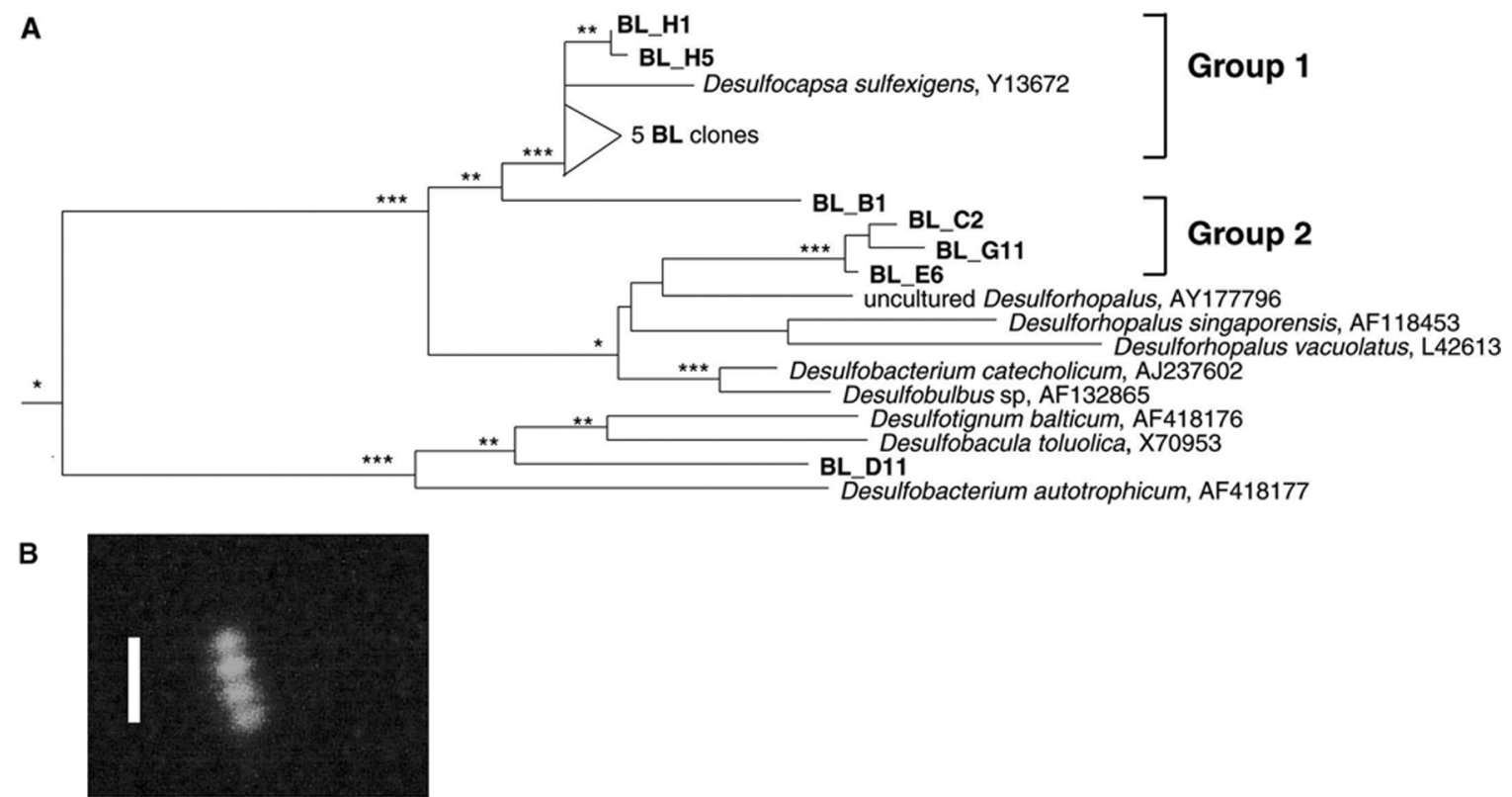

Figure 6-2: The use of $16 \mathrm{~s}$ rDNA sequencing and in situ hybridization to identify individual species of magnetotactic bacteria, in this case a barbell-shaped organism exhibiting south polarity (Simmons et al., 2006b). (a) Two clusters of $16 \mathrm{~s}$ rDNA sequences (marked with $\mathbf{B L}_{-}{ }^{*}$ ) were obtained from samples highly enriched in the barbell bacterium. The tree was constructed using maximum likelihood analysis and 1000 bootstrap replicates in Phylip. Nodes with greater than $90 \%$ bootstrap support are marked with ***, 60-90\% with **, and 50-60\% with * (b) Greyscale image of the barbell hybridizing with a HRP-labeled probe (visualized with Cy3-tyramides) targeting Group 2 sequences (related to Desulforhopalus spp.). Scale bar 5 microns. Modified from Figure 2 in (Simmons et al., 2006b) and reprinted with permission. 

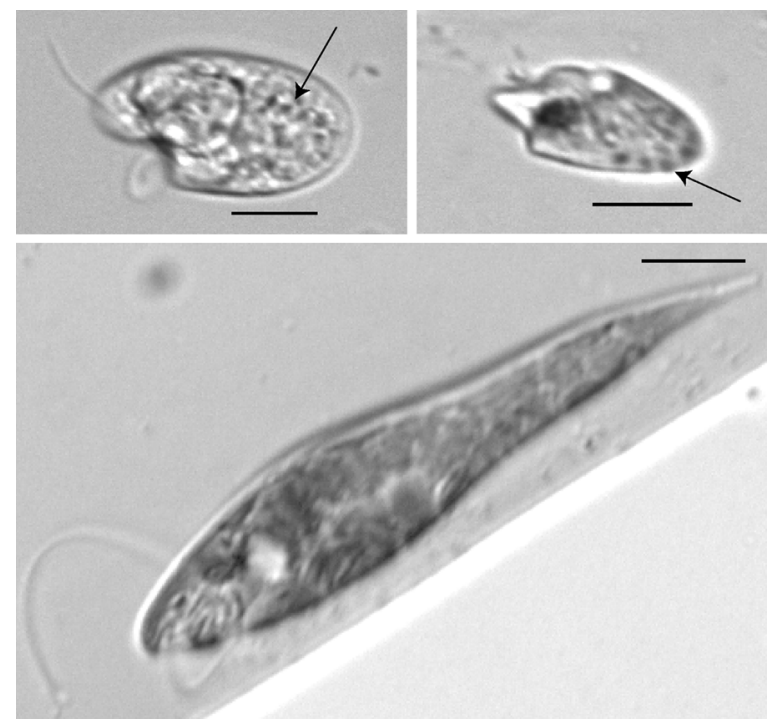

Figure 6-3: Three morphologies of magnetotactic protists observed in the chemocline of Salt Pond, September 2004. Arrows indicate possible magnetosomes. All scale bars 10 microns. 


\section{Bibliography}

Amann R, Ludwig W (2000) Ribosomal RNA-targeted nucleic acid probes for studies in microbial ecology. FEMS Microbiology Reviews 24: 555-565.

Anbar A, Knoll A (2002) Proterozoic ocean chemistry and evolution: a bioinorganic bridge? Science 297: 1137-1142.

Anderson T, Raiswell R (2004) Sources and mechanisms for the enrichment of highly reactive iron in euxinic Black Sea sediments. Am J Sci 304: 203-233.

Arnold GL, Anbar AD, Barling J, Lyons TW (2004) Molybdenum Isotope Evidence for Widespread Anoxia in Mid-Proterozoic Oceans. Science 304: 87-90.

Bazylinski DA, Dean AJ, Williams TJ, Long LK, Middleton SL, et al. (2004) Chemolithoautotrophy in the marine, magnetotactic bacterial strains MV-1 and MV-2. Archives of Microbiology 182: 373-387.

Bazylinski DA, Frankel RB (1992) Production of iron sulfide minerals by magnetotactic bacteria in sulfidic environments. In: Skinner HC, Fitzpatrick RW, editors, Biomineralization Processes, Iron, Manganese, vol. 21, pp. 147-159, Catena.

Bazylinski DA, Frankel RB, Heywood BR, Mann S, King JW, et al. (1995) Controlled biomineralization of magnetite $\left(\mathrm{Fe}_{3} \mathrm{O}_{4}\right)$ and gregite $\left(\mathrm{Fe}_{3} \mathrm{~S}_{4}\right)$ in a magnetotactic bacterium. Appl Environ Microbiol 61: 3232-3239.

Bazylinski DA, Frankel RB, Jannasch HW (1988) Anaerobic magnetite production by a marine magnetotactic bacterium. Nature 334: 518-519.

Bazylinski DA, Heywood BR, Mann S, Frankel RB (1993) $\mathrm{Fe}_{3} \mathrm{O}_{4}$ and $\mathrm{Fe}_{3} \mathrm{~S}_{4}$ in a bacterium. Nature 366: 218.

Bazylinski DA, Schlezinger DR, Howes BH, Frankel RB, Epstein SS (2000) Occurrence and distribution of diverse populations of magnetic protists in a chemically stratified coastal salt pond. Chem Geol 169: 319-328. 
Benning LG, Wilkin RT, Barnes HL (2000) Reaction pathways in the Fe-S system below 100 degrees C. Chemical Geology 167: 25-51.

Blakemore RP (1975) Magnetotactic bacteria. Science 190: 377-379.

Blakemore RP (1982) Magnetotactic bacteria. Ann Rev Microbiol 36: 217-238.

Boenigk J, Matz C, Jurgens K, Arndt H (2001) Confusing Selective Feeding with Differential Digestion in Bacterivorous Nanoflagellates. The Journal of Eukaryotic Microbiology 48: 425-432.

Canfield DE (1998) A new model for Proterozoic ocean chemistry. Nature 396: 450453.

Canfield DE, Berner R (1987) Dissolution and pyritization of magnetite in anoxic marine sediments. Geochem Cosmochim Acta 51: 645-659.

Canovas P (2006) The redox and iron-sulfide geochemistry of Salt Pond and the thermodynamic constraints on native marine magnetotactic bacteria. M.S. Thesis, Massachusetts Institute of Technology- Woods Hole Oceanographic Institution Joint Program.

Chang SB (1989) Magnetofossils, the magnetization of sediments, and the evolution of magnetite biomineralization. Ann Rev Earth Planet Sci 17: 169-195.

Chang SB, Kirschvink JL, Stolz J (1987) Biogenic magnetite as a primary remanence carrier in limestone deposits. Physics of the Earth and Planetary Interiors 46: 289303.

Cornell R, Schwertmann U (1996) The iron oxides. Weinheim: VCH.

Cox BL, Popa R, Bazylinski DA, Lanoil B, Douglas S, et al. (2002) Organization and elemental analysis of $\mathrm{P}-, \mathrm{S}-$, and Fe-rich inclusions in a population of freshwater magnetococci. Geomicrobiology Journal 19: 387-406.

DeLong EF, Frankel RB, Bazylinski DA (1993) Multiple evolutionary origins of magnetotaxis in bacteria. Science 259: 803-806. 
Dubbels BL, DiSpirito AA, Morton JD, Semrau JD, Neto JNE, et al. (2004) Evidence for a copper-dependent iron transport system in the marine, magnetotactic bacterium strain MV-1. Microbiology 150: 2931-2945.

Egli R (2004a) Characterization of individual rock magnetic components by analysis of remanence curves, 1. Unmixing natural sediments. Studia Geophysica Et Geodaetica 48: 391-446.

Egli R (2004b) Characterization of individual rock magnetic components by analysis of remanence curves. 3. Bacterial magnetite and natural processes in lakes. Physics and Chemistry of the Earth, Parts A/B/C 29: 869-884.

Farina M, Esquivel D, de Barros HL (1990) Magnetic iron-sulphur crystals from a magnetotactic microorganism. Nature 383: 256-258.

Flies CB, Jonkers HM, de Beer D, Bosselmann K, Bottcher ME, et al. (2005a) Diversity and vertical distribution of magnetotactic bacteria along chemical gradients in freshwater microcosms. FEMS Microbiology Ecology 52: 185-195.

Flies CB, Peplies J, Schüler D (2005b) Combined Approach for Characterization of Uncultivated Magnetotactic Bacteria from Various Aquatic Environments. Appl Environ Microbiol 71: 2723-2731.

Grünberg K, Wawer C, Tebo BM, Schüler D (2001) A Large Gene Cluster Encoding Several Magnetosome Proteins Is Conserved in Different Species of Magnetotactic Bacteria. Appl Environ Microbiol 67: 4573-4582.

Heijnen J (1993) In search of a thermodynamic description of biomass yields for chemotrophic growth of microorganisms. Biotechnology and Bioengineering 39: 833-858.

Heywood BR, Bazylinski DA, Garrett-Reed AJ, Mann S, Frankel RB (1990) Controlled biosynthesis of greigite $\left(\mathrm{Fe}_{3} \mathrm{~S}_{4}\right)$ in magnetotactic bacteria. Naturwissenschaften 77: 536-538. 
Jorgensen BB, Fossing H, Wirsen CO, Jannasch HW (1991) Sulfide oxidation in the Black Sea chemocline. Deep-Sea Research Part A: Oceanographic Research Papers 38: S1083-S1103.

Jørgensen BB, Kuenen JG, Cohen Y (1979) Microbial transformations of sulphur compounds in a stratified lake (Solar Lake, Sinai). Limnol Oceanogr 24: 799-822.

Kao SJ, Horng CS, Roberts AP, Liu KK (2004) Carbon-sulfur-iron relationships in sedimentary rocks from southwestern Taiwan: influence of geochemical environment on greigite and pyrrhotite formation. Chemical Geology 203: 153-168.

Kim BY, Kodama KP, Moeller RE (2005) Bacterial magnetite produced in water column dominates lake sediment mineral magnetism: Lake Ely, USA. Geophys J Int 163: 26-37.

Komeili A, Li Z, Newman DK, Jensen GJ (2005) Magnetosomes Are Cell Membrane Invaginations Organized by the Actin-Like Protein MamK. Science 311: 242-245.

Kopp RE, Nash CZ, Kirschvink JL, Leadbetter JR (2004) A possible magnetite/maghemite electrochemical battery in the magnetotactic bacteria. Eos Trans AGU 85: Fall Meet. Suppl., GP34A-06.

Lovley DR (2003) Dissimilatory Fe(III)- and Mn(IV)-reducing prokaryotes. In: Dworkin M, editor, The Prokaryotes: An Evolving Electronic Resource for the Microbiological Community, 3rd ed., New York: Springer-Verlag.

Ludwig W, Strunk O, Westram R, Richter L, Meier H, et al. (2004) ARB: a software environment for sequence data. Nucl Acids Res 32: 1363-1371.

Luther III G, Glazer B, Hohmann L, Popp J, Taillefert M, et al. (2001) Sulfur speciation monitored in situ with solid state gold amalgam voltammetric microelectrodes: polysulfides as a special case in sediments, microbial mats, and hydrothermal vent waters. J Environ Monit 3: 61-66. 
Lyons TW (1997) Sulfur isotopic trends and pathways of iron sulfide formation in upper Holocene sediments of the anoxic Black Sea. Geochem Cosmochim Acta 61: $3367-3382$.

Majzlan J, Grevel KD, Navrotsky A (2003) Thermodynamics of Fe oxides: Part II. Enthalpies of formation and relative stability of goethite (alpha-FeOOH), lepidocrocite (gamma-FeOOH), and maghemite (gamma-Fe2O3). American Mineralogist 88: 855-859.

Mann S, Sparks NHC, Board RG (1990a) Magnetotactic bacteria: Microbiology, biomineralization, paleomagnetism and biotechnology. Adv Microbial Physiol 31: 125181.

Mann S, Sparks NHC, Frankel RB, Bazylinski DA, Jannasch HW (1990b) Biomineralization of ferrimagnetic greigite $\left(\mathrm{Fe}_{3} \mathrm{~S}_{4}\right)$ and iron pyrite $\left(\mathrm{FeS}_{2}\right)$ in a magnetotactic bacterium. Nature 343: 258-261.

Murray J, Codispoti L, Friedrich G (1995) Oxidation-reduction environments: the suboxic zone in the Black Sea. In: et al Huang, C, editor, Aquatic Chemistry, vol. 244 of ACS Advances in Chemistry, pp. 157-176, American Chemical Society.

Muyzer G, Waal ED, Uitterlinden A (1993) Profiling of complex microbial populations by denaturaing gradient gel electrophoresis analysis of polymerase chain reactionamplified genes coding for 16s rRNA. Appl Env Microbiol 59: 695-700.

Noble RT, Fuhrman JA (2000) Rapid Virus Production and Removal as Measured with Fluorescently Labeled Viruses as Tracers. Appl Environ Microbiol 66: 37903797.

Nolan T (2004) Getting Started- The Basics of Setting up a qPCR Assay. In: Bustin SA, editor, A-Z of Quantitative PCR, pp. 529-543, La Jolla, CA: International University Line.

Pernthaler A, Pernthaler J, Amann R (2002) Fluorescence In Situ Hybridization 
and Catalyzed Reporter Deposition for the Identification of Marine Bacteria. Appl Environ Microbiol 68: 3094-3101.

Pernthaler J (2005) Predation on prokaryotes in the water column and its ecological implications. Nat Rev Micro 3: 537-546.

Petermann H, Bleil U (1993) Detection of live magnetotactic bacteria in deep-sea sediments. Earth Planet Sci Lett 117: 223-228.

Petersen N, von Dobeneck T (1986) Fossil bacterial magnetite in deep-sea sediments from the South Atlantic Ocean. Nature 320: 611-615.

Pósfai M, Buseck PR, Bazylinski DA, Frankel RB (1998) Reaction sequence of iron sulfide minerals in bacteria and their use as biomarkers. Science 280: 880-883.

Pósfai M, Cziner K, Marton E, Marton P, Buseck PR, et al. (2001) Crystal-size distributions and possible biogenic origin of Fe sulfides. European Journal of Mineralogy 13: 691-703.

Ramsing N, Fossing H, Ferdelman T, Andersen F, Thamdrup B (1996) Distribution of bacterial populations in a stratified fjord (Mariager Fjord, Denmark) quantified by in situ hybridization and related to chemical gradients in the water column [published erratum appears in Appl Environ Microbiol 1996 Oct;62(10):3914]. Appl Environ Microbiol 62: 1391-1404.

Roberts AP, Reynolds RL, Verosub KL, Adam DP (1996) Environmental magnetic implications of greigite $\left(\mathrm{Fe}_{3} \mathrm{~S}_{4}\right)$ formation in a 3 my lake sediment record from Butte Valley, northern California. Geophysical Research Letters 23: 2859-2862.

Robie R, Hemmingway B (1995) Thermodynamic Properties of Minerals and Related Substances at 298.15 K and 1 Bar (105 Pascals) Pressure and at Higher Temperatures. Tech. rep., US Geological Survey.

Rouxel OJ, Bekker A, Edwards KJ (2005) Iron Isotope Constraints on the Archean and Paleoproterozoic Ocean Redox State. Science 307: 1088-1091. 
Sakaguchi T, Arakaki A, Matsunaga T (2002) Desulfovibrio magneticus sp. nov., a novel sulfate-reducing bacterium that produces intracellular single-domain-sized magnetite particles. Intl J Syst Evol Microbiol 52: 215-221.

Scheffel A, Gruska M, Faivre D, Linaroudis A, Plitzko JM, et al. (2005) An acidic protein aligns magnetosomes along a filamentous structure in magnetotactic bacteria. Nature 440: 110-114.

Schramm A, Fuchs BM, Nielsen JL, Tonolla M, Stahl DA (2002) Fluorescence in situ hybridization of $16 \mathrm{~S}$ rRNA gene clones (Clone-FISH) for probe validation and screening of clone libraries. Environmental Microbiology 4: 713-720.

Schüler D (2004) Molecular analysis of a subcellular compartment: the magnetosome membrane in Magnetospirillum gryphiswaldense. Archives of Microbiology 181: 17.

Shen Y, Knoll AH, Walter MR (2003) Evidence for low sulphate and anoxia in a mid-Proterozoic marine basin. Nature 423: 632-635.

Simmons S, Bazylinski DA, Edwards KJ (2006a) Population dynamics of marine magnetotactic bacteria in a meromictic salt pond described with quantitative PCR. Submitted .

Simmons S, Edwards KJ (2006) Unexpected diversity in populations of the manycelled magnetotactic bacterium. In prep .

Simmons SL, Bazylinski DA, Edwards KJ (2006b) South-seeking magnetotactic bacteria in the Northern Hemisphere. Science 311: 371-374.

Simmons SL, Sievert SM, Frankel RB, Bazylinski DA, Edwards KJ (2004) Spatiotemporal Distribution of Marine Magnetotactic Bacteria in a Seasonally Stratified Coastal Salt Pond. Appl Environ Microbiol 70: 6230-6239.

Snowball I, Zillen L, Sandgren P (2002) Bacterial magnetite in Swedish varved lakesediments: a potential bio-marker of environmental change. Quaternary International 88: 13-19. 
Snowball IF, Sandgren P, Petterson G (1999) The mineral magnetic properties of an annually laminated Holocene lake-sediment sequence in northern Sweden. Holocene 9: $353-362$.

Spring S, Amann R, Ludwig W, Schleifer K, van Gemerden H, et al. (1993) Dominating role of an unusual magnetotactic bacterium in the microaerobic zone of a freshwater sediment. Appl Environ Microbiol 59: 2397-2403.

Spring S, Amann R, Ludwig W, Schleifer KH, Petersen N (1992) Phylogenetic diversity and identification of nonculturable magnetotactic bacteria. System Appl Microbiol 15: 116-122.

Spring S, Amann R, Ludwig W, Schleifer KH, Schüler D, et al. (1994) Phylogenetic analysis of uncultured magnetotactic bacteria from the alpha-subclass of Proteobacteria. System Appl Microbiol 17: 501-508.

Spring S, Bazylinski DA (2000) Magnetotactic Bacteria. In: Dworkin M, editor, The Prokaryotes: An Evolving Electronic Resource for the Microbiological Community, online release 3.4, Springer Verlag.

Spring S, Lins U, Amann R, Schleifer KH, Ferreira LCS, et al. (1998) Phylogenetic affiliation and ultrastructure of uncultured magnetic bacteria with unusually large magnetosomes. Archives of Microbiology 169: 136-147.

Stoltz J, Chang SBR, Kirschvink J (1986) Magnetotactic bacteria and single-domain magnetite in hemipelagic sediments. Nature 321: 849-851.

Stolz JF (1992) Magnetotactic bacteria: Biomineralization, ecology, sediment magnetism, environmental indicator. In: Skinner HC, Fitzpatrick RW, editors, Biomineralization Processes of Iron and Manganese: Modern and Ancient Environments, pp. 133-145, Cremlingen-Destedt: Catena Verlag.

Stumm W, Morgan JJ (1996) Aquatic Chemistry. 3rd ed., New York: John Wiley \& Sons. 
Suzuki T, Okamura Y, Calugay RJ, Takeyama H, Matsunaga T (2006) Global Gene Expression Analysis of Iron-Inducible Genes in Magnetospirillum magneticum AMB-1. J Bacteriol 188: 2275-2279.

Tang J, Myers M, Bosnick KA, Brus LE (2003) Magnetite $\mathrm{Fe}_{3} \mathrm{O}_{4}$ nanocrystals: Spectroscopic observation of aqueous oxidation kinetics. Journal of Physical Chemistry B 107: 7501-7506.

Tonolla M, Demarta A, Peduzzi S, Hahn D, Peduzzi R (2000) In situ analysis of sulfate-reducing bacteria related to Desulfocapsa thiozymogenes in the chemocline of meromictic Lake Cadagno (Switzerland). Appl Environ Microbiol 66: 820-824.

Vali H, Kirschvink JL (1990) Observations of magnetosome organization, surface structure, and iron biomineralization of undescribed magnetotactic bacteria: evolutionary speculations. In: Frankel RB, Blakemore RP, editors, Iron Biominerals, pp. 97-115, New York: Plenum Press.

Wallner G, Fuchs B, Spring S, Beisker W, Amann R (1997) Flow sorting of microorganisms for molecular analysis. Appl Environ Microbiol 63: 4223-4231.

Whitman WB, Coleman DC, Wiebe WJ (1998) Prokaryotes: The unseen majority. PNAS 95: 6578-6583.

Wilkin RT, Barnes HL (1996) Pyrite formation by reactions of iron monosulfides with dissolved inorganic and organic sulfur species. Geochim Cosmochim Acta 60: $4167-4179$.

Wilkin RT, Barnes HL (1997a) Formation processes of framboidal pyrite. Geochimica et Cosmochimica Acta 61: 323-339.

Wilkin RT, Barnes HL (1997b) Pyrite formation in an anoxic estuarine basin. American Journal of Science 297: 620-650.

Williams T, Zhang C, JH S, Bazylinski DA (2006) Evidence for autotrophy via the reverse tricarboxylic acid cycle in the marine magnetotactic coccus strain MC-1. Appl Environ Microbiol 72: 1322-1329. 
Wolfe R, Thauer R, Pfennig N (1987) A 'capillary racetrack' method for isolation of magnetotactic bacteria. FEMS Microbiol Ecol 45: 31-35.

Yamazaki T, Kawahata H (1998) Organic carbon flux controls the morphology of magnetofossils in marine sediments. Geology 26: 1064-1066. 


\section{Appendix A}

\section{Development of a fine-layer}

sampler and application of

\section{voltammetric microelectrodes to}

\section{MTB studies in Salt Pond}

\section{Summary of contents}

This appendix includes a proposal I submitted to the WHOI Ocean Venture Fund in January 2005 to develop a sampler for accurately sampling thin layers of stratified bacterial populations in Salt Pond, coupled with the use of voltammetric microelectrodes to describe the water chemistry. The goal of the proposal was to determine how water chemistry affects the boundary between magnetite- and greigite-producing MTB. The proposal was funded, and Craig Taylor helped me with the sampler design. It was constructed by the WHOI shop and used in Salt Pond during summer 2005. Following the proposal text, I provide an update on the outcome of the project. 


\title{
A.1 Proposal to the Ocean Venture Fund
}

\author{
Linking biomineralization and environmental redox chemistry in magne- \\ totactic bacteria: towards a predictive understanding of magnetofossils
}

\begin{abstract}
Magnetotactic bacteria (MB) are motile bacteria whose directional swimming behavior is affected by the Earth's geomagnetic field. They contain highly ordered intracellular chains of magnetic iron minerals, either magnetite (iron oxide), greigite (iron sulfide), or both. MB are ubiquitous in modern chemically stratified marine environments analogous to the ancient ocean, and their biominerals are preserved in the sedimentary rock record. Their value as paleoclimate indicators is severely constrained by the lack of information on the physical and chemical factors controlling MB populations. My initial studies have demonstrated that the abundance of magnetite- and greigite-producing MB varies systematically with the degree of water column stratification. I propose to use three local stratified marine environments with abundant $\mathrm{MB}$ as model systems to quantitatively constrain the redox chemistry regulating intracellular biomineralization.
\end{abstract}

\section{Rationale}

Magnetotactic bacteria (MB) precipitate intracellular single domain ferromagnetic iron oxide (magnetite) or iron sulfide (greigite) minerals, causing them to respond to geomagnetic fields. These bacteria are globally distributed in suboxic to anoxic freshwater (Sakaguchi et al., 2002, Spring et al., 1993, 1992) and marine (Petermann and Bleil, 1993, Stoltz et al., 1986) sediments, soils (Fassbinder et al., 1990), and stratified marine water columns (Bazylinski et al., 1995, Simmons et al., 2004). MB are typically found at or below the interface between oxic and sulfidic environments, and can reach significant population densities. We have observed $10^{4}$ to $10^{5}$ magnetotactic bacterial cells $\mathrm{ml}^{-1}$ in seasonally stratified Salt Pond (Falmouth, MA) (Simmons et al., 2004) and the permanently stratified Pettaquamscutt Estuary, RI (Simmons and Edwards, unpublished data).

The apparent ubiquity and abundance of MB in marine semi-anaerobic basins, ponds, and sediments suggests that the MB play important roles in Fe and S cycling in these environments. They accumulate high intracellular concentrations of Fe, on 
the order of picograms per cell. This translates into nanomolar to micromolar concentrations of Fe sequestered as minerals in biomass when populations reach $\sim 10^{5}$ cells $\mathrm{mL}^{-1}$. Fe and $\mathrm{S}$ cycling is also linked to the metabolism of most MB that have been characterized physiologically. All known marine magnetite-producing bacteria (MMB) are chemolithoautotrophic S-oxidizers (Casamayor et al., 2000), and many store intermediates $\left(\mathrm{S}^{0}\right)$ intracellularly for use as electron acceptors (Spring et al., 1993). Greigite-producing bacteria (GMB) are found in anoxic, sulfidic waters and marsh sediments, and some are suggested to function as sulfate reducing bacteria, but this group is poorly characterized. The role of Fe in MB metabolism, if any, is unknown.

Magnetite and greigite formed by MB ("magnetofossils") have a strong, largely unfufilled potential as paleoclimate indicators. They have characteristic morphologies distinct from inorganic minerals (Casamayor et al., 2000) and are important carriers of remanent magnetism in the sedimentary rock record (Petersen and von Dobeneck, 1986, Stolz, 1992). Magnetite magnetofossils are present in rocks as old as 700 Mya (Chang, 1989). Greigite is also abundant and well-preserved in the rock record (Kao et al., 2004, Pósfai et al., 2001, Roberts et al., 1996). Although greigite with nearly identical morphology to biogenic magnetite is present in modern reducing sediments (Demitrack, 1985), as yet the unique morphology of magnetofossil gregite has not been used to distinguish it from inorganic greigite. It is also possible to identify magnetofossil greigite using the unique size distribution of biogenic crystals (Pósfai et al., 2001).

Magnetotactic bacteria are abundant in present-day stratified environments with low or no oxygen and high concentrations of iron. The distribution of modern populations of magnetite and greigite MB is clearly related to concentrations of oxygen, iron, and sulfide (Bazylinski et al., 1995, Simmons et al., 2004), which change dramatically across marine chemoclines (O'Sullivan et al., 1997, Zopfi et al., 2001). Morphologically and phylogenetically distinct populations producing each mineral appear to prefer distinct redox conditions. Their presence in the fossil record is therefore a strong indicator of a particular redox environment existing at the time of deposition. 
Both the abundance (Snowball et al., 2002) and crystal morphology (Yamazaki and Kawahata, 1998) of magnetofossil magnetite are also linked to sedimentary organic carbon content. Modern stratified environments where MB are abundant are strong analogues for the ancient oceans, now widely thought to have contained oxic surface and iron-rich, sulfidic deep waters (Canfield et al., 1998). The key factor limiting the use of magnetofossils as reliable paleo-indicators, however, is the lack of quantitative constraints on the redox environments favoring magnetite or greigite production by MB.

I propose to determine how intracellular mineral deposition in $\mathrm{MB}$ is regulated by iron and sulfur redox chemistry, using three local stratified marine environments as model systems. My central aim is to establish a quantitative model of how redox state and iron and sulfur speciation determine the type of mineral precipitated by MB.

\section{Background}

In prior work we showed a broad correlation between the distribution of MB and total iron and sulfide concentrations in seasonally stratified Salt Pond (Simmons et al., 2004). Magnetite-producers (MMB) were found largely at the top of the chemocline and greigite-producers (GMB) were found at and below the chemocline, as well as in the sulfidic hypolimnion (Fig.A-1). The abundances of MMB and GMB were inversely related, with GMB dominating during periods of intense stratification. We used chemical data collected in the summer of 2003 (bulk Fe, sulfide, ammonium, nitrate+nitrite, phosphate) to construct preliminary $\mathrm{E}_{h} / \mathrm{pH}$ diagrams showing mineral stability fields at different points in chemocline development (Fig.A-2). These diagrams suggest that the depths at which we found MMB and GMB may correlate with stability fields of magnetite and greigite, respectively. The distribution of magnetiteand greigite-producing MB in the Pettaquamscutt Estuary, a stratified basin, showed a similar pattern to Salt Pond (Bazylinski et al., 1995).

In our work in Salt Pond, we relied on prior characterization of the mineral types in $\mathrm{MB}$ of different morphologies to define which organisms were of each type. Ad- 
ditionally, we used spectrophotometric techniques to measure bulk iron and sulfide concentrations. We were not able to determine the redox speciation of iron to high precision due to methodological issues with the ferrozine method (Viollier et al., 2000), and also did not measure other important sulfur species (elemental sulfur, thiosulfate, polysulfides) known to be important in the chemistry of oxygen-sulfide interfaces (Zopfi et al., 2001).

Elemental mapping was used in early MB studies to characterize the type of intracellular magnetic mineral present (Amann et al., 1990, Bazylinski et al., 1993, Heywood et al., 1990). Magnetotactic cocci from a freshwater pond were also shown to possess intracellular phosphorus and elemental sulfur inclusions (Cox et al., 2002). None of these studies attempted to correlate the elemental content of cell inclusions with environmental redox chemistry.

\section{Proposed Research}

\section{Hypothesis}

The type of intracellular minerals (magnetite, greigite, elemental sulfur) produced by magnetotactic bacteria varies systematically with environmental redox chemistry across the oxygen-sulfide interface. This intial hypothesis is well supported by our prior work in Salt Pond (Simmons et al., 2004).

\section{Main objective}

Determine how the elemental composition of intracellular minerals in magnetotactic bacteria is linked to environmental redox chemistry.

- Collect magnetotactic bacteria with a high resolution water sampler to be developed as part of this proposal and quantitatively analyze the elemental composition of their intracellular minerals.

- Parallel to bacterial collection, measure the depth distribution and concentration of multiple iron and sulfur redox species in three stratified marine environ- 
ments at high resolution using a recently acquired voltammetric system (Brendel and Luther III, 1995, Luther III et al., 2001).

\section{Methods}

\section{Sampling sites and water collection}

I will collect magnetotactic bacteria for elemental analysis and take electrochemical depth profiles in three stratified basins in New England during summer 2005: Salt Pond (Falmouth), Siders Pond (Falmouth), and the Pettaquamscutt Estuary (RI). I have previously collected MB in all three of these environments. Each has a distinct chemistry and morphological assemblage of MB, which should allow for greater generalization of the analysis. Salt Pond is a seasonally stratified, organic-rich pond with an extensive mid-summer chemocline and salinity values of 20-30 ppt (Simmons et al., 2004). Siders Pond is a permanently stratified brackish pond with typical salinity 7-15 ppt (Simmons, unpublished data). The Pettaquamscutt is a permanently stratified, restricted marine basin with salinity values in between Salt and Siders Ponds (Simmons, unpublished data).

I will collect water samples across the chemocline in duplicate 1 liter Nalgene bottles using a Geotech peristaltic pump and a new intake device to be constructed as part of this proposal. As magnetotactic bacterial populations are highly stratified around the chemocline, it is important to sample discrete layers of water. I will collect water at $10 \mathrm{~cm}$ intervals with a high resolution sampler to be constructed following the design of Jørgensen et al. (1979). The water layer sampled is only two to three cm

thick (Jørgensen et al., 1979). Electrodes for physical/chemical measurements will be attached to the sampler such that they measure chemical species at the same depth as the water intake.

\section{Elemental analysis of magnetotactic bacteria}

Magnetotactic bacteria are usually not abundant enough in the water column to collect for elemental analysis without additional magnetic enrichment. I will enrich 
for magnetotactic bacteria from duplicate water samples using the south pole of a laboratory bar magnet on one bottle and the north pole of a bar magnet on the other bottle. This procedure enriches for north- and south-swimming bacteria respectively. My preliminary data suggests that north- and south-swimming populations can be morphologically and phylogenetically distinct. It is of some interest to determine whether their mineral compositions are also systematically different.

Bacteria collect near the magnet and can be removed into a small tube with a glass Pasteur pipette. We have developed an enrichment procedure to further purify MB away from other iron/sulfur particles in the water column that might affect the elemental analysis. The pellet of MB is transferred to a new bottle containing seawater that has been filter sterilized and purged with $\mathrm{N}_{2}$, re-enriched with a bar magnet, and transferred to a new bottle of sterile, deoxygenated seawater. This procedure is repeated 2-4 times and does not significantly affect the survival of MB. I will verify the presence of MB in the sample and document morphology and behavior using a light microscope prior to the elemental analysis.

I will collect $\mathrm{MB}$ on carbon-coated nickel grids for transmission electron microscopy. A simple procedure is highly effective in preparing $\mathrm{MB}$ for this type of analysis (R.B. Frankel, pers. communication). The grid is placed on a piece of parafilm, which is placed on the pole of an upright bar magnet. A small drop of water containing $\mathrm{MB}$ is placed on the grid. After several minutes, MB have swum toward the magnetic pole and collected on the grid. The excess water is removed with blotting paper and the grid is air-dried. Grids will be stored under $\mathrm{N}_{2}$ prior to analysis to prevent oxidation of intracellular minerals.

I will perform the elemental analysis using the HB603 Scanning Transmission Electron Microscope in the Center for Materials Science and Engineering at MIT. I have confirmed the feasibility of this analysis with the microscope operator, Anthony Garratt-Reed. Dr. Garratt-Reed has prior experience with elemental analysis of magnetotactic bacteria using this equipment (Heywood et al., 1990) and has agreed to assist me. I will take elemental maps of $\mathrm{Fe}, \mathrm{O}$, and $\mathrm{S}$ within individual cells from each depth. It may not be necessary to acquire full maps of every cell, which 
requires 15 minutes per cell. Point analyses may be sufficient as Fe oxides, Fe sulfides, and S inclusions typically have high contrast in the image (A. Garratt-Reed, pers. communication).

\section{Electrochemistry}

Our lab has recently acquired a standard three-electrode voltammetric system with a DLK-60 potentiostat (current detection limits $100 \mathrm{nA}-10 \mathrm{~mA}$ ) for measurement of redox-active iron and sulfur species (described in (Brendel and Luther III, 1995, Glazer et al., 2002, Luther III et al., 2001)). The system can measure $\mathrm{O}_{2}, \mathrm{HS}^{-}, \mathrm{S}^{0}$, thiosulfate, polysulfides, thiols, iron sulfides, Fe(II), and Fe(III), among others, in a scan of a few milliseconds. The system is portable and suitable for use in Salt Pond. We plan to attach the electrodes to our sampling device such that we obtain chemical measurements of iron and sulfur species from the same depths as our water samples. The detection limits for each species will have to be experimentally determined, but previous work with a similar system has found detection limits of $0.2-15 \mu \mathrm{M}$ for various sulfur species (Luther III et al., 2001).

$\mathrm{E}_{h}$, depth, temperature, $\mathrm{pH}$, and salinity will also be measured with an Environmental Equipment, Inc. instrument to be obtained as part of this proposal. It is essential to measure Eh accurately to match in situ chemical conditions with theoretical Eh/pH mineral stability diagrams. Peter Canovas will construct diagrams for each sampling depth using standard thermodynamic equations and the physical/chemical data from each site, inputted into Geochemist's Workbench 4.0 (sample diagram, Fig. A-2). The high resolution electrochemical data will allow for much greater accuracy in reconstruction of the redox environment for each site.

\section{Broader Impacts}

Since magnetite and greigite produced by magnetotactic bacteria are easily distinguished from inorganic minerals, their presence in the sedimentary record indicates the past presence of MB. The current lack of knowledge about the physical/chemical 


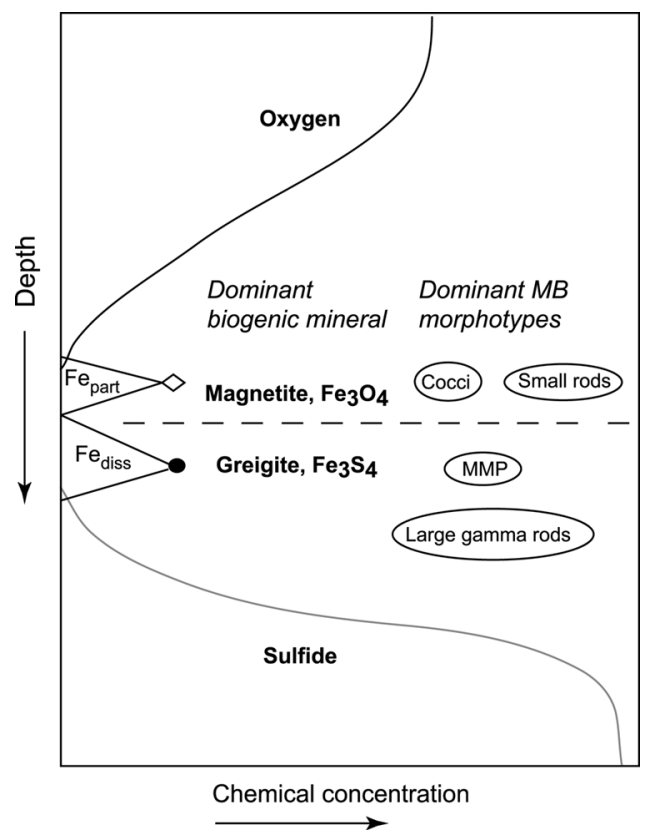

Figure A-1: Schematic of the distribution of magnetite and greigite-producing magnetotactic bacteria across the seasonal chemocline in Salt Pond. $\mathrm{Fe}_{\text {part }}$, total particulate Fe. $\mathrm{Fe}_{\text {diss }}$, total dissolved Fe. From Simmons et al. (2004).

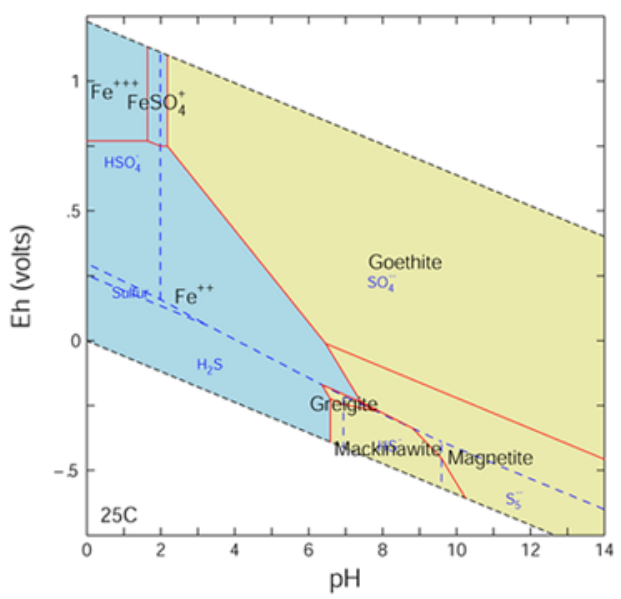

Figure A-2: Sample $\mathrm{E}_{h} / \mathrm{pH}$ diagram using chemical data collected in Salt Pond 8/15/2003. Blue dashed lines, sulfur species. Solid red lines, iron species. Note that greigite is stable at neutral $\mathrm{pH}$ and slightly negative $\mathrm{E}_{h}$, conditions typical of the Salt Pond chemocline. Hematite, pyrite, and $\mathrm{Fe}(\mathrm{HS})_{2}$ were suppressed to show the metastable species greigite and magnetite. The diagram was constructed by Peter Canovas using ACT2 in Geochemist's Workbench 4.0 software. 
factors regulating intracellular mineral precipitation by MB severely limits the use of magnetofossils as paleoclimate indicators. This study aims to supply this knowledge through elemental analysis of MB in conjunction with precise chemical measurements in present-day stratified water columns where MB are abundant. I will construct a predictive model for the type of intracellular mineral precipitation most likely for a given redox environment. I selected three stratified marine environments for this study, each with different chemistry, to enable broad generalization of the results. The presence of magnetofossils, in combination with other indicators, will then allow other researchers to make detailed inferences about the redox environment in water columns at the time of deposition.

\section{Project Timeline}

I will design and test the high resolution water sampler in spring 2005, in collaboration with Dan Rogers, who will calibrate and test our new electrochemical analysis system in Salt Pond. Sampling in Salt Pond, Siders Pond, and the Pettaquamscutt Estuary for electrochemistry and collection of magnetotactic bacteria will be carried out in mid-summer 2005. I will perform the elemental analyses of MB at MIT during the summer and fall of 2005 .

\section{Budget Justification}

The major item in the budget is the acquisition of a new Environmental Equipment Inc. electrode and datalogger (YSI 600QS, quoted at \$3720) for measurement of $\mathrm{E}_{h}$, dissolved oxygen, depth, pH, temperature, and conductivity. At present we do not have any instruments capable of measuring $\mathrm{E}_{h}, \mathrm{pH}$, and depth in situ. Accurate measurement of $\mathrm{E}_{h}$ and $\mathrm{pH}$ at the precise depth sampling occurs is crucial. Without it, I will not be able to connect results from the elemental analysis to the $\mathrm{E}_{h} / \mathrm{pH}$ mineral stability diagrams described above. The voltammetric system I propose to use for measurement of redox species is not capable of measuring $\mathrm{E}_{h}$ and $\mathrm{pH}$.

I also request funds for shop time and supplies to develop a water sampler following 
the design of Jørgensen et al. (1979). The intake design will allow me to collect thin (2$3 \mathrm{~cm}$ ) horizontal layers of water to achieve high resolution sampling of magnetotactic bacteria across a narrow oxycline. The sampler will be integrated with a Geotech peristaltic pump already in our lab. Additionally, I request funds for use of the HB603 Scanning Transmission Electron Microscope in the Center for Materials Science at MIT and associated consumables. Anthony Garratt-Reed at MIT has informed me that there is a per hour charge for training $(\$ 60 / \mathrm{hr}$ for his time) and a $\$ 30 / \mathrm{hr}$ charge for unsupervised use. As it takes 15 minutes to acquire an elemental map of one cell I have requested funds for a substantial number of hours. I will be collecting cells from 5-6 depths for each sampling date, which will require analysis of at least a hundred cells per date. I also request funds to cover page charges for a publication resulting from this work. Since I am not currently supported by any external funding source, I also request one month of salary/tuition. 


\section{A.2 Preliminary results}

The sampler described in the proposal was built by the WHOI mechanical shop in April 2005. I attached glass microelectrodes to the outside of the sampler (pictured in Fig. A-3), positioned such that the tips of the electrodes overlapped with the water intake area. These were attached to a DLK-60 potentiostat via a specialized 50 foot cable. The potentiostat was controlled in the field with a PC laptop computer. Not pictured is the YSI 600QS sonde for measurement of oxygen, temperature, salinity, depth, pH, and oxidation-reduction potential. The sonde was attached to the sampler deployment chain such that the sonde electrodes were also positioned next to the water intake. Tubing for the peristaltic pump was placed in the top of the sampler and fastened in place with water-tight silicone adhesive. The sampler was lowered over the side of a small rowboat by fastening the chain to the boat oarlock with an S-hook.

Initial trials showed problems with the glass microelectrodes, and they were replaced by homemade electrodes constructed by Dan Rogers and myself. These consisted of wire embedded in epoxy within 1/4" diameter PEEK tubing connected to external wires via underwater connectors. The system consisted of three electrodes: working, reference, and counter. The working and reference electrodes contained 1 $\mathrm{mm}$ gold wire. The larger diameter wire is preferable for detecting iron at the lower concentrations found in Salt Pond (5-10 $\mu \mathrm{M})$ (G. Druschel, pers. comm.). The wire was embedded in epoxy in each electrode and trimmed so that it was flush with the epoxy surface. Following embedding, the end of the wire in the working electrode was polished with grit sizes decreasing successively to $1 / 4 \mu \mathrm{m}$. The working electrode was then plated with $\mathrm{Hg}$ and the reference electrode was plated in a saturated $\mathrm{KCl}$ solution. The working electrode was polarized by the application of a $-9 \mathrm{~V}$ current while submerged in $1 \mathrm{M} \mathrm{NaOH}$ with the counter electrode. The counter electrode consisted of bare Pt wire. These and similar homemade electrodes were used in subsequent samplings. Greg Druschel (UVM) instructed me in electrode construction. There were many technical issues with the electrodes and we were only able to collect qual- 
ity data from two sampling dates. Concentrations of iron and sulfur species derived from one of these dates $(9 / 22 / 05)$ are described in Peter Canovas's masters' thesis (Canovas, 2006).

The YSI 600QS sonde collected high-quality data on every deployment, and I was able to use the ORP data in conjunction with observations of swimming behavior in MTB (Chapter 4). The fine-layer sampler did not achieve the desired sampling precision due to rocking motion of the boat and the lack of a stable platform for deployment. Accurate measurements with the electrodes were impeded by this motion because the electrode tips encountered thin layers with markedly different chemical characteristics. Future work with this system will require a different deployment method. The ideal solution would be construction of a stable sampling platform either in Salt Pond or the permanently stratified Pettaquamscutt Estuary, RI, which has a unique MTB community (Bazylinski et al., 1995).

I conducted some preliminary elemental analysis on MTB collected with the new sampler using the HB603 STEM at MIT, with the assistance of Dr. Anthony GarrattReed. The goal, as outlined in the proposal, was to correlate the elemental composition of MTB collected at given depths in Salt Pond with the electrode-determined chemical concentrations at those depths. Optimal use of the STEM required first mapping the location of cells on EM finder grids using the TEM at the MBL, as it is time-consuming and difficult to locate cells using the STEM interface. The cells could then be rapidly located with the STEM using these maps. It is necessary to use finder grids for collection of MTB in this analysis. A rapid elemental analysis for Fe, $\mathrm{S}, \mathrm{P}, \mathrm{O}$, and trace elements could be conducted for each cell within 5-10 minutes. Examples of the data collected using this method are shown in Figs. A-3. Because of the lack of resolution in the electrode data, I was not able to correlate these measurements with water chemistry as originally proposed.

I believe that this method could be a valuable contribution to our understanding of how environmental chemistry regulates the type of intracellular mineral precipitation by MTB. The steps required for this method to be viable are first, to establish a stable sampling platform for optimal use of the fine-layer sampler, and second, to 
optimize use of the voltammetric microelectrodes. The elemental analysis of MTB on the STEM is time-consuming, but there are no technical obstacles. 

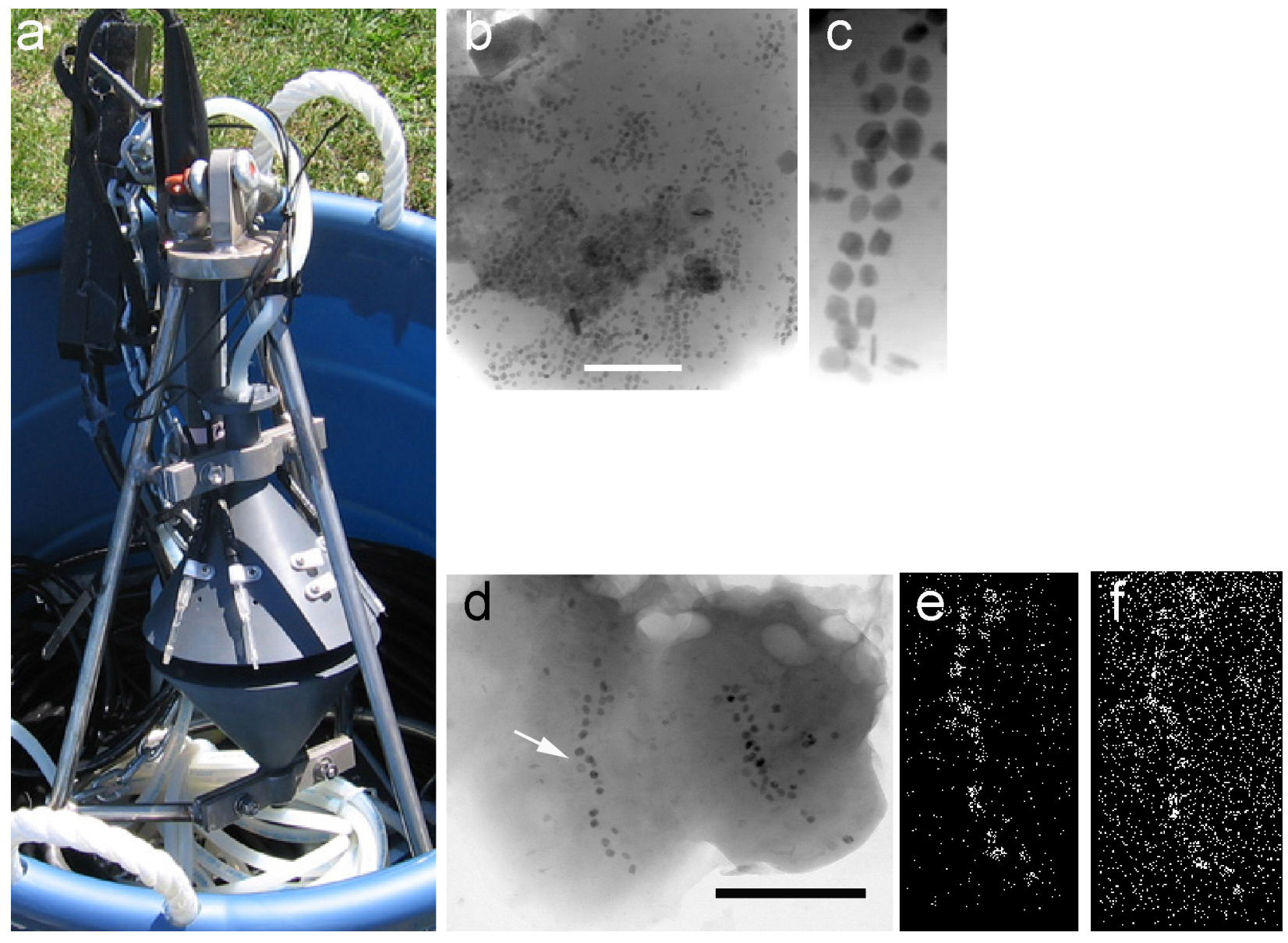

Figure A-3: (a) Sampler constructed by the WHOI mechanical shop after the design of Jørgensen et al. (1979), with design help from Craig Taylor. Glass microelectrodes for the voltammetric measurement of oxygen, iron, and sulfur species are shown fastened to the outside of the sampler. Electrodes were connected to a DLK-60 potentiostat via a specialized cable. (b) A many-celled magnetotactic prokaryote collected from Salt Pond on September 22, 2005 and imaged using the MIT HB603 STEM; scale bar $1 \mu \mathrm{m}$. (c) Closeup of an individual magnetosome chain from the MMP. (d) Brightfield image of two unidentified greigite-producing MTB collected from Salt Pond September 22, 2005 and imaged using the MIT HB603 STEM; scale bar $1 \mu \mathrm{m}$. The magnetosome chain shown in parts e and $\mathrm{f}$ is indicated with an arrow. (e) Elemental map of Fe from one of the chains; (f) elemental map of $\mathrm{S}$ from the same chain. The co-location of Fe and $\mathrm{S}$ in the maps shows that the cells contain greigite. Graininess in the elemental maps is due to the low resolution of the scan; higher resolution is possible. 


\section{Bibliography}

Amann R, Binder B, Olson R, Chisholm S, Devereux R, et al. (1990) Combination of 16s rRNA-targeted oligonucleotide probes with flow cytometry for analyzing mixed microbial populations. Appl Environ Microbiol 56: 1919-1925.

Bazylinski DA, Frankel RB, Heywood BR, Mann S, King JW, et al. (1995) Controlled biomineralization of magnetite $\left(\mathrm{Fe}_{3} \mathrm{O}_{4}\right)$ and gregite $\left(\mathrm{Fe}_{3} \mathrm{~S}_{4}\right)$ in a magnetotactic bacterium. Appl Environ Microbiol 61: 3232-3239.

Bazylinski DA, Garratt-Reed AJ, Abedi A, Frankel RB (1993) Copper Association with Iron Sulfide Magnetosomes in a Magnetotactic Bacterium. Archives of Microbiology 160: 35-42.

Brendel PJ, Luther III GW (1995) Development of a gold amalgam voltammetric microelectrode for the determination of dissolved Fe, Mn, O2, and S(-II) in porewaters of marine and freshwater sediments. Environ Sci Technol 29: 751-761.

Canfield DE, Thamdrup B, Fleischer S (1998) Isotope Fractionation and Sulfur Metabolism by Pure and Enrichment Cultures of Elemental SulfurDisproportionating Bacteria. Limnol Oceanogr 43: 253-264.

Canovas P (2006) The redox and iron-sulfide geochemistry of Salt Pond and the thermodynamic constraints on native marine magnetotactic bacteria. M.S. Thesis, Massachusetts Institute of Technology- Woods Hole Oceanographic Institution Joint Program.

Casamayor EO, Schafer H, Baneras L, Pedros-Alió C, Muyzer G (2000) Identification of and spatio-temporal Differences between microbial assemblages from two neighboring sulfurous lakes: comparison by microscopy and denaturing gradient gel electrophoresis. Appl Environ Microbiol 66: 499-508.

Chang SB (1989) Magnetofossils, the magnetization of sediments, and the evolution of magnetite biomineralization. Ann Rev Earth Planet Sci 17: 169-195. 
Cox BL, Popa R, Bazylinski DA, Lanoil B, Douglas S, et al. (2002) Organization and elemental analysis of $\mathrm{P}-, \mathrm{S}-$, and Fe-rich inclusions in a population of freshwater magnetococci. Geomicrobiology Journal 19: 387-406.

Demitrack A (1985) A search for bacterial magnetite in the sediments of Eel Marsh, Woods Hole, Massachusetts. In: Kirschvink JL, Jones D, Macfadden BJ, editors, Magnetite Biomineralization and Magnetoreception in Organisms, pp. 625-645, New York: Plenum Press.

Fassbinder JWE, Stanjek H, Vali H (1990) Occurrence of magnetic bacteria in soil. Nature 343: 161-163.

Glazer BT, Cary SC, Hohmann L, Luther III GW (2002) In situ sulfur speciation using $\mathrm{Au} / \mathrm{Hg}$ microelectrodes as an aid to microbial characterization of an intertidal salt marsh microbial mat. In: Taillefert M, Rozan T, editors, Environmental Electrochemistry: Analyses of Trace Element Biogeochemistry, ACS Symposium Series, pp. 283-305, Washington, DC: American Chemical Society.

Heywood BR, Bazylinski DA, Garrett-Reed AJ, Mann S, Frankel RB (1990) Controlled biosynthesis of greigite $\left(\mathrm{Fe}_{3} \mathrm{~S}_{4}\right)$ in magnetotactic bacteria. Naturwissenschaften 77: 536-538.

Jørgensen BB, Kuenen JG, Cohen Y (1979) Microbial transformations of sulphur compounds in a stratified lake (Solar Lake, Sinai). Limnol Oceanogr 24: 799-822.

Kao SJ, Horng CS, Roberts AP, Liu KK (2004) Carbon-sulfur-iron relationships in sedimentary rocks from southwestern Taiwan: influence of geochemical environment on greigite and pyrrhotite formation. Chemical Geology 203: 153-168.

Luther III G, Glazer B, Hohmann L, Popp J, Taillefert M, et al. (2001) Sulfur speciation monitored in situ with solid state gold amalgam voltammetric microelectrodes: polysulfides as a special case in sediments, microbial mats, and hydrothermal vent waters. J Environ Monit 3: 61-66. 
O'Sullivan DW, Hanson Jr AK, Kester DR (1997) The distribution and redox chemistry of iron in the Pettaquamscutt Estuary. Estuar Coast Shelf Sci 45: 769-788.

Petermann H, Bleil U (1993) Detection of live magnetotactic bacteria in deep-sea sediments. Earth Planet Sci Lett 117: 223-228.

Petersen N, von Dobeneck T (1986) Fossil bacterial magnetite in deep-sea sediments from the South Atlantic Ocean. Nature 320: 611-615.

Pósfai M, Cziner K, Marton E, Marton P, Buseck PR, et al. (2001) Crystal-size distributions and possible biogenic origin of Fe sulfides. European Journal of Mineralogy 13: $691-703$.

Roberts AP, Reynolds RL, Verosub KL, Adam DP (1996) Environmental magnetic implications of greigite $\left(\mathrm{Fe}_{3} \mathrm{~S}_{4}\right)$ formation in a 3 my lake sediment record from Butte Valley, northern California. Geophysical Research Letters 23: 2859-2862.

Sakaguchi T, Arakaki A, Matsunaga T (2002) Desulfovibrio magneticus sp. nov., a novel sulfate-reducing bacterium that produces intracellular single-domain-sized magnetite particles. Intl J Syst Evol Microbiol 52: 215-221.

Simmons SL, Sievert SM, Frankel RB, Bazylinski DA, Edwards KJ (2004) Spatiotemporal Distribution of Marine Magnetotactic Bacteria in a Seasonally Stratified Coastal Salt Pond. Appl Environ Microbiol 70: 6230-6239.

Snowball I, Zillen L, Sandgren P (2002) Bacterial magnetite in Swedish varved lakesediments: a potential bio-marker of environmental change. Quaternary International 88: 13-19.

Spring S, Amann R, Ludwig W, Schleifer K, van Gemerden H, et al. (1993) Dominating role of an unusual magnetotactic bacterium in the microaerobic zone of a freshwater sediment. Appl Environ Microbiol 59: 2397-2403.

Spring S, Amann R, Ludwig W, Schleifer KH, Petersen N (1992) Phylogenetic diversity and identification of nonculturable magnetotactic bacteria. System Appl Microbiol 15: 116-122. 
Stoltz J, Chang SBR, Kirschvink J (1986) Magnetotactic bacteria and single-domain magnetite in hemipelagic sediments. Nature 321: 849-851.

Stolz JF (1992) Magnetotactic bacteria: Biomineralization, ecology, sediment magnetism, environmental indicator. In: Skinner HC, Fitzpatrick RW, editors, Biomineralization Processes of Iron and Manganese: Modern and Ancient Environments, pp. 133-145, Cremlingen-Destedt: Catena Verlag.

Viollier E, Inglett PW, Hunter K, Roychoudhury AN, Cappellen PV (2000) The ferrozine method revisited: Fe (II)/Fe (III) determination in natural waters. Appl Geochem 15: 785-790.

Yamazaki T, Kawahata H (1998) Organic carbon flux controls the morphology of magnetofossils in marine sediments. Geology 26: 1064-1066.

Zopfi J, Ferdelman TG, Jørgensen BB, Teske A, Thamdrup B (2001) Influence of water column dynamics on sulfide oxidation and other major biogeochemical processes in the chemocline of Mariager Fjord (Denmark). Mar Chem 74: 29-51. 


\section{Appendix B}

\section{Ancillary data for chapter 3}

This appendix presents all data obtained with the quantitative PCR method described in Chapter 3. The first page shows cell counts for all dates and morphotypes in units of cells $\mathrm{ml}^{-1}$. Each date is coded with a numeric identifier (Table B.1), and followed by the sample depth in ft. Depth profiles of the water column chemistry for each date are shown following the qPCR data.

"SD" refers to one standard deviation from the mean, calculated from duplicate measurements. "MMP melt peak" refers to the melting temperature of the PCR product from the primers designed to amplify DNA from the many-celled magnetotactic prokaryote. The melt temperature was observed in the melt curve run immediately following quantitative PCR amplification. The presence of multiple melt peaks in the PCR product likely indicates the presence of multiple sequence variants.

The second page shows the relative abundance of each morphotype (in \%) for each sample analyzed. The relative abundance was calculated as the MTB cell count divided by the eubacterial cell count, with the eubacterial count also obtained with quantitative PCR (see Table 3.1, page 66). Samples where MTB comprised more than $1 \%$ of the total eubacterial counts are highlighted in grey. The standard deviation $\sigma_{q}$ of the ratio $\mathbf{q}$ was calculated as follows: 
$\sigma_{q}=\bar{q} \times \sqrt{\left(\frac{\sigma_{x}}{\bar{x}}\right)^{2}+\left(\frac{\sigma_{y}}{\bar{y}}\right)^{2}} \begin{cases}\bar{x} & \text { mean of replicate MTB cell counts } \\ \sigma_{x} & \text { standard deviation of replicate MTB cell counts } \\ \bar{y} & \text { mean of replicate eubacterial cell counts } \\ \sigma_{y} & \text { standard deviation of replicate eubacterial cell counts } \\ q & x / y \\ \bar{q} & \text { mean of replicate ratios } x / y\end{cases}$

This formula for error analysis was obtained from Taylor (1982).

\begin{tabular}{cc}
\hline Series ID & Sampling Date \\
\hline 2 & $6 / 26 / 03$ \\
3 & $7 / 3 / 03$ \\
4 & $7 / 10 / 03$ \\
5 & $7 / 22 / 03$ \\
6 & $8 / 7 / 03$ \\
7 & $8 / 15 / 03$ \\
8 & $8 / 21 / 03$ \\
9 & $8 / 28 / 03$ \\
10 & $9 / 11 / 03$ \\
11 & $9 / 24 / 03$ \\
\hline
\end{tabular}

Table B.1: Sample identification codes for qPCR data.

\section{Bibliography}

Taylor JR (1982) An Introduction to Error Analysis. A Series of Books in Physics, Sausalito, CA: University Science Books. 


\section{Cells per ml}

\begin{tabular}{|c|c|c|c|c|c|c|c|c|c|c|c|}
\hline \multirow[t]{2}{*}{$\begin{array}{l}\text { Series-Depth } \\
\text { (in ft) }\end{array}$} & \multicolumn{2}{|l|}{ Eub } & \multicolumn{2}{|l|}{ MMP } & \multicolumn{2}{|l|}{ Cocci } & \multicolumn{2}{|l|}{ Barbell } & \multicolumn{2}{|l|}{ Greigite rod } & \multirow[t]{2}{*}{$\begin{array}{l}\text { MMP melt } \\
\text { peak (deg } \\
\text { C) }\end{array}$} \\
\hline & Average & $S D$ & Average & $S D$ & Average & $S D$ & Average & $S D$ & Average & $S D$ & \\
\hline $2-12$ & $2.33 E+06$ & $1.17 \mathrm{E}+05$ & $1.87 \mathrm{E}+03$ & & $1.50 \mathrm{E}+02$ & $7.48 \mathrm{E}+01$ & $7.09 E+04$ & $1.03 E+05$ & NS & & 86 \\
\hline $2-13$ & & & & & $3.35 E+01$ & $1.43 \mathrm{E}+01$ & & & $2.47 \mathrm{E}+02$ & na & \\
\hline $2-14$ & & & & & $2.31 \mathrm{E}+01$ & $1.82 \mathrm{E}+01$ & $5.63 E+03$ & $4.33 E+03$ & $4.54 \mathrm{E}+01$ & na & 86 \\
\hline 2-btm & $5.51 \mathrm{E}+06$ & $8.28 \mathrm{E}+05$ & $1.06 \mathrm{E}+05$ & $7.58 \mathrm{E}+04$ & & $0.00 \mathrm{E}+00$ & 4.07E+03 & $6.04 \mathrm{E}+03$ & NS & & 83 \\
\hline $4-11.5$ & $1.38 \mathrm{E}+06$ & $2.02 \mathrm{E}+06$ & & & $1.69 \mathrm{E}+02$ & $2.54 \mathrm{E}+02$ & $5.38 \mathrm{E}+04$ & $1.05 E+05$ & $1.40 \mathrm{E}+02$ & na & 86 \\
\hline $4-12$ & $3.79 \mathrm{E}+06$ & 1.13E+06 & & & $8.85 E+02$ & $9.90 \mathrm{E}+01$ & $5.24 \mathrm{E}+04$ & $1.49 \mathrm{E}+04$ & $4.54 \mathrm{E}+01$ & na & 86 \\
\hline $4-12.5$ & $2.25 \mathrm{E}+06$ & $2.27 \mathrm{E}+05$ & & & $5.32 \mathrm{E}+02$ & $1.12 \mathrm{E}+02$ & $5.24 \mathrm{E}+04$ & $1.49 \mathrm{E}+04$ & ND & & 86 \\
\hline $4-13.5$ & $1.89 \mathrm{E}+06$ & $9.96 \mathrm{E}+05$ & & & $6.10 \mathrm{E}+02$ & $4.28 \mathrm{E}+01$ & & & ND & & 86 \\
\hline $4-15$ & & & & & ND & & $5.52 \mathrm{E}+03$ & $5.11 E+03 n$ & ND & & 86 \\
\hline $5-10.5$ & $1.07 \mathrm{E}+05$ & $0.00 E+00$ & & & $2.39 \mathrm{E}+03$ & $6.66 \mathrm{E}+02$ & ND & & NS & & 83 \\
\hline $5-11$ & $1.55 \mathrm{E}+05$ & $6.77 \mathrm{E}+04$ & & & $4.16 \mathrm{E}+03$ & $4.11 \mathrm{E}+03$ & $9.43 E+02$ & $1.12 \mathrm{E}+03 \mathrm{~N}$ & NS & & 83 \\
\hline 5-11.5 & $6.56 \mathrm{E}+05$ & $3.30 E+04$ & & & $6.17 \mathrm{E}+03$ & $2.40 \mathrm{E}+03$ & $7.60 \mathrm{E}+03$ & $0.00 \mathrm{E}+00 \mathrm{~N}$ & NS & & 83 \\
\hline $5-12$ & $1.46 \mathrm{E}+06$ & $3.63 E+05$ & $2.06 \mathrm{E}+03$ & $6.40 \mathrm{E}+02$ & $2.75 E+03$ & $7.66 \mathrm{E}+02$ & $3.00 E+04$ & $3.75 E+04 N$ & NS & & 86 \\
\hline $5-13$ & $9.84 \mathrm{E}+05$ & $4.31 \mathrm{E}+05$ & & & $2.38 \mathrm{E}+03$ & $2.98 \mathrm{E}+03$ & $2.21 \mathrm{E}+04$ & $1.08 E+04 N$ & NS & & 86 \\
\hline $5-15$ & & & & & & & & & & & \\
\hline $6-10$ & $1.44 \mathrm{E}+05$ & $1.05 \mathrm{E}+05$ & & & $1.79 \mathrm{E}+03$ & & $1.16 \mathrm{E}+03$ & $2.01 E+03 n$ & NS & & both \\
\hline $6-10.5$ & $2.10 \mathrm{E}+05$ & $8.40 \mathrm{E}+04$ & & & $2.73 E+03$ & & $4.15 E+03$ & $6.16 \mathrm{E}+03$ & $4.42 \mathrm{E}+02$ & na & both \\
\hline $6-11$ & $1.62 \mathrm{E}+06$ & $9.25 E+05$ & $5.64 \mathrm{E}+03$ & $3.80 \mathrm{E}+02$ & $5.22 \mathrm{E}+03$ & $8.78 \mathrm{E}+03$ & $4.29 E+04$ & $2.67 \mathrm{E}+04$ & $2.61 \mathrm{E}+02$ & $3.69 \mathrm{E}+02$ & 86 \\
\hline $6-12$ & $1.63 \mathrm{E}+06$ & $4.85 \mathrm{E}+05$ & & & $1.22 \mathrm{E}+03$ & $3.41 \mathrm{E}+02$ & $1.20 \mathrm{E}+04$ & $1.18 \mathrm{E}+04$ & $7.35 \mathrm{E}+01$ & $1.04 \mathrm{E}+02$ & \\
\hline $6-14$ & $4.50 E+05$ & $1.97 \mathrm{E}+05$ & & & $1.09 \mathrm{E}+03$ & $7.66 \mathrm{E}+01$ & $3.15 E+03$ & $2.91 E+03$ & $7.25 E+02$ & $1.03 \mathrm{E}+03$ & \\
\hline 7-9.5 & $9.96 \mathrm{E}+04$ & $1.00 \mathrm{E}+04$ & ND & & $5.51 \mathrm{E}+02$ & $1.53 \mathrm{E}+02$ & ND & & NS & & 83 \\
\hline $7-10.5$ & $1.70 \mathrm{E}+05$ & $8.96 \mathrm{E}+04$ & ND & & $3.31 \mathrm{E}+02$ & $2.22 \mathrm{E}+02$ & $4.30 \mathrm{E}+03$ & $6.14 \mathrm{E}+02 \mathrm{~N}$ & NS & & \\
\hline $7-11$ & $8.12 \mathrm{E}+05$ & $4.08 \mathrm{E}+04$ & $1.71 \mathrm{E}+03$ & $6.60 \mathrm{E}+02$ & $1.72 \mathrm{E}+02$ & $1.20 \mathrm{E}+01$ & $3.31 E+04$ & $2.48 E+04 \pi$ & NS & & 86 \\
\hline $7-11.5$ & $4.00 \mathrm{E}+05$ & $2.11 \mathrm{E}+05$ & $5.23 \mathrm{E}+02$ & 3.17E+02 & $7.79 \mathrm{E}+01$ & $4.75 \mathrm{E}+01$ & $2.60 \mathrm{E}+04$ & $1.62 \mathrm{E}+04 \mathrm{~N}$ & NS & & 86 \\
\hline $7-12$ & $7.31 \mathrm{E}+05$ & $7.35 \mathrm{E}+04$ & $3.28 \mathrm{E}+03$ & $3.08 \mathrm{E}+03$ & $2.59 E+02$ & $2.50 \mathrm{E}+02$ & $1.55 \mathrm{E}+04$ & $1.68 \mathrm{E}+04$ & $1.20 \mathrm{E}+02$ & $6.61 \mathrm{E}+01$ & 86 \\
\hline $7-13$ & & & & & $2.36 \mathrm{E}+02$ & $2.96 \mathrm{E}+02$ & $4.46 \mathrm{E}+03$ & $2.49 \mathrm{E}+03 \mathrm{~N}$ & ND & & 86 \\
\hline $8-8.5$ & & & & & & & & & NS & & \\
\hline $8-9$ & $1.47 \mathrm{E}+05$ & $3.67 \mathrm{E}+04$ & & & $1.48 \mathrm{E}+02$ & $1.01 \mathrm{E}+02$ & $9.03 E+03$ & $5.03 E+03 N$ & NS & & 83 \\
\hline 8-9.5 & $1.26 \mathrm{E}+05$ & $6.34 \mathrm{E}+03$ & & & $1.89 \mathrm{E}+02$ & $1.16 \mathrm{E}+02$ & $8.06 \mathrm{E}+03$ & $1.25 E+04 ~ N$ & NS & & 83 \\
\hline $8-10$ & $5.29 \mathrm{E}+05$ & $3.45 \mathrm{E}+05$ & $1.10 \mathrm{E}+03$ & $1.81 \mathrm{E}+02$ & $1.15 \mathrm{E}+03$ & $0.00 \mathrm{E}+00$ & $1.81 \mathrm{E}+05$ & $1.77 \mathrm{E}+05$ & $2.12 \mathrm{E}+02$ & $1.33 \mathrm{E}+02$ & 86 \\
\hline $8-10.5$ & $4.22 \mathrm{E}+05$ & $2.13 E+04$ & $1.25 \mathrm{E}+03$ & $1.23 \mathrm{E}+03$ & $7.81 \mathrm{E}+02$ & $1.10 \mathrm{E}+02$ & $1.04 \mathrm{E}+05$ & $9.61 \mathrm{E}+04$ & $1.40 \mathrm{E}+02$ & & 86 \\
\hline 8-11 & $1.02 \mathrm{E}+06$ & $7.82 \mathrm{E}+05$ & $2.48 \mathrm{E}+03$ & $2.74 \mathrm{E}+02$ & $7.87 \mathrm{E}+02$ & $2.20 \mathrm{E}+02$ & $1.98 \mathrm{E}+05$ & 1.83E+05 & $3.91 E+02$ & $2.76 \mathrm{E}+01$ & 86 \\
\hline $8-12$ & $5.95 E+05$ & $1.77 \mathrm{E}+05$ & & & $6.84 \mathrm{E}+02$ & $1.91 \mathrm{E}+02$ & $5.41 \mathrm{E}+04$ & $3.01 \mathrm{E}+04$ & $2.07 \mathrm{E}+02$ & $1.74 \mathrm{E}+02$ & \\
\hline 8-14 & $8.01 E+05$ & $6.67 \mathrm{E}+05$ & & & $6.79 E+02$ & $9.52 \mathrm{E}+01$ & 1.46E+04 & $6.19 \mathrm{E}+03$ & $9.55 E+01$ & $7.06 \mathrm{E}+01$ & \\
\hline $8-17.5$ & & & & & & & & & $2.45 E+01$ & $2.69 \mathrm{E}+01$ & \\
\hline $10-8.5$ & $2.67 E+05$ & $2.87 \mathrm{E}+05$ & & & $3.19 \mathrm{E}+01$ & $1.10 \mathrm{E}+01$ & 1.39E+03 & $1.46 E+03 N$ & NS & & \\
\hline $10-9$ & $4.94 \mathrm{E}+05$ & $3.95 E+05$ & & & $3.40 \mathrm{E}+01$ & $3.80 \mathrm{E}+01$ & $8.30 \mathrm{E}+04$ & $1.46 \mathrm{E}+05$ & $3.51 \mathrm{E}+02$ & & \\
\hline $10-9.5$ & $2.53 E+06$ & $1.65 E+06$ & $6.24 \mathrm{E}+03$ & $7.89 \mathrm{E}+03$ & $3.88 \mathrm{E}+02$ & $6.36 \mathrm{E}+02$ & $4.89 \mathrm{E}+05$ & $7.14 \mathrm{E}+05$ & $4.66 \mathrm{E}+02$ & & 86 \\
\hline $10-10$ & $2.45 E+06$ & $1.07 \mathrm{E}+06$ & & & $3.79 E+02$ & $5.59 \mathrm{E}+02$ & $3.64 \mathrm{E}+05$ & $2.27 E+05$ & $1.17 \mathrm{E}+03$ & & 86 \\
\hline $10-10.5$ & $1.21 \mathrm{E}+06$ & $3.61 \mathrm{E}+05$ & $5.88 \mathrm{E}+03$ & $3.90 \mathrm{E}+03$ & $6.55 E+02$ & $5.58 \mathrm{E}+02$ & $1.01 \mathrm{E}+05$ & $8.15 E+04$ & $7.41 \mathrm{E}+02$ & $1.56 \mathrm{E}+02$ & 86 \\
\hline $10-11.5$ & $1.02 E+06$ & $3.53 E+05$ & & & & $0.00 E+00$ & $9.57 \mathrm{E}+04$ & $7.17 \mathrm{E}+04$ & $1.80 \mathrm{E}+02$ & $1.27 \mathrm{E}+01$ & \\
\hline $10-12.5$ & $2.13 E+06$ & $2.61 \mathrm{E}+06$ & & & & $0.00 \mathrm{E}+00$ & $5.40 E+04$ & $4.04 \mathrm{E}+04$ & $1.68 \mathrm{E}+02$ & $9.25 \mathrm{E}+01$ & \\
\hline $11-9$ & $4.84 \mathrm{E}+05$ & $3.34 \mathrm{E}+05$ & & & $1.06 \mathrm{E}+02$ & $5.10 \mathrm{E}+01$ & 1.10E+05 & $1.38 \mathrm{E}+04$ & $1.06 \mathrm{E}+02$ & & \\
\hline $11-9.5$ & $1.14 \mathrm{E}+06$ & $1.15 \mathrm{E}+06$ & & & $8.39 \mathrm{E}+01$ & $4.58 \mathrm{E}+01$ & $1.10 E+05$ & $1.57 \mathrm{E}+05 \mathrm{~N}$ & NS & & \\
\hline $11-10$ & $1.27 \mathrm{E}+06$ & $4.37 \mathrm{E}+05$ & $4.12 \mathrm{E}+04$ & $4.28 \mathrm{E}+04$ & $1.22 \mathrm{E}+02$ & $2.16 \mathrm{E}+02$ & $7.28 \mathrm{E}+04$ & $2.58 \mathrm{E}+04$ & & & 86 \\
\hline $11-10.5$ & $4.28 \mathrm{E}+06$ & $4.30 \mathrm{E}+05$ & ND & & $1.73 \mathrm{E}+02$ & $8.33 \mathrm{E}+01$ & $2.92 \mathrm{E}+05$ & $8.30 \mathrm{E}+04$ & & & 86 \\
\hline $11-11$ & $1.46 \mathrm{E}+06$ & $5.04 \mathrm{E}+05$ & ND & & & $0.00 \mathrm{E}+00$ & $1.93 E+04$ & $2.00 E+04 N$ & NS & & 86 \\
\hline $11-10 \mathrm{Nt}$ & $3.04 \mathrm{E}+06$ & $1.73 E+06$ & ND & & $3.56 \mathrm{E}+02$ & $2.17 \mathrm{E}+02$ & 4.04E+05 & $6.59 E+05$ & ND & & \\
\hline $11-9.5 \mathrm{Nt}$ & 4.17E+05 & $1.24 \mathrm{E}+05$ & ND & & $1.38 \mathrm{E}+02$ & $1.54 \mathrm{E}+02$ & $4.34 \mathrm{E}+04$ & $7.27 \mathrm{E}+04 \Lambda$ & ND & & \\
\hline
\end{tabular}




\section{Relative abundance of each type (\% of Eubacteria)}

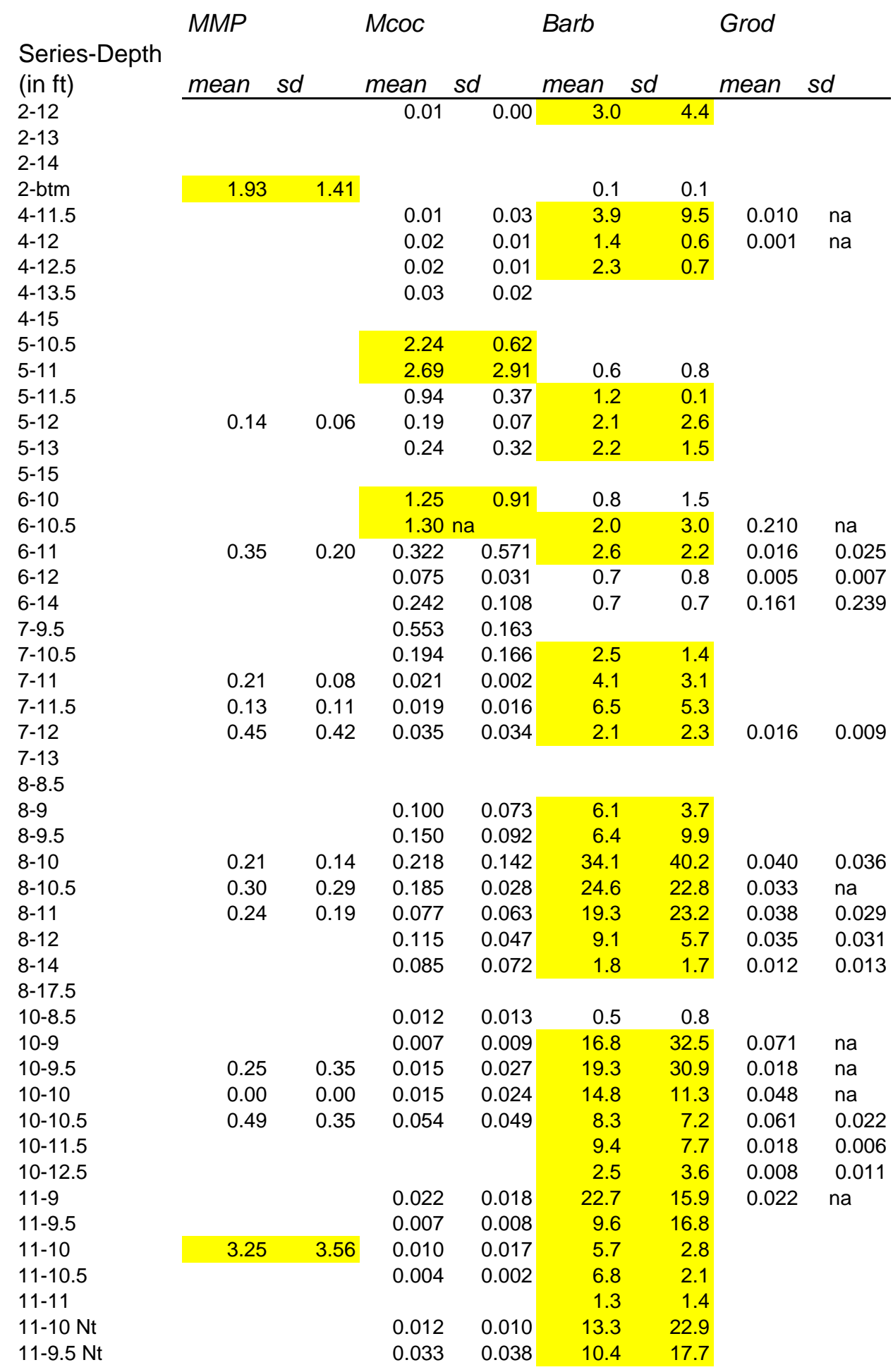


Oxygen (mg/L)

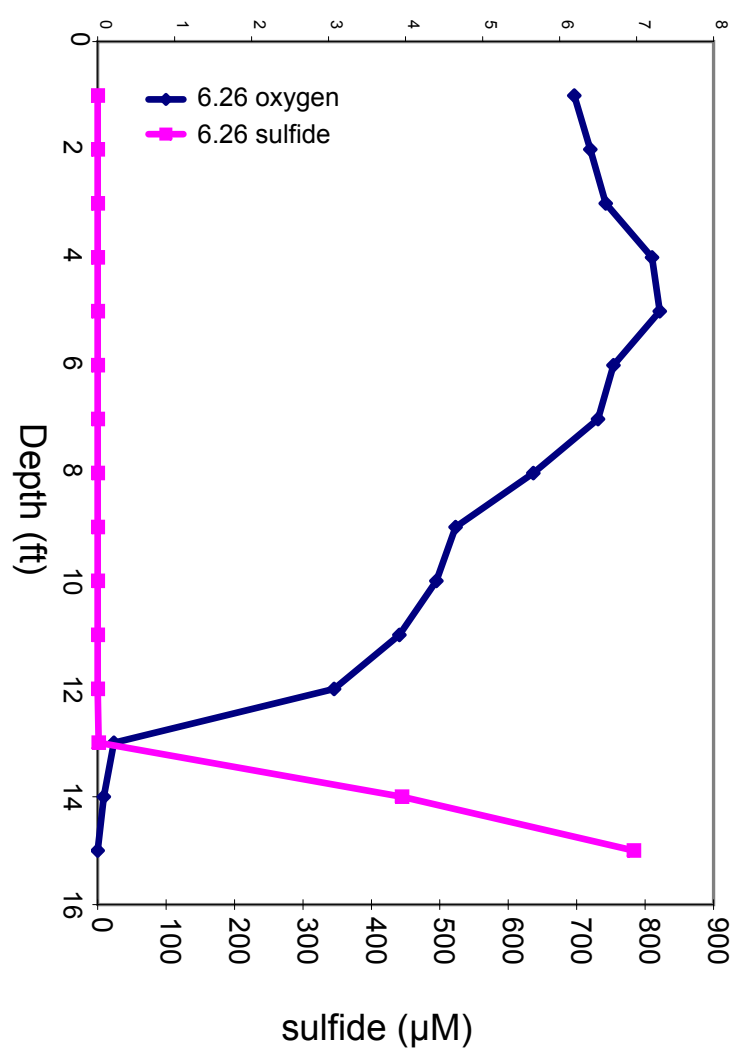

6.26.2003

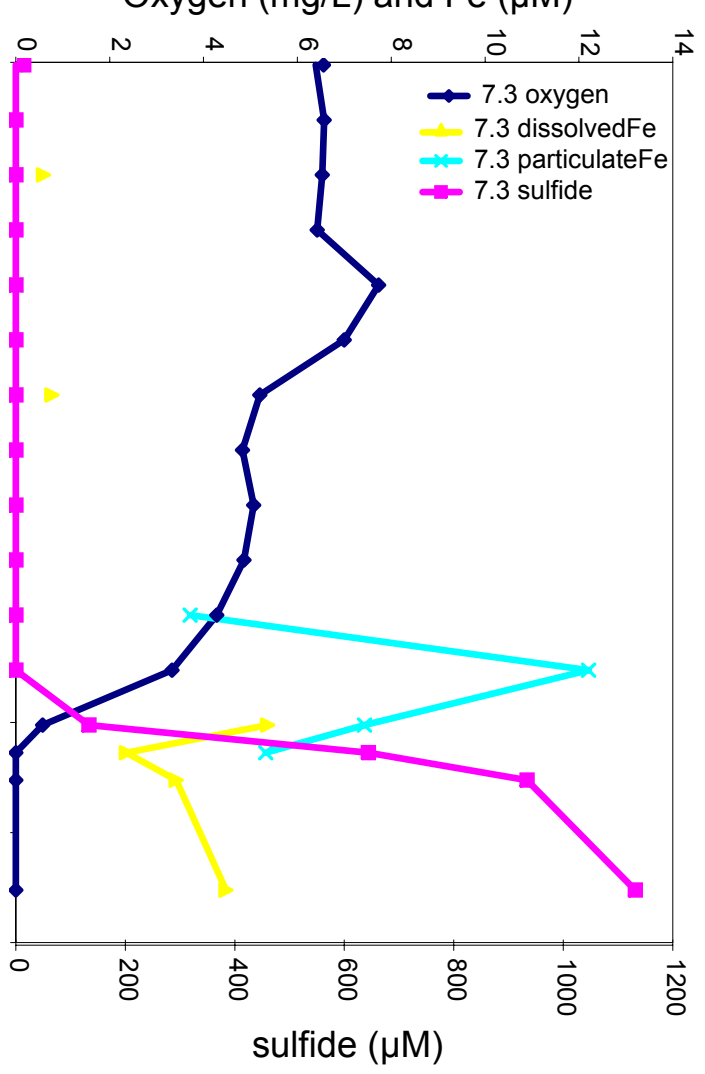

7.3.2003

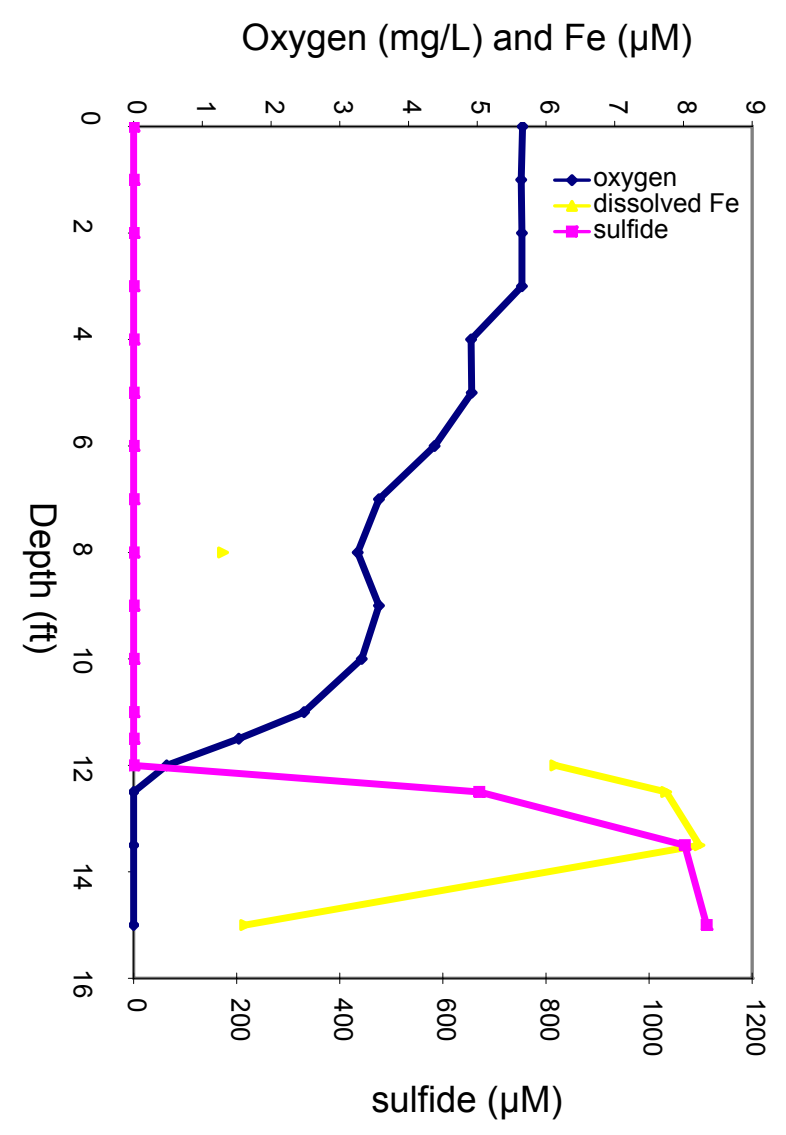

7.10.2003
Oxygen (mg/L) and Fe $(\mu \mathrm{M})$

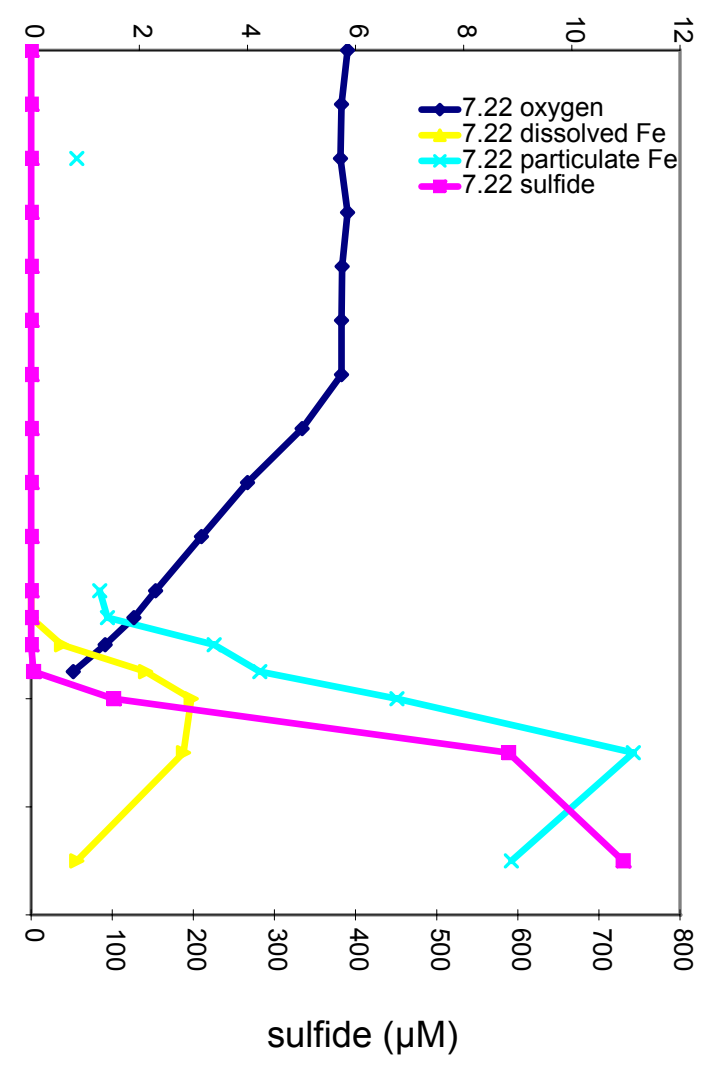

7.22.2003 
Oxygen (mg/L) and $\mathrm{Fe}(\mu \mathrm{M})$

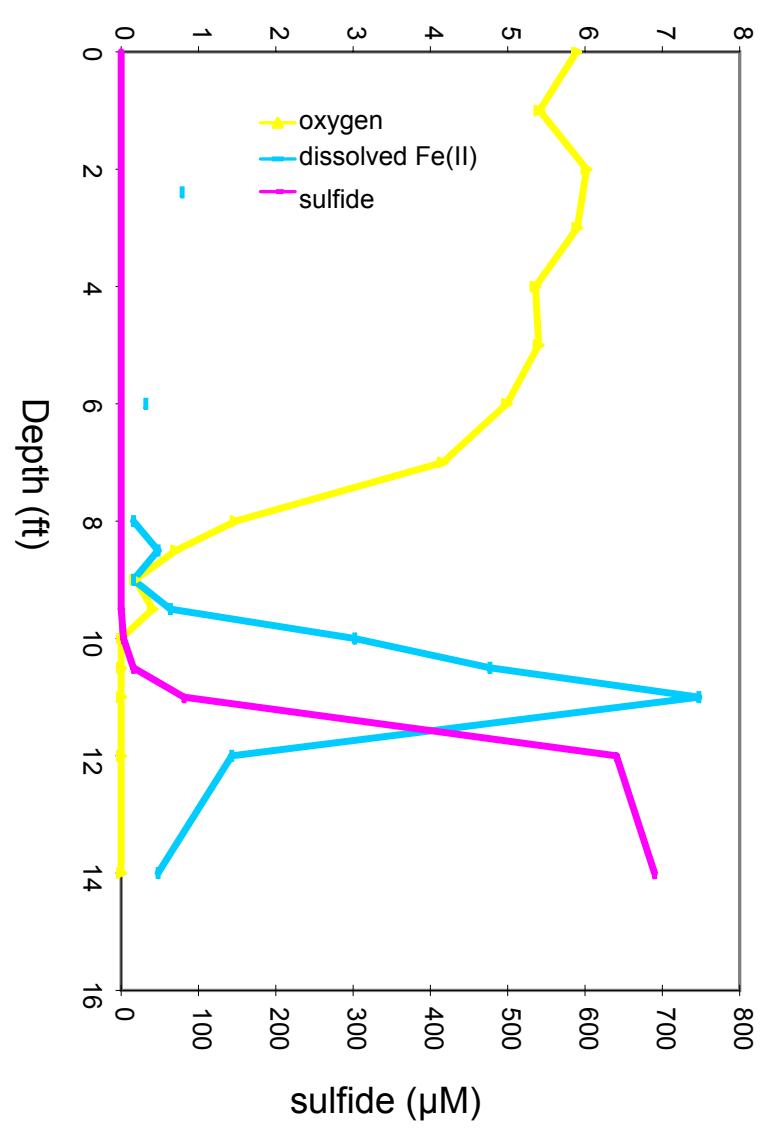

8.7.2003

sulfide $(\mu \mathrm{M})$

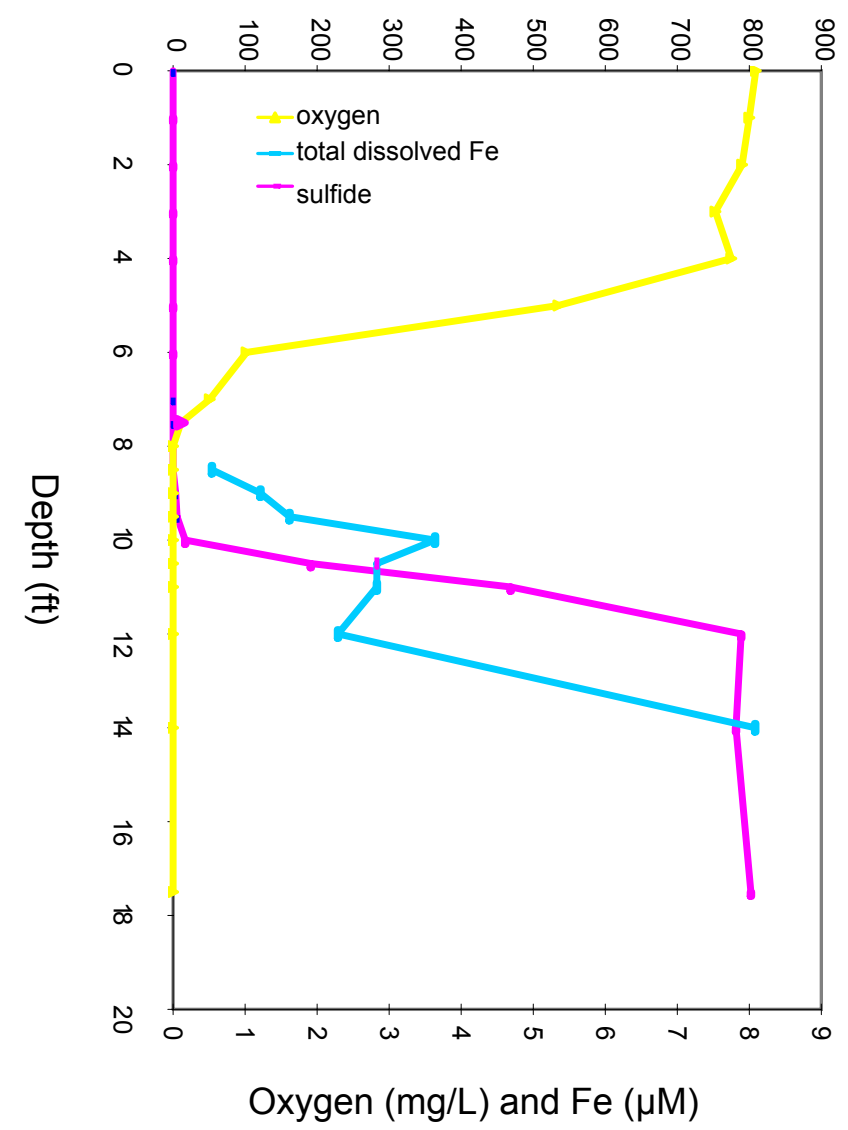

8.21 .2003
Oxygen (mg/L) and Fe $(\mu \mathrm{M})$

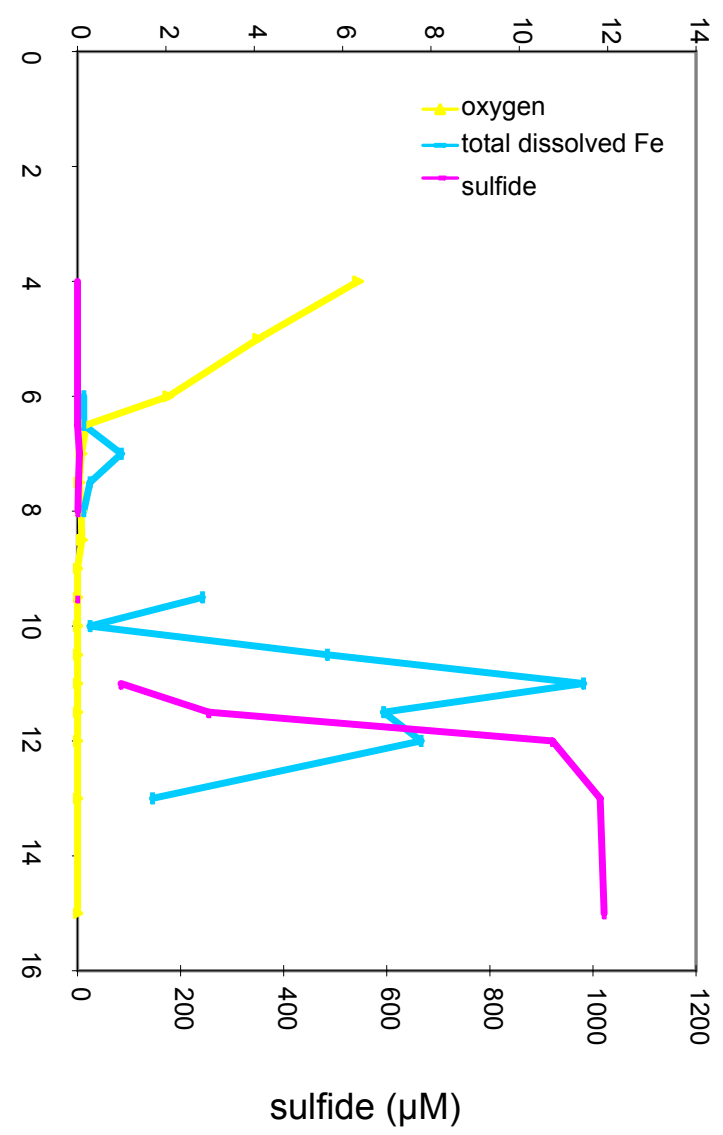

8.15.2003

Oxygen (mg/L) and $\mathrm{Fe}(\mu \mathrm{M})$

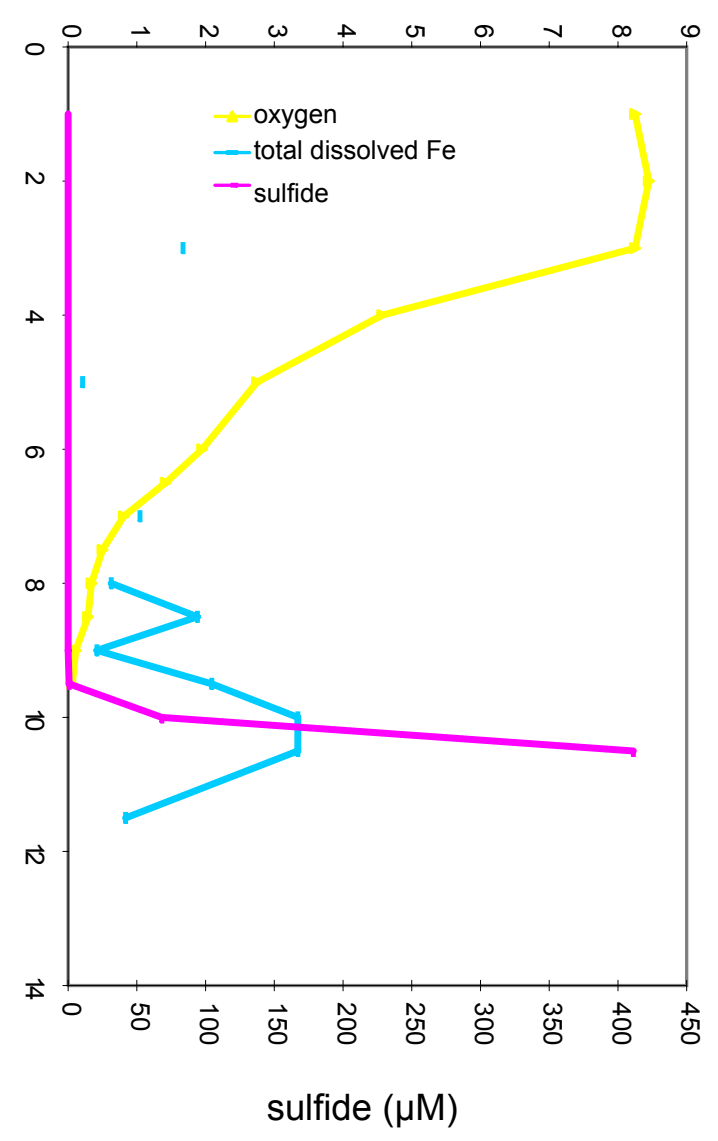

9.11 .2003 


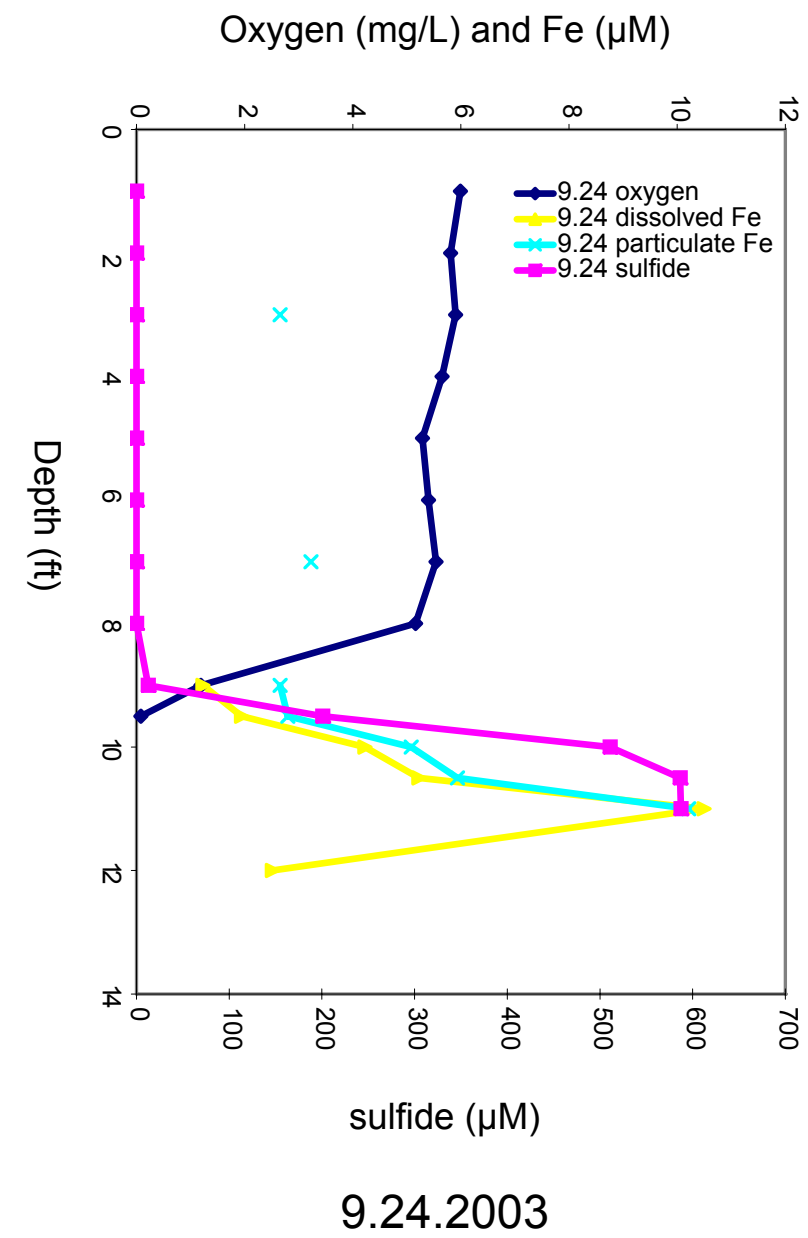




\section{Appendix C}

\section{Measurements of in situ carbon fixation in Salt Pond}

This appendix presents the results of in situ carbon fixation experiments conducted in Salt Pond on 9/17/2003 and 9/24/2003. The goal of these experiments was to determine the amount of photosynthetic and dark carbon fixation in the mixed layer, the chemocline, and the hypolimnion of Salt Pond. The location of the chemocline was determined using temperature, salinity, and oxygen profiles obtained with a YSI 85 sonde. The use of the carbon isotope ${ }^{14} \mathrm{C}$ in Salt Pond was approved by the WHOI Radiation Safety Committee.

A timecourse of light and dark carbon incorporation was obtained on 9/17/2003 using samples from the mixed layer and chemocline of Salt Pond, with the goal of determining the optimal incubation length for obtaining $\mathrm{C}$ incorporation rates in Salt Pond. Five samples were taken at different timepoints (0, $30 \mathrm{~min}, 1 \mathrm{hr}, 2 \mathrm{hr}, 3 \mathrm{hr}$ ) and the rate of incorporation versus time was measured. A detailed protocol for the timecourse incubation is included below.

Results of the timecourse incubation (Fig. C-1) indicated that a 1 hour incubation time would be optimal for the larger fixation experiment. While the 1 hour time likely underestimates mixed layer light production, as the incorporation rate does not reach an asymptote until 2 hrs, it allows for determinations of chemocline production without excessive time for recycling of labeled carbon within bottles. Since the main 


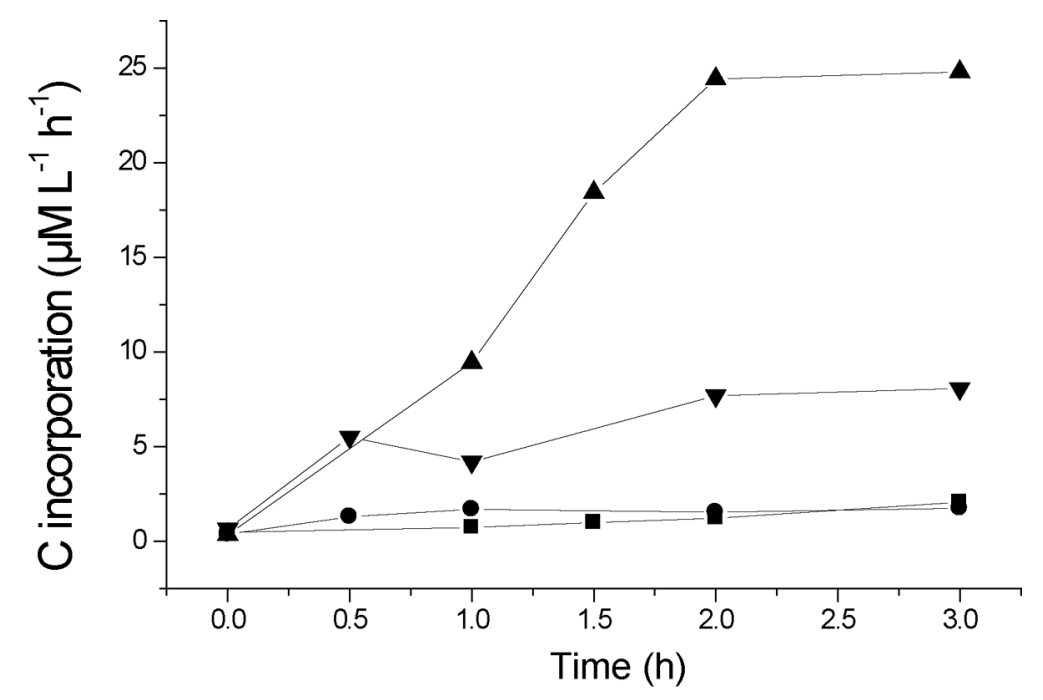

Figure C-1: Timecourse incubation to determine primary production rates in the Salt Pond mixed layer and chemocline. Upward triangles, mixed layer incorporation rates in the light incubation; squares, mixed layer rates for the dark incubation; downward triangles, chemocline rates for the light incubation; circles, chemocline rates for the dark incubation.

goal of the experiment was to determine rates of light versus dark incubation at the chemocline, this compromise seemed acceptable. Maximum incorporation rates in the mixed layer light incubation reached $25 \mu \mathrm{M} \mathrm{C} \mathrm{L}^{-1} \mathrm{~h}^{-1}, 7.7 \mu \mathrm{M} \mathrm{C} \mathrm{L}^{-1} \mathrm{~h}^{-1}$ in the chemocline light incubation, and $2 \mu \mathrm{M} \mathrm{C} \mathrm{L}^{-1} \mathrm{~h}^{-1}$ in both the mixed layer dark and the chemocline dark incubations.

The main in situ fixation experiment consisted of two parts: a daytime one hour incubation with light and dark bottles in the mixed layer, chemocline, and hypolimnion, and a nighttime one hour incubation in the mixed layer and the chemocline. With the help of Craig Taylor, I designed a custom-made sampling apparatus that was built by the WHOI shop (described below). Samples were collected for measurement of total dissolved inorganic carbon (DIC) from the mixed layer, chemocline, and hypolimnion (methods below; Table C.1). Accurate measurements of DIC are required for the rate calculations.

Results from the daytime incubation surprisingly showed little difference between light and dark incorporation rates in the chemocline (Fig. C-2), which contrasted with the timecourse results (Fig. C-1). A likely explanation is that light levels in 


\begin{tabular}{ccc}
\hline Depth $(\mathrm{ft})$ & Water mass & {$[\mathrm{DIC}]$} \\
\hline 3 & Mixed layer & $1413 \pm 4$ \\
9.5 & Chemocline & $2237 \pm 36$ \\
12 & Hypolimnion & $4051 \pm 221$ \\
\hline
\end{tabular}

Table C.1: DIC concentrations in Salt Pond on 9/24/2003, units $\mu \mathrm{M} \mathrm{L}^{-1}$.

the chemocline were lower on 9/24 than on $9 / 17$, when timecourse incubations were conducted. Light was measured at 5.5 microEinsteins in the chemocline on 9/24 with a LiCor meter and $4 \pi$ sensor, but was not measured on $9 / 17$. It is also possible that the chemocline dark incubation was inadvertently exposed to light, resulting in inflated incorporation rates. The rates of chemocline light and dark $\mathrm{C}$ incorporation exceeded hypolimnion incorporation rates by factors of 1.5-2, suggesting higher overall bacterial activity in the chemocline (inset, Fig. C-2).

The incorporation rate in the mixed layer after one hour was comparable to the rate measured during the timecourse experiment. Interestingly, rates of dark $\mathrm{C}$ incorporation in the daytime mixed layer were about three times higher than rates of dark $\mathrm{C}$ incorporation in the night-time mixed layer. This could indicate that photosynthetic populations are more active during the day and consequently incorporate more inorganic carbon in dark reactions. 
a

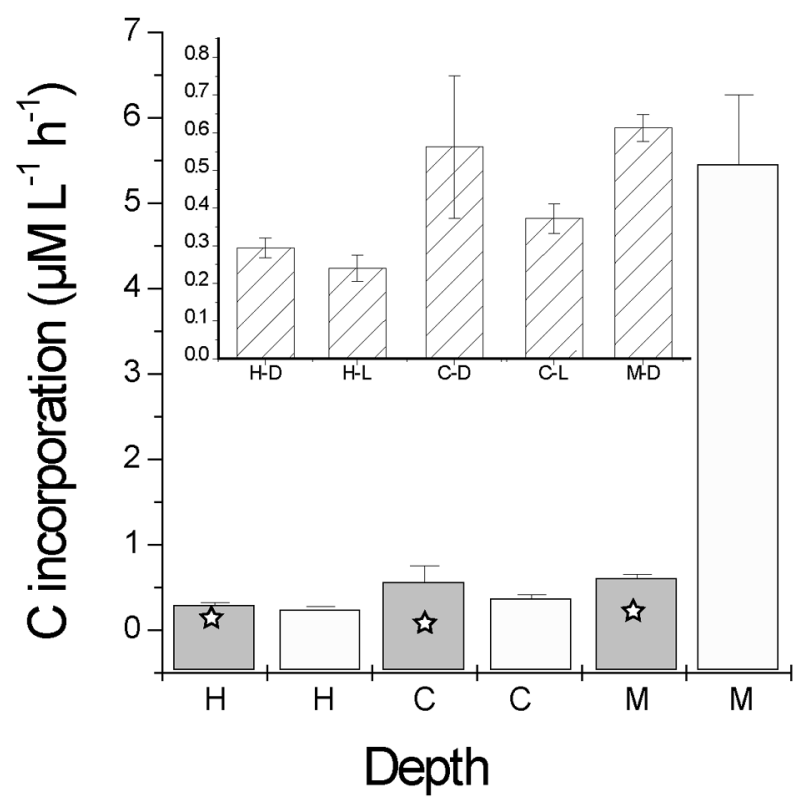

b

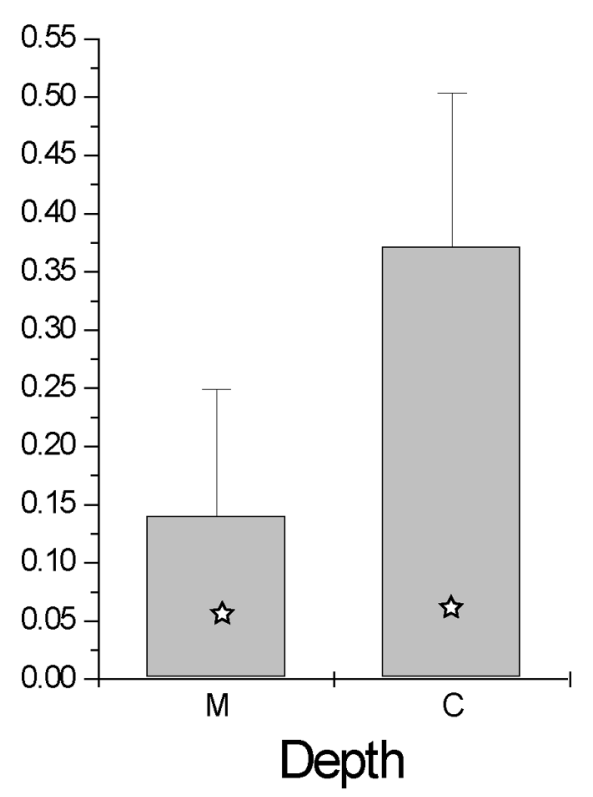

Figure C-2: (a) Results from parallel light and dark incubations conducted during the day in Salt Pond on 9/24/2003. Dark grey columns represent the dark incubations, and white columns represent the light incubations. $\mathrm{H}=$ hypolimnion, $\mathrm{C}=$ chemocline, and $\mathrm{M}=$ mixed layer. Stars indicate the measured rate at the zero timepoint. Inset shows data for all incubations except the mixed layer at higher resolution. $\mathrm{D}=$ dark incubation and $\mathrm{L}=$ light incubation. (b) $\mathrm{C}$ incorporation rates for the night-time incubation; stars indicate the zero timepoint rate. 


\section{C.1 Protocol for Salt Pond C fixation experiments, September 2003}

\section{C.1.1 Measurement of DIC}

Total dissolved inorganic carbon in the mixed layer, chemocline, and hypolimnion was measured using manometric methods in the laboratory of Dan McCorkle (WHOI). These methods involve acidifying the sample and measuring the pressure of evolved $\mathrm{CO}_{2}$ gas. Triplicate water samples of $10 \mathrm{ml}$ each from the mixed layer, chemocline, and hypolimnion were collected for DIC analysis on 9/24/2003. DIC concentrations in $\mathrm{mM} \mathrm{kg}^{-1}$ were converted to $\mu \mathrm{M} \mathrm{L}^{-1}$ by multiplying by the measured density of Salt Pond on the sampling date (approximately $1.011 \mathrm{~kg} \mathrm{~L}^{-1}$ ). The resulting DIC concentrations (Table C.1) were used in the rate calculations. Variation was higher in the hypolimnion samples due to interference of sulfide gas with the pressure measurements (D. McCorkle, pers. comm.).

\section{C.1.2 Calculation of $\mathrm{C}$ incorporation rates}

Carbon incorporation rates were calculated using a formula from the online manual of protocols used in the Joint Global Ocean Flux Study (http://www.pangaea.de/ Projects/JGOFS/Methods/):

$$
\frac{\mathrm{DPM} \text { per filter }}{\text { Volume filtered }(\mathrm{L})} \times \frac{[\mathrm{DIC}]}{\text { specific activity }(\mathrm{DPM})} \times W \times \frac{1.05}{\text { time }(\mathrm{h})}
$$

$\mathrm{W}$ is equal to the volume filtered for specific activity measurements in liters, and the factor of 1.05 corrects for slower uptake of ${ }^{14} \mathrm{C}$ versus ${ }^{12} \mathrm{C}$. The formula was simplified by substitution of the specific volumes and incubation time $(1 \mathrm{~h})$ used:

$$
1.05 \times 10^{-3} \times \mathrm{DPM} \text { per filter } \times \frac{[\mathrm{DIC}]}{\text { specific activity }(\mathrm{DPM})}
$$




\section{C.1.3 Protocol for in situ fixation experiments}

\section{Sampling apparatus}

I used a custom-made sampling apparatus designed to incubate 12 bottles at each of

three depths. The disk was fashioned of $1 / 4$ " Lexan, with twelve holes to accommodate the caps of $60 \mathrm{~mL}$ clear square polycarbonate bottles (for light incubations) and 60 $\mathrm{mL}$ round amber bottles (for dark incubations). A solid disk of the same size held bottles in place in a type of "sandwich." The disks were suspended from a PVC pipe with buoys attached on either end. The three disks were placed some distance apart on the pipe to allow for retrieval of one disk at a time, and the deployment time of each disk was also staggered. The length of rope for each disks was be determined in the field based on in situ water column profiles. One disk was suspended in the oxic mixed layer, one at the chemocline, and one in the sulfidic hypolimnion.

\section{Preparation}

1. Acid-clean bottles and plastic syringes in $10 \% \mathrm{HCl}$ for at least $24 \mathrm{hrs}$

2. Mount GF/F filters in Swinnex filter holders

3. Dispense $\mathrm{H}^{14} \mathrm{CO}_{3}^{-}$at $50 \mu \mathrm{Ci} / \mathrm{ml}$ into a scintillation vial, which is carried into the field in a waterproofed container with a foam liner to secure the bottle.

4. Fill triplicate scintillation vials with $0.2 \mathrm{ml}$ glacial acetic acid for filters

5. Fill triplicate scintillation vials with $0.2 \mathrm{ml}$ hyamine hydroxide for measurements of specific activity

6. Fill vials with $5 \mathrm{ml} 100 \%$ acetone for chlorophyll analysis

7. Prepare light meter: LiCor $4 \pi$ sensor taped to metal frame along with electrode and pump intake.

8. Bring into field: Swinnex filters pre-fitted with GF/F filters, sporks, tweezers, gloves, ziploc bags, electrical tape 
9. Prepare Nitex mesh in Buchner funnel for filtering out zooplankton

10. Prepare dark bottle for storing coarse-filtered sample before dispensing to individual bottles

\section{Field protocol}

1. Prior to incubation experiment, profile water column with YSI 85 sonde. Collect water samples for iron, sulfide, nutrients, and $\mathrm{pH}$ analysis as described in Chapters 2 and 3. Identify chemocline location for deployment of incubation disk.

2. Take samples for DIC measurement: fill $10 \mathrm{cc}$ syringe directly from pump outflow, cap, place on ice and transport to lab.

3. Adjust rope lengths on apparatus such that disks hang in the correct location relative to the water column profile, taking into account that the pipe sits on the surface of the water. Be sure to account for the length used to fasten rope around pipe and the length of the metal rod above the disk.

4. Collect light profile using Licor meter.

5. Redeploy pump intake without YSI electrode to selected depths to take samples for incubations. Filter water through Buchner funnel with Nitex mesh into amber container, then fill sample bottles with that water.

6. Add $200 \mu \mathrm{l} 50 \mu \mathrm{Ci} / \mathrm{ml} \mathrm{C}-14$ to sample bottles. Each depth has three light and three dark bottles. Place bottles back in apparatus and deploy. Stagger deployment of the three disks so all samples don't come up at the same time. Incubate for $1 \mathrm{hr}$.

7. Take zero timepoint in triplicate for each depth after isotope addition.

8. While samples are incubating in situ, filter water from each depth for chlorophyll analysis onto GF/F filters. Place filter into microcentrifuge tube, label, and put 
on ice. Keep in dark. Put in freezer ASAP on return (EPA protocol says shortterm storage on ice, $2-4 \mathrm{hr}$, is acceptable before freezing.)

9. On retrieval, put samples into box and close it to keep them from getting exposed to more light during filtration.

\section{Sample retrieval}

1. Place $50 \mu \mathrm{l}$ of sample into scintillation vial with $0.2 \mathrm{ml}$ hyamine hydroxide for measurement of specific activity.

2. Filter $50 \mathrm{ml}$ onto GF/F filter in Swinnex holder using $60 \mathrm{ml}$ syringe, place filter into vial with $0.2 \mathrm{ml}$ glacial acetic acid.

\section{Post-sampling}

1. Place filter vials uncapped in radiation hood to degas $\mathrm{CO}_{2}$ overnight. Leave specific activity vials capped.

2. Conduct standard post-sampling procedures for measurement of Fe, sulfides, and nutrients; preserve samples for microscopy and DNA preservation.

3. Put filters for measurement of chlorophyll in freezer right away. Extraction can be done later.

\section{Scintillation counting}

1. Using automatic dispensor, put $10 \mathrm{ml}$ Scintiverse into each vial. Agitate gently and let sit overnight to lessen chemiluminescence.

2. Prepare three vials containing only $10 \mathrm{ml}$ Scintiverse (no sample) to account for background dpm.

3. Determine radioactivity of samples using scintillation counter.

4. Vials go in cardboard box and into radioactive waste hood for disposal. 


\section{C.1.4 Protocol for timecourse experiment Experimental setup}

Light incubations were done in clear $60 \mathrm{ml}$ polycarbonate bottles, and dark incubations were done in $60 \mathrm{ml}$ round amber bottles. Bottles were suspended in situ from a long PVC pipe with buoys secured on either end. The pipe was tied to the fixed buoy in Salt Pond for security, but did not rely on that buoy for support. Individual bottles were be tied to ropes of the appropriate length and attached to the pipe. The bottles were secured with wire collars.

\section{Preparation}

1. 20 scintillation vials filled with $0.2 \mathrm{ml}$ glacial acetic acid and labeled on top with marker pen

2. 40 scintillation vials filled with $0.2 \mathrm{ml}$ hyamine hydroxide for measurement of specific activity, duplicate measurements per bottle

3. $1075 \mathrm{ml}$ clear bottles and $1075 \mathrm{ml}$ amber bottles, acid-washed and rinsed with DI water. Bottles fitted with wire collars to secure them to line. Bottles secured in boxes for easy transport.

4. Lines: $8 \times 3.5 \mathrm{ft}$, and $8 \times 12 \mathrm{ft}$. measure and cut.

5. Swinnex filter cartridges with combusted $25 \mathrm{~mm}$ GF/F filters

6. Sporks with Luer-Lok fitting

7. Isotope into small plastic bottle for field transport

8. Light meter taped onto frame

9. Fasten lines onto pipe apparatus

10. Tare filled bottles to obtain average volume 


\section{Deployment}

1. Basic water column profile to identify chemocline location, using electrode

2. Light measurements using $4 \pi$ sensor and Licor meter (C. Taylor)

3. Withdraw water samples from $3 \mathrm{ft}$ depth, inject into light and dark bottles either with syringe or directly from pump outflow, in either case filtering through Swinnex cartridge with Nitex mesh in it. Fill bottles to just below overflowing.

4. Inject isotope with pipettor. Mix gently. Secure line to bottle.

5. Deploy apparatus while chemocline water sample is being prepared.

6. Prepare zero timepoint sample for mixed layer. Fill bottle, inject isotope, and filter (see below) right away. Withdraw $0.1 \mathrm{ml}$ sample with pipettor (estimated activity, $28600 \mathrm{dpm}$ ) and place in specific activity vial (labelled _LS1 and _DS1).

7. Withdraw water from chemocline layer. Fill bottles as above, fasten to lines, and deploy.

8. Take zero timepoint from chemocline layer.

\section{Filtering and Specific Activity}

1. Bottles will be retrieved at $0,0.5,1,2$, and $3 \mathrm{hr}$ intervals.

2. First, withdraw $0.1 \mathrm{ml}$ sample with pipettor and place in appropriate specific activity vial. Repeat $1 \mathrm{x}$.

3. Next, withdraw $50 \mathrm{ml}$ from bottle with $60 \mathrm{ml}$ syringe with spork attachment. Remove spork. Suck in a little air into syringe. Attach to Swinnex filter cartridge with GF/F filter pre-mounted. Filter liquid back into sample bottle.

4. Remove filter from cartridge and place into appropriate vial containing $0.2 \mathrm{ml}$ glacial acetic acid. 